\title{
UAB
}

Universitat Autònoma de Barcelona

\section{THE ROLE OF RANKINGS IN THE MARKETING UNDERTAKEN BY UNIVERSITIES THROUGH THEIR INSTITUTIONAL WEBSITES}

\author{
Omid Morad Abadi
}

ADVERTIMENT. L'accés als continguts d'aquesta tesi queda condicionat a l'acceptació de les condicions d'ús establertes per la següent llicència Creative Commons:

(c) (i) (\$) $\mathrm{http}: / /$ cat.creativecommons.org/?page_id=184

ADVERTENCIA. El acceso a los contenidos de esta tesis queda condicionado a la aceptación de las condiciones de uso establecidas por la siguiente licencia Creative Commons: (c) (i) @ $@$ http://es.creativecommons.org/blog/licencias/

WARNING. The access to the contents of this doctoral thesis it is limited to the acceptance of the use conditions set by the following Creative Commons license: (c) (i) $\Theta($ ) $\mathrm{https}$ ://creativecommons.org/licenses/?lang=en 


\section{UAB}

Universitat Autònoma de Barcelona

DEPARTAMENT DE PEDAGOGIA APLICADA

THE ROLE OF RANKINGS IN THE MARKETING UNDERTAKEN BY UNIVERSITIES THROUGH THEIR INSTITUTIONAL WEBSITES

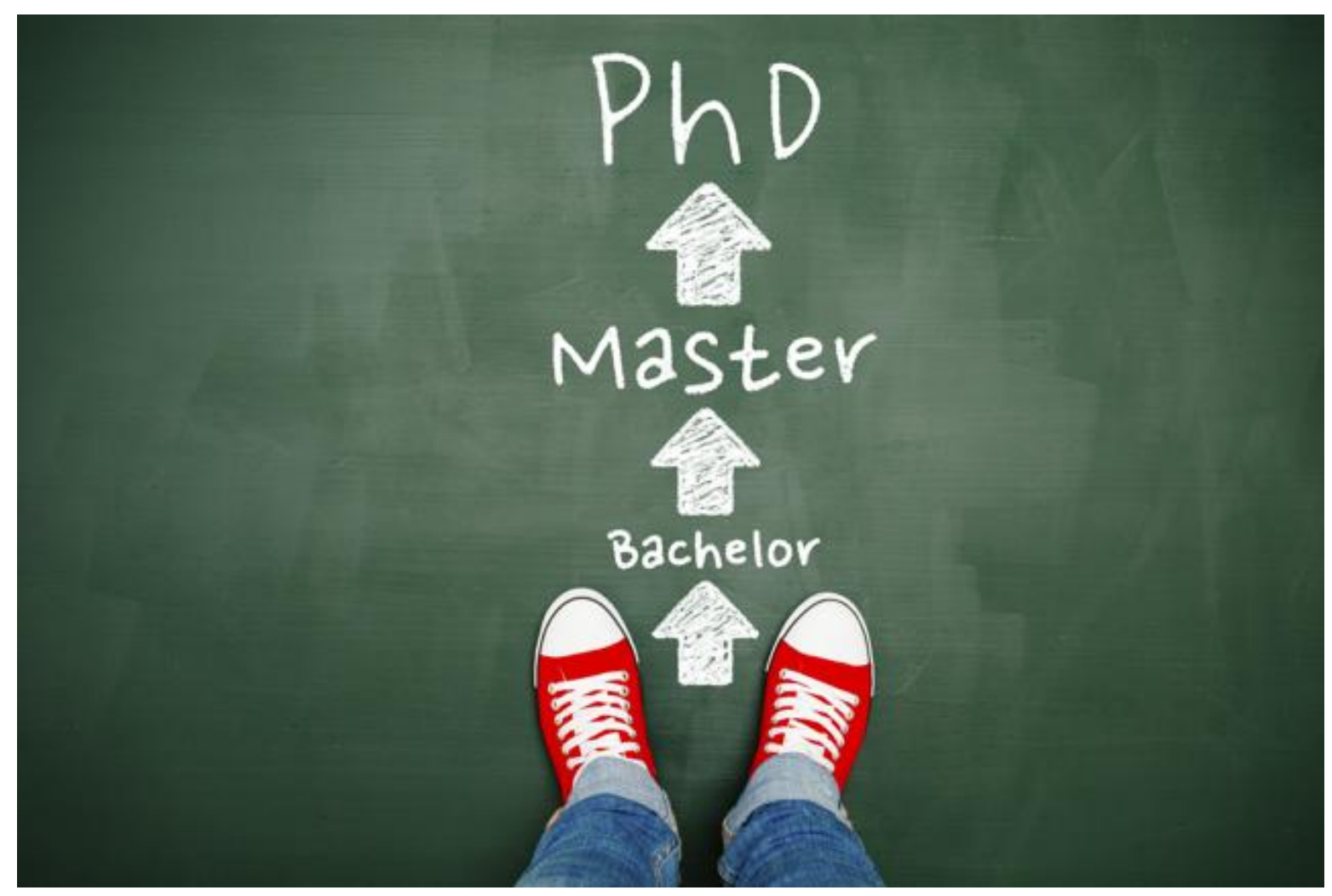

BELLATERA, SETEMBRE 2017 


\section{UAB}

Universitat Autònoma de Barcelona

DEPARTAMENT DE PEDAGOGIA APLICADA

\section{THE ROLE OF RANKINGS IN THE MARKETING UNDERTAKEN BY UNIVERSITIES THROUGH THEIR INSTITUTIONAL WEBSITES}

Nom i signatura de Doctorand: Omid Morad Abadi

Nom i signatura de Directora: Dra. Marina Tomás i Folch

Nom i signatura de Directora: Dra. Georgeta Ion

BELLATERA, SETEMBRE 2017 
Dra. Marina Tomás i Folch, professora del Departament de Pedagogia aplicada, amb seu a la Facultat de Ciències de l’Educació de la Universitat Autònoma de Barcelona.

Dra. Georgeta Ion, professora del Departament de Pedagogia aplicada, amb seu a la Facultat de Ciències de l’Educació de la Universitat Autònoma de Barcelona.

FEM CONSTAR QUE:

La Investigació realitzada sota la direcció de les signants Dra Marina Tomàs Folch i Dra Georgeta lon amb el títol EL PAPEL DE LOS RANKINGS EN EL MARKETING QUE REALIZAN LAS UNIVERSIDADES A TRAVÉS DE SUS WEBS INSTITUCIONALES, reuneix tots els requeriments científics, metodològics I formals exigits per la legislació vigent per la seva Lectura i Defensa pública davant la corresponent Comissió, per la obtenció del Grau de Doctor en Educació per la Universitat Autònoma de Barcelona, per tant considerem procedent autoritzar la seva presentació

Bellaterra,22 de setembre del 2017

Signat: Marina Tomàs Folch

Signat: Georgeta Ion 
I would like to express my special appreciations and thanks to my directors Dr. Marina Tomás i Folch and Dr. Georgeta Ion, who have been a tremendous support for me during all these 4 years of doctorate program. I would like to thank you for encouraging my research and your useful comments and advices for this research. Your advices on this research have been priceless and many thanks for all supports during these 4 years. I would also like to thank Dr. Jose Tejada Fernandez, who from very beginning of my doctorate program helped me a lot during this program. A special thanks to my family. Words cannot express how grateful I am to my, my mother, my wife and father for all of the sacrifices that you've made on my behalf. Your prayer for me was what sustained me thus far. I would also appreciate the director of department and would also like to thank all professors of the Applied Pedagogy department and staffs of secretary office who supported me in writing this thesis, and incented me to strive towards my goal. 


\section{TABLE OF CONTENTS}

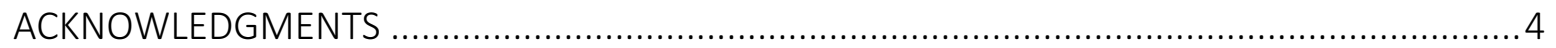

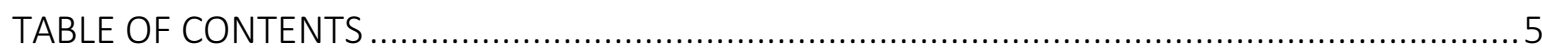

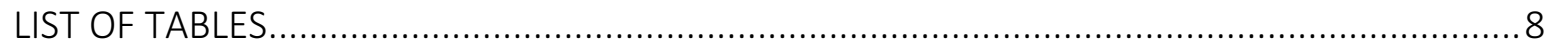

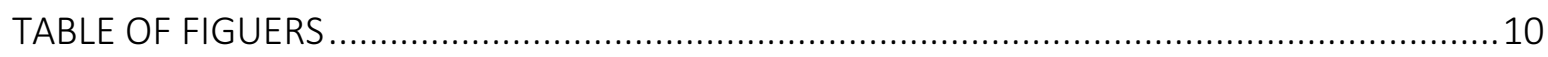

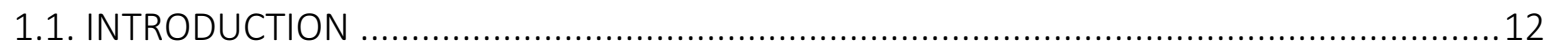

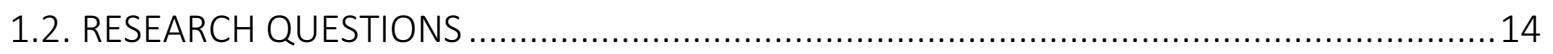

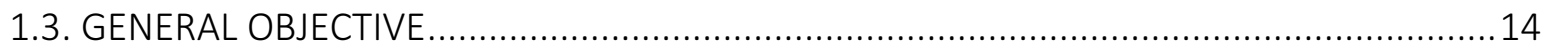

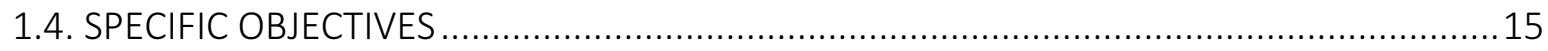

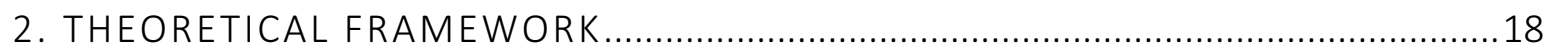

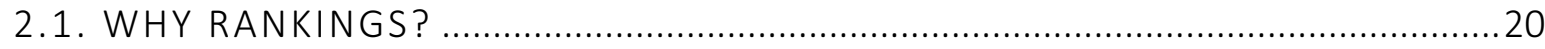

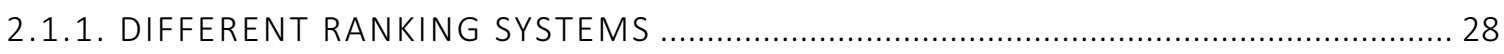

2.1.2. THE RANKING AND KEY PERFORMANCE METHODS ............................................

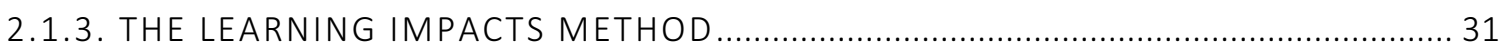

2.2. THE EMERGENCE OF UNIVERSITIES RANKINGS ..........................................33

2.2.1. HIGHER EDUCATION RANKINGS OF SHANGHAI JIAO TONG UNIVERSITY

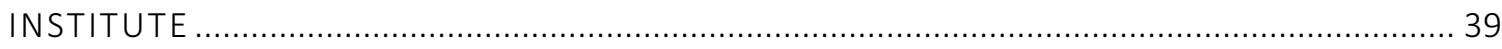

2.2.2. THE TIMES HIGHER EDUCATION SUPPLEMENT RANKINGS OF UNIVERSITIES ... 41

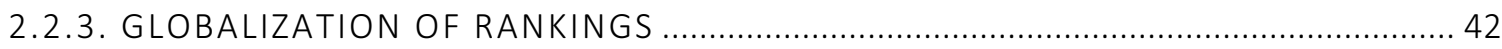

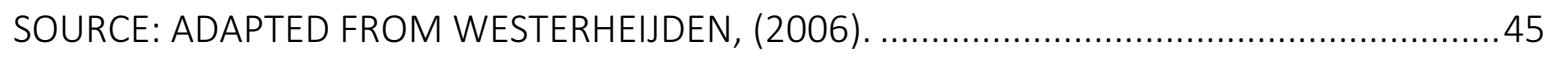

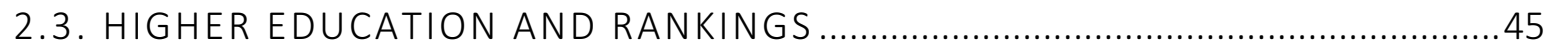

2.3.1. THE RANKING EFFECTS ON STUDENTS AND INSTITUTIONS ........................................... 49

2.3.2. THE IMPORTANCE OF RANKING FOR STUDENT CHOICES ………………………..........5 52

2.3.3. THE FLOWS OF TECHNOLOGY AND GLOBAL UNIVERSITY RANKINGS ………………......... 54

2.3.4. HIGHLIGHTS OF UNIVERSITY RANKING FRAME WORK ……………….........................5 57

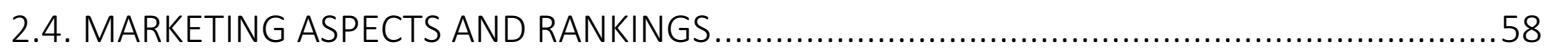

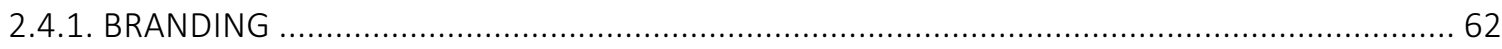

2.4.2. MARKETING APPROACHES AND CORE MARKETING CONCEPTS ……………………..........6

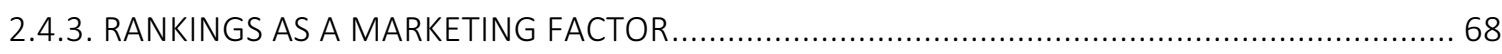

2.4.3.1. MARKETINGIN HIGHER EDUCATION AND RANKINGS .............................................. 70

2.4.4. MARKETING AND BRANDING ASPECTS APPLIED IN UNIVERSITIES..............................8

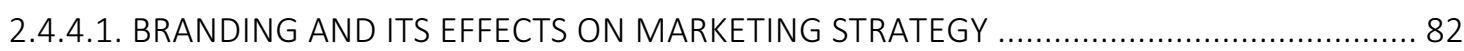

2.4.4.2. SOCIAL MEDIA AND DIGITAL TECHNOLOGY IN BRANDING OF HIGHER EDUCATION .... 84

2.4.4.3. RECRUITMENT AND ENROLLMENT OF ELITE STUDENTS …….................................. 86

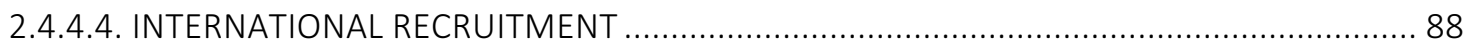

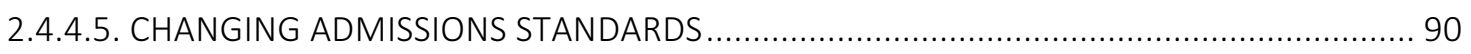


2.4.4.6. TECHNOLOGY AND HIGHER EDUCATION ONLINE LEARNING ................................... 91

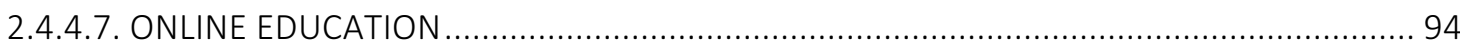

2.5. HIGHLIGHTING MARKETING AND ITS IMPACT ON HIGHER EDUCATION ......................97

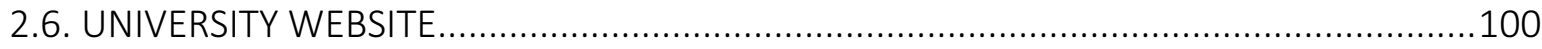

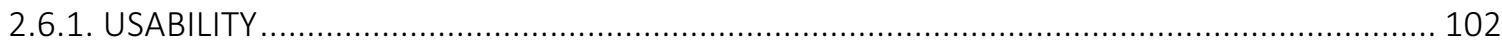

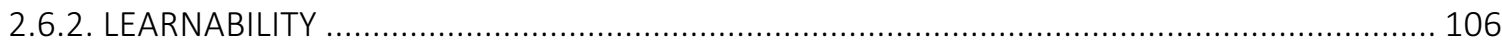

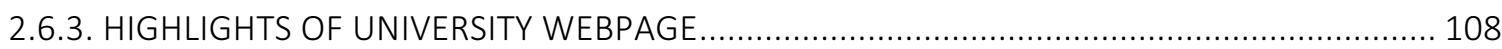

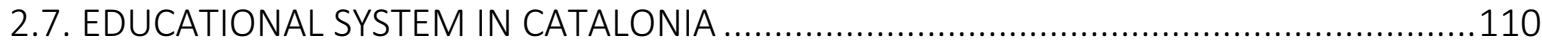

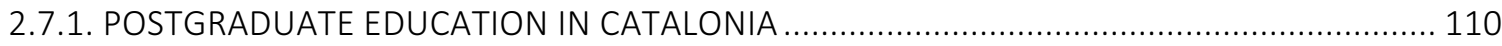

2.7.2. FOUR CATALAN UNIVERSITIES POSITIONS IN HIGHER EDUCATION RANKINGS ................. 114

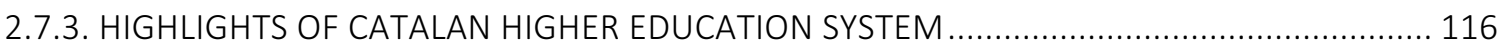

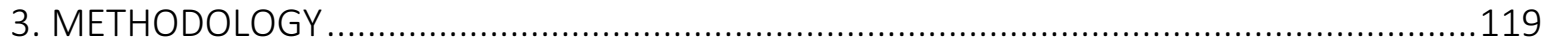

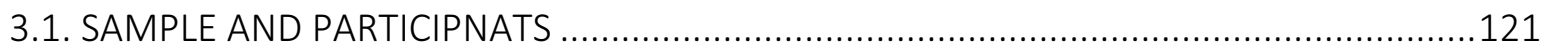

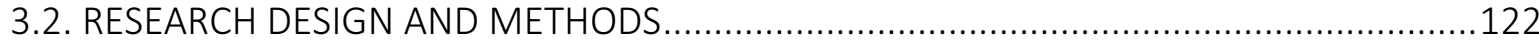

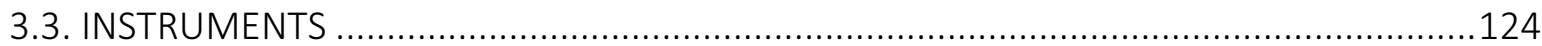

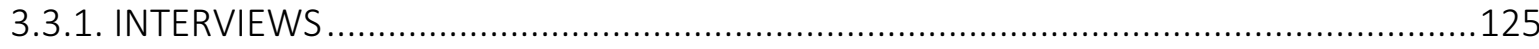

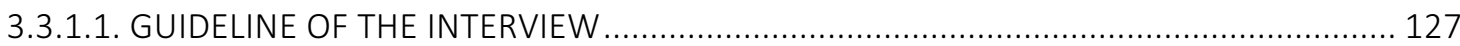

3.3.2. GUIDELINE FOR THE ANALYSIS OF THE WEBPAGES .......................................... 130

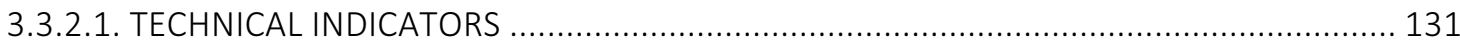

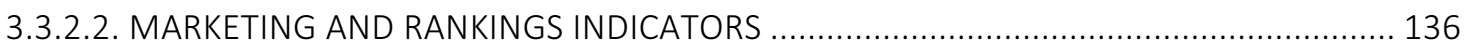

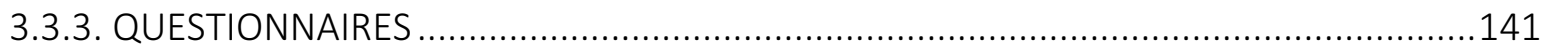

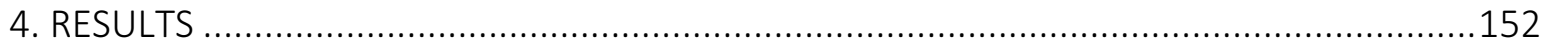

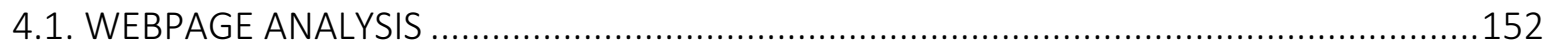

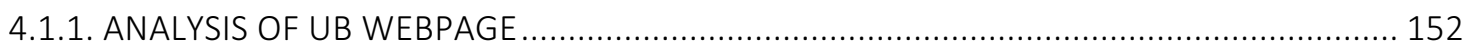

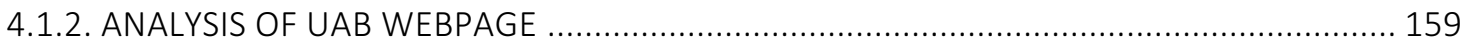

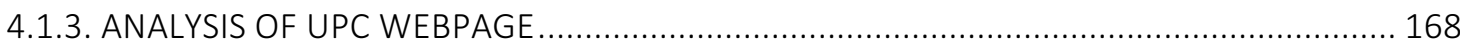

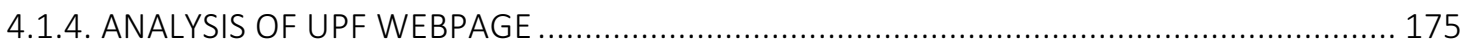

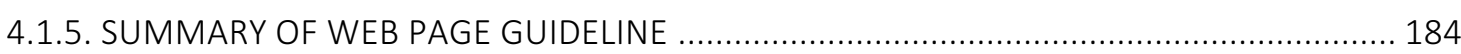

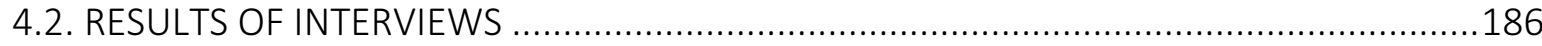

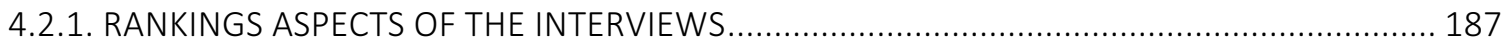

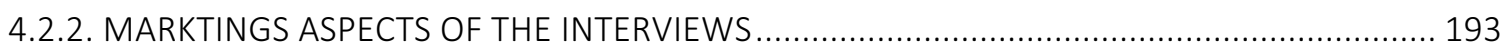

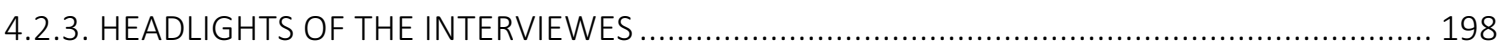

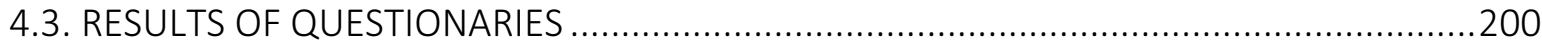

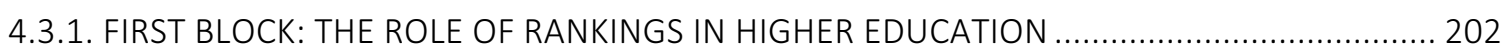

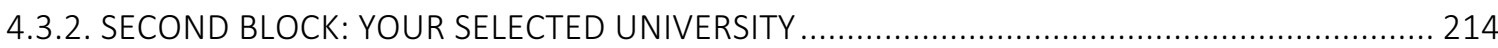

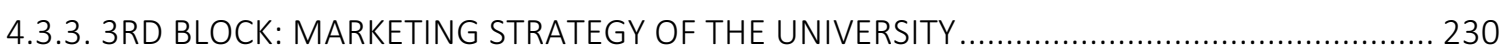

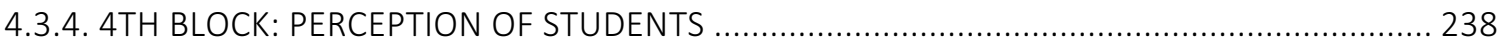

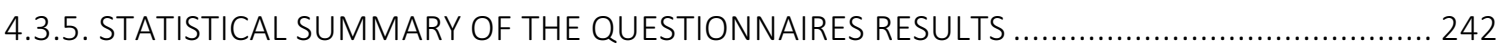




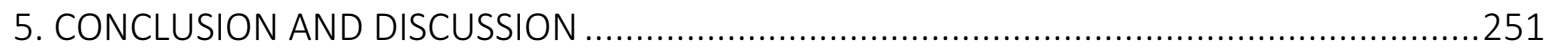

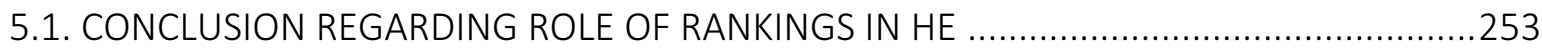

5.2. CONCLUSION REGARDING ADVANTAGE OF CATALAN UNIVERSITIES FROM RANKINGS

255

5.3. CONCLUSION REGARDING MARKETING STRATEGY OG CATALN UNIVERSITIES ...........257

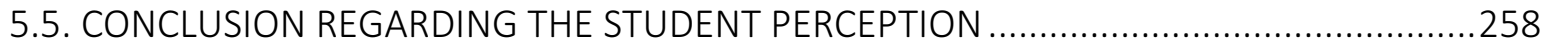

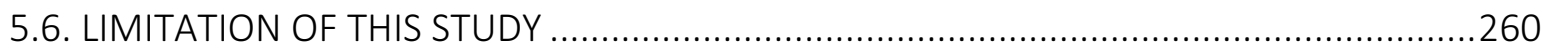

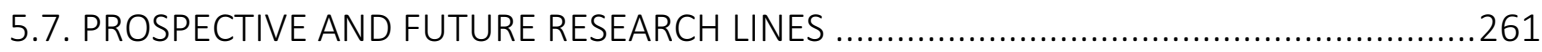

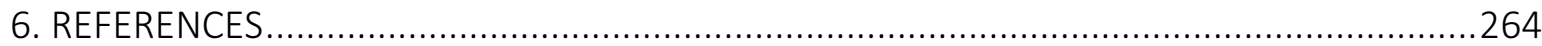

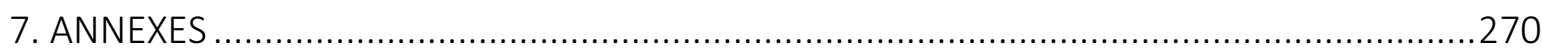

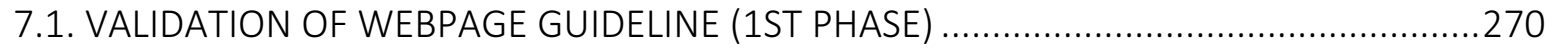

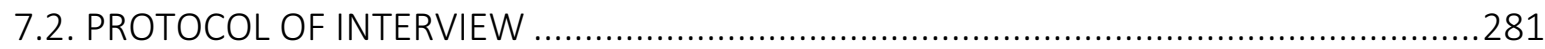

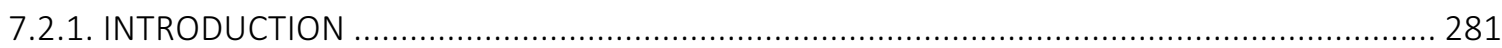

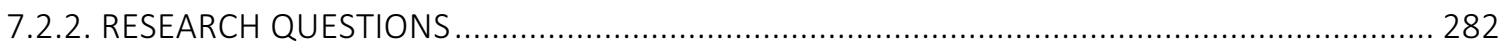

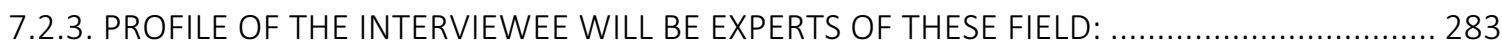

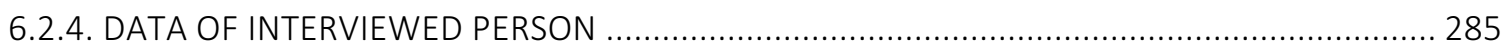

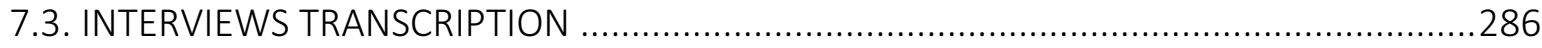

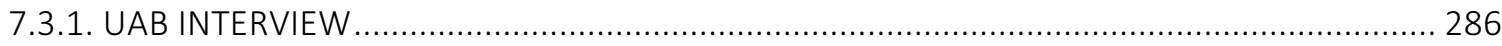

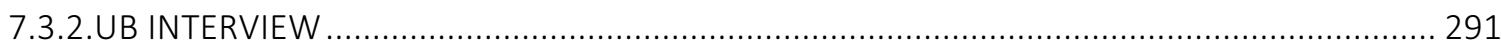

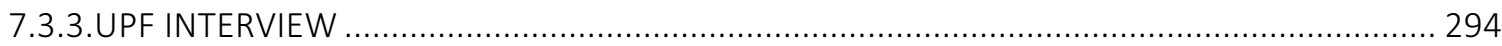


TABLE 1. DIFFERENT RANKINGS SYSTEM AND MEASUREMENT 36

TABLE 2. INDICATORS MEASURING SURVEY 38

TABLE 3.THE GLOBAL SUPER LEAGUE: THE WORLD'S LEADING UNIVERSITIES ACCORDING TO SJTUI 2010. 45

TABLE 4. TOP TEN STRATEGIES AND TACTICS FOR RECRUITMENT, BY INSTITUTION TYPE (2013) ....87

TABLE 5. ONLINE COURSES AVAILABLE FROM INSTITUTIONS IN THE TOP 100 ACADEMIC RANKING

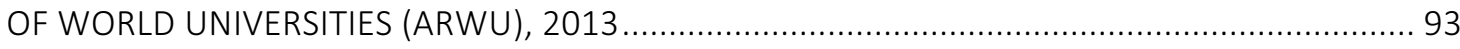

TABLE 6. GROWTH RATES OF POSTSECONDARY ONLINE ENROLLMENT, 2002-2011 _.................... 94

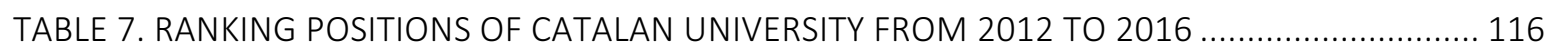

TABLE 8.PHD AND MASTER STUDENTS OF THE ACADEMIC YEAR 2015-2016 .............................. 122

TABLE 9. INSTRUMENTS OF THIS STUDYAND INFORMED PARTICIPANTS ..................................... 124

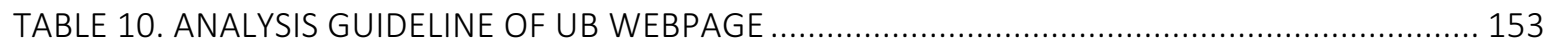

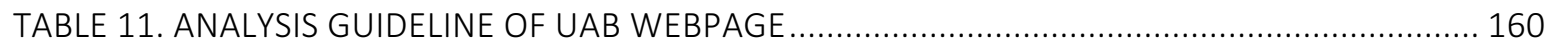

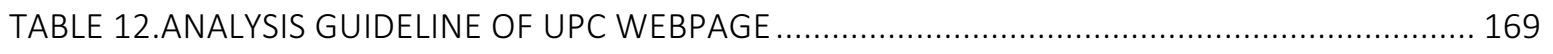

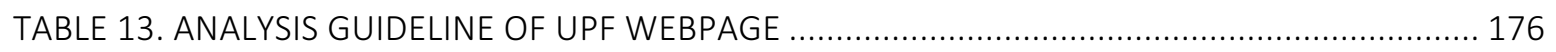

TABLE 14.RESUME OF THE GUIDELINE OF UNIVERSITIES WEBPAGES ........................................ 185

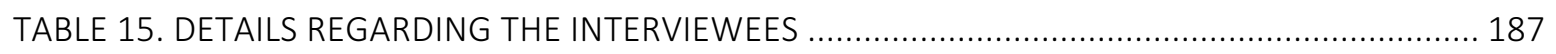

TABLE 16. METROPOLITAN 4 CATALAN UNIVERSITIES AS CASE STUDY ........................................ 201

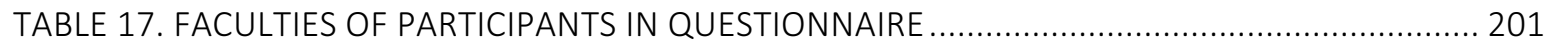

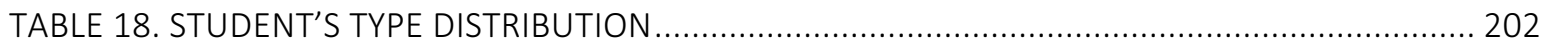

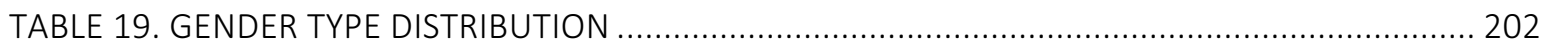

TABLE 20. IMPORTANCE LEVEL OF RANKINGS ON GENDER, STUDENTS AND HIGHER EDUCATION 203

TABLE 21. INFLUENCE OF RANKINGS ON INTERNATIONAL REPUTATION OF THE UNIVERSITY AND ITS

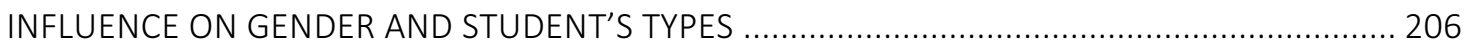

TABLE 22. INFLUENCE OF RANKINGS ON THE SELECTION OF STUDENTS, GENDER AND STUDENT'S

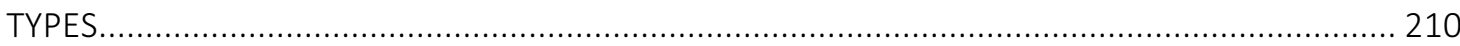


TABLE 23. IMPORTANCE LEVEL OF RANKINGS NOTIFICATION AND ITS IMPACT ON THE UNIVERSITY WEBPAGE BASED ON GENDER AND STUDENTS TYPES.

TABLE 24. RANKINGS NOTIFICATION ON THE WEB PAGE OF YOUR SELECTED UNIVERSITY BASED ON GENDER AND STUDENT'S TYPES

TABLE 25. WEB PAGE DESIGN AND ATTRACTIVENESS OF RANKINGS ON STUDENT'S SELECTION BASED ON GENDER AND STUDENT'S TYPES 218

TABLE 26. THE WEB DESIGN OF THE CURRENT UNIVERSITY OF STUDENTS BASED ON GENDER AND STUDENT'S TYPES 221

TABLE 27. THE EASINESS LEVEL OF NAVIGATION OF YOUR SELECTED UNIVERSITY WEBPAGE BASED ON GENDER AND STUDENT'S TYPES. 224

TABLE 28. THE CONNECTIVITY LEVEL OF WEB PAGE WITH SOCIAL NETWORKS BASED ON GENDER AND STUDENT'S TYPES 226

TABLE 29. THE INFORMATION REGARDING TUITION FEE AND STUDY PROGRAMS ON YOUR SELECTION WEBPAGE BASED ON GENDER AND STUDENT'S TYPES 230

TABLE 30. THE PRESENTATION OF VIRTUAL TOUR, CAMPUS, LIBRARY, FACILITIES AND TUITION FEE ON UNIVERSITY SELECTION WEBPAGE BASED ON GENDER AND STUDENT'S TYPES 233

TABLE 31. LEVEL OF IMPORTANCE OF THE DESIGN STYLE OF THE WEBPAGE ON YOUR SELECTION BASED ON GENDER AND STUDENT'S TYPES 236

TABLE 32. THE INFLUENCE OF RANKINGS ON STUDENT'S PERCEPTION TO CHOOSE A UNIVERSITY BASED ON GENDER AND STUDENT'S TYPES 238

TABLE 33. THE GRADE OF YOUR SELECTION BY THE RANKINGS POSITION OF THE UNIVERSITY BASED ON GENDER AND STUDENT'S TYPES

TABLE 34. HIGH LEVEL OF IMPORTANCE FOR THE MOST IMPORTANT ITEMS 243

TABLE 35-PRESENTS THE UNIQUENESS, RELEVANCY AND IMPORTANCE LEVEL OF TECHNIQUE INDICATORS

TABLE 36-PRESENTS THE UNIQUENESS, RELEVANCY AND IMPORTANCE LEVEL OF RANKING INDICATORS

TABLE 37-PRESENTS THE UNIQUENESS, RELEVANCY AND IMPORTANCE LEVEL OF MARKETING INDICATORS 


\section{TABLE OF FIGUERS}

FIGURE 1.TRENDS IN SOCIAL MEDIA USAGE AMONG U.S. COLLEGES AND UNIVERSITIES, 2008/2011 86

FIGURE 2.POST-SECONDARY COMPLETION AND FURTHER EDUCATION PARTICIPATION RATES, 25-64 YEAR OLDS 89

FIGURE 3. THE UB WEBPAGE REGARDING THE PAGE LAYOUT,2015 ....................................... 154

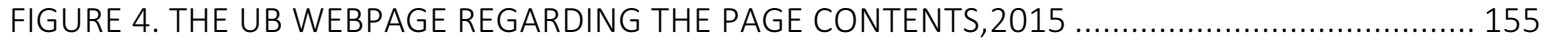

FIGURE 5. THE UB WEBPAGE REGARDING THE MARKETING AND RANKINGS INDICATORS,2015 ... 156

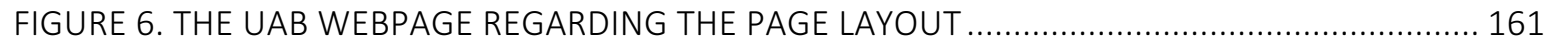

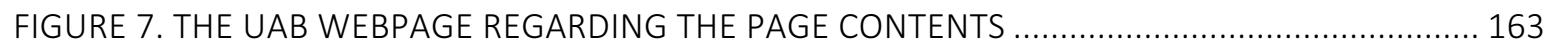

FIGURE 8. THE UAB WEBPAGE REGARDING THE MARKETING AND RANKINGS INDICATORS .......... 164

FIGURE 9. THE UAB WEBPAGE REGARDING THE MARKETING AND RANKINGS INDICATORS .......... 165

FIGURE 10. THE UAB WEBPAGE REGARDING THE MARKETING AND RANKINGS INDICATORS ........ 167

FIGURE 11. THE UPC WEBPAGE REGARDING THE PAGE LAYOUT ........................................... 170

FIGURE 12. THE UPC WEBPAGE REGARDING THE PAGE CONTENTS ….................................... 172

FIGURE 13. THE UPF WEBPAGE REGARDING THE PAGE LAYOUT,2015 ..................................... 177

FIGURE 14. THE UPF WEBPAGE REGARDING THE PAGE CONTENTS ......................................... 179

FIGURE 15. THE UPF WEBPAGE REGARDING THE RANKINGS AND MARKETING INDICATORS,2015 180

FIGURE 16. THE UPF WEBPAGE REGARDING THE RANKINGS AND MARKETING INDICATORS......... 181

FIGURE 17. THE UPF WEBPAGE REGARDING THE CONNECTIVITY WITH SOCIAL MEDIAS .............. 183 
Chapter 1

\section{General Introduction}




\subsection{INTRODUCTION}

The ranking phenomenon has expanded in line with the supply of higher education. Ranking is sometimes described as a way of simplifying and clarifying a complex scenario for students and other interested parties. Even if the ranking concept may cover many aspects, most rankings have a common factor in that they present indicators of quality explicit or implicit that are weighted to produce an outcome, which, in its turn, is ranked in comparison with all other such results. In other words, ranking is an attempt to measure the quality of higher education or research, but it differs from many other forms of quality assessment because it is relative there are no absolute criteria or norms for what may be regarded as minimum quality (Tomàs Folch \& Castro, 2015). The role of rankings in this perspective is an offering consumer information to the many buyers and sellers participating in the globalized game of higher education services. Global rankings offer players of the game information, which claims to compare higher education institutions across national borders. As such, rankings are part of the standardization of institutions in society with potentially negative consequences for institutional diversity (Dill and Sue, 2005).

The starting point for the ranking of universities and higher education institutions is normally regarded as the early 1980s, when the U.S. News and World Report magazine published a ranking of American universities. The fact is, however, that the ranking of higher education institutions may be observed much earlier than this. Such institutions were already being classified in 1870 in the United States, and various rankings were subsequently performed sporadically throughout the 20th century (Dill \&Sue, 2005). The first media ranking of universities and higher education institutions was published by the Chicago Tribune in 1957. However, the U.S. News and World Report's rankings in 1983 marked the start of considerably more extensive ranking activities in the higher education sector. There has been a very substantial expansion of the ranking market in recent decades, and not only in the university and higher education sector (Steinaker,2003). However, only a very few rankings are international in the sense that they cover universities and 
higher education institutions in many parts of the world but, on the other hand, they are the most well-known. The vast majority of rankings are national sometimes regional ranging from higher education institutions in an entire country to the ranking of certain specific education programs (Hazelkorn, 2011). The expansion of rankings in higher education has occurred in parallel with a very considerable growth in the number of organizations in the higher education sector. The flow of students in both the western world and elsewhere has also grown dramatically. As a result, it is hardly surprising that rankings have become increasingly popular, since they represent a way of organizing and simplifying a complex reality by classifying higher education institutions in terms of one or more measurable criteria.

In its turn, this makes it considerably simpler to compare the various institutions with one another, although the relevance of these comparisons obviously entirely depends on the indicators on which the ranking is based. One consequence of the growth of this sector is that competition on an increasingly global higher education market has become much keener. Higher education and research institutions are competing at the international and national levels for the "best students", the "best researchers" and, in particular, for funding. Potential students, in their turn, want to know where they should preferably invest their time and money to get the "best" education. At the same time, the governments of many countries have increasingly emphasized the importance of quality in higher education, and the links between research, innovation and economic growth. This has often resulted in greater requirements for opportunities to make demands on higher education and research institutions. There is also increased demand for information about the quality offered by the various institutions concerned (Steinaker, 2003).

Accreditation of programs, periodic assessments, and evaluations carried out by external experts, inspections, audits, performance-based contracts, benchmarking and the assessment and evaluation of research are all different forms of such demands for responsibility. Some of these measures are initiated by the organizations (higher education institutions) themselves, others are carried out externally by those who provide funding, quality assurance authorities, government bodies, vice chancellors' councils and so on (Dill \& Sue, 2005). A wider group of stakeholders for 
example the general public (via the media), student bodies and employer organizations also conducts various assessments of higher education and research, ranking is commonly said to be an instrument for the latter group.

\subsection{RESEARCH QUESTIONS}

This study tries to answer the questions mentioned below which will be the most concentration of this study:

1. How do these Catalan universities use their rankings positions in their marketing strategies for better competing?

2. What are the outcomes for the four mentioned Catalan universities by highlighting their rankings positions through their official website?

\subsection{GENERAL OBJECTIVE}

This investigation makes an analysis study through websites of the four Catalan universities: $U A B, U B, U P F$ and UPC, to analyze how their international rankings positions assist their marketing strategies to compete stronger among the other Catalan universities and in the other global universities. General objective of this study is to analyze, the role of rankings and to describe how effectively the website indicators such as: technical, marketing and rankings have been applied by those mentioned Catalan universities in their official website for burnishing their images among others as the main instruments for competing in the global markets. 


\subsection{SPECIFIC OBJECTIVES}

This study analyses the role of rankings notifications in the marketing strategy of the aforementioned four Catalan universities and try to recognize how effectively the web indicators as: technical indicators, marketing indicators and rankings indicators were applied in their official website in purpose of maintaining better marketing strategies among the other universities. This study investigates how these four Catalan universities makes advantages of their rankings position to add more credibility and validity among other competitors and to analyze their marketing strategy of four Catalan universities. This study tries to verify the student's perception regarding the ranking position of a university in the time of selecting his/her future university to continue their education 
General introduction 
Chapter 2

\section{Literature review}




\section{THEORETICAL FRAMEWORK}

Ranking of universities and other higher education institutions has become increasing common in recent years. Purpose of rankings is frequently to make complex circumstances more transparent, especially for students ranking phenomenon has expanded in line with the supply of higher education. Rankings are sometimes described as a way of simplifying and clarifying a complex scenario for students and other interested parties. Even if the ranking concept may cover many aspects, most rankings have a common factor in that they present indicators of quality explicit or implicit that are weighted to produce an outcome, which, in its turn is ranked in comparison with all other such results. In other words, ranking is an attempt to measure the quality of higher education or research, but it differs from many other forms of quality assessment because it is relative, there are no absolute criteria or norms for what may be regarded as minimum Quality and its partly, because, the ranking designers are often commercial entities newspapers or magazines with no direct responsibilities for the higher education sector (King \& Locke, 2008). Higher education worldwide is in a period of transition, affected by globalization, the advent of mass access, changing relationships between the university and the state, and the new technologies, among others.

Global perspectives on higher education provides cogent analysis and comparative perspectives on these and other central issues affecting postsecondary education worldwide. All students and researchers in higher education worldwide have noticed the rather frequent way universities nowadays are referred to in TV, newspapers or on the internet. The starting point for the ranking of universities and higher education institutions is normally regarded as the early 1980s, when the U.S. News and World Report magazine published a ranking of American universities. The fact is, however, that the ranking of higher education institutions may be observed much earlier than this. Such institutions were already being classified in 1870 in the United States, and various rankings were subsequently performed sporadically throughout the 20th century. The expansion of rankings in higher education has occurred in parallel with a very 
considerable growth in the number of organizations in the higher education sector. It is hardly surprising that rankings have become increasingly popular, since they represent a way of organizing and simplifying a complex reality by classifying higher education institutions in terms of one or more measurable criteria (Olds, 20110). In its turn, this makes it considerably simpler to compare the various institutions with one another, although the relevance of these comparisons obviously entirely depends on the indicators on which the ranking is based (Brooks, 2005). Through numerous rankings guides and reports, we are now learning which university is simply the best; in teaching or research, in a particular country, or within a region. Those universities that are not the best and they are many do not seem to be very pleased when journalists ask them why they are not on the top. They reply that the published rankings are unfair, methodologically unsound and measure only a small fraction of what universities do. Of course, if one of these universities actually ends up in a comfortable position in one of the many rankings around, they would perhaps also claim that this accomplishment is well deserved, and mirror the good work that has been done over a number of years. Hence, to most of the public, and perhaps too many academics working in universities, the emergent rankings are probably considered as nothing more than an entertaining read (Kruzhalinin\& Artjushina, 2008). Academics of universities express that the results of the existing rankings should be considered as an important development and much needed consumer information about which universities provide the best quality education information and should be relevant for the choices students make about where to study, information that should be the basis for decisions as to which university should receive public money for future research, or which university provides most value for money (Marmolejo, (2010).

Rankings have become a significant part of the tertiary education landscape, both globally and locally. In this landscape, rankings have risen in importance and proliferated in unimaginable ways. It has become commercialized and has the sophistication of companies and organizations that rank colleges and universities. (Clarke, 2005). Undoubtedly, rankings now play such a big role in shaping the opinions of current and potential students, parents, employers, and government about the quality of the education institutions (Dill \& Soo, 2005). Regarding the global importance of the ranking position for the universities in the current higher education system, and the 
procedure of evaluating and publishing the rankings list through the official website of the rankings agency, the literature review of this research is based on four main related sections to the subject of this research as:

1. Rankings: which this section discusses completely about the history and the emergence of rankings through the past decades and how rankings became a valuable measurement tools of measuring university education and teaching quality.

2. Marketing aspects: this section is concerned about the marketing aspects linked and applied to higher education, especially regarding the rankings positions and its effect on marketing strategy of the university.

3. University website: this section discusses about the important role of university official web page as a main media to manifest the rankings success and explains how exactly university webpage works and being designed and constructed.

4. Higher education system of Catalonia: this section discuses about the higher education system of Catalan universities and the role of ranking position on the progress and development of the four aforementioned Catalan universities in global higher education.

\subsection{WHY RANKINGS?}

The majority of the rankings and all the league tables attempt to reflect the quality of institutions and/or study programs in an ascendancy of the types and domains for which the listing is being done. Rankings is done for a variety of reasons, the most frequent being: to provide the public with information whatever the specifics of the ranking format on the standing of higher education institutions for individual or group decision-making potential students, parents, politicians, foundations, funding agencies, research councils, employers, international organizations; to foster healthy competition among higher education institutions; to provide 
additional evidence about performance of particular higher education institutions and study programs; to stimulate the evolution of centers of excellence; and to provide additional rationale for allocation of funds. It would be misleading to say that rankings provide an incontestable picture of the quality and performance of higher education. It is equally incontestable that rankings do have impact on institutions, policies and decision making at the individual, institutional and governmental level. However, it is an exaggeration to say that there is a worldwide obsession with league tables, despite the Organization for Economic Cooperation and Development (OECD) study showing that higher education institutions worldwide were much more concerned about league tables and ranking systems than expected. Rankings influence many areas crucial to the performance of higher education. They can be of assistance in such areas as strategic positioning and planning, staffing and organization, quality assurance, resource allocation, marketing and fundraising, admissions and financial aid, student and academic mobility, etc. All these areas are of great importance in the context of the new paradigm of higher education and the global competition for talent, resource and prestige, nowadays associated with seeking the status of a world-class university (Saldak \& Liu, 2008). It is very true that the domains of activities performed by higher education institutions that are then reflected in rankings are directly related to quality and performance as well as excellence and reputation. They can be defined, understood and interpreted differently by different stakeholders, thus representing a degree of fuzziness.

However, there is a simple evidence that these drawbacks do not totally prevent such exercises from being undertaken, nor from being taken into consideration in case of individual as well as group decisions. In the world of today, it is growing difficult for leaders of higher education institutions to contest external assessment using a shield of exceptionality for each study program or institution. Equally important, the higher education community and other stakeholders are better informed about what rankings can and cannot present. There is a growing understanding among leaders of higher education institutions that using a shield of exceptionality for each study program or institution has its limits and that externally carried-out assessment is part of the quality culture. Higher education (HE), and especially academic research, has become the focus of intense policy and geopolitical interest around the world as its role as the engine of economic growth and 
innovation has soared. Successful economies are deemed to be those which can develop and exploit new knowledge for competitive advantage and performance through investment in knowledge based and intellectual assets research and development, software, design new process innovation, and human and organizational capital (Brinkley,2008). Because higher education is viewed as critical to international competitiveness and individual opportunity, its quality and status have become vital indicators. Accordingly, interest in HE performance has rocketed since the publication of the first global ranking, the Academic Ranking of World Universities, by the Institute of Higher Education of the Shanghai Jiao Tong University (Florian, 2007). This Institute ranks universities according to indicators of academic or research performance including alumni and staff winning high-level awards such as Nobel Prizes, frequently cited researchers and articles published in leading scientific journals. Criteria are: quality of education, quality of faculty, research output, and size of institution.

Today, politicians across the political spectrum regularly refer to rankings as a measure of economic strength and ambition, students use them to help inform their choice, and universities use them to help set and define targets or brand and advertise themselves. Despite methodological flaws, global rankings do more than benchmark performance. They have become an exemplar of the marketization of higher education and the global battle for world-class excellence. By ranking higher education, they provide a framework through which national/supranational and institutional ambition and competitiveness can be measured as the number of knowledge producing capacity and talent catching Higher Education Institutions in the top 20,50 or 100 .

By privileging particular disciplines and fields of investigation, outputs and achievements, rankings like similar research assessment exercises help to reaffirm a traditional understanding of knowledge production and research, and its international division of labor. It is not easy to define rankings in a clear-cut way (Usher, 2009). The simplest answer but perhaps not the most exhaustive is that it is a collection of indicators. A fuller explanation is that: League tables, also referred to as institutional rankings and report cards, and are constructed by using objective 
and/or subjective data obtained from institutions or from the public domain, resulting in a quality measure assigned to the unit of comparison relative to its competitor (Salmi \& Saroyan, 2007). The above definition is still rather broad; however, rankings share a number of common characteristics, but there is also a considerable range in the character of rankings systems. Rankings involve a collection of indicators. Rankings are always based on one or more indicators, but there is considerable variation in the indicators employed. Rankings often entails quantification of resources (personnel, physical or economic resources), "input indicators", or results (of education programs or research) - i.e. "output indicators" -but there are also several other types of indicators. It is assumed that the indicators measure some form of quality. The priorities implied by a given ranking are not always explicitly stated, but the fact that the entity ranked first is regarded as the best implies that the rankings designers consider that the indicators represent something that is important or positive (Baty, 2009). Naturally, these important or positive factors vary, depending on the indicators selected, and on the interpretation of the ranking results. Ranking is closely linked with discussion of, and definitions of, the quality of higher education, as clearly demonstrated subsequently in the section covering the public debate on rankings.

Indicators are based on some source of information, but this may involve very different types of data ranging from subjective experiences to official statistics. The data used in the various rankings systems varies considerably. The use of several different types of sources for the various indicators in one and the same rankings is common practice. The indicators describe a specific unit, but the type of unit may vary ranging from entire higher education institutions to departments, disciplines or education programs. Some of the rankings that are perhaps the most familiar, cover entire higher education institutions in other words, the indicators measure all the characteristics of an entire university or comparable institution. Several rankings divide higher education institutions into various categories, however, and rank each category separately (Baty, 2009). There are also rankings that simply concentrate on certain types of institutions for example business schools. In addition, there are also rankings describe and rank programs or academic disciplines at higher education institutions. Indicators are sometimes but not always weighed up 
to provide a cohesive, aggregated result. In many rankings, the various indicators are weighed up to achieve a cohesive, aggregated result. This may take more or less sophisticated forms, applying more or less sophisticated statistical techniques. This often means that various indicators are given different weightings, depending on which indicators are regarded as the most crucial. There are also multidimensional rankings, however, in which the indicator results are reported separately, with no attempt to weight them to produce an overall result. Finally, ranking involves a listing in order of precedence of the units covered, involving comparison of the results achieved (Pratt, 2010). The ranking results resemble the results of a competition (league table) in which the various units compete for the best rating, as opposed to measurement and evaluation of results in terms of absolute criteria and quality standards. Defining quality by rankings that, the fact that ranking systems list units from best to worst indicates that what is measured is something desirable. The designers of ranking systems often state explicitly that they are measuring quality, although sometimes this is not clearly indicated. In any event, the choice of indicators and the aims are to be regarded as some sort of definition of quality. As regards external stakeholder users, the ranking system more or less deliberately determines the limits for the definition of quality (Usher \& Savino, 2007). As a result, the indicators that are actually included in a ranking are a key issue in an evaluation of the relevance of such a ranking for a specific user. There are, of course, an almost infinite number of potential indicators for higher education or research characteristics, but only a relatively limited number of them are employed in current ranking systems.

Distinctions are often made between different categories of higher education ranking indicators and other quality assessment systems. The classifications may vary to some extent, but for the most part the following categories are involved:

\section{- Characteristics of new students}

Characteristics describing students commencing higher education at a given unit institution, subject, education program. This may range from background variables such as gender, family and social or ethnic background to more intangible characteristics such as learning propensity, etc. In 
cases in which this type of indicator is applied, this normally takes the form of the qualifications of new students in terms of grades or test results.

- Resources for education or research (inputs)

This involves the resources supplied by the institution or department. In broad terms, and may involve personnel resources in terms of the number of teachers or, more specifically, the number of teachers with PHD qualifications. Financial and physical resources are also taken into account, for example as regards disbursement per student or access to computers and library facilities.

- Results of the education program or research (outputs)

Indicators of this nature indicate the direct outcome of higher education (or research), and may encompass measures such as student through flow the number of degrees and student credits. They may also cover factors that are less amenable to measurement, for example students' analytical abilities.

- Final outcomes

Indicators describing the long-term benefits of higher education (or research). The most common measures are student's status in the labor market and future incomes, but it may also involve more indirect outcomes such as job satisfaction, good citizenship, general education (Usher \& Savino, 2007).

\section{- Academic reputation}

Most ranking systems also include an indicator that consciously or unconsciously denotes the reputation or prestige of the institution (or department) concerned. This often involves indicators based on student questionnaires or, more commonly, surveys of persons in the academic world, such as professors and vice-chancellors. Some rankings incorporate success in international rankings or successful attraction of research grants as an indicator of academic reputation (Usher \& Savino, 2007). 


\section{- Processes}

It has been widely suggested that there are certain indicators that fail to cover the above rather well-established categories. Some people consider that there is something that lies between resources and results a process that describes the actual learning process, for example in the form of the quality of teaching, educational methods, the interaction between teachers and students, the actual content of the program and opportunities for training placements (Dill \& Soo,2005).

- Value-added

Indicators (or methods) that capture the added value of an education program are applied to a limited extent, but are nonetheless frequently sought after. Instead of applying beginning characteristics in their own right, these characteristics are used as a form of control variable in a statistical model. If entrant characteristics are used as indicators of quality, they are interpreted in terms of, the attractiveness of the institution (department or program) in other words the competence of the students that the institution manages to recruit (Usher, 2012). However, from a value-added perspective, it is more relevant to look at the outcome related to the students' initial characteristics. In other words, an attempt is made to measure how the educational program has benefited the students, and not what the students have managed to achieve previously. Additional sophisticated measures in the same spirit are sometimes proposed, for example, measurement of the outcome, taking into accounts both beginning characteristics and resources. Hence, this involves a measure of efficiency: roughly speaking the degree of added value achieved per currency unit invested (Dill \& Soo, 2005)

\section{- Student welfare factors}

Factors that are not immediately related to the actual education program or institution are a category that is applied less frequently. This may involve a broad range of student welfare aspects such as access to accommodation, health care services, cultural, sports and leisure activities, or the attractiveness of the location of the institution itself. This type of indicator should not necessarily be regarded as a separate category. Student welfare resources may be included on the 
same lines as physical resources at the institution concerned (access to libraries, IT facilities, etc.) are regarded as educational resources. On the other hand, many of these factors can only be affected by a higher education institution to a limited extent and, furthermore, they involve resources in the student's overall situation during the education period rather than immediate resources in the education process. This classification of indicators is not completely self-evident, and this is partly because different indicators may be regarded from different angles, depending on the potential target group and who has designed the ranking system. Sometimes, for example, indicators covering research activities such as citation indexes or external research grants may be regarded as a form of resources. Such resources may benefit students and doctoral students in particular, but if the ranking is designed instead to measure the quality of research at the institution concerned, such indicators should obviously be regarded as reflecting results (Usher, 2012).

The most common indicators applied in the various rankings are measures of resources, results and reputation, but they are often supplemented by one or more indicators of entrant characteristics and final outcomes. Measures reflecting the actual learning process are seldom applied, and indicators of an added-value or student welfare nature are even more uncommon (Dill \& Soo,2005). This heavy concentration on resource, result and reputation indicators may be interpreted as suggesting that there is not much dispute about the definition of academic quality. But if we examine exactly which indicators are applied in greater detail, and the way they are measured, the interpretation must be the opposite that there are significant differences in definitions of quality in the rankings. Seen in this light, the quality of higher education appears to be a somewhat arbitrary concept. The differences in quality definitions may be explained to some extent by the fact that different rankings give priority to different aspects, and that the target groups envisaged also differ potential students and their parents, the general public, future employers, university administrators.

Cultural and geographical differences probably also have an impact on rankings that is to say what measures are considered to be important, but to a far from negligible extent, the 
differences in the various ranking lists reflect what indicators are available or can be readily gathered without undue expenditure of resources, rather than the result of deliberate choices. Ultimately, most ranking designers are commercial entities often media that are more interested in selling their product often newspapers and periodicals than in becoming deeply involved in definitions of quality in higher education (Pratt, 2010).

\subsubsection{DIFFERENT RANKING SYSTEMS}

Many ranking systems rate entire higher education institutions, although it is becoming increasingly common for such listings to be supplemented by rankings for different disciplines and subjects, departments or education programs. In some cases, (for example U.S. News \& World Report in the United States), different rankings of different types of higher education institutions are carried out, based on their different functions, for example a ranking of traditional "fullservice" universities, and another ranking for specialist institutions. On the other hand, several current ranking systems in particular British and international rankings apply the same technique for all higher education institutions, often backed by the argument that they have similar assignments and prerequisites. In other words, all institutions are evaluated on the same basis and are compared with each other, irrespective of their mutual differences. There are similar consequences for a policy of weighing up all indicators to produce a single aggregated result, as in the case of ranking all higher education institutions in terms of a single measure. The weighted result does not provide any indication of what the various indicators reveal for a specific institution (Dill \&Soo, 2005). A satisfactory result (high ranking) may be achieved by being relatively good for all the indicators covered, or by being unusually good in some respects, but considerably less satisfactory in others. Some form of weighting and normalization in connection with the averaging of indicators is often applied. Weighting occurs if it is considered that one or more of the Many ranking systems rate entire higher education institutions, although it is becoming increasingly common for such listings to be supplemented by rankings for different disciplines and subjects, departments or education programs. In some cases, (for example U.S. News \& World Report in the United States), different rankings of different types of higher education institutions are carried 
out, based on their different functions, for example a ranking of traditional full-service universities, and another ranking for specialist institutions. In other words, all institutions are evaluated on the same basis and are compared with each other, irrespective of their mutual differences. There are similar consequences for a policy of weighing up all indicators to produce a single aggregated result, as in the case of ranking all higher education institutions in terms of a single measure. Different ranking systems take their indicators from a number of different sources. These sources are sometimes classified in terms of three different types (Dill \& Soo, 2005).

Much of the information used in the various ranking systems is obtained directly from the institutions concerned. To some extent, of course, this is the richest source of information, but it is not subject to quality assessment in the same way as information supplied by third parties, and it is not always easy to compare. This way of classifying different types of sources involves the data collection methods employed by the designers of ranking systems. Other classification concepts may be envisaged, of course for example objective and subjective sources, or quantitative and qualitative information. But no classification system can be simultaneously comprehensive and, at the same time, consist of mutually exclusive categories. Information about what sources have been used in a ranking irrespective of how they are classified is crucial, however, in assessing the reliability of the ranking concerned. Ranking compared with other forms of quality assessment, normalization is another type of weighting employed by ranking designers. This involves taking differences between higher education institutions into account, often in terms of their differences in size so that certain indicators are weighted on the basis of the number of students at the institution concerned. Sometimes an attempt is made to weight results in accordance with the focus applied by the institution concerned, or on the basis of the various disciplinary areas covered. The clearest example is to take into account the extent of an institution's involvement in various disciplines in terms of bibliometric indicators, since the humanities and social sciences are inadequately reflected in international citation studies. Normalization is, of course, intended to avoid some of the problems of the one-size fits all concept, but it is not easy to weight out all types of differences between institutions or education programs. As a result, the overall weighted rankings particularly for entire higher education institutions are relatively one dimensional in their 
approach to quality. There is an underlying assumption that, in principle, the same quality definition fits all types of higher education institutions and programs.

If designers of ranking lists formulate a definition of quality via their choice of indicators implicitly or explicitly and then try to measure and rank it, the question of what distinguishes ranking from other types of quality assessment, such as accreditation of degree entitlements or education evaluations, obviously comes to mind. Due to a rather vague terminology for ranking phenomena, it is difficult to say with any degree of certainty whether there is any difference between different types of quality assessment. Most of the factors that are measured and compared may, of course, be described as ranking (Usher \& Savino, 2007). But if we consider the current ranking systems, most of them have a common denominator that distinguishes them from many other kinds of quality assessment. Ranking is conducted in relation to the units covered, and not in comparison with any absolute and clearly defined criterion for what is to be regarded as good or bad quality. There are no clear-cut distinctions between the different approaches, but they differ as regards the target group for the evaluation, what is to be evaluated, the method to be employed and what are the predominant types of indicators (Salmi, 2007). Higher Education quality evaluations may be said to belong to this category. This method provides a basis for periodic evaluations of higher education, and it is almost universally conducted at the subject level, not at the institution level. The minimum standards method is often applied by governments to require accountability from higher education institutions. The popularity of this method is no doubt because it is considered to be a legitimate central government function, in contrast with ranking. (Lalancette, 2010). The minimum standards method usually implies a combination of selfevaluation on the part of the institution concerned, followed by external assessment, often carried out by university experts and one advantage commonly cited is that it encompasses key quality aspects in higher education. As the name indicates, this method primarily involves checking that the institution or discipline concerned has acceptable quality and, although the reports may contain much useful information at the internal level they are not particularly transparent for external stakeholders. 


\subsubsection{THE RANKING AND KEY PERFORMANCE METHODS}

The ranking method distinguishes between two types of approach under this heading. The ranking method is described as the technique normally used by private sector entities, often newspapers or periodicals that focuses on resource indicators. The key performance method has been used, primarily in the United States and Canada, in the same way that the minimum standards method is applied in other countries, and has been used to require accountability on the part of higher education institutions, but normally with a focus on the entire institution, rather than on particular disciplines or subject-oriented departments. The key performance method is not synonymous with the ranking method, although they have much in common. Apart from the fact that they focus on somewhat different types of indicators, the key performance method is closer to the minimum standards method in that a key number often constitutes some sort of norm or benchmark. Ranking and key performance methods are almost exclusively quantitative (Marmolejo, 2010). Quality is measured in terms of statistical indicators of one kind or another frequently resource indicators in the ranking approach, and result indicators in the key performance method. The ranking and key performance methods are considerably more transparent and easy to understand than the minimum standards method, but have met with considerable criticism on the grounds that the indicators used are often meaningless and do not really reflect quality.

\subsubsection{THE LEARNING IMPACTS METHOD}

As Marmolejo discussed on (2010), the learning impacts method is, in many ways, a reaction to the ranking and key performance methods, especially as regards these methods focus on the wrong indicators. Since higher education institutions particularly in the United States and Canada considered that they were involved in teaching activities, they considered that it was unfair to evaluate quality on the basis of indicators that were not clearly correlated with the learning process. In view of this, several major questionnaire surveys targeted at students were developed, in an attempt to ascertain their experiences and assessments of the learning environment at the 
higher education institutions concerned. These evaluations were primarily designed to assist the internal quality process at these institutions. The techniques employed in the learning impacts method are exclusively quantitative, but the indicators differ from those employed in the ranking and key performance methods (Usher \& Savino, 2007). Instead of focusing on measures of resources and results, the learning impacts method tries to measure the actual learning process and also the value-added aspects of education. This means that this method is widely appreciated, since it tries to tackle factors in the actual education process which are difficult to measure. The disadvantage is that direct measurement is not possible everything depends on student's subjective experiences, and in this respect the results are not particularly transparent or easy to interpret.

The ranking, key performance and learning impact methods all emerged in North America in the 1990s. In Europe, the improvement method was developed as an alternative system, due to dissatisfaction with the minimum standards method, although this hardly represented a paradigm shift, since the improvement method is largely a variation of the minimum standards approach. The improvement method is used by both governments and higher education institutions to require accountability for quality issues. This method is also normally based on selfevaluation, combined with external assessment by experts (Marmolejo,2010). The main difference is that quality is defined in terms of processes in which each organization is itself responsible for goals, methods and the monitoring of quality development. In other words, this method evaluates the quality process in higher education institutions, rather than quality delivered in accordance with the minimum standards method. The assumption is that the improvement method provides incentives for quality development within the institution concerned in a way that cannot be achieved with the minimum standards method. However, in many ways both methods apply the same qualitative methodology. The advantage in both cases is that they evaluate aspects that are relevant at the internal level, and the disadvantage is that they are not sufficiently transparent at the external level. Although key performance ranking is used for government control purposes, this method is primarily confined to commercial entities, and this affects the type of quality assessment carried out. Newspapers and magazines that normally design and publish rankings of 
universities and other higher education institutions have no official responsibility for the quality of the education provided. As a result, the rankings do not apply any assumptions about causal factors; why the results look the way they do or what might be improved for the benefit of the quality of higher education. It is of course questionable whether the method employed in most of the existing rankings would support conclusions of this nature. The main purpose of ranking is (or perhaps should be) to promote transparency in higher education for external observers. From this point of view, quality development in higher education is, at best, a side effect of ranking (Federkeil, 2008).

\subsection{THE EMERGENCE OF UNIVERSITIES RANKINGS}

Global rankings are recent but they are also more influential; the SIT ARWU began in 2003, followed by Webometrics and Times QS World University Ranking in 2004, the Taiwan Performance Ranking of Scientific Papers for Research Universities in 2007, and US News \& World Report's World's Best Colleges and Universities in 2008 (Boulton,2010). The general disinterest in university rankings began to change in 1983 with the publication of 'America's Best Colleges' by the US News and World Report. For the first-time information about undergraduate programs in America's higher education institutions was made widely and publicly available to the country's high school population and their parents via a widely read popular medium. A decade later, in 1993, the first 'Times Good University Guide' was published in the United Kingdom, prompting as had happened previously in the United States public debate as to which institutions fared better or worse in the guide. The 1990s later witnessed diverse lists, league tables and rankings around the world, numbering everything from specialist subject schools, to MBA programs and private institutions, provoking as a result increasing wrangling and scrambling for positions on such lists, as well as skepticism from those institutions that appeared or did not appear on them. One generation ago, international relations in higher education, although often generative of new developments, were largely marginal to the ongoing, day-to-day operations of higher education institutions (HEIs) and systems, except in scientific research (Dill \& Soo, 2005). With global university rankings Shanghai Jiao Tong University Institute of Higher Education (SJTUIHE) and 
World University Rankings, especially the global ranking of research performance, higher education itself has entered an era of open global competition between nations and between individual HEls as global actors in their own right. Increasingly, national higher education systems and HEls are judged by where they stand in global terms (Florian, 2007). Across the world, national policy makers and HEls must take account of a global higher education environment in which international comparisons are constantly made, resources and educational status are unequally distributed, the English language and institutions from the Anglo-American nations (especially the United States) are often dominant, and the process of Europeanization is opening up new possibilities. The rise of global referencing does not signify that higher education has simply become a single worldwide network of HEIs (Liu, 2009). In global markets, studies of international student choice making indicate that, on the whole and with the partial exception of the small group of HEls, the Harvard and Oxford that are household names all over the world, the national identity of HEls continues to be more important in the eyes of the world than the institutional identity of the individual HEls (Organization for Economic Cooperation and Development, 2012). Though the role of the private sector which is growing worldwide and in some nations, it constitutes a majority of HEls in most nations foreign providers (which are all defined as part of the private sector when operating outside their own national jurisdiction) play only a marginal role, except in purely online education, which overall enrolls but a small proportion of students (Usher \& Savino, 2007).

In the multilateral General Agreement on Trade in Services and World Trade Organization negotiations, a national interest bias is strongly apparent. All of the Organization for Economic Cooperation and Development (OECD) has chosen to retain firm control over the national character of the systems under their jurisdiction. As reported in OECD (2008), among the exporting nations, a typical stance is to expect a greater degree of deregulation in foreign nations than the exporter is prepared to countenance at home. Yet globalization also has transformative implications for the internal relations between nation states and their HEIs. In one sense, the single worldwide logic of global rankings is confirmed in that within global networks universities directly deal with each other in their own right. The model of standalone global actors was long practiced 
among individual researchers and scholars and has always shaped the dealings of certain leading universities (mostly in the United States and the United Kingdom) with the rest of the world. The tide of attention paid to university rankings, however, well and truly swept over the sector a decade later in 2003 with the release of the Academic Ranking of World Universities (ARWU) by Shanghai Jiao Tong University in China and the Times Higher Education World University Rankings a year later. The Centre for science and technology studies at the university has developed its own global bibliometric ranking while the European Union has recently announced its intention to develop a new multidimensional university ranking system with global outreach. Rankings compare HEls using a range of different indicators, which are weighed differently according to each ranking system (Brooks, 2005). Information is generally drawn from three different sources: independent third party sources, e.g. government databases; HEl sources or survey data of students, employers or other stakeholders. Given the absence of reliable publicly available crossnational comparative data, global rankings measure researching broad-brush strokes, rather than the full range of HE activity.

As such, they rely heavily on traditional research outputs as captured in the bibliometric and citations databases developed (Van Rann, 2005). Research productivity is measured by the number of publications in peer reviewed journals, and research excellence and impact is measured by the number of citations. Essentially, peer publications and citations attempt to measure the extent to which research impacts on and influences the global science community and this argument was taken one step further by specifically focusing on publications in Nature and Science, and the number of Nobel or other major prizes winners employed by an individual HEI, as a proxy for scientific excellence. Because the outcome is a derivative of institutional size does attempt to control for this by assigning ten per cent of its score to this while the Taiwan system accounts for institutional age by assigning a special weighting for publications in the current year. Research capacity is measured by faculty output, which is also the reasoning behind prizes. It attempts to measure broader HE activity, including student learning, community engagement innovation and employability, through a combination of peer review and surveys or questionnaires. This is based on the fact that peer appraisal is essentially a reputational calculation 
based on research standing. Webometrics does what its name says; in line with the international movement towards open science, it measures research productivity according to the size and scale of HE web presence. SJT pioneered global rankings in 2003 as an effort to define the characteristics of a world class university in order to leverage funding from the Chinese Government in line with the latter's policy aspirations. Its publication reverberated around the world, as government leaders saw a gap opening up between their stated ambition and their perception of what rankings represent.

The other systems are arguably either a refinement or rebuttal of the SIT including the EU proposition which arises from concern that European HEls have performed poorly relative to the EU's ambitious Lisbon Agenda and concern that European higher education would henceforth be defined by Chinese or other criteria. The table 2, illustrates how the choice of indicators and the weightings attached to them reflect the priorities of each of the producers, while table 3 shows that national systems have a much wider range of indicators due to access to richer data. Despite these differences, research and its traditional outputs is the primary and easiest measurement, acting as a proxy for excellence.

\section{TABLE 1. DIFFERENT RANKINGS SYSTEM AND MEASUREMENT}

\begin{tabular}{|c|c|c|}
\hline RANKING SYSTEM & INDICATOR DIMENSION & WEIGHTING \\
\hline $\begin{array}{l}\text { SJT Academic } \\
\text { Ranking of World } \\
\text { Universities }\end{array}$ & $\begin{array}{l}\text { - Quality of Education } \\
\text { - No. Nobel Prize/Field Medal } \\
\text { - No. HiCi Researchers } \\
\text { - Nesearch Output } \\
\text { - No. Articles in Nature/Science }\end{array}$ & $\begin{array}{l}10 \% \\
20 \% \\
20 \% \\
20 \%\end{array}$ \\
\hline
\end{tabular}




\section{Literature review}

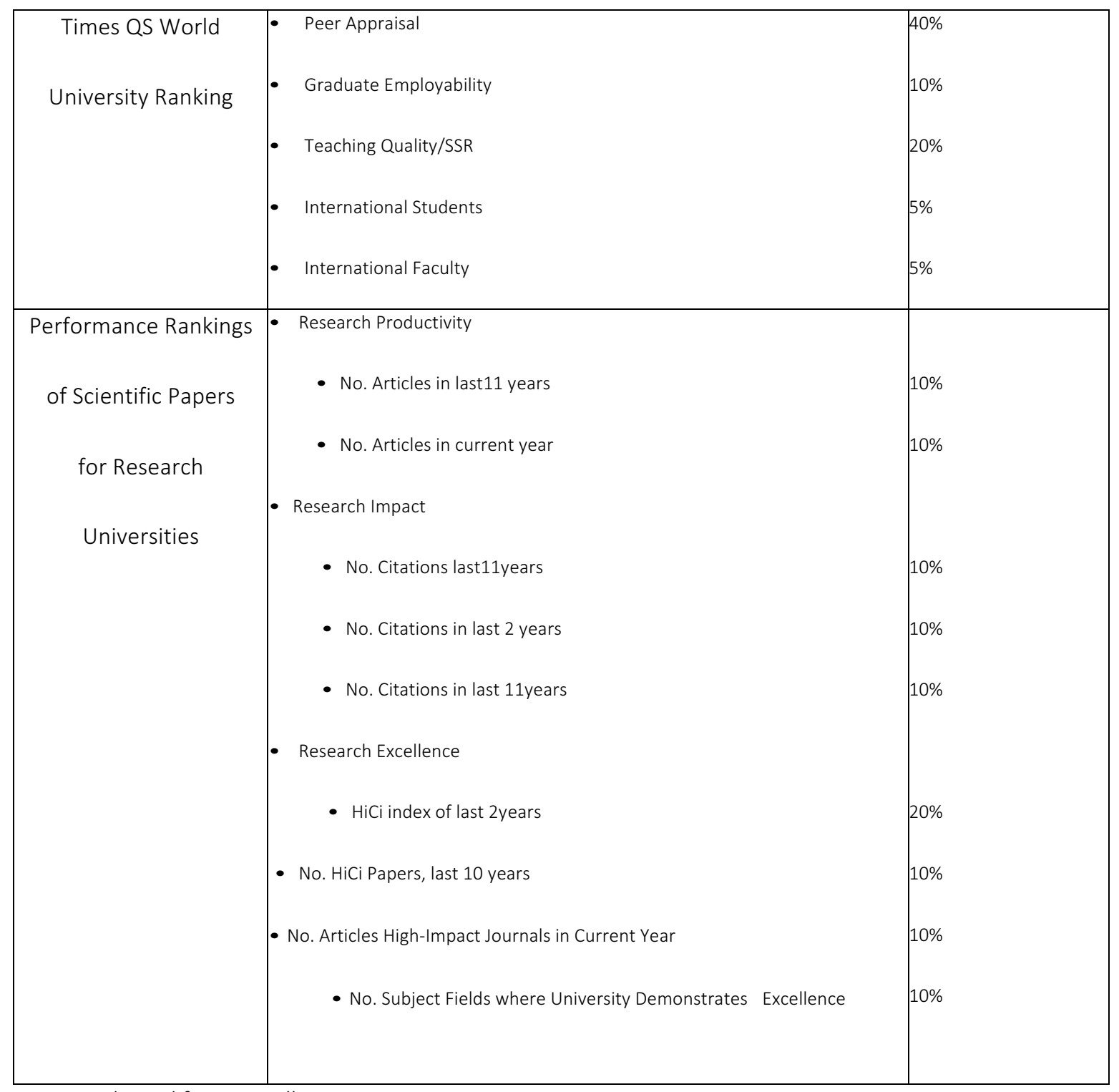

Source: Adapted from Hazelkorn, 2009 


\section{Literature review}

TABLE 2. INDICATORS MEASURING SURVEY

\begin{tabular}{|c|c|}
\hline INDICATORS USED FOR RESEARCH & RANKING SYSTEM (COUNTRY) \\
\hline Overall grants (money amount) & Slovakia \\
\hline Grants per faculty (money amount) & Austria, Germany, Italy \\
\hline Grants per faculty (absolute numbers) & Italy \\
\hline Research projects funded by the European Union (EU) & Italy \\
\hline Participation in int'I research programs & Poland \\
\hline Number of publications & Sweden \\
\hline Publications per researcher & Germany, Slovakia, Switzerland \\
\hline Citations per faculty & United Kingdom \\
\hline Citations per publication & Germany, Slovakia, Switzerland \\
\hline Number of int'I publications & Poland \\
\hline Percentage of articles cited within first two years after publication & Sweden \\
\hline Number of publications with $5+$ citations & Slovakia \\
\hline Percentage of articles belonging to top 5 per cent most cited articles ( $\mathrm{HiCi})$ & Sweden \\
\hline Number of patents (absolute number) & Germany \\
\hline Patents per faculty & Germany \\
\hline Ratio of the student's research & United Kingdom \\
\hline Research quality & Germany, United Kingdom \\
\hline Reputation for research & Austria, Germany \\
\hline
\end{tabular}

Source: Hendel and Stolz, 2008, p. 181. 


\subsubsection{HIGHER EDUCATION RANKINGS OF SHANGHAI JIAO TONG UNIVERSITY}

\section{INSTITUTE}

In compiling its Academic Ranking of World Universities, the SJTU group made a deliberate decision to focus on research performance (Liu and Cheng, 2005). The SJTU (Shanghai Jiao Tong University) rankings are not holistic university rankings, though they have been widely interpreted as such, notwithstanding the strenuous efforts by the SJTU group. It was considered impossible to compare teaching and learning on a worldwide basis, owing to the huge differences between universities and the large variety of countries, and because of the technical difficulties inherent in obtaining internationally comparable data. Nor did the SJTU group want to use subjective measures of opinion or data that were sourced from the universities themselves. It was believed that the only data sufficiently reliable for the purpose were broadly available and internationally comparable data of measurable research performance. An additional rationale for the use of research performance data is that, arguably, research is already the most important single determinant of global university reputation and the only indicator available that is unambiguously merit based. The SJTU group has widely consulted throughout the higher education world on the calculation of the index and the compilation of the data. The successive annual measures appear to be increasingly robust.

As mentioned in table 2, the major part of the SJTU index is determined by publication and citation performance in the sciences, social sciences, and humanities: $20 \%$ by citation in leading journals, $20 \%$ by articles in Science and Nature, and $20 \%$ by the number of HiCi researchers in the institution, researchers named in the Thomson and Institute for Scientific Information (ISI) classification of the leading 250 to 300 researchers in their broad field of study, of which nearly all are science-based disciplines, on the basis of citation performance ISI, 2006. Another 30\% of the index is determined by the location of the winners of Nobel Prizes and Fields Medals in mathematics, during their training (10\%) and in their current employment (20\%). The remaining $10 \%$ of the index is determined by taking the total derived from the above data and dividing by the number of staff. As such, the SJTU rankings favor universities that are large and comprehensive 
enough to amass strong research performance over a broad range of research fields while carrying relatively few staff who are research inactive. They also favor universities that are particularly strong in the sciences, favor universities from English-language nations because English is the language of research non-English language work is both published less and cited less, and favor universities from the United States because of nationally circular citation patterns: Americans tend to cite Americans (Altbach, 2006). Rankings usually reward older and larger comprehensive institutions with a medical school by aggregating outputs size does matter; accordingly, institutional restructuring and particularly the reorganization of research including the creation of research institutes and graduate schools often with special or targeted investment is pervasive across higher education. And, most of this activity tends to favor the sciences because this activity is best captured in internationally, publicly available and verifiable databases. Many HEls are developing and expanding English language facilities and capacity through the recruitment of international scholars and students; improving marketing and hence peer knowledge of the institution through expensive/extensive advertisement features, e.g. in nature, glossy brochures or marketing tours, rewarding faculty and Ph.D. students who publish in highly cited journals, and seeking to positively affect the staff/student ratio. Institutions everywhere are preoccupied with recruiting more high achieving students, preferably at Ph.D. level who, like international scholars, will be assets in the reputation race.

The arts, humanities and social sciences feel especially vulnerable in this environment. Professional disciplines, e.g. engineering, business and education, which do not have a strong tradition of peer reviewed publications, are also under pressure. There is little doubt that HEls are considering the costs associated with remaining in fields which are deemed less vital to their profile or perform poorly on comparative indicators. Their choice is boosting the performance of strong areas and perhaps redistributing earned funds to weaker areas later, bringing weaker areas up to the level of the strong or closing them down. There is also evidence of the relative strengthening of high science areas, accomplished by using the President's special fund to assign additional faculty to particular units or building new dedicated labs and other facilities, or indirectly by rewarding those departments which are especially productive or secure exemplary 
findings. The Nobel Prize criterion is perhaps the most controversial, as the prize is submission based and at times has been open to claims that an element of politicking enters the decisions (Bloom,2005). The scientific merit is not the only determining factor. Like the citation measures, the Nobel Prize criterion also works in favor of a small, select group of nations. Bloom (2005) notes that of the 736 Nobel Prizes awarded as of January 2003, 670 (91.0\%) went to people from high income countries as defined by the World Bank, and a majority went to people from the United States, with 3.8\% from Russia or the Soviet Union and Eastern Europe and 5.2\% from emerging and developing nations. People from the latter group had by far their best prospect of winning a Nobel Prize in the categories of literature (10.1\%) or peace $(19.8 \%)$, but these areas are excluded from the SJTU index of research performance. Furthermore, of the nine scientists who originated from emerging or developing countries and who won Nobel Prizes in chemistry, physics, physiology, or medicine, four were working in universities in the United States and two in the United Kingdom and Europe (Boulton, 2010).

\subsubsection{THE TIMES HIGHER EDUCATION SUPPLEMENT RANKINGS OF UNIVERSITIES}

The Times Higher Education Supplement has set out to provide a holistic ranking of HEls, self-described as the best guide to the world's top universities in world university rankings. The rankings appear to have been designed to service the market in cross border degrees. A high value is placed on institutional reputation and on the level of internationalization of HEls, and in the outcome, the rankings tend to favor HEls with a strong presence in the degree market. A total of $40 \%$ of the Times index is composed of an opinion survey of academics around the world, and another $10 \%$ of a survey of global employers. There are two internationalization indicators: the proportion of students who are international (5\%) and the proportion of staff who are international (5\%). Another $20 \%$ is determined by the student-staff ratio, which is treated as proxy for teaching quality. The remaining $20 \%$ of the Times index is composed of research citations per staff member using the Thomson and ISI database (Huang, 2010). The emphasis on reputation tended to favor the best-known universities in many nations. Along the way, the Times rankings boosted the number of leading British universities and reduced the number of U.S. universities in 
the world's top 100 from the 53 in Jiao Tong to just 31. However, the Times Higher Education Supplement rankings are open to a number of methodological criticisms.

Furthermore, the Times student internationalization indicator rewards supplier strategies of volume building rather than the quality of student demand or the quality of programs. Teaching quality cannot be adequately assessed using a resource quantity indicator such as the student staff ratio and research plays a relatively minor part in determining the Times rankings. An HEl's marketing division is better rewarded than its researchers. This does not square well with the way that higher education is understood in most nations. Furthermore, by favoring HEls active in the cross-border degree market, the Times rankings created anomalies (Huang ,2010). They inflated the performance of Australian universities, which achieved 12 universities in the world's top 100. Canada, a similar system in many respects, achieved only 3 universities in the top 100. Arguably, Canadian higher education is stronger in terms of system size, resources per student, level of participation, and research performance, though the Canadian system Australia's system. Subsequently, Newsweek World's Most Global, 2006 prepared a composite system of rankings that combines the research publication and citation measures from SJTU with the measures of internationalization, student staff ratios, and citations per head from the Times and that adds a metric for library holdings. By removing the reputational surveys from the Times index, Newsweek's data appear more plausible (Boulton, 2010).

\subsubsection{GLOBALIZATION OF RANKINGS}

Research is not only the most globalized of all activities in higher education, but research capacity is also a key marker in the higher education landscape because the research standing of HEls and nations feeds into both their capacity to produce globally salient outputs and their generic attractiveness to other HEls, to prospective students, and to economic capital. The SJTUIHE global university rankings provide data that enable the research performance of individual HEls and the upper research level of national systems to be compared. The data are largely based on measurable quantitative and qualitative indicators of research outputs, plus the incidence of 
Nobel Prizes and Fields Medals in mathematics. These data are helpful in mapping the global position of nations and HEls, especially to the extent that higher education is imagined as a competition among nations and among HEls for status and resources.

Canada and Australia are added; the English-speaking nations constitute $71 \%$ of the top 100. Cheng reported in (2010) for historical reasons and where resources and status have been concentrated in particular institutions, individual HEls play a larger role in the world than the global resource position of the nation would suggest. The China, which at this point lacks the level of research university performance commensurate with its standing as a world economic power, though its policy aims to redress the imbalance. National economic capacity is calculated by multiplying national income with national income per head, thus taking into account both quantitative economic weight and the intensity of wealth as measured by income per person. Each nation's share of global economic capacity is calculated by comparing its national economic capacity to the global total. As mentioned in table 3, the nations whose university systems are above average performers in research terms, relative to national economic capacity, are Israel, Sweden, Switzerland, the United Kingdom, Netherlands, Canada, Finland, Denmark, Australia, and the United States. The United States performs very well in its share of the top 100 research universities, but, interestingly, it underperforms in its share of the world's top 500. This indicates the stratification effects of a highly competitive system. In the United States, there is a concentration of research resources in the leading universities at the expense of the regional knowledge economies. Germany does well at the level of the top 500, indicating that there is a broad-based research capacity across the national system, but less well in its share of the top 100. Japan underperforms relative to economic capacity on both measures. China, Korea, Singapore, Belgium, Spain, Norway, Hungary, New Zealand, Brazil, South Africa, and others are strong in the top 500 group relative to economic capacity but have no top 100 research universities (Westerheijden, 2006).

It is significant that in the nations that do best relative to economic capacity, aside from the United States (which is so often the exception in national patterns of higher education), the 
private sector plays a relatively minor role in the sector, and, in most of these cases, especially in Europe, research resources are broadly distributed across the public university sector. Several nations that under perform at the top 100 level have large private sectors and a highly stratified research effort, including Japan, Korea, Poland, Brazil, and Mexico This underlines the dependence of research capacity on public investment; given the public good character of research and the other measures of the worldwide distribution of research output confirm the SJTU map of research performance. The United States alone produced almost a third of the world output of scientific articles in 2001, and its scientific literature accounted for $44 \%$ of citations in the world scientific literature (Westerheijden, 2006). Likewise, the potential for productive synergies between university research and industry is unequally distributed. Rich countries, home to $15 \%$ of the world's population, are responsible for over $90 \%$ of the patents granted. These patterns are replicated in research publishing. As mentioned Westerheijden, on (2006), scientists and social scientists in the United States published 200,870 articles in major journals. The volume of the articles from Japan was 57,420, the United Kingdom 47,660, Germany 43,623, France 31,317, and Switzerland 8,107. By contrast, in Indonesia, a midlevel developing nation with two thirds of the population of the United States, there were 207 articles. There were 11,076 from India and 20,978 from China (National Science Board [NSB], 2006). Though inequalities among nations in scientific capacity will persist, the specific patterns change over time. Table 3 provides each OECD nation's number and share of articles published in science and engineering fields. Social sciences, in 2000 and 2006, plus data for all other nations producing more than 1,000 articles in 2008 and emerging nations with populations of more than 100 million but little scientific infrastructure. OECD (20080), excluding the United Kingdom, published $29.4 \%$ of the world's articles in 2010, compared to $44.6 \%$ in all English-speaking countries.

The data show that there has been some pluralization of scientific publication since 2002. The number of articles from South Korea remarkably increased from 771 in 2002 to 11,037 in 2008 , from $0.2 \%$ to $1.7 \%$ of the world's output. The number of articles from China also grew rapidly, from 4,619 articles (1.0\%) in 2002 to 20,978 (3.2\%) in 2008. Likewise, Taiwan's share rose from $0.3 \%$ to $1.2 \%$ and Singapore's share rose from $0.1 \%$ to $0.4 \%$ (Westerheijden, 2006). The U.S. 
share of world scientific articles fell from $38.1 \%$ in 2002 to $30.9 \%$ in 2001. In 2008, the total output of scientific articles from Western Europe moved past that of North America. Between 2002 and 2008 , the total output of articles from North America rose by $13 \%$ compared to $59 \%$ in Western Europe and $119 \%$ in Asia (table3).

TABLE 3.THE GLOBAL SUPER LEAGUE: THE WORLD'S LEADING UNIVERSITIES ACCORDING TO SJTUI 2010.

\begin{tabular}{|c|c|c|c|c|c|c|c|}
\hline \multicolumn{2}{|c|}{ University } & Points & Nation & & University & Points & Nation \\
\hline 1 & Harvard U & 100.0 & United States & 1 & Harvard U & 100.0 & United States \\
\hline 2 & U Cambridge & 72.6 & United Kingdom & 2 & Massachusetts IT(MIT) & 86.9 & United States \\
\hline 3 & Stanford U & 72.5 & United States & 3 & U Cambridge & 85.8 & United Kingdom \\
\hline 4 & U California, Berkeley & 72.1 & United States & 4 & U Oxford & 83.9 & United Kingdom \\
\hline 5 & Massachusetts IT(MIT) & 69.7 & United States & 5 & Stanford U & 83.4 & United States \\
\hline 6 & California & 66.0 & United States & 6 & U California, Berkeley & 80.6 & United States \\
\hline 7 & Columbia U & 61.8 & United States & 7 & Yale U & 72.7 & United States \\
\hline 8 & Princeton U & 58.6 & United States & 8 & California IT(“Caltech") & 71.5 & United States \\
\hline 9 & U Chicago & 58.6 & United States & 9 & Princeton U & 64.8 & United States \\
\hline 10 & U Oxford & 57.6 & United Kingdom & 10 & E. Poly technique & 61.5 & France \\
\hline 11 & Yale U & 55.9 & United States & 11 & Duke U & 59.1 & United States \\
\hline 12 & Cornell U & 54.1 & United States & 11 & London School of & 59.1 & United Kingdom \\
\hline 13 & U California, San Diego & 50.5 & United States & 13 & Imperial College London & 59.0 & United Kingdom \\
\hline 14 & U California, Los & 50.4 & United States & 14 & Cornell U & 58.1 & United States \\
\hline 15 & U Pennsylvania & 50.1 & United States & 15 & Beijing U & 56.3 & China \\
\hline 16 & U Wisconsin-Madison & 48.8 & United States & 16 & Tokyo U & 55.1 & Japan \\
\hline 17 & U Washington(Seattle) & 48.5 & United States & 17 & U California, San Francisco & 54.9 & United States \\
\hline 18 & U California, San & 47.7 & United States & 17 & U Chicago & 54.9 & United States \\
\hline 19 & Tokyo U & 46.7 & Japan & 19 & U Melbourne & 54.5 & Australia \\
\hline 20 & Johns Hopkins U & 46.6 & United States & 20 & Columbia U & 53.9 & United States \\
\hline
\end{tabular}

Source: adapted from Westerheijden, (2006).

\subsection{HIGHER EDUCATION AND RANKINGS}

One generation ago, international relations in higher education, although often generative of new developments, were largely marginal to the ongoing day-to-day operations of higher education institutions (HEls) and systems, except in scientific research. Now the growing impact of the global environment in and through higher education systems and institutions is inescapable. Cross-border flows, relations, cooperation, and competition have become essential dimensions of 
national policymaking and of the strategic apparatus of executive and disciplinary leaders in individual HEIs. As reported in OECD (2010), the rise of global referencing does not signify that higher education has simply become a single worldwide network of HEls. In global markets, studies of international student choice making indicate that, the whole are household names all over the world, the national identity of HEls continues to be more important in the eyes of the world than the institutional identity of the individual HEls (King and Locke, 2008). Though the role of the private sector is growing worldwide and in some nations, it constitutes a majority of $\mathrm{HEl}$ in most nations foreign providers (which are all defined as part of the private sector when operating outside their own national jurisdiction) play only a marginal role, except in purely online education, which overall enrolls but a small proportion of students. In the multilateral General Agreement on Trade in Services and World Trade Organization negotiations, a national interest bias is strongly apparent. All of the Organization for Economic Cooperation and Development $(O E C D, 2008)$ governments have chosen to retain firm control over the national character of the systems under their jurisdiction. Among the exporting nations, a typical stance is to expect a greater degree of deregulation in foreign nations than the exporter is prepared to countenance at home.

Yet globalization also has transformative implications for the internal relations between nation states and their HEls. In one sense, the single worldwide logic of global rankings is confirmed in that within global networks universities directly deal with each other in their own right (Tomas Folch \& Castro, 2015). The model of stand-alone global actors was long practiced among individual researchers and scholars and has always shaped the dealings of certain leading universities mostly in the United States and the United Kingdom with the rest of the world. It is now much more widespread. But it is also argued that ranking fulfils a function. According to Hazelkorn (2009), some of the most important arguments are summarized in the following:

- Rankings simplify and clarify the student's picture of higher education

Students invest considerable time and money (either in the form of fees or student loans) in higher education. As a result, the choice of the education option is important. However, consider that it is difficult to obtain satisfactory information about the actual differences in quality 
between different higher education programs and institutions. Rankings provide relatively simple and direct information about the quality of higher education. Straightforward information of this kind is often considered to be particularly important for students with no experience of universities and the higher education sector.

- Rankings also simplify and clarify matters for interested parties outside the higher education sector

There is also a demand and need for information about the quality of various education programs and institutions outside the higher education sector. This may be a question of potential employers who need information about which programs or institutions provide education and training for people the employer wishes to recruit. And members of the general public may also be interested in information about the quality of the education services that they help to finance in the form of taxes.

- Ranking gives higher institutions free publicity

The considerable expansion of higher education makes it increasingly difficult to have a full picture on a worldwide basis of universities and institutions that provide higher education and conduct research. It is also difficult for the institutions concerned to inform the public about their operations (Provan \& Abercromby, 2008). Rankings are one way of enabling higher education institutions and their operations to make themselves known an efficient and cheap method, many people would claim. As a result, it is probably seldom easy to decide to withdraw from a ran-king system by failing to supply the relevant information.

- Rankings provide incentives for improving quality in higher education and research

Ranking can create incentives for improving various aspects of the quality aspects measured, by making the institutions concerned aware of their position in the ranking lists, thus enabling them to improve their rating.

- Rankings improve the quality of data collection in the higher education field 
If the designers of ranking lists indicate their methods clearly, ranking may result in an attempt by the institutions listed to improve the quality of the data on which the rankings are based. Information supplied directly by the institutions concerned is a crucial feature of many existing ranking systems, and the quality of data collection may be enhanced if the institutions cooperate.

- Rankings provide a many-sided picture of higher education

In many cases, rankings are influenced by the views of several different stakeholder and expert groups (both students and academic experts, for example), and are based on various statistical indicators, sometimes involving quality evaluations, etc. Hence, rankings collate information from many different sources and, as a result, provide a broader picture than specific indicators. Criticism of ranking is more common than its defense, however. Much of this criticism is at a detailed level, and we will be looking at some of these points in later chapters. However, there is also some general criticism, which may be summarized, in the present context.

- Ranking provides misleading picture of quality in higher education

Perhaps the most common criticism is that rankings fail to detect quality, and also that the wrong indicators are selected for the ranking process. Ranking designers are also criticized because they only measure what is available, they are not interested in quality, and they fail to define it. It is even more common to find, however, that the specific definition of quality used in the various rankings is subject to criticism. This is often a question of an undue focus on reputation as an indicator, or on traditional resource or result measures.

- Ranking provides a misleading and false picture of differences in quality

While the previous item involved the wrong choice of indicators in the various rankings, in this case the criticism is directed at the wrong method. Some of this criticism is concerned with the problem of combining various indicators to provide a single result. This involves a simplification, but a great deal of information about specific indicators is lost in the process. The weighting of the various indicators is also sometimes criticized on the grounds that an unduly 
heavy or light weighting is applied to one aspect or another or, more commonly, that the weighting is arbitrary or based on tradition in other words that there is no underlying theoretical concept. This heading also includes criticism of the robustness of the statistical methods used, for example that they are sensitive to minor changes and that the differences between units (higher education institutions) are not always statistically significant.

- Ranking provides a misleading picture of trends over time

Since several ranking systems frequently change their methods or indicators from one year to the next, the trend in the ranking lists give a false picture of the real changes that are taking place. What may appear to be major changes for a higher education institution from one year to another (upwards or downwards in the list) may be entirely due to a change in the method employed, or because some particular indicator has been added or excluded.

- Ranking lists encourage unreasonable behavior on the part of students and institutions

A consequence of the above criticisms. If ranking lists are unable to measure genuine quality, this may clearly have disastrous consequences if students base their choices on such rankings, or if higher education institutions endeavor to improve their position on these lists. In particular, this criticism is directed at "one size fits all" rankings which, since they treat all institutions in the same way, do not allow for any variation in assignments, activities or results. This, in its turn, stifles profiling and variation in higher education and instead promotes a conformity that is seldom desirable.

\subsubsection{THE RANKING EFFECTS ON STUDENTS AND INSTITUTIONS}

The ranking affects the perceptions of both institutions and students in certain respects. Those in favor of the ranking of universities tend, for example, to claim that potential students use rankings to make a rational choice when selecting an institution or education program, and that ranking encourages the institutions concerned to improve the quality of their programs (Kruzhalinin \& Artjushina, 2008). On the other hand, the critics consider that the ranking of 
universities leads to irrational behavior on the part of both institutions and students. But what do we actually know about the impact of rankings on institutions and students. In order to study this question, it would be reviewed some of the research in this area. First it will be discussed the existing information about the effects of ranking on institutions, and subsequently we discuss the research findings on the role played by rankings in potential students' choice of education program or institution. Although the impact of ranking on institutions is a widely-debated topic, the empirical research in this area is relatively limited. A few investigations are frequently cited, but they are exclusively based on data from other countries, particularly the United States. As regards the research that is available, it appears to be unanimously considered that ranking does affect the institutions in one way or another.

On the other hand, there are differences of opinion about the extent of the impact of ranking, or what effects are actually involved. Certain studies indicate that the ranking of universities has a considerable and predominantly negative impact on the behavior of higher education institutions. American higher education institutions often employ more or less honorable methods to improve their ratings, in particular in the U.S. News and World Report's ranking. This may involve, for example, reducing the admissions ratio at the institution concerned, or manipulating information on the results of the SAT admissions test. Clarke (2007) shows, in another study, that ranking may have a negative impact on an institution's recruitment from different social groups. This study is based on previous research, but also on media reporting from various parts of the world mainly from the United States and it indicates, among other things, that university rankings have a negative impact on the recruitment of students from minority and low income groups. As a result of rankings, the institutions concerned had a vested interest in recruiting students who were regarded as an asset in terms of maintaining or improving the institution's ranking in other words students who were high achievers.

Conversely, such institutions were less interested in recruiting students from low income groups or from ethnic minorities. According to Clarke (2007), the results suggest that ranking systems should give credit to institutions for their ability to educate students to a greater extent 
than at present, rather than recruiting students who are already high achievers (Clarke,2007). Research indicates that ranking has both positive and negative effects on the measures adopted by higher education institutions. In 2006, Hazelkorn carried out an extensive questionnaire survey covering more than 200 higher education institutions, primarily in Europe but also in other parts of the world. The results show that ranking is of considerable importance for both universities and other forms of higher education. Only 17 percent of the institutions concerned stated that rankings were of no importance whatsoever. More than half the institutions surveyed indicated that university rankings had had a positive impact on their reputation and publicity, and that, as a result, this had also helped the institution to attract students, initiate academic cooperation and recruit prominent researchers and teachers. It also emerged that almost than half the institutions surveyed had used the ranking results in their own marketing (Hazelkorn, 2007). The majority of the institutions surveyed had a formal process for evaluating ranking results, finding weaknesses in their own organization and taking any measures necessary. Most institutions also monitored the positions of other universities and institutions in the ranking lists. About forty percent of the institutions surveyed stated that rankings were an important factor in determining which institutions they were prepared to cooperate with, and an even higher proportion thought that ranking played a part in other universities and higher education institutions choice of partners. Furthermore, a majority consider red that rankings influenced other key groups, such as students, parents, the government, employers, present and future staff at the institution concerned and sources of research funding. This survey also indicated that most higher education institutions considered that the rankings had several weaknesses, mentioning for example that they favor institutions that are already well-established, that they mainly focus on research rather than education, and that they contain many errors. For its own part, the specific institution concerned regarded the effects of rankings as either positive or negative, depending on its position in the ranking tables. 


\subsubsection{THE IMPORTANCE OF RANKING FOR STUDENT CHOICES}

When discussing the effects of ranking on potential students' decisions concerning education programs, it may be useful to distinguish between their selection of an education program and their choice of the higher education institution at which they wish to study. The choice of education program tends to take priority over the choice of institution, even if these two decisions are clearly not completely independent of each other. The potential student's decision process may be divided into three stages which, in practice are not always so clearly separated (Clarke,2007). In the first stage, the student decides whether or not he or she wishes to pursue higher education studies. In the second stage, information is collected and the student identifies a limited number of possible programs, based on personal interest, suitability and what is regarded as feasible. In the third stage, the student takes a final decision about which institution to apply for. In order to clarify the situation, we may note that university rankings may be a possible decision factor in the second or the third stages. On the other hand, it is less likely that rankings play any part in the decision to pursue higher education. There are some studies that investigate students' choice of education program and compare the results in several different countries. The results of the role played by university rankings point in different directions, however, depending on the survey method employed and the student groups investigated. It appears for example, that international students and students with parents with higher education make use of university rankings to a greater extent than other categories. Somehow, the university ranking is of relatively limited importance for students' choice of higher education institution. Instead, factors such as geographical location, the range of courses offered, study fees and social activities appear to be more important. In some case, the reputation of the higher education institution affects the student's choice to a considerable extent, but this is more likely to be based on information from their immediate environment rather than on rankings. The most important information comes from parents, friends, student counsellors and the institutions themselves (Stella \& Woodhouse,2006). 
Clarke on (2007) investigates, among other things, potential students' choice of university or college. According to Clarke, previous research indicates that this choice is influenced by several different factors: opinions about academic quality and the institution's or the program's reputation, entry requirements, geographical location, the existence of study fees, access to scholarships, the infrastructure, employment opportunities, social life, advice from the immediate surroundings and information provided by guidebooks and ranking lists (Clarke, 2007). On the one hand, there is research that suggests that ranking is not of any great importance for the majority of students. Studies in the United States, Great Britain and Germany, for example, indicate that students from high income families are the principal users of ranking lists. On the other hand, there is research that shows that the ranking of a higher education institution in a given year does actually affect the number of applicants and the number of new students at such an institution in the following year. Patterns of this nature apply in the United States, but also for example in Germany. In another international study, Hazelkorn (2009) interviewed a number of students in Germany, Australia and Japan. The results of this survey indicate that different student categories use rankings in different ways:

-National students at the undergraduate level normally study at the local university in their city or region, and only a limited proportion study else-where. Such students monitor regional ranking to some extent.

-International undergraduate students often travel abroad under the auspices of a program, but they take reputation factors that are sometimes based on ranking lists into account to some extent.

-National students at the second or third cycle levels use rankings, but often in combination with other information about the various institutions concerned.

- International students at the second or third cycle levels make the greatest use of ranking lists and not only the international lists but also national rankings, since they are often acquainted with a particular country, but are not familiar with its higher education institutions. 


\subsubsection{THE FLOWS OF TECHNOLOGY AND GLOBAL UNIVERSITY RANKINGS}

Globalization is about the convergence and partial integration of the different parts of the world and of its nations, institutions and people. As Kruzhaliin reported on (2008), the widening, deepening and speeding up of interconnectedness on a worldwide scale'. This is characterized by growing global flows across national borders, flows of people; flows of messages, ideas, knowledge and images; flows of goods, money, labor and production itself; flows of technology; flows of policies. Global convergence is both economic and cultural. The Internet sustains a global system

of communications and data transfer, a single worldwide library of information, which is a staggering change, and brings cultures into closer contact with each other. The Internet has been the most important element in conditioning globalization during the last 15 years, followed by the cheapening of air travel. The Internet secures much of its unifying and universal character from the role of the English language, which is even more dominant in communications, and in research and knowledge, than it is in global business. Globalization has been forcing change across all knowledge-intensive industries (Kruzhalinin, 2008). These developments have been intensified by the global financial crisis and the adjustment period that has defined its aftermath. Yet, even before the transition to this new economic reality, world-wide comparisons were becoming increasingly significant.

At the same time, the knowledge society is placing a premium on education and high educational attainment. While countries are increasingly dependent upon talent, many are under severe demographic pressure. Society is aging at the same time that the birth rate is falling, especially in the more developed countries. Because higher education plays a fundamental role in creating competitive advantage, this situation presents a challenge for national strategies based on growing knowledge intensive industries, and heightens competition for high-achieving students (Lalancette, 2010). These developments are having a profound impact on higher education. Questions are being asked about the way in which higher education is managed, funded and organized. There is increasing emphasis on value-for-money, international benchmarking and (public) investor confidence. Performance assessment of scientific-scholarly research is also 
increasingly important, especially for publicly funded research. Accordingly, many governments are busy reshaping/restructuring higher education systems and institutions to ensure they can better compete. Some countries are able to invest heavily in higher education and research, while others are financially restricted because of the severity of public and private debt. At the international and national level, these developments are driving greater differentiation between elite and mass HEls and systems.

According to international research conducted in 2006 and 2008, (Hazelkorn, 2007) higher education leaders around the world believe high achieving students use rankings to 'shortlist' university choice, especially at the postgraduate level, and stakeholders use rankings to influence their own decisions about funding, sponsorship and graduate recruitment. In return, they believe benefits flow from high ranking: by far and away the most important is reputational risk. Caught between not wanting to place public emphasis on their ranking ... and privately trying to avoid slipping (Griffith \&Rask,2007), HE leaders believe rankings are here to stay and they have little alternative but to take them into account because others do. Hence, they are taking the results very seriously and integrating them within their strategic planning processes. Based on the research of Hazelkorn (2007), 63 percent of respondents said they had taken strategic, organizational, managerial or academic action and were making significant changes while only 8 percent said they had taken no action. This presents a remarkable change from the 20 per cent and showed they ignored rankings in 2007. Most significantly, rankings appear to be influencing priorities, including curriculum. However, the biggest changes are apparent in rebalancing teaching, research and undergraduate/postgraduate activity, and re-focusing resource allocation towards those fields which are likely to be more productive, better performers, and indicator sensitive/responsive. Regardless of what kind of $\mathrm{HEI}$, the message is clear: research matters more now, not more than teaching necessarily but it matters more right now at this point in time. It is arguable, if the actions described below can be directly attributed to rankings as distinct from normal competitive factors, better professional organization, quality enhancement or the value placed on $\mathrm{S}$ and $\mathrm{T}$ research by research agencies, but there is a strong correlation between them and specific indicators. The simplest and most cost neutral actions are those that affect brand and 
institutional data, and choice of publication or language. Most non-native English HEls are busy encouraging their faculty to publish in the English language highly cited/international journals, and ensuring that a common institutional brand is used on all academic publications (Kruzhalinin, 2008). The latter is especially critical for HEls which have recently merged different organizations and units of which carried a separate identity or logo. In addition, accurate data collection whether the focus is research output or international student numbers is seen as vital. The aim is to ensure that all activity is captured by the ranking organizations and accurately reflected. After this, the costs rise potentially exponentially. The most globally influential global rankings are those prepared by the Shanghai Jiao Tong University (SJTU), first issued in 2003. The second set of global rankings, prepared by the Times Higher Education Supplement, was first published in 2004. Although there is disquiet about the impact of the rankings and some instances of critique of the methods (particularly in HEls and nations where performance was worse than expected), there have been few concerted efforts to discredit the rankings process, which appears to have secured public credibility. Given this, research universities know that they must succeed within the terms of the measures. The rankings have generated a strong drive to improve comparative position, particularly in the SJTU rankings, which are seen as more credible. Within national systems, the rankings have prompted strong desires to achieve high-ranking research universities both as a symbol of national achievement and prestige and as engines of economic growth in a global knowledge economy. There has been a growing emphasis on strategies of institutional stratification and concentration of research resources, some of which predated the rankings. At the same time, global rankings have stimulated global competition for leading researchers and the best younger talent. All of these responses have both cemented the role of the rankings themselves and further intensified competitive pressures. 


\subsubsection{HIGHLIGHTS OF UNIVERSITY RANKING FRAME WORK}

Rankings and league tables of higher education institutions and programs are a global phenomenon. They serve for many purposes: they respond to demands from consumers for easily interpretable information on the standing of higher education institutions; they stimulate competition among them; they provide some of the rationale for allocation of funds; and they help differentiate among different types of institutions and different programs and disciplines. In addition, when correctly understood and interpreted, they contribute to the definition of "quality" of higher education institutions within a particular country, complementing the rigorous work conducted in the context of quality assessment and review performed by public and independent accrediting agencies. This is why rankings of higher education institutions have become part of the framework of national accountability and quality assurance processes, and why more nations are likely to see the development of rankings in the future. Given this trend, it is important that those producing rankings and league tables hold themselves accountable for quality in their own data collection, methodology, and dissemination. University leaders believe rankings help maintain and build institutional position and reputation; good students use rankings to 'shortlist' university choice, especially postgraduates; and key stakeholders use rankings to influence their decisions about accreditation, funding, sponsorship and employee recruitment. Respondents say 'reputation derived from league tables is a critical determinant for applicants. Rankings also influence national and international partnerships and collaborations. Leaders say they consider a potential partner's rank prior to entering into discussion about research and academic programs. In addition, rankings influence the willingness of others to collaborate with them or support their membership of academic/professional associations. Rankings are a manifestation of global competition and are used as a policy instrument. Many governments proclaim the desire to establish at least one, if not more, 'world class' universities. Rankings inflate the academic 'arms race' locking institutions and governments into a continual 'quest for ever increasing resources'. A world-class university is $\$ 1.5 b$ a year operation, plus an additional $\$ 500 m$ if there is a medical school. This would require many HEls increasing their overall funding by at least 40\% (Usher, 2006; Saldak and Liu 2007). Few societies or (public) institutions can afford this level of investment, 
without sacrificing other social and economic objectives. Evidence suggests rankings are propelling a growing gap between elite and mass higher education with greater institutional stratification and research concentration. HEls which do not meet the criteria or do not have 'brand recognition' will effectively be devalued.

\subsection{MARKETING ASPECTS AND RANKINGS}

In the recent years, huge changes in policy, environmental changes, such as privatization, diversification, decentralization, internationalization and increased competition in higher education are common to most countries, and massive changes in governance, structure and status of higher education have been taken place all over the (Saldak, Merisotis \&Liu, 2008). These changes have an effect on how higher education institutions operate nowadays and they are seen as the driving forces for the marketization of higher education. For instance, the privatization of higher education and cost sharing through the introduction of tuition fees in many European countries have increased the consumerist approach to higher education and the need to consider student's expectations more (Stensaker, 2007). The strengthening of competition at institutional, national and international level requires new operating modes through the adoption of more market oriented and business like forms of operation within higher education institutions. The marketing concept has known a number of evolutionary stages in the developed countries and these stages are also known as marketing approaches or marketing philosophies. Some have associated such approaches with the history of the businesses and come up with a number of orientations according to the different aspects emphasized by the organizations in time: the production era, the sales era, the marketing concept era and the societal marketing era. Five concepts under which organizations conduct their marketing activity are:

1. the production concept

2. the product concept

3. the selling concept

4. the marketing concept 
5. the societal marketing concept

Among those, the last two are of interest to us, as they contain the core of the marketing concept, as it is used today by most organizations: The marketing concept holds that the key to achieving organizational goals consists in determining the needs and wants of target markets and delivering the desired satisfaction more effectively and efficiently than competitors. The marketing approach, as opposed to the previous one's places in the center of the organization's activity the consumer and its wants and needs. Such a consumer-focused philosophy (as opposed to the selling philosophy), adds to the approach other concepts specific to the marketing orientation, such as consumer behavior, market segmentation, positioning, marketing mix activities: product policy, pricing policy, distribution policy and promotion policy. In order to satisfy the consumers, organizations have to find out first who are these consumers. Therefore, concepts such as market segmentation are used to identify different target markets secondly the organizations have to identify what consumers need and want. Segments of interest the organization decides on the positioning strategy, usually based on differentiation from their competitors. Further on, based on the information gathered through the previous activities, organizations have to produce what consumers need and want. Such products that satisfy the needs and wants of consumers are to be marketed using the basic marketing mix activities: product, price, distribution and promotion, also called the transactional marketing. Marketing theories and concepts, which have been effective in business, are gradually now being applied by many universities with the purpose to gain competitive advantage (Helmsley-Brown, 2006). The higher education sector has two main features that influence, the marketing ideas that can be applied to it. First of all, higher education in most countries is a non-profit sector, therefore marketing concepts applied to the sector do not function as in the business sector, where the primary goals are profit making. Second higher education is a service, therefore all peculiarities applicable to the marketing of services apply to higher education. Considering these two aspects, we will be looking to the extent to which the previously mentioned marketing concepts apply to higher education (Hazelkorn, 2008). 
Taking into discussion the targeted markets in higher education, it is highly accepted that the sector has multi-clients, as students, employers and society are seen to be the main beneficiaries of higher education services. Even though the whole notion of students as consumers attracts criticism, students are the direct and immediate customers of the higher education services (Hazelkorn, 2008). Employers, too, benefit of the results of the higher education processes, as they use the skills and the abilities that graduates acquired during their studies. Some called graduates products of higher education, while the employers were seen as customers, but we consider that both students/graduates and employers are consumers of higher education services. While students are principal consumers, employers can be seen as secondary or indirect consumers of higher education services. Finally, the society as a whole benefits of the results of the higher education. The three categories are seen as the main stakeholders of higher education and as the main clients, with the students being the primary ones. Furthermore, there are other stakeholders that have an interest in higher education: along, students, employers and society, there are also the parents, the government and other funding bodies, quality assurance agencies and other authorities, professional bodies.

Sometimes the needs and the wants of the different stakeholders do not totally coincide and higher education has to satisfy more constituencies, making its activity more complex. Students as primary clients are usually segmented and treated differently, but all other stakeholders are more difficult to segment. Three major student market segments: international students, mature students, and high school leavers, segments with different motivations when making their higher education choice and different needs and wants from educational services. To conclude, market segmentation and targeting works in higher education for the sectors' primary clients, the students, but there are many more other stakeholders that have to be satisfied and to whom typical marketing segmenting does not fully apply. Consumer behavior in our case refers to student behavior, as primary client and stakeholder of higher education, and it is one aspect worth studying. Aspects such as student expectations and student choice are characteristic to consumer behavior in higher education. 
Student's expectations are seen as a valuable source of information, as their satisfaction depends on the relationship between their expectations and their perceptions of the actual performance. Similarly, knowing the reasons applicants choose universities and courses of studies, is important to developing institutional positioning. Consumer of higher education are no longer passive consumers; they became informed consumers who make rational choices of higher education courses and institutions (Hazelkorn, 2009). Research in higher education choice by examining the decision-making process and potential student's search for information takes usually place illustrating the application of these marketing concepts to the higher education sector. However, the specificity of higher education is that most students (undergraduates) are one time consumers, as opposed to the business sector where repeat purchases take place often. This results in differences in consumer behavior in the two sectors and possible different marketing strategies to address consumers in the two sectors.

Positioning strategies, the very essence of institutional positioning is to differentiate itself from competitors. This is rather difficult to do in the higher education, as academic products are seen to be rather similar and differences between universities as seen as not being decisive while it is accepted that there is a lack of real differentiation in the sector in general. Consequently, positioning in the higher education sector rather involves to effectively present institutional image and develop their position in the minds of the public than differentiation. In spite of the similarity of products in higher education, there are suggested key factors to be used by universities to occupy positions of distinctiveness: teaching-led vs. research-led; science-based vs. arts based; basic teaching vs. higher level teaching (Hazelkorn, 2009). But even those factors cannot ensure totally differentiated positions of universities (especially where the national higher education sectors have numerous universities). Therefore, we can state that there are limitations in using the positioning concept in the real sense (differentiation) in the higher education sector. Marketing mix activities or the 4P's model (product, price, distribution and promotion) is a marketing concept used as such to a limited extent in higher education, with its different components being paid different levels of attention in the sector. Pricing and promotion policies are used more in higher education as marketing concepts, product policy not always being defined 
as such, is highly used in higher education institutions (program portfolio, product quality, branding), while distribution policy is not considered at all, as not being applicable to the sector. Product policy in higher education refers to the services the sector offers. We have on the one hand, educational services as main products and support services as associated services, and we have on the other hand, the three main activities of universities as services offered: teaching, research and the third sector services (Hemsley-Brown, 2010). The nature of services in general and their specific characteristics simultaneity, perishability, intangibility, heterogeneity affect also higher education services and their marketing.

Service marketing principles apply to higher education. To exemplify, it is well known that when we talk about services, both external and internal marketing becomes equally important, as the nature of the interpersonal interaction between the customer and the contact employee (in our case the contact between students and teachers and support personnel) often affects satisfaction. Therefore, relationship marketing is one viable strategy in the context of higher education, as service staff (lecturers, secretaries, administration offices personnel etc.) are to be responsive to the student's needs and expectations. Quality of higher education institution's services becomes important as a trigger for customer satisfaction. But, every stakeholder in higher education has a particular view of quality, dependent on their specific needs, consequently higher education institutions have to fulfil multiple needs. For instance, when we talk about quality of educational services designated to students, the teaching and learning activities are the two faces of the same coin and the results depend on both teachers and students, who have to participate in the process to obtain a quality service.

\subsubsection{BRANDING}

According to Stensaker (2007), branding is another marketing concept that started to be used by higher education institutions. Branding can be seen as part of both product policy and promotion policy and it has specific characteristics in the higher education sector. When talking about branding in higher education, the relationship between concepts such as brand, reputation 
and image has to be considered. Branding and reputation share common grounds, but they are not identical. Reputation is generally seen as something that is more naturally built over time, while a brand is more constructed. Reputation is seen to be the collective presentation of past images of an institution established over time, while image (and based on it the brand) is the immediate set of meanings associated with a particular institution. Reputation is also seen by universities chief executives, to better reflect reality than brand does. For universities reputation is they're very being and what they actually sell every day. So, reputation rather than branding is a more suitable concept for the higher education sector (Stensaker, 2007).

Branding is associated usually with the creation of images with the purpose of increasing sales. In higher education, the purpose of developing a brand is not to sell products and services, but to communicate corporate identity in order to promote attraction and loyalty. It is suggested that the concepts of institutional image and reputation can be interpreted differently in higher education compared to other sectors, as usually a good reputation for a company is associated with increased sales, while in higher education high reputation is often linked with minimal sales, as the more prestigious a university is the fewer students accepts in its educational programs. This illustrates again the differences between marketing concepts applied to the business sector and to the higher education sector (Usher, 2012). The higher education sector encounters challenges in branding due to the high degree of uniformity of the sector and consequently the difficulty to differentiate and create unique images for most higher education institutions, most universities are actually doing very like most other universities in branding they play with some mix of excellence, quality, achievement none remotely unique (Hemsley-Brown, 2010).

The fact that higher education has multiple stakeholders, makes the branding effort much more complex and a multiversity perspective that shows multiple images at the same time is recommended by some. There are indications that branding played so far a modest role in higher education and it is appreciated that there are a number of concepts associated with branding that have still to be explored in higher education. Distribution policy is rather not considered, as having too little applicability to the higher education sector. Promotion policy concentrates in higher 
education around marketing communications and dissemination of information, mainly in the context of choices made by potential students.

This type of activity that emphasize on the use of communication tools (such as advertising, public relations, personal selling) in order to attract students, it can be associated with the selling approach, if the information provided at admission about the HEl and its services, does not correspond to reality. Subsequent efforts to ensure good student experience through valuable teaching experience and good support services and to prepare students for their profession (as main requirements of students from higher education are to be done to ensure correspondence between reality and the communicated image and to maintain promotion policy within the marketing philosophy that concentrates on the consumer. Pricing policy that deals with setting the prices for the educational services has a number of peculiarities in the higher education sector (Usher, 2009). First of all, until a decade ago, in many countries mainly the European ones higher education was totally state budgeted that meant from the student's point of view that it was free of charge. Since tuition fees have been introduced, they encountered different forms in different countries as full costs, as partial contribution to the educational costs but the state still plays a major role in setting tuition fees which illustrates how the application of this marketing concept has limitations in higher education, as the sector does not have always the freedom to set its own prices. This does not mean that the importance of price related aspects should be ignored. Price related information tuition fees, cost of living, scholarships are given equal importance as the programmer's characteristics in the potential students' choice, given the recent increased consumerism in higher education choice.

The use of these marketing specific concepts in higher education varies highly from one country to another. In USA as compared many times to Europe marketing concepts in higher education have been assimilated to a higher extent, as USA has gone through the clash of cultures between the traditional academic values and the market-focused values ten years earlier. Even in Europe there are differences, with UK being seen among the earliest in Europe to introduce more market like approaches to higher education. But in many countries marketing related activities are 
at initial stages in higher education, communication being usually the first step to introduce a marketing orientation in the institution. To conclude, the most frequently met type of marketing activity that universities conduct is strong promotion and communication towards potential applicants related to increasing recruitment and admission.

However, marketing specific actions should not stop here, the essence of satisfying the consumer (the student as primary consumer) is to offer him quality services (educational and support services). Therefore, providing good student experience plays a major role in ensuring student satisfaction. Institutional image and reputation and based on them a constructed brand are important in attracting students. Images, reputations and brands are formed based on delivering quality services towards students and other stakeholders. In the case of higher education, the product itself (teaching, research, third sector services, and support services) are more important to deliver customer satisfaction, than any other marketing activity. In general terms, we can state that many marketing concepts are applicable to the higher education sector, if we consider their main meaning. However, the practical ways in which they are applied to the higher education sector present a number of peculiarities that rather make to state that for most of them, there are limitations in their application to the higher education sector. In other words, marketing principles and marketing ideas can be applied to the higher education sector, but not in the same way as in the business sector (Stensaker, 2007). The differences in types of products/services offered, the scope of targeted markets and the organization of specific marketing activities that exist between the business and the higher education sectors make marketing concepts only partially applicable to the higher education sector. This is in accordance with others opinion that approaches taken from other sectors or from commercial marketing are not readily transferable to higher education (Marginson, 2007). However, there are not to be forgotten the lessons that higher education can learn from the business sector and it is up to the higher education sector to use the marketing concepts to the extent to which it makes sense and provides useful results. However, at the moment it is considered that despite the existence of substantial literature on marketization of higher education and consumer behavior, the literature is incoherent and lacks theoretical models to reflect upon the particular context of higher 
education and the nature of its services. Research on many marketing activities, such as branding it is seen to be at a pioneer stage. The marketing field it is still to be developed and adapted for the higher education sector.

One interpretation of what rankings mean for higher education is associated with the changes in how the sector is regulated and governed. In this perspective, the state has abdicated as the key regulator of higher education, and the governance of the sector is more diffuse and complex than in the past, creating hybrid governance arrangements (Marginson, 2007). As part of these hybrid governance arrangements, the state has facilitated a number of market-based or quasi market- based governing strategies, including increased competition between higher education institutions. Rankings can be said to be linked to this governing approach in a number of ways. An interesting aspect here is the fact that some countries link institutional positions in ranking exercises to resource allocation. The Research Assessment Exercise in the United Kingdom, and the Performance-Based Research Fund in New Zealand are prime examples (Clarke, 2005), a development that can be interpreted to represent an 'outsourcing' of the instruments of governance. While such a direct link between ranking exercises and governmental funding is still rather unusual, it is intriguing since the governments in such cases also may pave the way to align their policy-making to the design of (global) rankings. Even more intriguing are the potential consequences of this transfer, if one also considers the possibility that some of the rankings might be based on questionable methodology. The role of rankings in this perspective is not only that of being a means in a more market-regulated sector, where rankings could be considered an instrument for regulation. One could even argue that rankings may also be a driver of the development. Since rankings are open, available and easy accessible to the public, the broader public also gets more insight into the activities and into the performance of higher education. A likely consequence is that the public may more easily develop its own opinion about the quality of the sector, and that they subsequently want, or will be given a stronger voice in the policy-making process (Usher, 2009). 


\subsubsection{MARKETING APPROACHES AND CORE MARKETING CONCEPTS}

In order to better analyze how different marketing concepts, apply to the higher education sector, this section will overview some of the main general marketing approaches and concepts. It is widely accepted that the marketing concept has known a number of evolutionary stages in the developed countries and these stages are also known as marketing approaches or marketing philosophies (Usher, 2009). Some have associated such approaches with the history of the businesses and come up with a number of orientations according to the different aspects emphasized by the organizations in time: the production era, the sales era, the marketing concept era and the societal marketing era. Similarly, Usher (2009) considers that there are five concepts under which organizations conduct their marketing activity, namely the production concept, the product concept, the selling concept, the marketing concept and the societal marketing concept. Among those, the last two are of interest to us, as they contain the core of the marketing concept, as it is used today by most organizations: the marketing concept holds that the key to achieving organizational goals consists in determining the needs and wants of target markets and delivering the desired satisfaction more effectively and efficiently than competitors. The marketing approach, as opposed to the previous one's places in the center of the organization's activity the consumer and its wants and needs. Such a consumer-focused philosophy, adds to the approach other concepts specific to the marketing orientation, such as consumer behavior, market segmentation, positioning, marketing mix activities: product policy, pricing policy, distribution policy and promotion policy: in order to satisfy the consumers, organizations have to find out first who are these consumers.

Therefore, concepts such as market segmentation are used to identify different target markets; secondly, the organizations have to identify what consumers need and want. The use of the concept of consumer behavior and the study of the consumers' behavior is one way to fulfil the marketing core goal. Usually the steps of the consumer buying decisional process are used to characterize consumer behavior; after targeting the market segments of interest the organization decides on the positioning strategy, usually based on differentiation from its competitors; further 
on, based on the information gathered through the previous activities, organizations have to produce what consumers need and want (Helmsley - Brown, 2010).

Such products that satisfy the needs and wants of consumers are to be marketed using the basic marketing mix activities: product, price, distribution and promotion, also called the transactional marketing; product policy envisages the offering of products and services in accordance with the consumer expectations. Part of the product policy is also branding, seen as the creation of an attractive image of an institution in the market place (Stensaker, 2007); pricing policy envisages the exchanges that take place for the ownership of the good or service. However, from the consumers' perspective, pricing refers to the value of the perceived quality received in exchange for the paid price; distribution policy refers to the ways through which the organization makes the product/service available to the consumers; promotion policy deals with means of communications between the organization and its targeted markets. Such marketing approaches and concepts have a critical role for the organizations and for society and it is considered that at the present time, marketing rather than production skills have become the key to creating competitive advantage (Doyle, 2000). Most of these concepts have been conceived in the business environment.

\subsubsection{RANKINGS AS A MARKETING FACTOR}

Various corporate marketing strategies are being employed in the academic world as universities search for ways to improve ranking and conduct a broad survey to better understand in-state perceptions of top universities, their characteristics and how best to communicate information concerning the university, but still there is a lot to be studied. The identity package project is part of the University's effort to improve its reputation though the ranking, and build community support to improve student recruitment through consistent communication. An increasingly competitive higher education marketplace, branding with the help of ranking has become big business for universities. Institutions know that, in a sense, the degrees they confer

are worth only as much as their brand. In nations where tuition fees are established, students buy 
a brand that will appeal to the right businesses when it is time to find a job; their choice of university will become part of their own "brand identity". To attract the right caliber of academics, a university relies on its brand. And when those same academics submit a proposal for research funding or a paper to a leading journal, the brand of their institution may play a role in how their research is judged. The university's brand becomes part of their own brand as an academic. An alternative perspective would see rankings as part of the increasing process of globalization of higher education. Within this global economy, higher education is regarded as just another economic sector (Helmsley-Brown, 2010), of which it is important to collect, systematize and compare the service providers. From being a mainly nationally oriented sector, most higher education institutions nowadays have a strategy for internationalization, and taking part in that also implies the need for greater transparency. The role of rankings in this perspective is that of offering consumer information to the many buyers and sellers participating in the globalized game of higher education services. Global rankings offer players of the game information which claims to compare higher education institutions across national borders. As such, rankings are part of the standardization of institutions in society with potentially negative consequences for institutional diversity.

The difference to the former perspective is that while the state in a market perspective allows market mechanisms to play a role, it is the market that is 'in charge' in the latter perspective, restraining the possibilities of the state to interfere in the governance of the sector. Given the expansion of higher education in most countries in terms of the number of students that enter university education and the resources spent on the sector, an increasing interest has emerged in the 1990s as to whether the sector delivers with respect to outcomes and results (Westerheijden et al. 2007). While discussions about effectiveness and efficiency in the past often could be characterized as a closed conversation between the state and the universities, this discussion has been opened up as a consequence of the rise of the audit society. A key factor leading to this development is again the expansion of higher education, and not the least, due to the many new providers entering the sector. As in many sectors in society, quantitative expansion often triggers worries about the quality achieved. In the last decades, higher education has been 
confronted with a number of methods and schemes aiming at assessing quality. However, although we have witnessed a considerable spread of quality assurance schemes in this period, one could still argue that quality assurance has failed in addressing issues concerning learning outcomes, performance and results (Stensaker, 2007). In an audit society perspective, rankings then could be seen as a new accountability mechanism in higher education a mechanism that has developed because existing mechanisms have not been able to answer the critical questions of the public. While the accountability function of rankings could be interpreted within a market perspective, one can nevertheless also argue that rankings fulfil an important democratic function in society as an independent source of information about a sector that is becoming more important.

If we change the level of analysis from a macro level to the institutional level, quite a different perspective on rankings emerges. While many rankings proclaim their purpose to be that of affecting student choice and student behavior, one should not rule out the possibility that those mostly taking action vis-à-vis rankings are the higher education institutions themselves in a race for prestige and position in the academic pecking order (Dill \& Soo, 2005). Rankings provide institutions with prestige, depending on their position in the hierarchy created. As it has mentioned before in a study of university emulation in the United States, universities consider other universities' reputation and position as crucial for their own strategic development. In this perspective, rankings function as a fashion arena in which institutions compare themselves, and in which they strive to create and build their own identity. As in other fashion arenas, rankings define who is hot and who is not, due to the emphasis on hierarchy and exclusivity. Whether the identity intended to be built is useful or relevant in a systems perspective is of less importance here. Fashion creates its own field with quite different norms, values and logics, then in other societal arenas.

\subsubsection{MARKETINGIN HIGHER EDUCATION AND RANKINGS}

While a globalization perspective emphasizes the quantitative expansion of higher education, the mobility of knowledge and trading within the existing knowledge base, a 
knowledge-society perspective would rather emphasize the qualitative changes in the production and structuring of knowledge. In the latter perspective, the innovative aspects of knowledge are valued and appreciated how knowledge can be applied and exploited commercially in the market place. As knowledge producers, universities for centuries have provided ideas and theories relevant for many different purposes and contexts. Rankings may contribute to change this picture (Westerheijden et al. 2007). Hence, in this perspective ranking is a symptom of the emerging knowledge society, and the tendency to emphasize certain dimensions of the knowledge production. The function of ranking in this perspective is that of a structuring device of knowledge.

Although the external information function is part of this perspective, the important aspect is how higher education may change internally as a result of this development. According to Marginson (2007), rankings through their emphasis on certain indicators including research, patents, employability and the links between higher education and industry may contribute to change the conceptions about what kind of knowledge is considered as valuable, and how knowledge should be structured. Somewhat paradoxically, the idea about the knowledge society may actually restrain our beliefs about the many values of knowledge with rankings playing the role as the normative filter (Marginson \& Wan der Wende, 2007). While rankings often proclaim a common-sense approach to the primary processes of higher education, emphasizing what is claimed to be objective and not self-reported data and giving priority to indicators with considerably legitimacy. For example, Nobel Prizes, a serious epistemological analysis should also question our belief system, our knowledge about the sector and our attitudes towards the methods and strategies used to create the rankings. Recently, initiatives have been taken to establish some sound standards as to how rankings should be carried out but the beliefs about higher education, on which many rankings are based, are perhaps the aspect most difficult to challenge. A starting point here could be the fact that prior to the appearance of any published ranking, there actually exist considerable tacit knowledge inside and outside of higher education, about which institutions could be considered to be the 'best' and the most 'excellent' not only nationally, but also internationally. Beliefs that many rankings today replicate and seem to take for granted. Given the many faculties, schools, and departments inside a university, one could 
question the belief of whether every unit can be excellent still a considerable number of rankings do not break down data from the institutional level. Other beliefs which are important for the construction of the rankings are related to the relationships between research and education, between formal competence and student learning and to the importance given to certain dimensions of the knowledge production in universities. Such beliefs are frequently visualized through indicators such as student-teacher ratios, resources spent on staff and students or various indicators concerning the infrastructure. The links between these other related indicators, and the quality of the provision offered are, at best, rather uncertain (Marginson, 2007). A related problem is that many indicators used in rankings could be characterized as input factors providing little information of the outcome, for example, in terms of student learning. Even indicators that seem to be output-based, such as research publishing, should actually be perceived as input indicators if they are used to establish a causal relationship between research and teaching. A third problematic issue concerning rankings is related to the way indicators are selected, weighted and given priority in the overall analysis of the available data. Many ranking use data collected for other purposes in their analyses, without checking such data for validity and reliability.

Furthermore, although not all rankings priorities among indicators, most of them do. However, these weightings seem to be a rather subjective process. Although a given reader is informed about the fact that certain indicators count more than others, the reason for the same and the technicalities associated with the actual weight given is, in most cases, not disclosed. A final area for concern relating to the epistemic dimension of rankings is the assumption that knowledge can be deconstructed, quantified and summarized in overall scores (Westerheijden et al. 2007). While writers on higher education for a long time have argued that the knowledge created in universities is contextual, integrated, and culturally embedded, rankings treat knowledge almost as an externality of the university. As such, the new survey provides an impressing overview of central characteristics of ranking systems, although a key message is that diversity rather than uniformity still dominates the different rankings. Although they do point out that 'age', 'faculty size' and 'per-student expenditure', are factors that are likely suspects in explaining why some institutions always come on top. Following from this, the future of rankings 
probably lies in the growing amount of information from institutional sources, which may further increase the number and types of rankings available. This development to some extent may contribute to 'democratize' rankings in that more power is transferred to the consumer and the user of rankings (Marginson, 2007). Interestingly, one could argue that consumer or user power is already taken into account in some of the rankings published by the weight given to the views by academics and students on the quality of various higher education providers. Hence, in other sectors of society, targeting the consumers or users of a given service about their views of the services offered is in general regarded as the common-sense approach. The interest in reputation in higher education by linking the concept to inherent characteristics of the sector, but points out that although reputation is a symbolic aspect with much attention attached, it does not make the concept more valid or reliable as an input to ranking exercises. Reputation may differ significantly between departments within the same institution, between different groups of stakeholders and between and across countries. The consequences of misusing reputation indicators in rankings are further elaborated, and it is shown how reputation indeed is a social construction, meaning that it is impossible to find a joint agreement on reputation as such; one can only come across an agreement on reputation among a particular sample of people in a particular context.

The issue about reputation indicators in rankings, and points to the links between global university rankings and knowledge economy in a global age as an explanation for the emphasis given to reputation. To deal with the problem, it is suggested a reconstruction of global rankings by including benchmarking into the ranking process to ensure that comparisons made are comparing what is actually comparable. This would necessitate comparison at the program or basic unit level, department/faculty or at the level of disciplines, rather than at institutional level. The advantages of benchmarking exercises in terms of generating valid indicators, choosing variables and definitions and validate the data and information generated. The insistence on quantitative measures and benchmarking in the establishment of global university rankings is seen as a new paradigm, which might serve the purpose of rankings better, and provide the public with more reliable and valid information. 
Providing the public, most often students, with better information about the quality of higher education providers is often the rationale behind the growth of ranking systems. Quantitative and precise information about central characteristics of universities and colleges may, in this respect be seen as the right way forward. However, the existence of certain quantitative data sets, and our trust and sense making of such data can be problematic. While quantitative data in general are interpreted as more 'trustworthy' than qualitative data, changes in university positions in a given ranking may depend on the way data are collected and/or reported, and that the numbering of rankings may over-exaggerate what in reality may be quite small differences and changes. Rankings are carried out to provide intending students with better information on which they can base their choices in terms of institution and program, but they argue that given the way some quantitative data are systematized and presented, the result may actually be potentially misleading to students, and have serious negative implications for a given institution. Three conclusions are drawn from the analysis. First, more attention should be paid to the publication of what a university is able to offer to international students; second, there is a necessity for data management within an institution; and third, ranking statistics and data should be offered in a customized form, or in such a way that users may interact with the original data. University rankings or 'league tables', a novelty as recently as 15 years ago, are today a standard feature in most countries with large higher education systems. They were originally created over 20 years ago by US News and World Report in order to meet a perceived market need for more transparent, comparative data about educational institutions. Reviled by critics but popular with parents, copy-cat ranking systems began popping up all over the world, usually shortly after the introduction of or a rapid rise in tuition fees (Usher \& Savino,2007). Wherever rankings have appeared, they have been met with a mixture of public enthusiasm and institutional unease. One of the main causes of institutional unease is the tendency of institutional ranking schemes to use weighted aggregates of indicators to arrive at a single, all-encompassing quality 'score', which in turn permits institutions to be ranked against one another. By selecting a particular set of indicators and assigning each a given weight, the authors of these rankings are imposing a specific definition of quality on the institutions being ranked. The fact that there may be other legitimate 
indicators or combinations of indicators is usually passed over in silence. The world's main ranking systems bear little if any relationship to one another, using very different indicators and weightings to arrive at a measure of quality. The issue concerning the relevance of rankings in an international setting is also a key concern for rankings or report cards as they prefer it to be labelled often are designed according to a particular cultural context that may be of less benefit to students or people from other cultural contexts. Acknowledging the importance of rankings for university and college choice, point out that report cards lack an important element which often determines choice, namely the issue of 'culture' and cultural differences.

As Marginson and Wan der Wende stated on (2007), that indicators used in report cards may be interpreted differently by different social and cultural groups, and that many rankings are currently dominated by the Western 'cultural conventions'. The problems in handling this challenge, but do argue that new technology and the possibilities of 'targeting' information to particular groups could make report cards more relevant as an information source for a more multi-cultural society. While the mainly focus on methodological issues, validity and reliability of rankings provide a comprehensive and multifaceted description of central characteristics and shortcomings of modern rankings, the issues of the potential links between rankings good or bad ones, irrespectively and the future development of the sector in terms of diversity and structure. The point of departure is the concern that rankings may be a powerful, although still not the only, driving force contributing to change central values and functions of higher education, and consequently also the whole organization of the sector. While diversity in missions, academic profiles and links to society in general has been seen as an important aspect of higher education, rankings may contribute to change this considerably (Salmi \& Saroyan, 2007). However, there are also other potential implications of rankings that should be taken into account. Rankings sometimes redistribute public and private goods in the higher education market, and how this may result in fewer public goods, but quite a number of private goods especially for those universities which fare well in the rankings. One of the main problems is that many rankings become an end in themselves with few or absent linkages to quality improvement of the sector as such (Salmi, 2009). The research emphasis that characterizes many rankings are also a concern of potential 
implication of current rankings is an exceedingly expensive 'academic arms race' for prestige which more and more substitutes the measurement of real performance. One important implication of such an arms race is increased costs for students (tuition fee) and/or a drive to increase the expenditures of higher education in general once again reducing the public good. Salmi (2010) argues that one runs the risk of developing universities that only become quite costly 'screening' mechanisms for the labor market rather than producers of human capital and new knowledge. Hence, the government regulation may be needed to offer alternative sources of information to students and others who want to know what learning outcomes universities may provide. Whether or not particular governmental regulations may have an impact on the rankings can still be questioned, since the rankings that are 'going global' seem to strengthen their position and importance. Identify some of the challenges the new expectations related to the idea of 'worldclass universities' may create for European and Asian higher education institutions (Salmi, 2007). The meaning of the concept 'world-class' is somewhat fluid and also depends on the indicators used, in both of these world regions, competitiveness and the strife for excellence and international standing has clearly increased. As one of the results, the concentration of research funding to ensure world-class status for a few universities to the detriment of the majority of institutions which have to struggle to maintain their level of funding. Such a negative consequence can endanger the (national) system of higher education as a whole because governments may neglect the losers in this race, and even the world class institutions will have to rely on the strength and reputation of the system as a whole. For some especially developing countries the authors argue that global rankings may actually have damaging effects for the development of more comprehensive and domestically relevant higher education systems for the sake of international competition. Rankings and their implications are contextualized and related to current developments of the sector, and how the landscape of higher education may look in the future (Salmi, 2007). The development of higher education systems is the key concern of higher education and the current restructuring process of this policy copying, and growing internationalization. While some contributors to the need for governmental action to be taken to counteract some of the unwanted consequences of rankings, it is also possible to see how many 
ranking schemes fit well with governmental policies, emphasizing more differentiation and stratification of the sector. The rankings also influence national policy agendas both in terms of introducing policies for stronger differentiation, and of legitimizing such initiatives politically (Helmsley - Brown, 2010). Hence, the argument launched is that the influence of ranking systems on national policy making should not be underestimated, and may cause 'biased' policy initiatives to be taken not only in developing countries but also in well- developed countries. Although ranking systems are intertwined with a number of other developments and policy initiatives, not only affecting higher education institutions, but also the policy framework governing the sector.

Larger historical developments of higher education, and points out that although ranking currently is enjoying the center stage of academic and political attention, the higher education sector has proven to be quite robust and resistant to a number of extrinsic attempts to instigate change over time. This does not mean that higher education is not changing or not responding to societal demands or needs, it is just a reminder that the sector is complex, and that the driving forces triggering change may sometimes be contradictory or having side effects, which we are not aware of at this stage (Salmi, 2009). Certainly, the new media of which rankings are an integrated part, are indeed a new force to enter the field of higher education and with high impact potential on policy making. Still, the new media are not the only force, although they focus our attention on the vertical dimension of institutional diversity (the best) and marginalize the horizontal one (the rest). But if we are entering the so-called knowledge society, there is a need to cater to the characteristics and contributions of the whole higher education system. Therefore, there is a need to improve information in Europe about the impacts of the university experience in general, and to develop alternative scenarios for the development of institutional patterns of higher education systems which do not only embrace the 'elite' functions of the system.

Rankings or report cards as they prefer it to be labelled often are designed according to a particular cultural context that may be of less benefit to students or people from other cultural contexts (Salmi, 2010). Acknowledging the importance of rankings for university and college choice, the authors point out that report cards lack an important element which often determines 
choice, namely the issue of 'culture' and cultural differences. They argue that indicators used in report cards may be interpreted differently by different social and cultural groups, and that many rankings are currently dominated by the Western 'cultural conventions'. The problems are in handling this challenge, but the new technology and the possibilities of 'targeting' information to particular groups could make report cards more relevant as an information source for a more multi-cultural society. While the five issues that mainly focus on methodological issues, validity and reliability of rankings provide a comprehensive and multifaceted description of central characteristics and shortcomings of modern rankings. While diversity in missions, academic profiles and links to society in general has been seen as an important aspect of higher education, rankings may contribute to change this considerably. The argument often raised is that the emphasis on research and research output may create more similar institutions unable to cater to the diverse needs of a multi- cultural and complex society (Salmi, 2007). Rankings sometimes redistribute public and private goods in the higher education market, and how this may result in fewer public goods, but quite a number of private goods especially for those universities which fare well in the rankings. One of the main problems is that many rankings become an end in themselves with few or absent linkages to quality improvement of the sector as such. The research emphasis that characterizes many rankings are also a concern of potential implication of current rankings is an exceedingly expensive 'academic arms race' for prestige which more and more substitutes the measurement of real performance. One important implication of such an arms race is increased costs for students (tuition fee) and/or a drive to increase the expenditures of higher education in general - once again reducing the public good. Dill argues (2005), that one runs the risk of developing universities that only become quite costly 'screening' mechanisms for the labor market rather than producers of human capital and new knowledge. Hence, the author concludes that government regulation may be needed to offer alternative sources of information to students and others who want to know what learning outcomes universities may provide.

Whether or not particular governmental regulations may have an impact on the rankings can still be questioned, since the rankings that are 'going global' seem to strengthen their position and importance. Identify some of the challenges the new expectations related to the idea of 
'world-class universities' may create for European and Asian higher education institutions. As one of the results, the authors note a concentration of research funding to ensure world-class status for a few universities to the detriment of the majority of institutions which have to struggle to maintain their level of funding. Such a negative consequence can endanger the (national) system of higher education as a whole because governments may neglect the losers in this race, and even the world-class institutions will have to rely on the strength and reputation of the system as a whole. For some especially developing countries global rankings may actually have damaging effects for the development of more comprehensive and domestically relevant higher education systems for the sake of international competition. Rankings and their implications are contextualized and related to current developments of the sector, and how the landscape of higher education may look in the future. The development of higher education systems is the key concern of higher education and the current restructuring process of this policy copying, and growing internationalization. While some contributors to the need for governmental action to be taken to counteract some of the unwanted consequences of rankings, it is also possible to see how many ranking schemes fit well with governmental policies, emphasizing more differentiation and stratification of the sector. The rankings also influence national policy agendas both in terms of introducing policies for stronger differentiation, and of legitimizing such initiatives politically. Hence, the argument launched is that the influence of ranking systems on national policymaking should not be underestimated, and may cause 'biased' policy initiatives to be taken not only in developing countries but also in well-developed countries. Although ranking systems are intertwined with a number of other developments and policy initiatives, not only affecting higher education institutions, but also the policy framework governing the sector (Usher, 2008). Larger historical developments of higher education, and points out that although ranking currently is enjoying the center stage of academic and political attention, the higher education sector has proven to be quite robust and resistant to a number of extrinsic attempts to instigate change over time.

This does not mean that higher education is not changing or not responding to societal demands or needs, it is just a reminder that the sector is complex, and that the driving forces 
triggering change may sometimes be contradictory or having side effects, which we are not aware of at this stage. Certainly, the new media of which rankings are an integrated part, are indeed a new force to enter the field of higher education and with high impact potential on policy-making. Still, the new media are not the only force, although they focus our attention on the vertical dimension of institutional diversity (the best) and marginalize the horizontal one. But if we are entering the so-called knowledge society, there is a need to cater to the characteristics and contributions of the whole higher education system (Saldak \& Liu, 2007). Therefore, there is a need to improve information in Europe about the impacts of the university experience in general, and to develop alternative scenarios for the development of institutional patterns of higher education systems which do not only embrace the 'elite' functions of the system.

\subsubsection{MARKETING AND BRANDING ASPECTS APPLIED IN UNIVERSITIES}

As universities find the need to appeal to an ever increasing and diverse student base, successful branding and marketing have become increasingly important activities for institutions. Universities must now go to greater lengths to differentiate themselves from competitor institutions. Successful branding can help with increasing enrollment, expanding fundraising capabilities, and other outcomes (Siegel, 2009). Today, effective strategic planning and brand management require more than traditional advertising, marketing or identity development. Institutions that craft, present and manage a unified brand message, experience and environment achieve a competitive advantage in recruiting, retaining and building loyalty amongst their students, parents, staff, faculty, alumnae and donors. Communicating a brand successfully to students, both current and prospective, requires strategic planning and effective tools. This section will explore some of the recent ways branding and marketing has been used in the higher education industry. As indicated above, institutions are focusing on branding and marketing far more than in previous years. Many have hired marketing professionals from the corporate world and invested significant time and money to create strong institutional brands. In some cases, such as at Northwestern University in the U.S., this has meant creating Chief Marketing Officer (CMO) positions and making brand creation and marketing campaigns a core function of the institution. 
For some institutions, this sort of re-trained perspective and corporate mentality has drawn praise as well as rebuke. Purdue University, for example, spent a half million dollars in 2010 on its markers all branding campaign which was poorly received by students and alumni (Helmsley-Brown, 2006).

However, like reported Siegel (2009), there is evidence that universities do not have to spend significant amounts of money to be effective. The other industry experts identify several top trends, and many of these branding and marketing approaches are feasible for most colleges universities. Unsurprisingly, they are heavily centered on the use of technology:

Responsive website design: Institutions are placing more emphasis on responsive web design to create intuitive and easy to navigate websites that can be viewed on multiple devices and platforms.

Search engine optimization: Administrators want their institutions to receive a prominent spot in search engine results, particularly Google. Especially for institutions that offer niche programs, it is increasingly important to ensure that search results include these programs at the top.

Use of web analytics: Colleges and universities are relying on data-driven analytics to determine who, how, and where they are reaching their audiences. The use of analytics software is increasing as the higher education web ecosystem is becoming increasingly complex, and the amount of material institutions have online is expanding (domains, subdomains, etc.). Getting a better handle of this data is a new area of concentration for colleges and universities (Siegel, 2009).

Strategic social media: While recent polls indicate nearly every institution of higher education use some form of social media, it is unclear that many are realizing any ROI on simply establishing Facebook or Twitter accounts. These trends are explored further in this section.

Mobile development: Alongside the rise of mobile technology and connected devices, colleges and universities are making greater investments in having a mobile presence. This includes not only mobile versions of websites and other content, but also making a greater amount of course content mobile-friendly. 
CMS and CRM systems: Alongside the use of web analytics and other methods of harnessing "big data" in higher education, colleges and universities are relying more heavily on content management and customer relations systems. CRM systems are especially important tools for admissions professionals engaged in outreach to prospective students.

Beyond the changes brought by technology, marketing and branding trends have shown a progressive reliance on more creative outreach efforts, as well as design and advertising campaigns. Some are more artistically oriented than others, but most attempts are to appeal more personally to students that may be interested in higher education. Examples include placing QR codes in public places, crowdsourcing. Photos and videos to share campus events, making creative advertising videos (with the intent to go viral), and upgrading housing and other facilities to attract students. More traditional marketing and branding strategies, such as open house events and sponsored visits for students are also still extremely popular, as the next section will discuss in more detail.

\subsubsection{BRANDING AND ITS EFFECTS ON MARKETING STRATEGY}

In reality, only the larger institutions have adapted their communications policies to include the brand angle and integrated it into their strategies. According to a recent report by Salmi (2010), 93\% of administrators in higher education already considered their institution to be a brand. However, that same report notes that in many cases, this is really more wishful thinking than objective truth. As institutions turn more to guidance from corporate CMOs or otherwise pursue a fundamental revamp of their marketing and branding strategies, several successful guidelines have emerged for higher education. The four main elements to branding strategy for higher education: Branding requires patient and rigorous effort, and relies heavily on timing (Salmi, 2010). A university brand can be damaged much more quickly than it can be successfully built, so consistency in purpose and messaging is necessary. For instance, a mediocre ranking is not catastrophic, but a series of low rankings can do long-term damage to the image. It is very important to keep promises, particularly when it comes to the quality of the education provided. Institutions must be committed to maintaining and improving quality. In turn, their 
communications must constantly be underpinned by facts, data, and irrefutable evidence: rankings, accreditations, applicant data (number and quality), recruitment of professors, placement of graduates, agreements with prestigious partners, media presence anything that demonstrates the quality, as the excellence of the institution helps craft and strengthens its brand. It is essential to ensure consistency among positioning, identity, strategy, stated goals, and communications. It is also important to carefully monitor the consistency not only of the messages expressed by the communications department, but also those of the professors, students, governing authorities. They must all speak with the same voice." Institutions should ensure that their brand is not diluted by attempting to "cover every market at once and meet everyone's expectations. Institutions should leverage multiple angles in order to maximize growth of a brand. This includes mobilizing alumni networks and current students to be brand ambassadors; maximizing merchandising potential (e.g., branded clothing and apparel, gifts, and other items, particularly related to athletics); and taking advantage of event organization in order to attract greater public attention (e.g., conferences, galas, or forums for students and businesses).Canadian institutions have employed these types of branding and marketing strategies, but the country as a whole has also prioritized "increasing its market share of international students (Boulton, 2010). In terms of branding and marketing, universities all around the world has attempted to redefine its national education system as wholly different from others in the global marketplace. As Boulton (2010) reported international education: a key driver of future prosperity outlines strategies for marketing and recruiting, including: Prioritizing specific market, the provinces identified Southeast Asia, the Caribbean, the Middle East, and Africa as priorities beyond the more established markets. The international students often select their country of choice first and then select the institution, universities should ensure to develop comprehensive communications strategies for prospective students from priority countries that promote the brand in all areas of marketing, media relations, event promotion, and digital communications. Employing a sophisticated digital communication system, including a website that is easy to navigate, highlights the advantages of studying in modern universities, and may include video testimonials of current international students, for example. Social media resources such as China's version of Twitter, called Weibo, can also be very 
valuable marketing tools. Some of the digital efforts endorsed by pioneer universities in UAS and that are being used by institutions to promote their brand are discussed below. Nevertheless, Noel-Levitz's 2013 survey of international students revealed that "direct email or phone conversation was more than twice as important as social media" for students to get information on institutions. The survey found that the university website was the most important source of information, followed by an electronic prospectus, input from friends, advertisement emails, and university fairs.

\subsubsection{SOCIAL MEDIA AND DIGITAL TECHNOLOGY IN BRANDING OF HIGHER EDUCATION}

One of the most significant ways branding and marketing of higher education has changed in recent years has been in the online space, using a variety of new platforms for external engagement and communication. The terms "social" and "digital" refer to the use of both social media and digital marketing more generally, and include the role of effective and intuitive websites. Institutions are making greater use of social media and digital platforms like Twitter, Facebook, YouTube, and podcasts to market their programs, while website design and interface is proving a crucial component in how colleges and universities present themselves to prospective students. According to Noel-Levitz's 2013 study, which refers to the university website as "the ultimate brand statement," a homepage is a key component in the student experience, and can make or break decisions about whether to attend: A university's homepage is the hub of its web presence and in attempting to appeal to a diverse range of visitors, the challenge is staying intuitive and uncluttered (Olds,2010). If visitors have to go back to your homepage every time to find the content they're seeking, they aren't likely to stay on your site very long. Website navigation is an integral component of overall site architecture from which all content can flow from. To achieve this, it has become common for universities to ensure their homepage is a clearly laid out portal to all of the content that students are looking for online. This means websites often now feature elements such as "well-placed navigation bars" and engaging visuals (e.g., slideshows, multimedia content, etc.), and ensure that "calls to action" (e.g., "Apply Now" buttons) feature prominently throughout the website experience. Broader trends in the use of social media 
platforms, however, have shown that while their use at colleges, universities, community colleges, and other academic institutions has exploded in the last few years, the success of such enterprises is uncertain.

Most institutions have experienced significant growing pains in their attempts to manage the variety of initiatives that are taken up by various programs, departments, academic units, and schools, which in many instances leads to a duplication of efforts. According to Noel-Levitz's 2013 survey, more than 950 institutions showed that a full 96 percent of respondents were actively using social media, but that many are struggling to manage their social media initiatives. If the evolution of social media is like raising a child, we're at the end of the toddler years. The latest poll indicated that 100 percent of respondent institutions are now using some form of social media but there is no reliable data on how effective the use of such tools are in terms of enrollment or elevating institutional. In terms of the specific platforms used, the survey highlighted wider adoption of the following social media platforms: Facebook is the most common form of social networking being used, with $98 \%$ of colleges and universities reporting having a Facebook page, Data from recent years show significant growth in the adoption of social media such as podcasting and Linkedln (figure 1):

- $84 \%$ report having some form of an institutional Twitter account

- $86 \%$ report having an institutional YouTube channel/presence

- $66 \%$ report maintaining some kind of blog

- $41 \%$ report the use of podcasting

- $47 \%$ of admissions professional's report using Linkedln 
FIGURE 1.TRENDS IN SOCIAL MEDIA USAGE AMONG U.S. COLLEGES AND UNIVERSITIES, 2008/2011

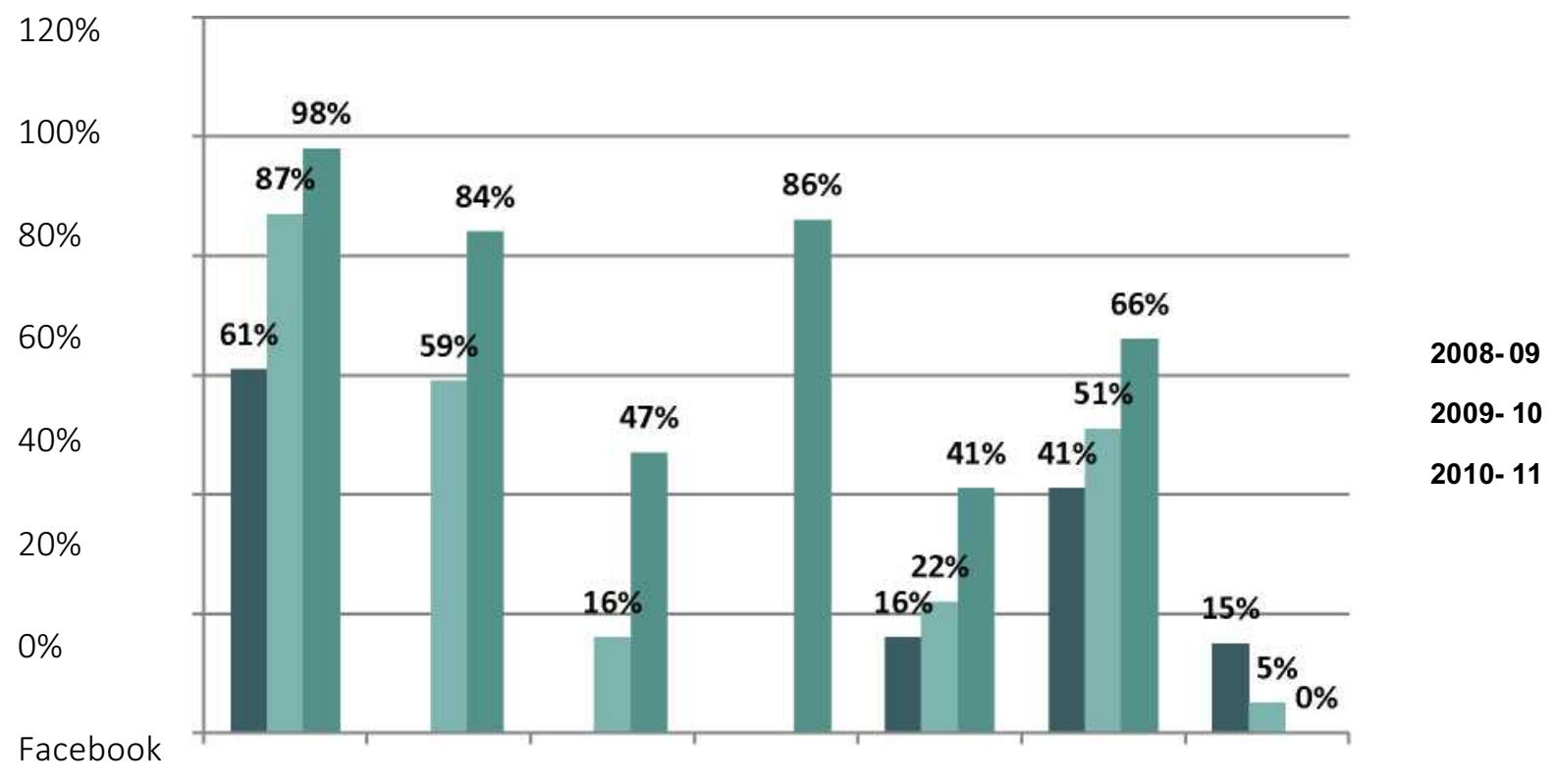

Twitter Linkedln YouTube Podcasting Blogging Do not use any

Source: Center for Marketing Research, U-Mass Dartmouth, IBID p.3, 2008/2009.

\subsubsection{RECRUITMENT AND ENROLLMENT OF ELITE STUDENTS}

There are a number of trends in recruitment and enrollment that are having a significant impact on how institutions go about attracting students. This includes shifts in demographics and increased mobility of students, as well as the increasing cost of higher education in many countries. Many of these are unsurprising, such as the rise online offerings, shifts in public perception of higher education and its value, and perhaps most notably, changes in demography and the need to tap into two very important markets: adult learners and international students. A poll conducted by Noel-Levitz in 2013 asked admissions officers what the five most effective marketing strategies for recruitment at polled institutions. Table 4 shows which strategies were the top ten strategies were for the prior year. 


\section{Literature review}

TABLE 4. TOP TEN STRATEGIES AND TACTICS FOR RECRUITMENT, BY INSTITUTION TYPE (2013)

\begin{tabular}{|c|c|c|}
\hline 1 & Campus open house events & Campus open house events \\
\hline 2 & Campus visit days for high school students & Campus visit days for high school students \\
\hline 3 & $\begin{array}{l}\text { Encouraging prospective students to apply on } \\
\text { the admissions website }\end{array}$ & $\begin{array}{l}\text { Encouraging prospective students to apply } \\
\text { on } \\
\text { the admissions website }\end{array}$ \\
\hline 4 & Encouraging prospective students to schedule campus visits on the admissions website & Weekend visits for high school students \\
\hline 5 & Using enrolled student in marketing/recruiting & $\begin{array}{l}\text { Encouraging prospective students to } \\
\text { schedule } \\
\text { campus visits on the admissions website }\end{array}$ \\
\hline 6 & Weekend visits for high school students & Community College articulation agreements \\
\hline 7 & $\begin{array}{l}\text { Routine contacts by admissions office professional staff to assess student reactions to financial } \\
\qquad \text { aid awards }\end{array}$ & $\begin{array}{l}\text { Campus visit events designed for school } \\
\text { counselors }\end{array}$ \\
\hline 8 & Campus visit events designed for school counselors & $\begin{array}{l}\text { Using enrolled student in } \\
\text { recruitment/marketing }\end{array}$ \\
\hline 9 & $\begin{array}{l}\text { Tele-counseling program to coordinate continuous, regularly scheduled flows of phone calls at a } \\
\qquad \text { high volume }\end{array}$ & $\begin{array}{l}\text { College-paid trips to campus for prospective } \\
\text { students }\end{array}$ \\
\hline 10 & $\begin{array}{l}\text { High school visits by admission } \\
\text { representatives to primary markets }\end{array}$ & $\begin{array}{l}\text { Off campus group meetings for prospective } \\
\text { students and/or their parents }\end{array}$ \\
\hline
\end{tabular}

Source: Noel-Levitz, 2013. https://www.noellevitz.com/papers-research-higher-education/2013/marketing-student-recruitmentpractices- benchmark-report

Notably, most of these are event driven and involve direct interaction with prospective students. Thus, while institutions are indeed relying on social media and digital presence to define their brand and attract students, traditional forms of outreach are still among the most effective 
and popular recruitment strategies that institutions use to increase enrollments. Other findings about marketing in higher education include: among the least effective strategies and tactics for both private and public four-year institutions were radio ads, asking current students or alumni for applicant referrals, online college fairs, and billboard/bus/outdoor advertising. Running television ads was rated a top practice in 2013 only by two-year public institutions, but was not being used by more than a quarter of survey respondents in this sector. Four-year public institutions increased their volume of written contacts direct mail, e-mail, and texting, and their purchasing of search list names from list vendors since Noel-Levitz's 2013 study. Only about onethird to one-half of respondents reported having a strategic, multiyear enrollment plan that they believed was of high quality. The preferred method of communication with potential students during first and subsequent contacts is email, though mailers and brochures are still used by a significant number of institutions.

\subsubsection{INTERNATIONAL RECRUITMENT}

Among the most competitive areas for colleges and universities, increasingly across the globe is the international/foreign student market. The combination of increased mobility of students and the lower number of first time applicants at universities in English speaking countries has created enormous pressures to compete for international students. In addition to the marketing and recruitment strategies outlined above, including strategies to attract international students, some institutions have elected to hire companies such as Pearson to engage in direct targeting of international students on their behalf. The company's progression website gives students (most likely exam clients) admission and pathway information on universities that partner with Pearson: Alongside its Degree Course Finder service for students, Pearson is now enabling a new marketing channel direct to students, for a fee. Institutions can decide their level of collaboration with the website, starting at just a listing and extending to being specifically promoted at one of the company's 80 centers worldwide. To achieve these numbers, U.S. institutions have had to change their strategies for recruitment such as maintaining a presence at conferences and job fairs overseas, offering generous financial aid packages to international 
students, as well as improving social media outreach efforts (Olds, 2010). Outside of international student recruitment, trends in higher education indicate that another key audience for enrollment is adult and non-traditional learners. In the United States, the number of adult learners returning to higher education, particularly for continuing education, has been rapidly increasing. According to the National Center for Education Statistics, in recent years, the percentage increase in the number of students age 25 and over has been larger than the percentage increase in the number of younger students, and this pattern is expected to continue. By 2020, the percentage of enrollments for students 25 and older is projected to increase by 20 percent over 2010 levels. In Canada, similar trends are expected. According to the Centre for the Study of Education and Work's WALL Surveys, there has been "a rapid intergenerational increase in the extent of engagement" in adult further education, and at least half of the population aged pursues some kind of continuing higher education. In addition, the same surveys indicate that as of 2010, almost 20 percent of that age bracket was facing problems of unmet need in further education. Figure 2 indicates the growth in further education participation rates among adults over the last several decades:

FIGURE 2.POST-SECONDARY COMPLETION AND FURTHER EDUCATION PARTICIPATION RATES, 25-64 YEAR OLDS

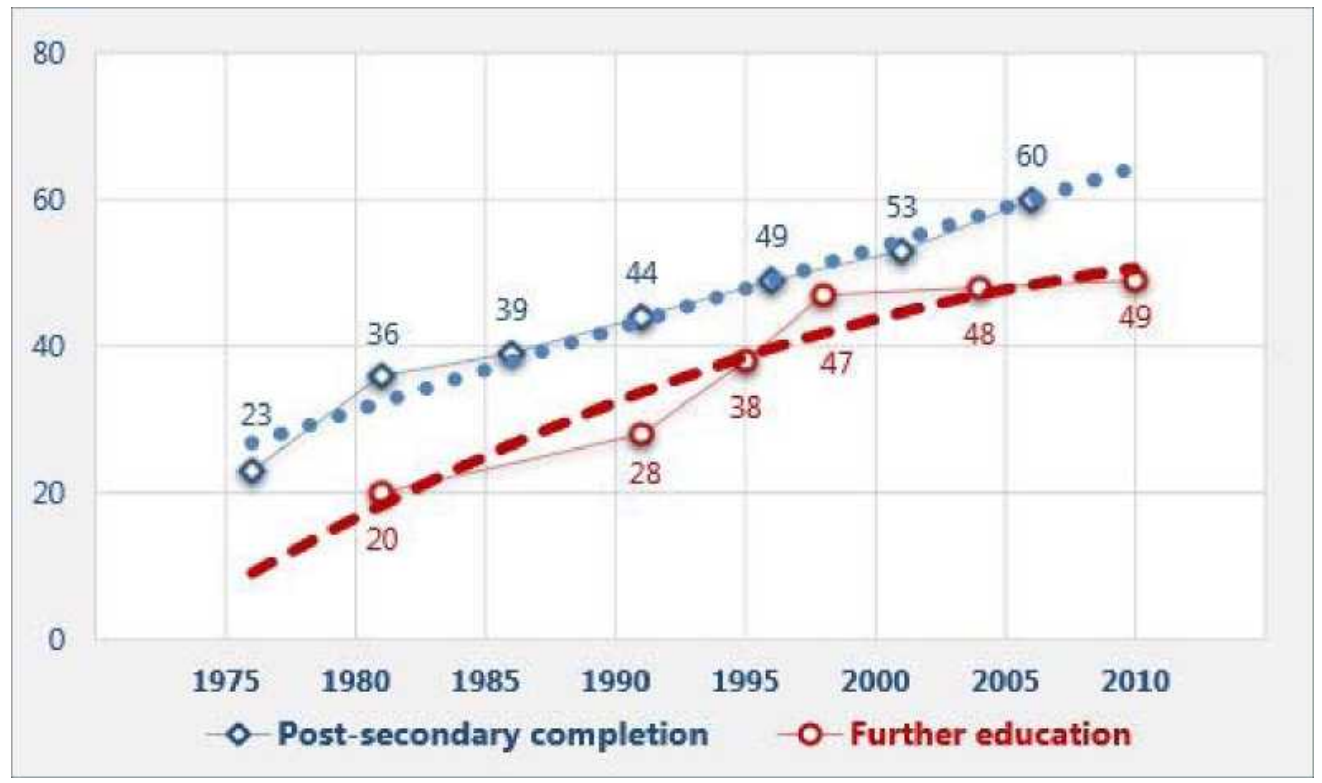

Source: Centre for the Study of Education and Work (Allen I.E. and Seaman, J. Changing Course: 
Recruiting these students will tap an unmet demand and growing market segment for both countries, and has required recruitment strategies that speak directly to this demographic. While some of the methods are the same as recruiting traditional students (e.g., quality communication methods, effective websites, using social media, etc.), other trends are noticeable in how institutions make their programs more attractive to adult learners (Olds, 2010). One of the most common practices is the design of highly flexible programs that meet the needs of working professionals, including expanding offerings in the part-time and evening course segments, and increasing the number of options for online education. Additional strategies institutions have pursued include providing greater flexibility for transfer credits, improving lead quality when identifying students, and designing programs specifically for students as opposed to merely adapting existing programs.

\subsubsection{CHANGING ADMISSIONS STANDARDS}

For some institutions, one practice that feeds directly back into the expansion of enrollments for foreign and adult students is the lowering of admissions standards in order to boost numbers. This naturally brings both positive and negative effects to a university, and there has been brisk discussion about this topic more generally in a variety of venues, and on several fronts. While the net positive impacts of lowering enrollment standards are likely an increase in admissions and thus higher enrollment numbers (and revenues), the net negative impacts can be far more significant and the effects of lowered admissions standards on universities facing both lower graduation rates and reductions in state funding. Using evidence-based cases, the article concludes that there are several ways universities have subtly changed the dialogue surrounding higher academic standards for incoming students in order to not appear as though standards actually are made lower (Olds, 2010). Any institution hoping to merely boost enrollment figures should be mindful of. In several cases, the suggestion is made that opening the floodgates in this way can easily lead to lower graduation rates overall when compared to similar institutions (admits 90 percent of applicants but has six years' graduation rate of 57 percent). This can have a severe impact on rankings, institutional profile and reputation, and an overall strain on resources that 
could better serve students more likely to succeed in the long run. Other institutions have chosen to relax standards in other areas to boost their international enrollments in particular, such as required language proficiency, in favor of admitting those students that exhibit strong academic backgrounds. A trend in recent years for U.S. institutions has been to admit international students with weak language skills (but strong academic skills) on a conditional basis, allowing students to strengthen language abilities once admitted. These types of admissions are often called "intensive English enrollments," and several institutions have reported a distinct increase in enrollments as a result of such admissions policies that feature remedial language programs. However, relaxing standards in these realms is not without problems from the perspective of university admissions (Olds, 2010). Particularly among Chinese students, there have been issues with students offering falsified credentials, thanks in part to a reliance on education agents and consultants that act as intermediaries to shepherd foreign students through the application process at U.S. institutions. The results of such practices are disheartening. A Chinese consulting company, Zinc, published a report in 2012 that found that 90 percent of Chinese applicants submit false recommendations, 70 percent have other people write their personal essays, 50 percent have forged high school transcripts, and 10 percent list academic awards and other achievements they did not receive.

\subsubsection{TECHNOLOGY AND HIGHER EDUCATION ONLINE LEARNING}

Online education has evolved to such a degree that as a method of educating and as a platform for global branding, it bears little resemblance to what it was merely a few years ago. Institutional strategies for how to engage with these changes have evolved as well, given how colleges and universities worldwide have responded to some of the latest developments in online learning. Changing trends in educational technology are thus the driving force behind many of the educational strategies institutions now introduce. These include new delivery methods, increased access to courses, and different ways of employing technology in teaching (such as "flipped classroom" teaching, "gamified" courses, and employing adaptive learning). Online is a medium that continues growing at a robust rate. A 2013 report from the Sloan Consortium, an organization that has tracked developments in online education in the United States for over a decade, found 
that "the number of students taking at least one online course has now surpassed 6.7 million." Online enrollments continue growing at a robust rate, forcing many institutions to engage with the online space more vigorously, or perhaps for the first time.

The same report indicated that nearly 70 percent of chief academic leaders say online learning is critical to their long-term strategy. However, not all institutions are shaping their online strategies around simple popularity of courses, or even the explosive public discussions surrounding concepts. Indeed, most top-tier universities do not offer online courses at all, save for limited engagements with providers such as Coursera or FedEx. For instance, the top two institutions in the United Kingdom Oxford and Cambridge have publicly stated that neither intends to join the movement, despite moves by competitors to do so. Table 5 presents a random global cross section of institutions from the Academic Ranking of World Universities (ARWU) for 2013, based on whether the institutions in question offer online courses in three areas:

a) As part of continuing education programs;

b) As a MOOC (Massive Open Online Course option) either independently or in coordination with a provider

c) As part of normal institutional course offerings - here labeled "traditional online courses," indicating courses offered online, for credit, either as standalone courses or as part of a larger degree program. 
TABLE 5. ONLINE COURSES AVAILABLE FROM INSTITUTIONS IN THE TOP 100 ACADEMIC RANKING OF WORLD UNIVERSITIES (ARWU), 2013

\begin{tabular}{|c|c|c|c|c|}
\hline \multirow[b]{2}{*}{ Ranking } & \multicolumn{4}{|c|}{ Online Courses by Availability } \\
\hline & Institution & $\begin{array}{c}\text { Continuing \& } \\
\text { Executive Education }\end{array}$ & MOOC/Open Courses & $\begin{array}{l}\text { "Traditional" } \\
\text { Online Courses }\end{array}$ \\
\hline 1 & Harvard University & Yes & Yes & No \\
\hline 2 & Stanford University & Yes & Yes & No \\
\hline 5 & University of Cambridge & Yes & No & No \\
\hline 10 & University of Oxford & Yes & No & No \\
\hline 20 & Swiss Federal & Yes & Yes & No \\
\hline 21 & The University of Tokyo & No & Yes & No \\
\hline 28 & University of Toronto & Yes & Yes & Yes \\
\hline 42 & University of Copenhagen & No & Yes & Yes \\
\hline 61 & University of Munich & No & Yes & No \\
\hline 85 & Ghent University & No & No & No \\
\hline
\end{tabular}

Source: Ladd, L. "For-profit higher education setbacks may transform nonprofit learning." Grant Thornton. April $29,2013$. http://www.grantthornton.com/issues/library/articles/nfp/2013/NFP-2013-04-For-profit-higher-education- setbacks.aspx

However, the trend towards online education is not without its critics. The disruptive innovation that is online learning, many have argued, may offer lower costs and increased revenue, but comes at the price of inferior quality and diminished performance. Critics of moving away from standard practices and expanding both delivery methods and revenue generation models through online education underscore the risk averse nature of traditional postsecondary institutions, and those currently running them. Given recent financial troubles experienced by for profit institutions, many in the non-profit world feel validated in their skeptical position and have even argued that the troubles of for-profit educators will prove beneficial for non-profit education. In addition, there remains a problem with the legitimacy that faculty grant to online education, and this may be the lasting impediment to wider adoption. Most of those closely watching the evolution of online education nevertheless agree that technology and the internet is fundamentally transforming higher education, and whether it takes the form of MOOCs or not, the change is here to stay. As a recent article in Inside Higher Ed reported, MOOCs may have snared most of the headlines, but the traditional, credit-based online learning continued to chug along just fine last year. The growth rate is slower than it has been in recent years, yet online 
education is nevertheless moving forward. As table 6 indicates, the number of students taking some form of online course has risen steadily over the last ten years:

TABLE 6. GROWTH RATES OF POSTSECONDARY ONLINE ENROLLMENT, 2002-2011

\begin{tabular}{|c|c|c|c|c|}
\hline YEAR & $\begin{array}{l}\text { STUDENTS TAKING AT } \\
\text { LEAST } 1 \text { ONLINE COURSE }\end{array}$ & $\begin{array}{l}\text { ONLINE ENROLLMENT } \\
\text { INCREASE OVER PREVIOUS } \\
\text { YEAR } \\
\end{array}$ & $\begin{array}{c}\text { ANNUAL GROWTH } \\
\text { RATE } \\
\text { ONLINE ENROLLMENT }\end{array}$ & $\begin{array}{l}\text { ONLINE ENROLLMENT } \\
\text { AS A PERCENTAGE, OF } \\
\text { TOTAL ENROLLMENT }\end{array}$ \\
\hline 2002 & $1,602,970$ & $\mathrm{n} / \mathrm{a}$ & $\mathrm{n} / \mathrm{a}$ & $9.6 \%$ \\
\hline 2003 & $1,971,397$ & 368,427 & $23.0 \%$ & $11.7 \%$ \\
\hline 2004 & $2,329,783$ & 358,386 & $18.2 \%$ & $13.5 \%$ \\
\hline 2005 & $3,180,050$ & 850,267 & $36.5 \%$ & $18.2 \%$ \\
\hline 2006 & $3,488,381$ & 308,331 & $9.7 \%$ & $19.6 \%$ \\
\hline 2007 & $3,938,111$ & 449,730 & $12.9 \%$ & $21.6 \%$ \\
\hline 2008 & $4,606,353$ & 668,242 & $16.9 \%$ & $24.1 \%$ \\
\hline 2009 & $5,579,022$ & 972,669 & $21.1 \%$ & $27.3 \%$ \\
\hline 2010 & $6,142,280$ & 563,258 & $10.1 \%$ & $29.2 \%$ \\
\hline 2011 & $6,714,792$ & 572,512 & $9.3 \%$ & $32.0 \%$ \\
\hline
\end{tabular}

Source: Allen, I. "Changing Course: Ten Years of Tracking Online Education in the United States." Babson Survey Research Group. January, 2013.

3. http://www.onlinelearningsurvey.com/reports/changingcourse.pdf

\subsubsection{ONLINE EDUCATION}

Within the broader realm of technology trends in higher education, online education is far from the most dynamic. Several new forms of content delivery that involve new technology have emerged that have the potential to change pedagogical norms. Among the most recent developments include concepts such as the "flipped classroom," adapted learning and experiential learning, and innovative approaches to instruction like "gamified" teaching and learning. The emerging technologies, as opposed to more established ones such as hybrid or collaborative teaching/learning platforms, multimedia-driven instruction, and other technology employed to attract new students over the last few years. A number of changes to learning management in the last decade (and even within the last year) go beyond mere Web integration, and this is an example of one that institutions hope boost enrollment. This is the trend of introducing game-based 
learning platforms and "social learning" models. This is an example of much more "engaged" eLearning, and which borrows from concepts and experiences seen in video gaming cultures, as well as those underpinning the majority of 21st Century social media interaction. The idea is that students in the current generation have undergone a different neurological development than previous generations, and that this was largely the result of being born into a technology-centric learning environment. Studies have identified several areas where gaming has a positive impact on learning more generally:

- Engaging learners in learning environments

- Increasing motivation

- Intensifying retention of information

- Improving problem-solving skills

As a model of learning in an online higher education environment, game-based or gamified learning involves a much more significant level of interaction from students than more passive activities such as message boards. Flipping the classroom refers to a "pedagogical model in which the typical lecture and homework elements of a course are reversed," and in-classroom experiences reconstructed to rely less on passive learning and more on active engagement. The concept behind flipped classrooms again has much to do with accessibility and convenience, as it allows students to consume the core elements of a course whenever, regardless of time or place. This means professors can re-allot classroom time completely and make room for other activities, such as experiential or collaborative learning opportunities as opposed to passive learning through lectures: By leveraging online platforms, lectures can now be pre-recorded and core content accessed by students anytime, anywhere, and as many times as they need. This means that classroom time can instead be used to augment the lecture content, whether through discussion, group exercises or quizzes. As a trend within higher education, the "flipped" model has gained some high-profile supporters, especially in the United States. Among the higher profile institutions using the flipped classrooms model include Stanford University, which is currently working in conjunction to deliver medical education. Course lectures move online in the form of videos and other digital content, and in-person sessions become optional interactive sessions (Olds, 2010). 
By moving content out of the classroom, the hope is that students will both progress faster and be able to narrow in on a specialization more quickly. In addition, the flipped model engages students much more fully, as it pays attention to why students miss classes in the first place, and allows them to swap lectures for something practically oriented during their classroom time.

Several other top tier ARWU-ranked U.S. universities have also adopted a flipped classroom approach to various subjects, including engineering at Boston University, chemistry and biology at Duke University, and economics at Vanderbilt University. At Boston University, a computational fluid dynamics course was "flipped" to turn classroom lectures into a mixed cohort of graduate students and seniors that used that same period as an opportunity to interact and compare software solutions and notes on their individual progress with one another. The shift was one from whiteboard to workshop: Creating an active and engaged learning environment is automatic when flipping a class, and with today's technology for creating multimedia learning materials, it can be done without losing any of the content. In Canada, the University of British Columbia has also success in using the flipped classroom model in a physics course (Olds, 2010). By way of an experiment, one section of the course was taught "traditionally" and another was taught using a flipped approach. The results showed that for students in the flipped section, "engagement nearly doubled and attendance increased by $20 \%$." Furthermore, students in the flipped course scored more than twice as well as students in the traditional section, and 90 percent of the students in the flipped section reported enjoying the interactive learning methods of the flipped model. In mid-2013, the two announced that both had worked on a new adaptive eLearning platform, which it hopes to introduce a personalized online learning platform. Of note is that while both describe the platform as revolutionary, it still stems from an asynchronous learning concept. Named "Guided Learning Pathways, the platform hopes to address problems in online learning, such as the lack of customizability to individual learners' needs, and finding the proper fit between students and appropriate learning materials. The research led to two new breakthroughs: Two technologies have been developed and applied in the research. One is navigation technology, which can organize massive online learning materials into multi-layer topics. The other technology developed is the students' learning behavior simulation based on an 
advanced probabilistic learner model. These technologies break up atomized elements nuggets of student learning based on their interactions online very similarly to how companies like Google or Facebook use algorithms to estimate what users are looking for or like, or how Netflix makes suggestions on what users may like to watch based on previous viewing habits (Olds, 2010). The result is a personalized pathway through the material students take on over the course of a70program. The Apollo Group a long-time standard-bearer in online education announced it had made a near \$1 billion investment in its own adaptive online learning platform and associated infrastructure. The company recently received a patent for an adaptive activity stream related to its online learning platform, which is likely key to the success of its future in online learning. Little about how this system will work is currently available, but observers have pointed to the importance of data mining and related personalization processes to its success much like Fujitsu and MIT have seemingly operationalized.

\subsection{HIGHLIGHTING MARKETING AND ITS IMPACT ON HIGHER}

\section{EDUCATION}

More than two decades after US News and World Report first published its special issue on "America's Best Colleges" and almost a decade since Shanghai Jiao Tong University published the Academic Ranking of World Universities (ARWU), university rankings continue to dominate headlines for several reasons. First, they present a simple and easy comparison of educational performance and productivity nationally and across international boundaries. Second, by drawing attention to the characteristics and performance of the top universities world-wide, rankings have become a major tool for measuring educational quality and excellence. This is true for HEls but also for nations and given the importance of higher education to social and economic growth and prosperity, especially in these difficult times, rankings are often interpreted as an indicator of a nation's global competitiveness. The higher education sector has two main features that influence, the marketing ideas that can be applied to it. First of all, higher education in most countries is a non-profit sector, therefore marketing concepts applied to the sector do not function as in the 
business sector, where the primary goals are profit making. Second higher education is a service, therefore all peculiarities applicable to the marketing of services apply to higher education. Today, politicians regularly refer to rankings as a measure of their nation's economic strengths and aspirations, universities use them to help set or define targets mapping their performance against the various metrics, academics use rankings to bolster their own professional reputation and status, and students use them to help them make choices about where to study.

Globalization has been forcing change across all knowledge intensive industries. These developments have been intensified by the global financial crisis and the adjustment period that has defined its aftermath. Yet, even before the transition to this new economic reality, world-wide comparisons were becoming increasingly significant. Globalization, characterized by the evolution towards a single world market in goods and services, is most recently signified by the rise in global rankings. Nations, their institutions and all aspects of daily life, are regularly measured against each other according to indicators in which comparative and competitive advantages come into play with geopolitical implications. At the same time, the knowledge society is placing a premium on education and high educational attainment. While countries are increasingly dependent upon talent, many are under severe demographic pressure. Society is aging at the same time that the birth rate is falling, especially in the more developed countries. Because higher education plays a fundamental role in creating competitive advantage, this situation presents a challenge for national strategies based on growing knowledge-intensive industries, and heightens competition for high-achieving students.

These developments are having a profound impact on higher education and the way in which higher education is managed, funded and organized. There is increasing emphasis on value for money, international benchmarking and (public) investor confidence. Performance assessment of scientific scholarly research is also increasingly important, especially for publicly funded research. Accordingly, many governments are busy reshaping/restructuring higher education systems and institutions to ensure they can better compete. Some countries are able to invest heavily in higher education and research, while others are financially restricted because of the 
severity of public and private debt. Even though the whole notion of students as consumers attracts criticism, students are the direct and immediate customers of the higher education services. Employers, too, benefit of the results of the higher education processes, as they use the skills and the abilities that graduates acquired during their studies. Some called graduates products of higher education, while the employers were seen as customers, but we consider that both students/graduates and employers are consumers of higher education services. While students are principal consumers, employers can be seen as secondary or indirect consumers of higher education services. Finally, the society as a whole benefits of the results of the higher education. At the international and national level, these developments are driving greater differentiation between elite and mass HEls and systems. The EU is no exception. The publication of the Shanghai Jiao Tong Academic Ranking of World Universities in 2003 and followed quickly by the Times Higher Education-QS Top University Ranking in 2004 challenged the perceived wisdom about the reputation and excellence of European universities especially when placed alongside the Lisbon strategy's objectives. A year later, June 2005, the German government launched the excellenzinitiative (Initiative for Excellence), followed by a report by the French Senate arguing its researchers were disadvantaged in favor of English- speaking institutions. In 2008, under the auspices of the French Presidency of the European Commission, a conference was organized championing a new EU ranking. Europa 2020 has restated the challenge: "Europe must act: ... According to the Shanghai index, only two European universities are in the world's top 20". It speaks about the need to "Enhance the performance and international attractiveness of Europe's higher education institutions and raise the overall quality of all levels of education and training in the EU..." Today, there are 10 main global rankings some are more popular than others. Over 60 countries have introduced national rankings, especially in emerging societies, and there are a number of regional, specialist and professional rankings. More recently several system-level rankings have emerged. While undergraduate, domestic students and their parents were the initial target audience for many rankings, today rankings are used by myriad stakeholders, including governments and policy-makers; employers and industrial partners; sponsors, philanthropists and private investors; academic partners and academic organizations; the media 
and the public. Postgraduate students, especially those seeking to pursue a qualification in another country, are the most common target audience and user.

\subsection{UNIVERSITY WEBSITE}

The first electronic web service of the last century has spread across the globe in various shapes and changing the faces of many organizations. The new internet revolution is not only reducing the global divide but also transforming societies into knowledge-based society all over the world. Shortly after the commercialization of the internet, the multimedia component of the internet (web) experienced the phenomenal growth (Claridge, 2011). As a part of this growth, businesses and individuals raced to place web pages and content on the web. Recently, a proliferation of electronic websites with a tremendous amount of information either with high quality, or with low quality, as well as sites that are outright misleading. The explosion of the web has determined the need of measurement criteria to evaluate the aspects related to the quality in use, such as usability and accessibility of a web application (Caglar, 2012). The objective is to make the website useful, profitable, user linkable, and accessible. Awareness of quality issues has recently affected every industrial sector. A university with a website that is difficult to use and interact can make the university position lower. Therefore, it is important for any organization to have the ability to make an assessment of the quality of their e-services to improve their offerings over time and benchmark against competitors and the best practices in any industry. The web is playing a dynamic role in diverse application domains such as business, education, industry, and entertainment. The internet technology has globally become a paramount necessity to the educational the continent as the traditional approach of managing student's record is no longer an option in the 21st century (Claridge, 2011). This cognizance alone has increased the number of prospective students seeking admission into higher institutions, creating an uncomfortable platform for universities to manage and process student records and information on a yearly basis given the rate of their demands to acquire knowledge. The internet in most organizations gives communication access to users and enhances interaction with the public. The technological impact of the internet in education enhance access information and operational processes for 
efficient management of students' academic, institutional tasks and administrative activities via the portal technology.

A web portal by definition is a gateway, a front door to other portals or sites. The internet is radically changing the traditional way that organizations interact with public. For organizations, the web gives access to a large audience and improves operational efficiency. Web sites are becoming key components of an organization's survival in the globalized competition. The web site represents an organization, communicating an organization's culture, values, and vision. The web site acts as a delivery mechanism for services that facilitate various tasks a stakeholder needs to perform. The site also serves as a platform through which an organization can interact with its stakeholders. University web sites are no exception (Caglar, 2012). The university website is not only a cost efficient and timely method to communicate with various stakeholders such as students, faculty, administrative staff and visitors it is also a way for a university to shape its image.

Universities need to do everything within their power to keep positive images with their various constituents, and one way to do this is to make use of the opportunities website presents. Observations mentioned above underline the vitality of usability issue for the websites. Usability has assumed a great deal of importance in terms of satisfying web site users' needs and expectations (Patterson \& Ellis, 2004). Developing a website should be passed through several design guidelines to ensure that the website can achieve the purposes and goals intended to be accomplished. Additionally, an organization's website is a gateway to its information, products, and services. As such, it should ideally be a reflection of the needs of the clients it serves. Unfortunately, website design is often driven by technology, organizational structure, or business objectives, rather than by user's needs. However, in recent years, website owners and developers have gradually begun to acknowledge and address the issue of usability. Based on the International Standards Organization (ISO) definition of usability as the extent to which a site can be used by a specified group of users to achieve specified goals with effectiveness, efficiency, and satisfaction in a specified context of use. Note that this definition applies equally well to webpage usability. It also implies that usability is user and task dependent, as well as being related to how well the user 
is able to accomplish what they set out to do, how efficiently the user can do this, and how satisfied the user is during and after the process. Regarding the theme of usability, which has been a popular theme that is extensively merged in the field of human-computer interaction (Caglar, 2012). The website usability he mentioned that usability is a requirement to survive in internet environment and also Nielsen (2000), states the usability rules the web. Those mentioned authors discussing significantly regarding the usability which this shows that this subject is an extremely important aspect of individual website and overall website design. Accordingly, the web design must directly face users with the specific needs, and must make sure that users are pleasant to successfully complete tasks with web. The number of studies on usability of university web sites is very limited and it can be mentioned that this subject needs more studies and research to be done. The universities websites mostly are neglecting performance and quality criteria and the challenges encounters by users during their attempt to complete the tasks in three areas, namely content presentation, information structure, and navigation. Website Analysis and Measurement Inventory: attractiveness, controllability, helpfulness, efficiency and learnability.

\subsubsection{USABILITY}

An organization's Web site is a gateway to its information, products and services. As such, it should ideally be a reflection of the needs of the clients it serves. Unfortunately, Web site design and development is often driven by technology or by organizational structure or business objectives, rather than by user needs. In recent years, however, Web site owners and developers have gradually begun to acknowledge and address the issue of usability. The discussion as to what constitutes a "usable" Web interface is ongoing. To a certain degree usability depends upon the purpose and target audience of a particular site. However, there is general agreement that a usable Web interface is one that is accessible, appealing, consistent, clear, simple, navigable and forgiving of user blunders. Web users are notoriously impatient and fickle if they are frustrated on a site, they will quickly go somewhere else and likely not return. For commercial sites, this is critical. site that is confusing or difficult to use may result in the loss of clients or reduced revenues due to unsuccessful transactions. The usability is defined in different terms by multiple 
researchers. Shackel (2009), describes usability as a technology's capability to be used easily and effectively by the specified range of users, given specified training and user support, to fulfill the specified range of tasks, within the specified range of environmental scenarios. The usability is measured of in which a system can be learned and used, its safety, effectiveness and efficiency and the attitude of its users towards it. For informational sites, lack of attention to usability principles may result in users being unable to find the information they need. In recent Web usability studies (Shackel, 2009), users were able to find the correct answers to test questions only 42 percent of the time. Anyone using any kind of web browsing technology must be able to visit any site and get a complete understanding of the information, as well as have the full and complete ability to interact with the site if that is necessary. Usability refers to terms such as ease of use and ease of learning that implied providing users with systems requiring minimum cognitive and physical effort to accomplish users' needs and expectations. Usability engineering for the Web grew out of the software development discipline of Human Computer Interaction $(\mathrm{HCl})$. However, the Web is different from software, and the nature of the Web poses new challenges to designers and developers who are trying to incorporate usability into their sites. Due to the global nature of the Web and the wide-ranging demographics of people accessing the Internet, a target audience can be difficult to define. Diversity in end user configurations (hardware, software, browsers, connectivity and bandwidth) means that users may have wildly different experiences of the same site. Inflated user expectations of Internet technology can be difficult to satisfy. The rapidly changing nature of the Web results in short development schedules, making it difficult to incorporate user-centered design techniques (Caglar, 2012). Unlike a software package, the user has not made an investment in a particular site, and other options are easily available and accessible. Usability of the website plays a central role in establishing a healthy communication between the university and its stakeholders. The healthy communication between the university management and the stakeholders can undoubtedly contribute to good governance of the university in many ways.

The web site usability as "the extent to which a site can be used by a specified group of users to achieve specified goals with effectiveness, efficiency, and satisfaction in a specified 
context of use". In other words, the web site usability is a test on the successfulness of web site's user in doing some task or finding information in the web site. First, a well-managed website with high usability can stimulate a healthy dialogue between the university and its stakeholders. Dialogue lies at the hearth of communication and plays a central role in communication. Listening to the stakeholder's concerns will give university administrations the opportunity to make well planned decisions (Claridge,2011). Thus, another contribution of dialogue with the stakeholders is the reduction of conflicts due to the increased confidence between the parties (Burchell \& Cook, 2008). The engagement established on a healthy dialogue with stakeholders may lead to the inclusion of stakeholder demands and expectations to become a part of decisions made by the university administrators.

The inclusion of the stakeholders' expectations shaped via dialogue to the decision process will add value to the good governance practices. Focusing on stakeholders with legitimate expectations and managing the relationships with them will contribute towards transparency which is the fundamental ingredient of good governance. There are numerous tests for evaluating the website usability. The attractiveness of recruitment websites by looking at a variety of dimensions, such as colors, fonts, layouts, pictures, and type of text exposed applicants to three websites that varied in terms of their appeal and found that applicants preferred to work for the organization that maintained the website with the most appealing colors, fonts, and pictures. Additionally, the role of website appeal has also found appeal to be positively correlated with people' s overall impressions of websites, their ratings of organizational attractiveness, and their intentions to apply for a position with the hiring companies that maintain these websites. Attractiveness is one of the key factors to a successful website (Claridge, 2011). Attractiveness is the capability of the software product to be attractive to the user (e.g., through use of color or graphic design. Attractive websites are visually pleasant, and appeal the interest of the users, whether it is functionality or information. The appearance of a website is a crucial factor that improves the perception of information in order for subjects to perform better cognitive mapping and assessment of decisions for execution and the graphical representations such as icons, colors, images and animations, give website a higher attractiveness. This could improve the degree of 
users' satisfaction with the website. According to Shackel on (2009), the other important items like in the case of attractiveness are: controllability and helpfulness

\section{$\checkmark$ Controllability}

The degree of control a person reports has over his/her interaction with a particular website. In other words, controllability is whether users feel that they are in control of the software product. If a site is well on controllability the users most probably feel they can navigate around it with ease and do the things they want to do. Poor controllability of a website usually means a poorly organized site that disrupts the way they normally expect to do things. Efficiency According to international organization for standardization (ISO) efficiency refers to the resources used in completing a task. The website efficiency as a representation of resources expended in relation to achieving goals while visiting a website. The users perceive efficiency when they can achieve goals with a quick visit without putting forth much cognitive effort. When site users give, a high efficiency rating they feel they can quickly locate and do what is of interest to them in an effective and economical manner. They feel that the web site responds at a reasonable speed. Disorientation, or the tendency to lose one's sense of location in a Web site, can cause users to become frustrated, lose interest, and experience a measurable decline in efficiency (Hazelkorn, 2009).

\section{$\checkmark \quad$ Helpfulness}

Helpfulness is the key to web success. Finding ways to help users for every step of their visit: before they reach the site, during their visit, and after the visit play a crucial role on the usability. A website which is high on helpfulness corresponds with the users' expectations about its content and structure. A site with a low level of helpfulness can be misleading about its layout and content. 


\subsubsection{LEARNABILITY}

Learnability is related to achieving a sufficient level of competence with the device to be able to complete goals in an efficient and effective manner. In order to achieve the best efficiency and effectiveness possible while using a device, users must first learn how to interact with the device. The ease, in time or effort, with which users can learn a device, is its learnability. Learnability or the ease with which the features required for achieving particular goals can be mastered. It is the capability of the software product to enable users to feel that they can productively use the software product right away and then quickly learn other new for them functionalities (Liu, 2009). Learnability refers to how easy it is for casual users to learn a system. In the websites with high learnability users feel they are able to start using the site with the minimum of introductions and everything is easy to understand from the start. In the websites with low learnability users feel that the site may be using concepts or terminologies which are unfamiliar and need more explanations. Whether to venture to a new city and move away from home, or save money and go to our local university. Picking a university was never easy and this was before the days of spiraling fees. This year's batch of fresher will be the first to see the effects of the restructuring of the higher education and increased tuition fees. Helping prospective students feel they've made the right decision has never been more important. To complicate matters, universities are scrambling to reap the rewards of the international student market, while absorbing their share of upward demand in postgraduate interest. These factors all contribute to the complex nature of the recruitment process. Catching the attention of international students has become a huge marketing challenge for universities, keen to get a share of the overseas students contribute all around the word, particularly as the educational infrastructure in countries like India and China improves. Faculties and departments need to be able to reach prospective international applicants, while clearly depicting the university's prowess and accreditations. As a solution universities are looking to their global shop window the internet. The value of a good website is widely recognized, but many institutions still struggle to reflect a coherent branding strategy that transmits across the entire organization on and offline. Individual faculties often operate without any interaction, while sub-level departments may pursue their own agendas 
altogether. According to Sindhuja and Surajith on (2009), creating a brand consistency across these many microcosms is no small task but there are certainly ways to achieve uniformity across the board while allowing personalities to shine through:

\section{$\checkmark \quad$ Establish brand guidelines}

A framework for all departments within the university will ensure design consistency across the board. At a basic level, selecting and maintaining a complimentary color palette throughout is a simple way of aesthetically uniting different areas and micro sites, while providing some level of flexibility to communicate the unique character of each department and/or faculty. Similarly, consistency in font supports brand recognition and uniformity in site design.

\section{$\checkmark$ Clarify department goals}

A digital solution can only be effective by truly understanding and clarifying the goals of each department within the university. So, for example, while one university department needs its website to attract more prospective students to apply, another is a leader in its field, using the platform only to qualify the highest caliber of entries. The end goal must always be to allow individual faculties to put across information that is relevant to their overall objectives, while still in keeping with the university's overall aspirations.

\section{$\checkmark$ Create building blocks}

To ensure brand consistency while maintaining flexibility, develop a range of modules from which to build each individual web page. The core structure and main features of the page will stay the same, ensuring visual compatibility across the university's website, but departments and faculties will be able to customize the content, combination and compilation of modules, maintaining relevant content and communicating their individual objectives and character more clearly.

\section{$\checkmark$ Be visual as well as verbal}

Visualization can be an effective tool to attract international students, not only communicating the university's qualifications and capacity as an international university, but also overcoming 
potential language barriers. Visuals provide alternative means of communicating information, whilst also supporting the written content within the site.

\section{$\checkmark$ Personalize your welcome}

A university's website presents endless opportunities allowing institutions to produce personalize landing pages while still maintaining overall brand coherence. Separate homepages can be created for different user groups and personas, for instance fresher, international visitors, staff, and investors. The possibilities for tailored approaches are endless: personalized logins, homepages or interactive student calendars all mean disparate user groups can satisfy their online needs from one central point. The aim of any university website should be to provide information in a clear and accessible format, promoting the best user experience possible. As organizations see the value of investing more resources into their online strategy, we hope to see more of these personalized approaches for varying user groups (Shackle, 2009). Each should reflect a harmony in overall brand architecture while demonstrating the merits of individual departments, letting the institution as a whole flaunt its many attributes. Each should reflect a harmony in overall brand architecture while demonstrating the merits of individual departments, letting the institution as a whole flaunt.

\subsubsection{HIGHLIGHTS OF UNIVERSITY WEBPAGE}

There important criteria deal with the content of web sites rather than the graphics or site design. Apply these criteria when you research on the internet. Authority reveals that the person, institution or agency responsible for a site has the qualifications and knowledge to do so. Evaluating a web site for authority: Authorship: It should be clear who developed the site. Contact information should be clearly provided: e-mail address, mail address, phone number, and fax number. Credentials: the author should state qualifications, credentials, or personal background that gives them authority to present information. Check to see if the site supported by an organization or a commercial body. The purpose of the information presented in the site should be clear. Some sites are meant to inform, persuade, state an opinion, entertain, or parody something or someone. Evaluating a web site for purpose: The content should support the 
purpose of the site. The information geared to a specific audience (students, scholars, general reader) and the site organized and focused. The outside links should be appropriated for the site and the links. It is difficult to assess the extent of coverage since depth in a site, through the use of links, can be infinite. One author may claim comprehensive coverage of a topic while another may cover just one aspect of a topic. Evaluating a web site for coverage: the site should be selective or comprehensive and the topics should be explored in dep and the value of the site's information compared to other similar sites should be more remarkable. The links should go to outside sites rather than its own and the site provide information with relevant outside links.

Currency of the site refers to: 1) how current the information presented is, and 2) how often the site is updated or maintained. It is important to know when a site was created, when it was last updated, and if all of the links are current. Evaluating a web site for currency involves finding the date information was first written, placed on the web, last revised and the links should be up-to-date and provide reliable contents. Information provided should be related that its usefulness is limited to a certain time. Objectivity of the site should be clear. Beware of sites that contain bias or do not admit its bias freely. Objective sites present information with a minimum of bias. Evaluating a web site for objectivity, the information presented with a particular bias or try to sway the audience. The site advertising should not conflict with the content and the site should try to explain, inform, persuade, or sell something. There are few standards to verify the accuracy of information on the web. It is the responsibility of the reader to assess the information presented. Evaluating a web site for accuracy and reliability, the author should be affiliated with a known respectable institution. References, statistics and other factual information should be receiving proper references as to their origin. The reading you have already done on the subject make the information seemed accurate. The information comparable to other sites on the same topic and the text follow basic rules of grammar, spelling and composition and bibliography or reference list should be included. 


\subsection{EDUCATIONAL SYSTEM IN CATALONIA}

Pre-school education for children up to the age of 6, which is not compulsory in Spain, is provided in both state funded and private centers. Full-time education is compulsory for children from the age of 6 to 16 and is divided into compulsory primary and compulsory secondary education. The upper level of secondary education (from 16-18) is either vocational (with two educational levels or tiers) or academic/general (baccalaureate) in nature. Vocational secondary education involves the teaching of practical, job related subjects whereas the baccalaureate has a threefold purpose in that it serves as a preparation for both university education and specific advanced vocational training, and ultimately insertion in the labor market. Based on AQU report (Aecia per a la Qualitat del Sistema Universitari de Catalunya, 2006), the $57 \%$ of all pupils in compulsory secondary education attend state-run institutions. Full time is percentage increases to $63 \%$ for baccalaureate students, $70 \%$ for vocational training students and $90 \%$ for university students.

\subsubsection{POSTGRADUATE EDUCATION IN CATALONIA}

The Spanish university system is regulated by the Organic Law on universities. In particular, this regulates the organization, administration and management of higher education institutions, academic organization and research, and also determines the powers of the regional Autonomous Communities in the field of higher education. The principle of university autonomy, as regards educational and training aspects, is laid down in the Spanish Constitution (1978). Universities are responsible for the organization and establishment of the educational programmers that they intend to offer, as well as for drawing up and proposing the syllabuses that lead to the various degrees they award. Nevertheless, in order to ensure education under equal conditions for all students and to permit the validation of degrees, syllabuses are subject to certain general directives regarding organization, material and course load.

The Government of Catalonia has jurisdictional powers with regard to higher education, pursuant to the Catalan Universities. There are seven public universities, three private universities 
and one distance learning university in Catalonia. Application to the university admissions process (pre-enrolment) is required in order to be admitted to any of these in situations. The $80 \%$ of all university students attend the 7 public universities. The university system includes the Polytechnics. General directives determine a minimum of $30 \%$ of the total number of credits for first-cycle studies, and $20 \%$ for second-cycle studies; general directives will determine 50-75\% of the total number of credits of the new Bologna Bachelor (Agència per a la Qualitat del Sistema Universitari de Catalunya, 2006). Fees are determined by the Autonomous Communities within the limits set by the Spanish government, except for non-recognized university degrees, the fees of which are determined by the universities themselves. Admission procedures to higher education are organized to ensure that all Spanish students have equal rights. No university can refuse to fill places in an establishment if there are applicants who meet the legally established requirements. Students who wish to undertake university studies must possess a baccalaureate certificate and also have to pass a university entrance exam. The number of students has declined slightly in recent years whereas the number and diversification of the degrees offered has increased. As a result, large classes are no longer a problem.

There are two types of main undergraduate degrees according to the length of study: The Diploma (3 years or 180 ECTS), and the Honors degree (4-5 years, 240-300 ECTS). The Bologna Masters is being introduced from 2007 onwards. Doctoral programs are offered to university graduates who wish to extend their knowledge and to conduct research into a specific area related to the disciplines they have studied previously. PhD programs comprise taught courses (at least 32 credits) and sufficient exposure to research experience to be able to produce a thesis and subsequently submit it to a tribunal. PhD studies are normally organized within university departments (which are organized on a disciplinary basis). In recent years, however efforts have been made by the Government to encourage cooperation between different universities as a way of enhancing efficiency in the system. The $90 \%$ of students passed the last university entrance exam (June 05) at the first sitting. In 2004, 86 \% of students were enrolled to study their firstchoice degree program at their first-choice institution. 
Admission requirements and periods for student registration are laid down by Spanish legislation. Admission to a postgraduate program requires a minimum of 300 ECTS (Bachelor degree (Licenciatura), Architecture or Engineering). The number of places offered is determined by the department or center responsible for the specific subject area at each university, which also administers selection and enrolment procedures. A candidate's first degree must be related in subject area in which doctoral studies will be pursued. Registration is carried out at the department or center with administrative responsibility for the doctoral program and within the stipulated period for the two semesters (in September or February).

\section{$\checkmark$ Doctoral program consists of three periods:}

Teaching period (first year): Training in research techniques and methods through specific courses and seminars in a specific field of knowledge is given during the first year. A minimum of 20 credits are required in order to pass this level, at which stage the student is awarded a certificate.

Research period (second year): One or more research projects must be undertaken, and a draft thesis produced. A minimum of 12 credits are required in order to pass this level, at which stage the student receives an Advanced Studies Diploma(DEA). Although this certificate is not a recognized qualification, it is standard in all universities in Spain and allows the student to begin the final stage of writing the thesis. Thesis (subsequent years): this is a research project conducted on an original and unpublished theme that deals with one specific aspect of a particular area of knowledge. It is the last stage of the doctorate and the thesis has to be produced under the supervision of a qualified teacher from the appropriate department. After revision, the student then has to gain permission to submit the thesis for the final reading and defense. If it is evaluated positively, the student may then request the award of the title of Doctor.

\section{$\checkmark$ Supervision}

As laid down in Royal Decree 778/1998, a thesis must be supervised by a PhD who has either permanent or temporary links with the department or institution coordinating the doctoral program (in the case of inter-departmental or inter-university doctoral programs, the supervisor 
may be linked to any of the participating departments or institutes). Other PhD's may act as supplementary supervisors (subject to the approval of the university's doctoral committee). There are no regulations or even guidelines about how supervision is to be organized. Appropriate supervision basically depends on the supervisor's knowledge, although universities are increasingly drawing up their own internal regulations for supervisors.

\section{$\checkmark$ Study conditions}

Fees are approximately 55 euros per teaching credit and 77 euros per research credit (with some variation for some credits involving work of an experimental nature). The total cost for the two doctoral courses is around 2,000 euros. A wide range of grants are available, including FPI grants issued by the Spanish Government (1,100 euros per month), FI grants issued by the Catalan Government, Spanish government university teaching training grants, and grants awarded by the universities themselves. Grant awards are made in two stages: one is for the first two taught courses and for taking the advanced studies diploma, while the second is for thesis development. Students with grants are incorporated into the corresponding departments, under the supervision of a full professor and with certain teaching commission. A maximum of 45 teaching hours per year is permitted in the first stage, and 90 hours in the second stage. Students in the second stage receive a formal contract, with social security benefits.

\section{The labor market}

No statistical data are available on the insertion of PhD holders in the labor market. The general impression is that the labor market in Spain is not particularly favorable for those with PhD's. It is may be explained by the industrial structure of the Spanish economy, which relies more on services than research and development (R\&D). As a result, Catalan PhD's may on occasion go to other countries to obtain posts as researchers. Nevertheless, there are exceptions to this; for example, a doctorate can be useful in the compulsory education system (in terms of a professional career), in higher education (for lecturers, assistant professors or full professor), and in commercial areas which involve a large amount of research (for example, the biomedical and biotechnological fields, which are both highly developed in Catalonia). 


\subsubsection{FOUR CATALAN UNIVERSITIES POSITIONS IN HIGHER EDUCATION RANKINGS}

Regarding the table 7, given below it can be considered that all four Catalan universities made an ascending progress during these last 5 years since from 2012 to 2016 . For example, the UAB form 2012 honored as a position of between 300 to 400 which in 2016 with a significant and remarkable progress positioned as 146 in the World university rankings and 200 to 300 in the Shanghai rankings system which these progress shows that the UAB tried to be enhance their quality of the university in many aspects. The other university UB constantly was the best ranked university among the other and as mentioned in the table 7, only in the year 2016 was ranked as the $3^{\text {rd }}$ Catalan university. Regarding the case of the UPF as it shows the table during these 3 years ranked under 190 which is huge progress comparing with the year 2013 which ranked under 230 in the world rankings system and after 2013 constantly continued to be under 165 position. In the case of UPC as it can be considered form the table 7, during these there last years from 2012 up to 2015 it was ranked between 300 to 400 but in the year 2016 it is a progress that it ranked as 299. UAB holds a leading position in the most prestigious and influent international university rankings. In recent years, this award has been favored by the growing impact of the research, the constant improvement of the quality of teaching and the ability to attract international talent.

This progress has been decisive in going forward to leading positions among Spanish universities in the two main university rankings: the QS World University Ranking and the Times Higher Education World University Ranking. The UAB is the first Spanish university in the coauthorship index (the indicator of collective work versus individual work in publications). The Observatory ranks the $U A B$ in second place for the average of citations and papers written by academic staff; it is ranked as the third university in Spain in number of publications in 3 leading journals for each field of specialization. The Spanish University Research-Activities Observatory (IUNE) is a tool with which to understand and analyze $\mathrm{R}+\mathrm{D}+\mathrm{i}$ in public and private universities. It is an initiative coordinated by the UC3M Laboratory on Metric Information Studies carried out within the framework of the Alliance 4 Universities $(A 4 U)$, including the UAB, the UPF and the Universidad Autonoma de Madrid. The IUNE presents the most significant results in the scientific and 
innovative activity of 73 Spanish universities (48 public and 25 private). The UAB ranks among the top 3 universities in Spain in 6 out of 12 scientific fields analyzed by the ISI Ranking of Spanish Universities. The UAB ranks in second place in four ambits (Earth Sciences and the Environment, Agricultural Sciences, Biological Sciences, and Medicine). The ISI Ranking of Spanish universities is based on research published in journals of highest impact and visibility.

There are twenty-nine European institutions in the top 100 and the remainder are from North America and Asia. Top of the list is the California Institute of Technology, followed by Harvard University, Stanford University, the University of Oxford and Princeton University. The (Times Higher Education) ranking indicates the absolute position of the 200 best universities and the brackets in which the rest are situated to include the world's 400 best universities, among which there are eight Spanish universities. Of the eight best situated Spanish universities, three are Catalan: The University of Barcelona (UB) and the Autonomous University of Barcelona (UAB) in the [201-225], and the Polytechnic University of Catalonia (UPC) in the [351-400]. In the rest of the State, the highest scoring university is the Autonomous University of Madrid (UAM) in the [276-300] bracket, followed by the Universities of Zaragoza (UNIZAR) and of Valencia (UV) both in the [351-400]. On a European scale the best positioned is the University of Oxford, in fourth place, closely followed by the University of Cambridge, in sixth place. In 77th place, UPF is the first Spanish university in the European ranking, and the prevalence of Catalan institutions within the Spanish university system is confirmed since UPF, UB and UAB are among the top 100 European universities. The University of Barcelona holds a place among the top 250 world universities, according to the new edition of the ranking edited by the British journal The Times Higher Education (THE). The University of Oxford (United Kingdom), the California Institute of Technology (CalTech, USA), the universities of Stanford (USA) and Cambridge (United Kingdom) and the Massachusetts Institute of Technology (USA). In the edition for 2016-2017, Catalan universities are once more the ones holding best positions in Spain. According to the indicators of the ranking in The Times Higher Education, the University of Barcelona stands out for citation indicators, a field with which holds the 169 position. 


\begin{tabular}{|c|c|c|c|c|c|c|c|c|c|c|}
\hline Years & \multicolumn{2}{|c|}{2012} & \multicolumn{2}{|c|}{2013} & \multicolumn{2}{c|}{2014} & \multicolumn{2}{c|}{2015} & \\
Rankings & Shanghai & World & Shanghai & World & Shanghai & World & Shanghai & World & Shanghai & World \\
Website & & university & & university & & university & & university & university \\
\hline UAB & $301-400$ & $201-225$ & $201-300$ & $201-225$ & $201-300$ & $226-250$ & $201-300$ & $226-250$ & $201-300$ & 146 \\
\hline UB & $201-300$ & $201-225$ & $201-300$ & $201-225$ & $151-200$ & $226-250$ & $151-200$ & $201-225$ & $151-200$ & 174 \\
\hline UPF & $401-500$ & 186 & $301-400$ & $201-225$ & $301-400$ & 164 & $201-300$ & 165 & $301-400$ & 164 \\
\hline UPC & $301-400$ & $350-400$ & $301-400$ & $350-400$ & $301-400$ & $301-400$ & $301-400$ & 337 & $301-400$ & 299 \\
\hline
\end{tabular}

Source: Shanghai and World university webpage, 2006 reports

\subsubsection{HIGHLIGHTS OF CATALAN HIGHER EDUCATION SYSTEM}

The Catalan higher education system consists of twelve universities, seven of which are public, four private and one of a mixed nature. Four of the public universities have their campuses in Barcelona and the city's metropolitan area: the Universitat de Barcelona (UB, 1837), the Universitat Autònoma de Barcelona (UAB, 1968), the Universitat Politècnica de Catalunya (UPC, 1971) and the Universitat Pompeu Fabra (UPF, 1990). The remaining three public universities have their area of influence in the three other provincial capitals in Catalonia: the Universitat de Girona (UdG, 1990), the Universitat de Lleida (UdL, 1990) and, in Tarragona, the Universitat Rovira i Virgili (URV, 1990). The Universitat Oberta de Catalunya (UOC, 1995), which offers distance learning courses, is a private university governed by a foundation, the main stakeholder of which is the Government of Catalonia (Generalitat de Catalunya). The other universities that make up the higher education system in Catalonia are the Universitat Ramon Llull (URL, 1991), the Universitat de Vic (UVic, 1997), the Universitat Internacional de Catalunya (UIC, 1997) and the Universitat Abat Oliba (UAO, 2003), all four of which are private, with three located in Barcelona and one in Vic.

The OECD coordinated PISA (Program for International Student Assessment) has made the public aware that teenagers have much better science, math, and reading skills in some places 
than others. For Catalonia and Spain, public perception is that the PISA reports show that their education systems are underperforming. Their 2006 average scores have been below the OECD average in all three subject areas, and did not improve with respect to the 2000 and 2003 reports. This should be an important concern as there is a consensus that the skills of the labor force are key for high productivity and wages. Catalonia needs to foster human capital development for new and changing jobs. There is a need to balance the current strong focus on talent attraction with nurturing talent at home and by improving the access of new immigrants to tertiary education. Catalonia and its universities need to view job creation as a key goal for innovation and adopt a wide innovation concept beyond science push. At the regional and institutional level, stronger incentives for regional engagement could be provided through performance-based funding and challenge-driven competitive calls. There is also a need to monitor the rate of return and effectiveness of public investment in research and innovation. To unleash the full potential of universities in regional and local development, it is necessary reform the university governance in Spain, by strengthening the institutional autonomy of universities and building effective accountability structures and continuing collaboration between regional and local governments, private sector and tertiary education institutions is necessary. 
Chapter 3

Methodology 


\section{METHODOLOGY}

This chapter presents the methodological approach adopted for the collection, treatment and detailed examination of the university rankings data and indicators used in the official webpage of Catalan universities. This study is an analytical study and a combination of both qualitative and quantitative methods through analysis of the webpages indicators as: technique, marketing and rankings which were applied by Catalan universities in their official website. Then, a review of the research tools and methods, which were employed to describe and analyze the empirical data, is provided. Namely, the fundamental principles of Conversation Analysis (CA) will be implied through interviews with staff of communication and promotion department of four Catalan universities. Then, a combination of theoretical tenets and methodological tools derived from the former termed here will be proposed in section as the analytical approach appropriate for the examination of the role of rankings in marketing strategy of universities and the indicators adopted in the universities official webpage. To continue, the data corpus is presented. This includes the description of data and participants and the explanation of the procedures followed in treatment and selection of datasets to be examined in analytic method to provide basic contextual information on the datasets selected for a fine-grained exploration in analytical chapters. Drawing on current sociocultural approaches to higher education which conceptualize the rankings as emerging and occurring in higher education were chosen as a theoretical framework of reference for this research and this dissertation adopted a primarily exploratory, interpretive and holistic qualitative methodology which allows researchers to further understanding of the complex phenomena that constitute the role of rankings in higher education and especially in marketing strategy of universities through their official webpages which this process as it takes place in interactive settings in the educational system. Firstly, it needs to be established the basic set of beliefs and the observations (Reitor, 2011). The results should not stand alone without meaning and context. This set of beliefs that will be leading my decisions and actions through this investigation constitutes the thesis model. This research model 
is directly tied to the research questions and reflect the approach on how do Catalan universities apply the rankings position in their marketing strategies through their official webpages.

Thus, several interviews with communication department of each Catalan universities (depends on the possibilities) and questionnaires of PHD students and master students conducted. The created content depended on the individuals involved in the interview: their perception of reality, their self-concepts and their concepts of their surroundings. This means that interpretations and conclusions that were driven from the interviews are understood cohesively and are not isolated from their context. This contemplation already suggests that within the frame of this thesis, there must be more than one single and universal worldview. Furthermore, would be useful to adopt Conversation Analysis (CA) through interviews with people of communication department of Catalan universities for better understanding of webpages indicators and elements. In this approach, the interviewees are regarded as principal actors that interpret the process of construction of the university webpages and how they are taking care of the updating the content of the webpage and especially news about the ranking. It is very crucial to understand the life worlds of the interviewees with special respect to them being individuals. Nonetheless, given that the individuals share a cultural and social background provided the possibility of detecting common patterns that could be linked back to the background information and the theoretical framework. In the other the student's elaborations by the help of questionnaires a great help in answering the research questions and were remained open to unexpected findings. The other tools were an analytical guideline of universities webpages which helped to see how universities compete with each other through their official webpages which the principal elements of media for them. Need to mention that would be possible since the objective is not to test the theories a practice often will be associated with quantitative methods and a positivist, but to inspire the collection of empirical data and to help organizing and analyzing it thereafter. In line with the contemplations above, the approach in this research try to shows that the generated knowledge is made up by subjective meanings and social phenomenal by taking into account the details of the situation. This This study tried to find out and realize the credential role of ranking and tried 
to recognize how these Catalan universities use their rankings success and news in their official website as the main instruments for competing in the global markets.

\subsection{SAMPLE AND PARTICIPNATS}

The target population or sample of these research were master and PhD international and national students registered on 2015 to 2016 which the total number of master students was 15550 and the PhD students was 10221. The questionnaires were emailed to international and national PhD and Master students of four aforementioned metropolitan Catalan universities through the Google drive system in order to know understand the role of ranking position of their favorite university in the time of choosing the university. Principally, this study tried to recognize how effectively, the rankings of universities played an essential role in the choosing process for students (international and national) and tries to verify if the rankings was one of the most important reason of choosing their university. Furthermore, this investigation studied, how properly and successfully the marketing strategy of chosen university worked. Due to the time limitation and confidential issues of participants, the number of 558 responses received from all four universities through sending the email to all the students of different disciplines and faculties of four Catalan universities. It extremely cooperated this study to recognize the university selection process by students and to see how rankings played a role in this process and furthermore to understand how the web pages of these Catalan universities designed after achieving the better rankings positions. It helped this study to verify how their marketing strategy adopted based on rankings success to attract the students and researchers. 
TABLE 8.PHD AND MASTER STUDENTS OF THE ACADEMIC YEAR 2015-2016

\begin{tabular}{|c|c|c|}
\hline University name & Mater students (2015-16) & PhD students (2015-16) \\
\hline UAB & 5290 & 1473 \\
\hline UB & 5300 & 2322 \\
\hline UPC & 3832 & 1296 \\
\hline UPF & 1128 & 10221 \\
\hline Total N. of students & 15550 & \\
\hline
\end{tabular}

Source: Webpages of the aforementioned universities: UAB, UB, UPC and UPF

\subsection{RESEARCH DESIGN AND METHODS}

Research design is the overall plan for connecting the conceptual research problems to the pertinent and achievable empirical research. In other words, the research design articulates what data is required, what methods are going to be used to collect and analyses this data, and how all of this is going to answer your research question. Both data and methods, and the way in which these will be configured in the research project, need to be the most effective in producing the answers to the research question (taking into account practical and other constraints of the study). Different design logics are used for different types of study. Quantitative researchers are interested in exploring groups in society. It is often the meanings behind the behavior they are interested in and not so much the interpretation of the behavior in a certain context. Oftentimes, quantitative methods like social survey research have been shown to relate poorly to people's actual behavior's. Therefore, many researchers feel strongly about employing qualitative research methods when exploring human beings within their social world and want to distance themselves from a quantitative approach and a positivist research philosophy. Given these contemplations for a most part of this investigation as qualitative research design and were applied unstructured or semi-structured techniques as individual interviews and questionnaires from PhD and master international and national students registered from 2012 to 2016to collect the data regarding how 
rankings news of Catalan universities affected their university choosing process. Due to this fact that there is no secondary available data related to this filed of investigation it was a challenge to gather the primary data for better investigating this issue. The theoretical framework of this study is consisting of a variety of peer reviewed literatures about ranking and marketing trends in $\mathrm{HE}$. Although the theories represent a vital part of this research, the main focus lies on the primary data were generated through the questionnaires, interviews as constitutional central piece of my investigation. In accordance with the research questions, to recognize profoundly the process of choosing a university by specially the international students and to find out how the universities rankings positions affected their choice and in the other words how positively it could be defined the rankings role of university in the process of university selection. Engaging people in a dialogue is one of the most fruitful ways of coming to a better understanding because deeper and more genuine expressions of beliefs and values can emerge through it while painting a more accurate picture of the held views. This means that the desired data will be preferably gathered through the means of questionnaires and interviews since this research focuses on the understanding of human behavior and not, for example, on the causality of two phenomena or the generalization of certain findings. Argues that interviews can help to gather knowledge about one specific person or institution or even illustrate more phenomena that are embedded in large context. The volume and content for comparison among the participants and the discovery of tendencies and patterns is another important issue. Given that the theoretical framework plays an inherent role also while gathering the empirical data a semi-structured interview was chosen. The background literature composes of different theories offered a pool of ideas from which several interview topics are condensed. The formulation of the interview questions and questionnaires based on two important dimensions: Marketing and Rankings. A pilot guide then will come into practice while conducting a pilot interview. The questions within this final guide will include descriptive, general, direct as well as very specific questions. The benefits and implications of this particular interview structure elaborated in data collection section. The interview design or an interview guide will be presented in the upcoming sections. 


\subsection{INSTRUMENTS}

A great deal of qualitative material comes from talking with people whether it be through formal interviews. Observation is the main methods employed in qualitative research which could be done through: interviews and analysis guideline. The qualitative research is a type of research which is different from quantitative research because the researcher is a large part of the process and can be considered one of the qualitative instruments. In this research were applied interviews, questionnaires and guideline to reach the proper response to the objectives of this research which is presented in the table 9 .

TABLE 9. INSTRUMENTS OF THIS STUDYAND INFORMED PARTICIPANTS

\begin{tabular}{|c|c|c|c|}
\hline Instruments & & & \\
\hline Special objectives & & & \\
\hline Analyses the role of rankings & $x$ & $x$ & $x$ \\
\hline $\begin{array}{l}\text { To recognize, how Catalan universities makes advantages of the } \\
\text { rankings position to add more credibility }\end{array}$ & $x$ & $x$ & \\
\hline $\begin{array}{l}\text { To analyze and recognize deeply the marketing strategy of } 4 \\
\text { Catalan universities }\end{array}$ & $x$ & $x$ & $x$ \\
\hline $\begin{array}{l}\text { Analyzing student's perception regarding the marketing strategy } \\
\text { used by university based on rankings position through official web } \\
\text { page }\end{array}$ & $x$ & & \\
\hline
\end{tabular}




\subsubsection{INTERVIEWS}

There are three fundamental types of research interviews: structured, semi-structured and unstructured. Structured interviews are, essentially, verbally administered questionnaires, in which a list of predetermined questions asked, with little or no variation and with no scope for follow-up questions to responses that warrant further elaboration. The purpose of the research interview is to explore the views, experiences, beliefs and/or motivations of individuals on specific matters (factors that influence their attendance at the dentist). Qualitative methods, such as interviews, are believed to provide a 'deeper' understanding of social phenomena than would be obtained from purely quantitative methods, such as questionnaires. Interviews are, therefore, most appropriate where little is already known about the study phenomenon or where detailed insights are required from individual participants. They are also particularly appropriate for exploring sensitive topics, where participants may not want to talk about such issues in a group environment. If interviews are going to tap into the depths of reality of the situation and discover subjects' meanings and understandings, it is essential for the researcher: to develop empathy with interviewees and win their confidence; to be unobtrusive, in order not to impose one's own influence on the interviewee. In addition, narratives are utilized as well as observation by the researcher in the field. The data is analyzed using different methods to produce information that is in the form of words or images and can be coded for further analysis. The researcher is considered one of the major qualitative instruments in this type of research, as he or she is a large part of the process. When the researcher conducts an interview, or observes a party, he or she is affecting and becoming involved in the situation. This is different from quantitative research that aims to be objective instead of subjective by utilizing instruments that have been formed on previous populations. The best technique for this is the unstructured interview. Here, the researcher has some general ideas about the topics of the interview, and may have an aide memories of points that might arise in discussion for use as prompts, if necessary. However, the hope is that those points come up in the natural course of the discussion as the interviewee talks. Care is needed, therefore, to avoid leading questions or suggesting outcomes, and skill is called for in discovering what the interviewee really thinks. The researcher aims to appear natural, not 
someone with a special role, but one who engages with interviewees on a person to person basis. Attention will be paid to where the interview is held, arrangement of seating, how the researcher dresses, manner of approach, all in the interests of equality. There might be a certain amount of pleasant chat before getting into explaining what the research is about. If rapport has been established, there should not be a difficulty in getting people to talk. The problem, rather, might be that they talk too inconsequentially, or off the subject, or vaguely. There are a number of techniques researcher uses in the natural course of the conversation to aid clarity, depth and validity. The other instruments could be a focus groups that are used to get groups talking about a certain subject while the members are under observation. A qualitative researcher generally develops the questions that he or she asks before the study begins, as the aim in qualitative research is to get a personal look at the subject, or subjects, being studied. Interviews are often important instruments in qualitative research, and they can be done in both structured and unstructured ways. Structured interviews include a set of questions that the researcher has formulated beforehand. Unstructured interviews allow the researcher and subject to simply talk with one another and share information in an informal atmosphere. In this thesis, the semistructured interviews and opened interviews applied to have better outcome which fits better my investigation approach. By open interview expected to face the new issues and contents from the communication department of any university regarding rankings and official web pages which are unpredictable. Interview will be conducted in this research to learn the opinions and experiences of the experts of communications and marketing who are involving and engaging in the process of designing and constructing the official websites of universities. It will be the great chance to have interviews with related staffs and responsible of university to see how basically and technically the marketing strategy of theses universities got affected by the rankings positions.

\section{$\checkmark$ Profile of the interviewee will be experts of these field:}

Preferably to have interview with Catalan universities communication department which hopefully would be four interviews and he profile of the experts and staffs of the universities will be as following: 
Ranking

Marketing

Techniques of Informatics

* Management

\subsubsection{GUIDELINE OF THE INTERVIEW}

Interviews are a systematic way of talking and listening to people and another way to collect data from individuals through conversations. The researcher or the interviewer often uses open questions. Data is collected from the interviewee. The researcher needs to remember the interviewer's views about the topic are not of importance. The interviewee or respondent is the primary data for the study. Interviewing is a way to collect data as well as to gain knowledge from individuals and an interchange of views between two or more people on a topic of mutual interest, sees the centrality of human interaction for knowledge production, and emphasizes the social situated of research data. Interviews are ways for participants to get involved and talk about their views. In addition, the interviewees are able to discuss their perception and interpretation in regards to a given situation. It is their expression from their point of view. The interview is not simply concerned with collecting data about life: it is part of life itself, its human embeddedness is inescapable." The researcher has to know and select the appropriate method for addressing the needs of the research question. Then, the researcher has to make a decision and choose the right method for that study. Data collection has its complexities and demands. It is the role of the researcher to ask questions. The questions ought to elicit valid response from respondents. The questions have dual goals of motivating the respondent to give full and precise replies while avoiding biases stemming from social desirability, conformity, or other constructs of disinterest. Interviewers that have been properly trained, and play the proper role of the interviewers along with well-designed questions can conduct a good interview. The proper training and proper interviewer behavior can help greatly in achieving the goals. There are many reasons to use interviews for collecting data and using it as a research instrument as: 
- There is a need to attain highly personalized data.

- There are opportunities required for probing.

- A good return rate is important.

Respondents are not fluent in the native language of the country, or where they have difficulties with written language. It is necessary for the researcher to prepare before the actual interview. The interview starts before the interview actually begins. This is the researcher's preparation stage. Once the interview is conducted the researcher needs to make sure that the respondents have:

- A clear idea of why they have been asked

- Basic information about the purpose of the interview and the research project of which it is a part

- Some idea of the probable length of the interview and that you would like to record it (explaining why)

- A clear idea of precisely where and when the interview will take place

Also, the interview needs to be effective and this is the responsible of the researcher. The researcher ought to have the following skills and abilities:

- An ability to listen

- An ability to be non-judgmental

- A good memory

- Ability to think on his/her feet

An interview guide is also an essential component for conducting interviews. An interview guide is the list of questions, topics, and issues that the researcher wants to cover during the interview. The interview guide should be clear and avoid ambiguity. The researcher ought not ask personal or illegal questions and be comfortable with silences and wait for the respondent to speak. There are six suggested steps to devise an interview guide, which include:

- Identify appropriate topics and questions 
- Decide on the level of detail

- Draft the questions

- Order the questions

- List any probes or prompts

- Pilot the questions have the informant identify the problems during the pilot.

There are many types of interviews, which include:

- structured interviews

- semi-structured interviews

- unstructured interviews

- non-directive interview

Interviews are particularly useful for getting the story behind a participant's experiences. The interviewer can pursue in depth information around a topic. Interviews may be useful as follow-up to certain respondents to questionnaires, to further investigate their responses and the open-ended questions are asked during interviews. Interviews provide a qualitative method of gathering evidence, data or information. Responses are not usually expressed in numerical terms, as might be the case with questionnaires. Interviewing with all four aforementioned universities could be a great opportunity for this study, but finally 3 interviews could be done due to the reason that was the interviewee of a university didn't accept to do it and unfortunately it couldn't be achieved. The profile of the chosen experts and staffs of those four Catalan universities were from the field of:

- Rankings

- Marketing

- Informatics

- Communication and promotion department of universities

By open-interview it was expected to discover and understand more issue and founding from the communication and promotion department of four Catalan universities who are the main 
responsible regarding the rankings contents and their official web pages to achieve the main objectives of this investigation. Interview were applied in this research to learn the opinions and experiences of the experts of communication and marketing department who are involving in the process of designing, constructing and updating the contents of the official websites of aforementioned Catalan universities. It was the great opportunity to have interviews with related staffs and responsible of those mentioned Catalan universities to recognize how basically and technically the marketing strategy of has being used in their webpage and to see how these universities designed their web page for having better presentation for their audiences. The interview was based on 2 dimensions as:

- Rankings

- Marketing aspects

In order to collect data, the researcher should be able to access the data that needs to be collected for the study. Data can be gathered from a number of sources including written documents, records, workplaces, the Internet, surveys or interviews. These three interviews helped this study to gather information about publishing and analyzing process of the rankings notifications in the official webpage of the aforementioned universities. By the help of these interviews tried to recognize is there any direct influence of rankings success on the design and construction of the official web page of universities or how rankings notifications affected the website design and frame of any of aforementioned Catalan universities.

\subsubsection{GUIDELINE FOR THE ANALYSIS OF THE WEBPAGES}

The pressure on universities worldwide has increased to transform themselves from isolated educational institutions to profit generating businesses. The visibility of a web page plays a role in attracting potential clients, as more and more young users are depending on the web for their everyday information needs. The existence of a correlation between website visibility ranking and academic ranking provide a repeatable method of measuring university website visibility, and for comparison with measurement of other institutes websites as: a scoring system was designed 
to cater for subjective measurements, producing a ranked list of university homepages. In some cases, it homepages were designed based on good practice, while in others little or no effort was expended to achieve a high degree of visibility. There is a correlation between the two types of ranking. Website visibility is a design feature often ignored in the design of university homepages in many universities, which could lead to missed opportunities. Guidelines are provided to improve this situation. It is clear from both the industry and academic research that marketing is essential to push products and services out to the consumer.

The use of websites to achieve this has been a common tactic since the early days of the internet. Lately, universities have been forced to change from being isolated academic enterprises to real life businesses, competing for common pools of paying clients. Their websites have played a central role in this effort to market a university. A university's website is expected to be a flag waving device for its reputation for teaching and research. In parallel with this, there has been a paradigm shift of focus onto social media, where the younger generation is highly aware of and dependent on technology for their social interactions. It is a combination of these factors which have caused university Websites to shift from operating in a traditional academic environment to the public realm. On this platform, students expect to be able to interact with their university through its website and the learning management system on a daily basis. This analysis guideline was based on two principal indicators section of universities websites as:

1. Technical indicators

2. Marketing and rankings indicators

\subsubsection{TECHNICAL INDICATORS}

The technical aspects of a websites and help to recognize how technically the website is set up and designed. Websites are complete abstraction and when we identify a site as such, what we're really describing is a collection of individual linked pages that share a common graphic and navigational look and feel. What creates the illusion of continuity across a cohesive "site" is the design features that pages share. Individual htm/ pages and how they are designed and linked are 
the atomic unit of web sites, and everything that characterizes site structure must appear in the page templates. These indicators are essential and playing a very important role to construct any website and follow as:

Layout: all sectors as main navigation, sub navigation, footer and search bar are regarded as page layout. As the web, has matured over the past decade, the structure of web pages in text driven information sites has become more uniform and predictable. Although not all web pages share the exact layout and features described, most web pages incorporate some or all of these basic components, in page locations that have become familiar to web users. Page headers are like miniature versions of the home page that sit atop each page and do many of the things that home pages do, but in a limited space.

Headers: provide site identity and global navigation, with search and perhaps other tools. The exact location and arrangement of the components vary from site to site, but the overall design pattern has become fairly consistent. Headers are the most visible component of site identity. What seems real is real: a collection of pages that share headers will be perceived as a "site" even if the pages originate from very different technical sources (net, blog software, portal systems, SharePoint, web applications, content management systems, and so on).

Respecting the current web layout or designing system and technologies can be regarded entirely different designing version than traditional web designing, and developers (especially fresher) must know about the pros and cons of responsive web designing. The basic instinct might be to choose media queries to develop a responsive site. However, the hassle one faces with media queries is that new queries can pop up from moment to moment; each time, the user experiences sudden and drastic changes to the look and organization of the site. Experts suggest using some CSS (Cascading Style Sheets: which means saves a lot of work. It can control the layout of multiple web pages all at once) transitions to ease the jump.

Pages that include data tables pose a special challenge to the responsive web designer. Data tables are extremely wide by default, and when someone zooms out to see the whole table, it becomes too small to read. When one tries to zoom in to make it readable, he or she is supposed 
to scroll both horizontally and vertically to look through it. Well, there are several ways to avoid this problem. Reformatting the data table as a pie or mini-graph is an approved solution and the mini graphics in narrow screens.

Home link: placing your organization or site logo in the upper left corner of the page and linking that logo to the home page is a widely-used convention and should be adopted perfectly. If you are not using a logo or graphic in your header, at least put a "home" link near the upper left corner of the page, where 99 percent of users will expect to find it.

Navigation: headers are the most frequent location for global navigation links that span the site. The ideal arrangement is to use an htm/ list of links, styled with special software to spread horizontally across a section of the header. This gives you:

Usability: global links where users most expect to see them

Semantic logic: the collection of global links should be marked up as a list, because, well, it is a list

Accessibility: the list format of links appears early in the code listing, where it should be

Search visibility: a collection of your major navigation keywords, linked and at the top of the code listing, is ideal for search engine optimization

Tabs are another widely used, easily understood convention for global navigation. The best way to implement tabs is to style an ordinary html list with a more elaborate treatment to form the "tab" graphic around each link. The graphic details right: the selected tab should be graphically unambiguous, and the remaining tabs should clearly be behind the selected tab. This type of you is here marker is essential in orienting users within the site. Tabs can also be used to implement a two-tiered navigation scheme, in which a secondary horizontal list of links appears under the selected tab, again as a simple html list, to keep things semantic, accessible, and search visible.

Credibility and validity of content: the world's leading researcher on web credibility has said that web credibility is about making your website in such a way that it comes across as trustworthy and 
knowledgeable. Your website is often the first point of contact for the customers, responsible for first impressions and of course sources of revenue. Companies that design for credibility have a strategic advantage over competition. There are four types of credibility: presumed credibility, reputed credibility, surface credibility, earned credibility.

- $\quad$ Author - Information on the internet with a listed author is one indication of a credible site. The fact that the author is willing to stand behind the information presented (and in some cases, include his or her contact information) is a good indication that the information is reliable.

- Date - The date of any research information is important, including information found on the Internet. By including a date, the website allows readers to make decisions about whether that information is recent enough for their purposes.

- $\quad$ Sources - Credible websites, like books and scholarly articles, should cite the source of the information presented.

- Domain - Some domains such as .com, .org, and .net can be purchased and used by any individual. However, the domain .edu is reserved for colleges and universities, while goo denotes a government website. These two are usually credible sources for information (though occasionally a university will assign a .edu address to each of its students for personal use, in which case use caution when citing). It should be regarded carefully with the domain .org, because .org is usually used by non-profit organizations which may have an agenda of persuasion rather than education.

- $\quad$ Site Design - This can be very subjective, but a well-designed site can be an indication of more reliable information. Good design helps make information more easily accessible.

- Writing Style - Poor spelling and grammar are an indication that the site may not be credible. In an effort to make the information presented easy to understand, credible sites watch writing style closely. 
Of course, there may be some reliable websites that do not include all these qualities and regarding the credibility of content the website could be verified by the information that can be found its source on the reliable information data base such as an encyclopedia or a book on the subject. The kind of websites you use for research can also depend on the topic you are investigating. In some cases, it may be appropriate to use information from a company or nonprofit organization's website, such as when writing an industry or company overview.

Easy access and use: Over the past few years, we have gotten used to certain standards in web design. In order to make a lasting impression on your visitors, you need to build experiences that go beyond those of a plain, usable website. This does not mean usability has become any less important. It just takes on a different role in web design, now forming the basis for a great user experience. Usability means user centered design. Both the design and development process are focused around the prospective user to make sure their goals, mental models, and requirements are met to build products that are efficient and easy to use. Here are a few of the basics of availability and accessibility,

- $\quad$ Server uptime - It's important to ensure the visitors don't get an error trying to load your site. Invest in good hosting.

- Broken links - Double check that there are no dead links on the site. Nothing sends a visitor back to Google search results faster than a 404 page.

- Mobile responsiveness - Make sure the site can handle different screen sizes and slow connections.

A clear and usable design can be achieved through:

- $\quad$ Simplicity - Focus on what's important. If the web doesn't t distract the visitors, they will be more likely to do what you want them to do.

- $\quad$ Familiarity - Stick to what people already know. There is nothing wrong with looking at other sites for inspiration. 
- Consistency - Don't get cute. Create a consistent experience across your entire website to keep your visitors mind at ease.

- Guidance - Take your visitors by the hand. Don't expect your visitors to explore your site all on their own. Instead, guide them through your site and show them what you have to offer.

- Direct feedback - Feedback is essential to any interaction. The moment people interact with your site, make sure to offer an indication of success or failure of their actions.

- Good information architecture - Understand the webpage visitors' mental models and how they would expect the web designer to structure the content on the site. Credibility is a crucial aspect of any website. Even if people find the content they are looking for, if they don't trust you, that content is worthless. The website could cause site visitors to be skeptical about the business in any number of ways including whether or not the university webpage really exists, the university reputation, or the quality of the content. It is important that people know the university fame and reputation. Offer a clear "About Us" page together with your contact details and if possible a physical address.

\subsubsection{MARKETING AND RANKINGS INDICATORS}

Presentation: good news should be shared in real time and real place first impression last impression; the successful page follows these hints. All four universities were UAB can be regarded as very eye-catching and full of useful contents in the first page which won't let you to shift to the other web pages, especially regarding the notification of rankings or the other news regarding the educational programs or seminars etc. ....

People make snap judgments. It takes only $1 / 10$ th of a second to form a first impression about a person, and websites are no different. It takes about 50 milliseconds (that's 0.05 seconds) for users to form an opinion about the website that determines whether they like your site or not, whether they'll stay or leave. This number comes from specific studies. In the first study, 
participants twice rated the visual appeal of web homepages presented for $500 \mathrm{~ms}$ each. In a follow-up study, they reduced the exposure time to $50 \mathrm{~ms}$. Throughout, visual appeal ratings were highly correlated from one phase to the next as were the correlations between the $50 \mathrm{~ms}$ and 500 ms conditions. Thus, visual appeal can be assessed within 50 ms, suggesting that web designers have about 50 ms to make a good first impression This first impression depends on many factors: structure, colors, spacing, symmetry, amount of text, fonts, and more. All the website screenshots of the aforementioned universities below are for illustrative purposes.

Even if you nail the content, design and structure, it doesn't mean a thing if no one sees it. Presentations aren't merely documents or files; they are a dynamic experience shared between a presenter and their audience. A great presentation is only as good as the delivery both by the presenter and by the presentation technology they use. Whether presenting in a boardroom, off an iPad, over the Web or as a print out, the right delivery can make all the difference between a great presentation, a missed opportunity or a presentation disaster. All the other elements don't matter if the delivery just doesn't work.

Delivery refers to both how the presenter delivers the presentation and what platform the personation is delivered. Presentation skill are necessary for anyone who plans on making a living from presentations o whose business depends on giving effective presentation. Just as important as the Presenter's skills is the platform and technology used to deliver university presentation. The tool that the universities use to deliver their presentation is one of the most overlooked elements of a presentation. Just as the content, design and structure need to match the situation and audience, how they deliver their presentation really matters. Presenting to a boardroom full of senior executives may require a different tool than a one on one presentation over lunch. PowerPoint technology calls for a different type of technology as well. Often people pick the presentation tool that they're most familiar with or just happens to be there (AKA, PowerPoint), and don't think about what the specific delivery needs are.

Compatibility: with smart phone and tablets, easy to open or any special format for smart phone. By new innovation and decade of high technology, the issue of compatibility with smart 
phone and tablets, easy to open or any special format for smart phone sounds to be more important than the other times.

Because most of the people prefer to use their smart phone for anything instead of computer or lap top and there is common belief that smart phones are handier and easy to carry. So, this is enough to consider this issue that compatibility with smart phones really plays a significant role in attracting the audiences. The difference between a mobile compatible website and a mobile optimized website continues to be a source of confusion. According to a recent Google study, sixty-one per cent of shoppers will leave a website if it is not optimized for their device. In other words, the experience of a non-optimized website can negatively impact a consumer's likeliness to book and overall perception of the brand. Many hoteliers are aware of this consequence but are still struggling to understand what characterizes a mobile optimized hotel website.

A mobile compatible website is an HTML based website that doesn't contain Flash. It means that a website is viewable on a Smartphone or Tablet, but it is not optimized for these devices. These websites have been designed for web browsers on PCs with much larger screens and navigation using a mouse. It is very noticeable a few things about these websites when you attempt to browse them on any Smartphone or Tablet only the audiences have to scroll left, right, up or down and figure out how the site "works", media may load slower, text is tiny so anybody has to zoom in to read it and the links are small and difficult to click with the fingertip. If audiences have done nothing to optimize the website for mobile devices, then it is likely compatible by default. It is also likely that visitors are abandoning the university site pretty quickly. Why? Because poor experiences do not convert customers. A mobile optimized website is a website that is designed specifically for a Smartphone or a Tablet, not a desktop computer or laptop.

A mobile optimized website doesn't require that someone pinch and zoom to read text. On a mobile optimized site, the navigation is built for efficiency, the images and media are optimized for quick loading and the content is succinct for maximum effectiveness. Additionally, mobile only functionality includes tap-to-call, tap-to-email and map functionality. If for example a 
hotel's website has been optimized for mobile devices it will know because not only it is much easier to navigate and use compared to the experience of a compatible website but because it will likely see less bounce rates, higher engagement levels and improved conversions. To help set the record straight, here is a table showcasing the main differences between the two and to illustrate the importance of having a hotel website that is optimized for mobile devices.

Target Group: the universities webpage generally was designed for all types of audiences and only special type of target audiences. All webpages of the universities are built in a general way and for all types of audiences and not only special type.

The defining a target audience is a very important and crucial part of any university webpage. But defining a target audience is a best practice for anyone that needs others to give them something. It might be a salary, an investment or money in exchange for a product or service, educational programs, scholarships and funds. Whenever you need something from someone you go through at least some of the steps in defining a target audience. The target audience process even at an early age. Think back to when you were a kid. When you wanted a treat, you went through the target audience process. You knew that your dad probably wouldn't be the one to approve your request so you went to your mom and you made sure to catch her in the right mood. That's an example of defining your target audience. It's a basic example, but businesses go through that process so they have more success. It doesn't make sense to try to please everyone. Your time, energy and money are better invested in a target audience. And that goes for defining the target audience for the personal brand too.

Simplicity: the marketing message of the page should be transferred clearly to audiences.

Differentiation: the features that makes university different from the others is clearly focused and emphasized. The differentiation features that makes university different from the others. As it mentioned in the marketing section of literature review, the differentiation now a day really play a very significant role in the marketing strategy of universities. 
Usability rather than Beauty: with respect to marketing aspects does the useful content and utile or just well designed to attract.

Eye-catching: which is the page and design eye catching that will not let the audience move to other pages.

Complementary images: for better transferring the message of university are images related and transferring the message

An image placed somewhere in the middle of text draws the reader's attention more than the text itself. It might even draw him out of the copy. For that reason, it's extremely important to have a caption under every image to press your main point home, and hopefully to get him back into the copy. Captions under images are read on average more than the body copy itself, so not using them, or not using them correctly, means missing out on an opportunity to engage a huge number of potential readers. The natural sequence for reading involves a very specific order. First we look at the image, if there is one. Then we scan the headline. Then we read the body copy (if the headline is interesting enough). An image at the top of the page is a common practice, to catch people's attention and draw them into the article. But if you're doing this, you'd better be sure it's above your headline.

Connectivity with Social networks, (Facebook, Twitter, Instagram...etc.). Connectivity with Social networks: (Facebook, Twitter, Instagram, linked in ...), it can be considered for all the universities web pages and especially for UPF which is strongly connected and has got a special web page or link for that.

Virtual tours, to give a primary insight and view to audiences about university's campus, library, classes, faculties \& environment. Virtual tours which gives a primary insight and view to audiences about university's campus, library, classes, faculties \& environment only can be noticed for UAB in the strong level and for the rest is not strong enough to show the university virtually and they cannot give some image to distanced university. 
First page visibility the ranking, is it located in the first page and highlighted well- enough. First page visibility of the ranking is located in the first page of UAB better than the other universities and highlighted well- enough and the rest not presenting well-enough their rankings notifications in the first page. Search engine of UAB web page can be considered as the best one among the other which is very complete and handy and it necessary to mention that the other universities webpage have got the useful search engine but not as good as UAB.

\subsubsection{QUESTIONNAIRES}

The key objective of a questionnaire is providing standardized interview across all subjects. This is so that all respondents are asked the questions that are appropriate to them, and so that, when those questions are asked, they are always asked in exactly the same way. The role of the questionnaire is to elicit the information that is required to enable the researcher to answer the objectives of the survey. To achieve this, the questionnaire should not only collect the data required, but also collect the data in most accurate way possible. Questionnaire design is one of the most crucial aspects of any academic research. It is never similar to writing a chapter or conducting analysis. Any researcher must have sound knowledge of statistics and should bear in his/her mind the hypothesis to develop questions which can be directly attributed to them. Choice of scales is also important and should be backed by rationale for using the same. Questionnaires provide a relatively quick and efficient way of obtaining large amounts of information from a large sample of people. Data can be collected relatively quickly because the researcher would not need to be present when the questionnaires were completed.

However, a problem with questionnaire is that respondents may not tell the truth due to social desirability. Most people want to present a positive image of themselves and so may lie or bend the truth to look good, pupils would exaggerate revision duration. Also, the language of a questionnaire should be appropriate to the vocabulary of the group of people being studied. For example, the researcher must change the language of questions to match the social background of respondents' age / educational level / social class / ethnicity etc. Questionnaires can be an 
effective means of measuring the behavior, attitudes, preferences, opinions and intentions of relatively large numbers of subjects more cheaply and quickly than other methods. An important distinction is between open-ended and closed questions. Questionnaires is a series of questions asked to individuals to obtain statistically useful information about a given topic and when properly constructed and responsibly administered, questionnaires become a vital instrument by which statements can be made about specific groups, or people, or entire populations. Adequate questionnaire construction is critical to the success of a survey. Inappropriate questions, incorrect ordering of questions, incorrect scaling, or bad questionnaire format can make the survey valueless, as it may not accurately reflect the views and opinions of the participants. A useful method for checking a questionnaire and making sure it is accurately capturing the intended information is to pretest among a smaller subset of target respondents. Questionnaires of this study aimed to help for having the better analysis of the official websites of the mentioned Catalan universities. To recognize how these indicators have been applied differently in their websites in purpose of highlighting their rankings success among the other Catalan universities, the questionnaires of this investigation were chosen as close ended, based on the three web indicators such as techniques, marketing and ranking divided on four blocks as:

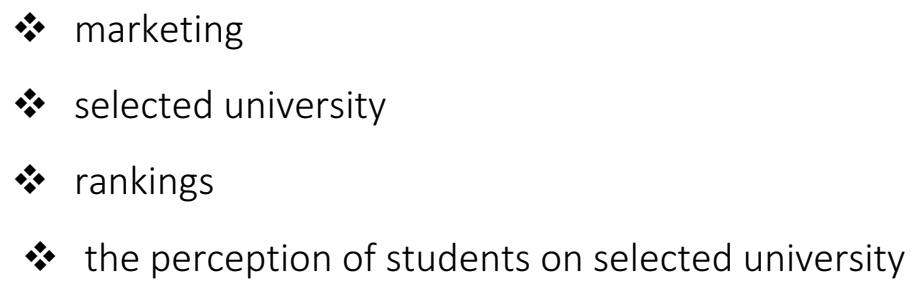

The format of sent questionnaire and questions were as:

1. Name of your university (Universidad)

2. Faculty of student (Facultad)

3. (1) PHD Student or (2) Master Student

4. Nationality (Nacionalidad) 
5. Age (Edad)

6. Gender(Género): (1) Male, (2) Female

\section{First Block: The role of rankings in higher education}

1er bloque: El papel de los rankings en la educación superior

7. In your opinion, the importance of university rankings in the current higher education system is:

En su opinión, la importancia de los rankings en el sistema de superior corriente es:

\section{Mark only one oval.}

1-High-Alta

2-Middle-Medio

3-Low-Baja

4-None-Ninguno

8. In your view, the international reputation of universities, is influenced by its rankings positions:

En su opinión, la reputación internacional de las universidades, está influenciada por sus posiciones de los rankings:

\section{Mark only one oval.}

1-High

2-Middle 
3- Low

4- None

9. In your opinion, the reports of rankings in the web page of the universities influence student's selection:

En su opinión, los informes de los rankings en la página web de las universidades influyen en la selección de estudiantes:

\section{Mark only one oval.}

1-High

2-Middle

3-Low

4-None

10. In your view, the importance of the rankings reports (news) on the universities web page is:

En su opinión, la importancia de los informes de los rankings(noticias) en la página web de la universidad es:

\section{Mark only one oval.}

1-High

2-Middle

3-Low

4-None 


\section{Second Block: Your selected university}

Segundo bloque: Su universidad seleccionada

11. Comparing with other Spanish universities, in the web page of your chosen university the reports of rankings are applied in a level:

Comparando con otras universidades españolas, en la página web de su universidad elegida los informes de los rankings se apliquen de nivel:

\section{Mark only one oval.}

1-High

2-Middle

3-Low

4-None

12. In comparison with other Spanish universities, the level of attractiveness of the web page of your chosen university is:

En comparación con otras universidades españolas, el nivel de atractivo de la página web de su universidad elegida es:

\section{Mark only one oval.}

1-High

2-Middle

3-Low

4-None 
13. Comparing with other Spanish universities, the design grade (level) of the webpage of your current university is:

Comparando con otras universidades españolas, el diseño de grado (nivel) de la página web de su universidad actual es:

\section{Mark only one oval.}

1-High

2-Middle

3-Low

4-None

14. In comparison with other Spanish universities, the level of easiness of using (navigation) of the webpage of your chosen university is:

En comparación con otras universidades españolas, el nivel de facilidad de uso (navegación) de la página web de su universidad elegida es:

\section{Mark only one oval.}

1-High

2-Middle

3-Low

4-Baja 
15. Comparing with other Spanish universities, the connectivity level of the web page of your chosen university with Social networks like: Facebook, Twitter, Instagram is:

Comparando con otras universidades españolas, el nivel de conectividad de la página web de su universidad elegida con las redes sociales como: Facebook, Twitter, Instagram es:

\section{Mark only one oval.}

1- Very good-Muy Buena

2-Good-Buena

3-Suffiecient-Suficiente

4-Inadequate-Insuficient

\section{Third Block: Marketing Strategy of the university}

Bloque tercero: Estrategia de Marketing de la universidad

16. Regarding with other Spanish universities, the number of offers referring to tuition fee and special programs in the webpage of your chosen university is:

Con respecto a otras universidades españolas, el número de ofertas que se refieren a la matrícula y programas especiales en la página web de su universidad elegida es:

\section{Mark only one oval.}

1-High

2-Middle

3-Low

4-None 
17. The presentation style of virtual tour, campus, library, classes, facilities and university environment in the web page of your chosen university, comparing with other Spanish universities is:

El estilo de presentación de tour virtual, campus, biblioteca, clases, instalaciones y ambiente universitario en la página web de su universidad elegida, comparando con otras universidades españolas es:

\section{Mark only one oval.}

1- Very good-Muy Buena

2-Good-Buena

3-Suffiecient-Suficiente

4-Inadequate-Insuficiente

18. Comparing with other Spanish universities, the design style of the webpage of your chosen university is:

Comparando con otras universidades españolas, el estilo de diseño de la página web de su universidad elegida es:

\section{Mark only one oval.}

1- Very good-Muy Buena

2-Good-Buena

3-Suffiecient-Suficiente

4-Inadequate-Insuficiente 
19. The level of usefulness of content of web page of your chosen university, comparing with other Spanish universities is:

El nivel de utilidad de los contenidos de la página web de su universidad elegida, comparando con otras universidades españolas es:

\section{Mark only one oval.}

1-High

2-Middle

3-Low

4-None

\section{Fourth Block: Perception of students}

Cuarto bloque: Percepción de los estudiantes

20. In your view, the influences level of international rankings on student's perception to choose a university is:

En su opinión, las influencias nivel de los rankings internacionales sobre la percepción de los estudiantes a elegir una universidad es:

\section{Mark only one oval.}

1-High

2-Middle

3-Low

4-None 
21. The level of using special marketing strategy by the help of rankings position in the website of your chosen university is:

El nivel de uso de la estrategia de marketing especial por la ayuda de la posición de los rankings en la página web de su universidad elegida es:

\section{Mark only one oval.}

1-High

2-Middle

3-Low

4-None

22. The presentation style of rankings success in the web page of your chosen university, comparing with other Spanish universities is:

El estilo de presentación de éxito de los rankings en la página web de su universidad elegida, comparando con otras universidades españolas es:

\section{Mark only one oval.}

1-High

2-Middle

3-Low

4-None

Comments - Comentarios

Powered by

非 Google Forms 
Chapter 4

Results 


\section{RESULTS}

This chapter is discussing regarding the results of questionnaires, interviews and webpage analysis of four mentioned Catalan universities. First part starts with the webpage analysis of the four Catalan universities webpage on 2015. The second part, discusses about the interviews, which conducted through three universities responsible of communication and promotion department as: UAB, UB and UPF and due to university regulation of UPC, the responsible person not accepted to do the interview. The third and last part of the results section, discusses about the questionnaires, which received through the 558 from $\mathrm{PhD}$ and master students.

\subsection{WEBPAGE ANALYSIS}

\subsubsection{ANALYSIS OF UB WEBPAGE}

The website of UB looks a complete abstraction and a collection of individual linked pages that share a common graphic and navigational look and feel and creates the illusion of continuity across a cohesive site and the design features that pages share. Regarding table 10, the layout all sectors as main navigation, sub navigation, footer and search bar regarded as a middle. By regarding this fact that the structure of web pages in text driven information sites has become uniform and all web pages not sharing the exact layout and features, most web pages incorporate some or all of these basic components and in the case of UB webpage, page headers are like miniature versions of the home page. Based on the table 10, the UB webpage could be regarded as the page, which is easy to access, and use and the headers, which provide site identity and navigation, are the most visible component of this website identity (figure 3). Respecting the current UB web layout and designing system and technologies can be regarded entirely different designing version. The header, the different links are well organized in the UB webpage. Site logo in the upper left corner of the page and linking that logo to the home page is a widely-used convention and it is adopted perfectly in the case of UB webpage. 
Results

TABLE 10. ANALYSIS GUIDELINE OF UB WEBPAGE

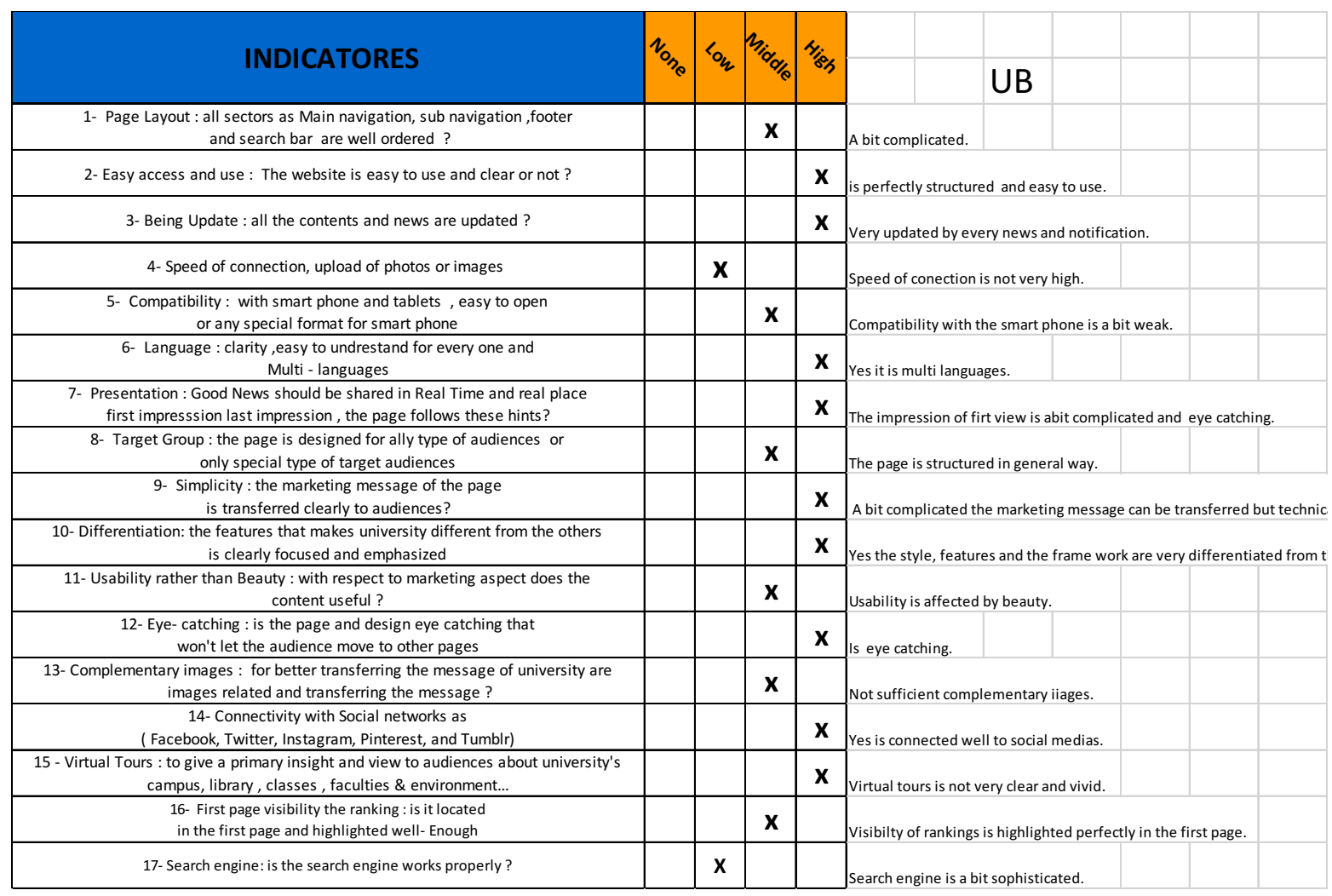

The exact location and arrangement of the components vary from site to site, but the overall design pattern of UB as you can see in figure 3 is consistent. With a website as sleekly designed, interactive, and easy to navigate as UB and its admissions site, it's no surprise the admission and information process will be very handy for interested students. There are a number of great design elements on this site and the playful fonts which pointed out are seemingly similar to the type used for reminiscent of higher education system, but with a sophisticated flair. Unique typography is an element of great modern web design, as it helps customers immediately identify them versus their competitors. For example, audiences in the very first glance as its unique style and appearance recognize UB typography. Usability, which is global, links where users most expect to see them regarded in the case of UB. Semantic logic, which is the collection of global links, should be marked up as a list sound to be regarded not very perfectly. 


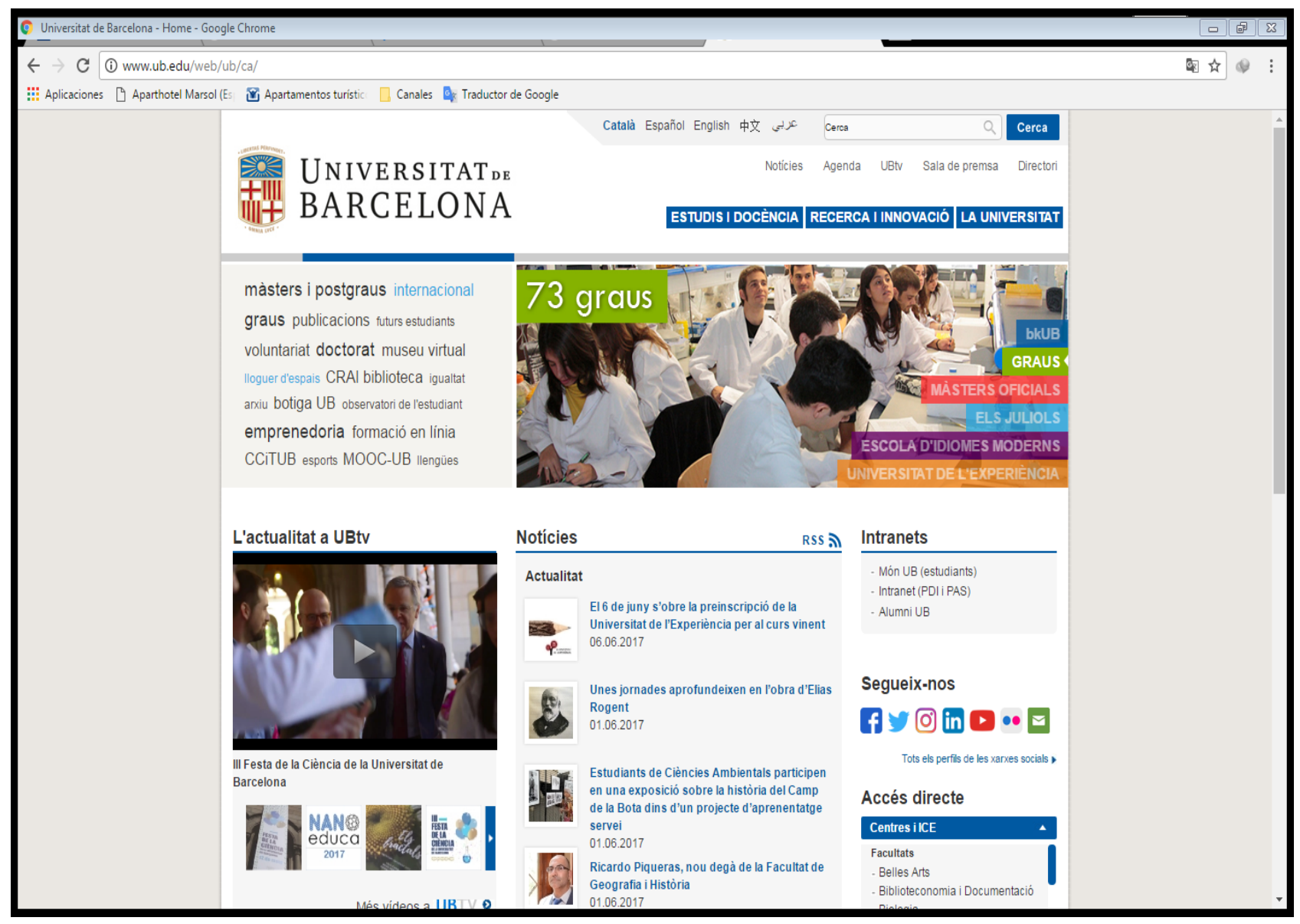

Regarding the credibility and validity of content the UB web, it could be considered strongly which is very important that the website is often the first point of contact for the customers, responsible for first impressions and of course sources of revenue. Companies that design for credibility have a strategic advantage over competition. There are 4 types of credibility: presumed credibility, reputed credibility, surface credibility, earned credibility. In the cases of the UB the credibility and validity of contents regarding the awards and ranking is perfectly organized and revised. The credibility and validity of contents are a very essential and important issue for any university webpage as you can see in the web page. It can be challenging to determine whether a 
website is credible. The UB site design this can be regarded in the middle level, but a well-designed site can be an indication of more reliable information. Good design helps make information more easily accessible. Of course, there may be some reliable websites that do not include all these qualities and regarding the credibility of content, the website could be verified by the information with its source on the reliable information database such as an encyclopedia or a book on the subject. The kind of websites you use for research can also depend on the topic you are investigating. In some cases, it may be appropriate to use information from a company or nonprofit organization's website, such as when writing an industry or company overview. Either if the web page distracts or confuses the visitors, they will need more time to find what they came for, or they might forget their initial goal all together. Either way, they will not experience the website as user friendly or chances are that they leave dissatisfied and with no intention of coming back. Visitors come to the website with certain goals in mind. It is the university job to help them reach these goals as quickly as possible. If the website considered to do that, the visitors will be pleased and the have laid the groundwork for a positive experience.

FIGURE 4. THE UB WEBPAGE REGARDING THE PAGE CONTENTS,2015

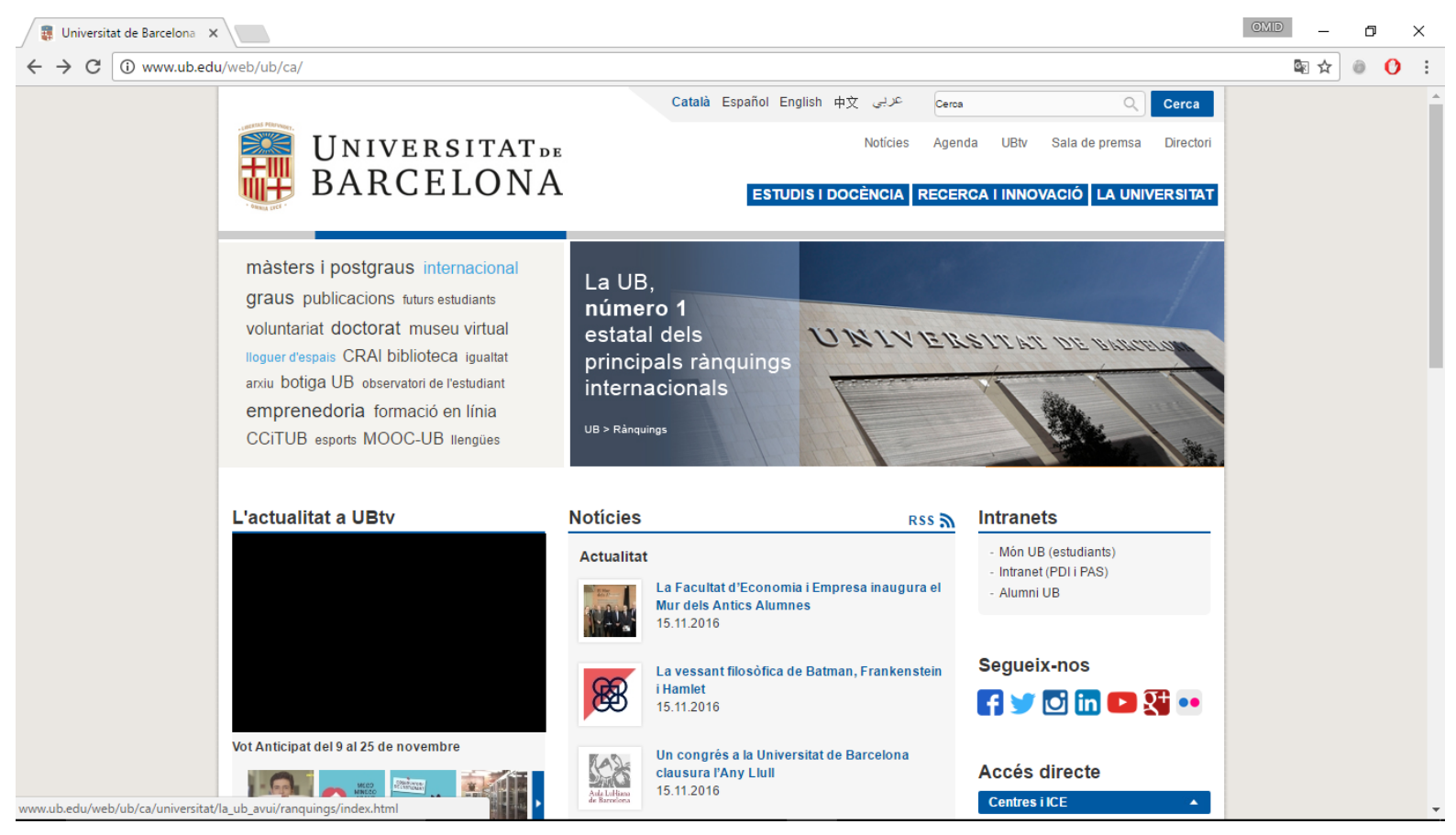


Regarding the marketing and rankings indicators of UB webpage, it can be considered that presentation which good news should be shared in real time and real place first impression last impression all are regarded perfectly. The UB webpage can be regarded as very eye-catching and full of useful contents in the first page, which won't let you to shift to the other web pages, especially regarding the notification of rankings or the other news regarding the educational programs or seminars. Even if you nail the content, design and structure, it doesn't mean a thing if no one sees it. Presentations aren't merely documents or files; they are a dynamic experience shared between a presenter and their audience. A great presentation is only as good as the delivery both by the presenter and by the presentation technology they use which all these mentioned issues and specification can be seen in the UB webpage and although presenting in a boardroom, off an iPad, over the Web or as a print out, the right delivery can make all the difference between a great presentation, a missed opportunity or a presentation disaster and all aforementioned specifications of a good presented web page can be regarded for UB webpage.

FIGURE 5. THE UB WEBPAGE REGARDING THE MARKETING AND RANKINGS INDICATORS, 2015

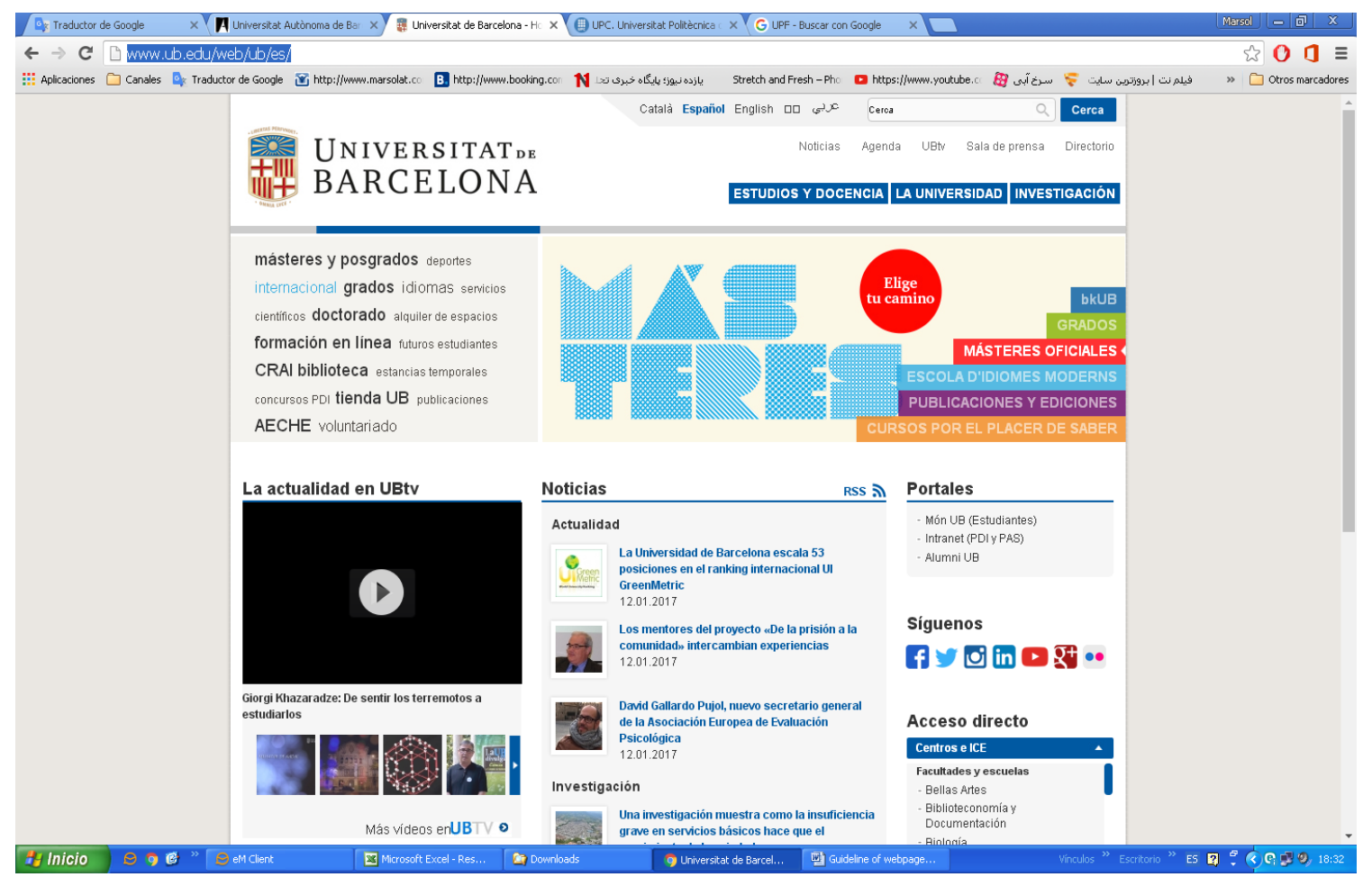


The other issue for the UB webpage can be regarded would be the issue of compatibility with smart phone and tablets and easiness to open or any special format for smart phone. By new innovation and decade of high technology, the issue of compatibility with smart phone and tablets, easy to open or any special format for smart phone sounds to be more important than the other times and in the UB case we can consider this item as a high level of compatibility. A mobile compatible website is an HTML based website that doesn't contain Flash which we can see this in the UB as well. It is very noticeable a few things about these websites when you attempt to browse them on any Smartphone or Tablet only the audiences have to scroll left, right, up or down and figure out how the site works, media may load slower, text is tiny so anybody has to zoom in to read it and the links are small and difficult to click with the fingertip but generally could be considered the UB webpage as compatible one with smarts phone and tablets. A mobile optimized website doesn't require that someone pinch and zoom to read text. On a mobile optimized site, the navigation is built for efficiency, the images and media are optimized for quick loading and the content is succinct for maximum effectiveness which we can see it in the UB webpage as well. Additionally, mobile only functionality includes tap-to-call, tap-to-email and map functionality. The UB webpage presents its contents in 3principal languages as: English, Spanish and Catalan although in some parts of the webpage the English links or contents not working properly but in majority all the principal links and pages are well organized and presented in 3 languages.

Regarding the target group of the UB webpage generally is designed for all types of audiences and not only special type of target audiences. All webpages of the universities are built in a general way and for all types of audiences and but a bit specialized for researcher and elite students. It is constructed very informative regarding all the educational plan or notifications of rankings and universities awards and researches fields. The defining a target audience is a very important and crucial part of any university webpage. But defining a target audience is a best practice for anyone that needs others to give them something which in the case of the UB it is complicated and is not very well designed. It might be a salary, an investment or money in exchange for a product or service, educational programs, scholarships and funds. Whenever you need something from someone you go through at least some of the steps in defining a target 
audience. The target audience process even at an early age. Think back to when you were a kid. When you wanted a treat, you went through the target audience process. Considering the simplicity which the message of the page should be transferred clearly to audiences the UB page was well structured and simplicity can be noticed for all of them but in some cases like the departments and links of scholarships the UB webpage is a bit complicated and this is noticeable for the UB, and it can be noticed that all the pages even with simplicity transferring their message in a high level of presentation. Differentiation, the features that makes university different from the others is clearly focused and emphasized in the UB webpage. The differentiation features that makes university different from the others it can be noticed only for UB and especially with the blue color that was used for the frame of the webpage as differentiation. As it mentioned in the marketing section of literature review, the differ enation now a day really play a very significant role in the marketing strategy of universities. Usability rather than Beauty, with respect to marketing aspects does the useful content and utile or just well designed to attract. Usability rather than Beauty, respecting to marketing aspects the useful contents are just well designed to attract the researchers and elite students and it is noticeable that the UB have been regarded the usability rather than beauty and it is noticeable that almost beauty has got over come on the usability. Eye-catching, is the page and design that won't let the audience move to other pages. It can be considered that only UB webpage is almost eye catching and full of news and notifications which are very interesting and attractive.

Complementary images, for better transferring the message of university are images related and transferring the message. Complementary images for better transferring the message of university are images in the UB webpage can be noticed that sufficiently were provided complementary images. Captions under images are read on average more than the body copy itself, so not using them, or not using them correctly, means missing out on an opportunity to engage a huge number of potential readers. The natural sequence for reading involves a very specific order. First we look at the image, if there is one. Then we scan the headline. Then we read the body copy (if the headline is interesting enough). An image at the top of the page is a common practice, to catch people's attention and draw them into the article. But if you're doing this, you'd 
better be sure it's above your headline, and all above mentioned items can be seen in the UB webpage. Regarding the connectivity with Social networks, (Facebook, Twitter, Instagram...etc.). Connectivity with Social networks: (Facebook, Twitter, Instagram, linked in and etc.), it can be considered for the UB web pages and especially can be noticed which is strongly connected and has got a special web page or link for that. The virtual tours, to give a primary insight and view to audiences about university's campus, library, classes, faculties and environment cannot be noticed specially for the UB webpage which is a negative point among the other universities.

Virtual tours which gives a primary insight and view to audiences about university's campus, library, classes, faculties and environment only cannot be noticed for the UB in the strong level and it cannot give some image to distanced university. Considering the first page visibility the ranking, which should be located in the first page and highlighted well-enough in the case of the UB the first page visibility of the ranking is located in the first page highlighted well- enough and the rest not presenting well-enough their rankings notifications in the first page. Search engine of the UB web page can be considered as the one of the best among the other, which is very complete and utile.

\subsubsection{ANALYSIS OF UAB WEBPAGE}

The website of the UAB looks a graphical webpage that share a technical graphics sense and navigational look which gives you the feeling of continuity and won't let you leave the page to another webpage additionally can be noticed that all the required information for the educational audiences are gathered in the very complete complex. Regarding the analysis table 11, the layout sectors as main navigation, sub navigation, footer and search bar are regarded could be regarded as the high level of quality and techniques. The structure of web pages in text conceptual information has become more uniform and all web pages sharing the various and different layout and features and the most web pages incorporate some or all of the basic components and in the case of UAB webpage page headers and layout feature are like perfectly applied. Based on the 
Results

table 11 , the UAB webpage could be regarded as the page which is perfectly easy to access and use.

TABLE 11. ANALYSIS GUIDELINE OF UAB WEBPAGE

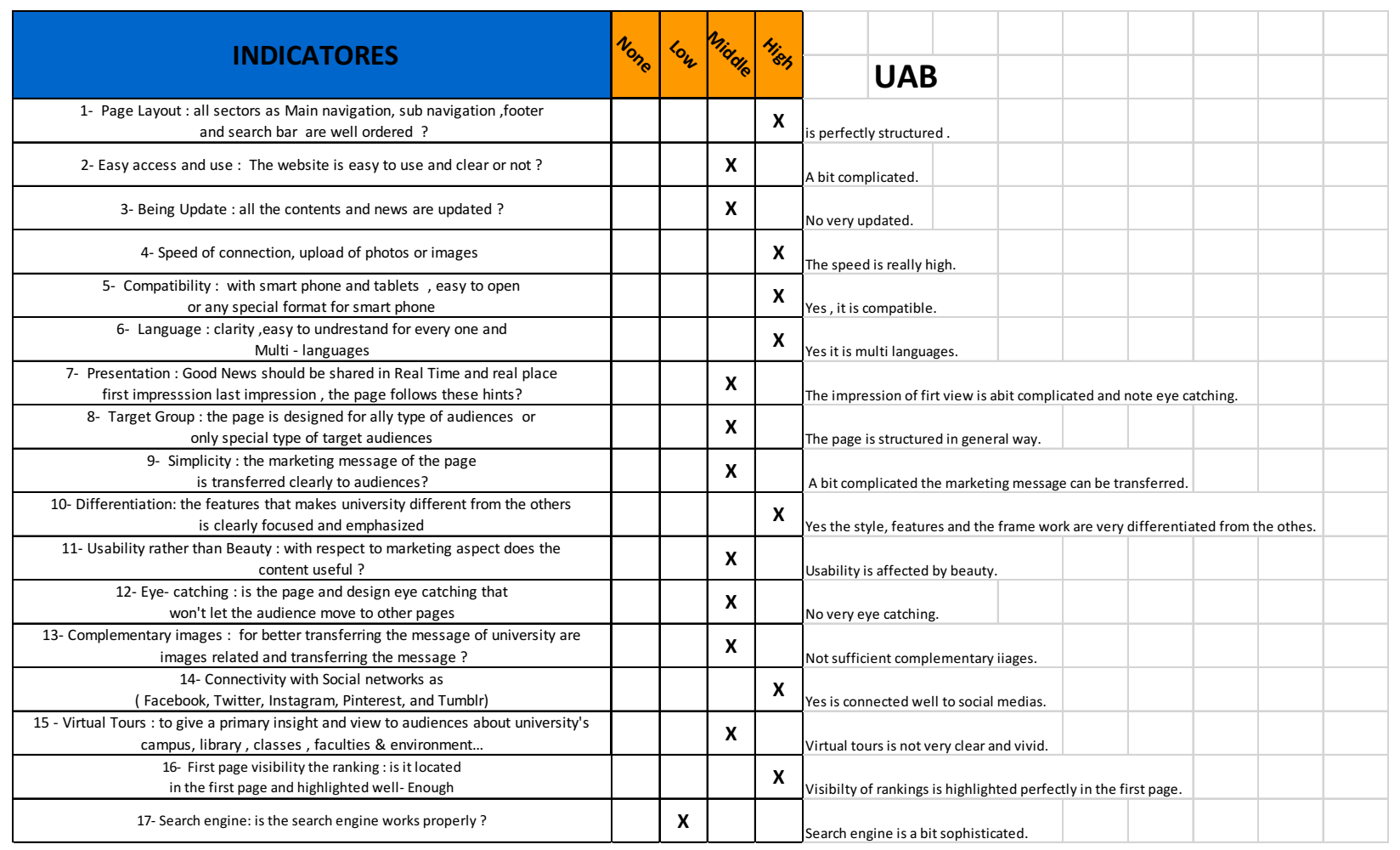

The headers which provide site identity and navigation are the most visible component of any university website identity were regarded perfectly for the UAB webpage (see figure 6of UAB). Respecting the UAB web (2015), layout and designing system and technical indicators which have been applied in the webpage, it can be regarded entirely different designing version of the university webpage and very unique one among the other Catalan universities. The header, the different links are well organized in the UAB webpage. Site logo in the upper left corner of the page and linking that logo to the home page is a widely-used convention and it was adopted perfectly in the case of UAB webpage. 


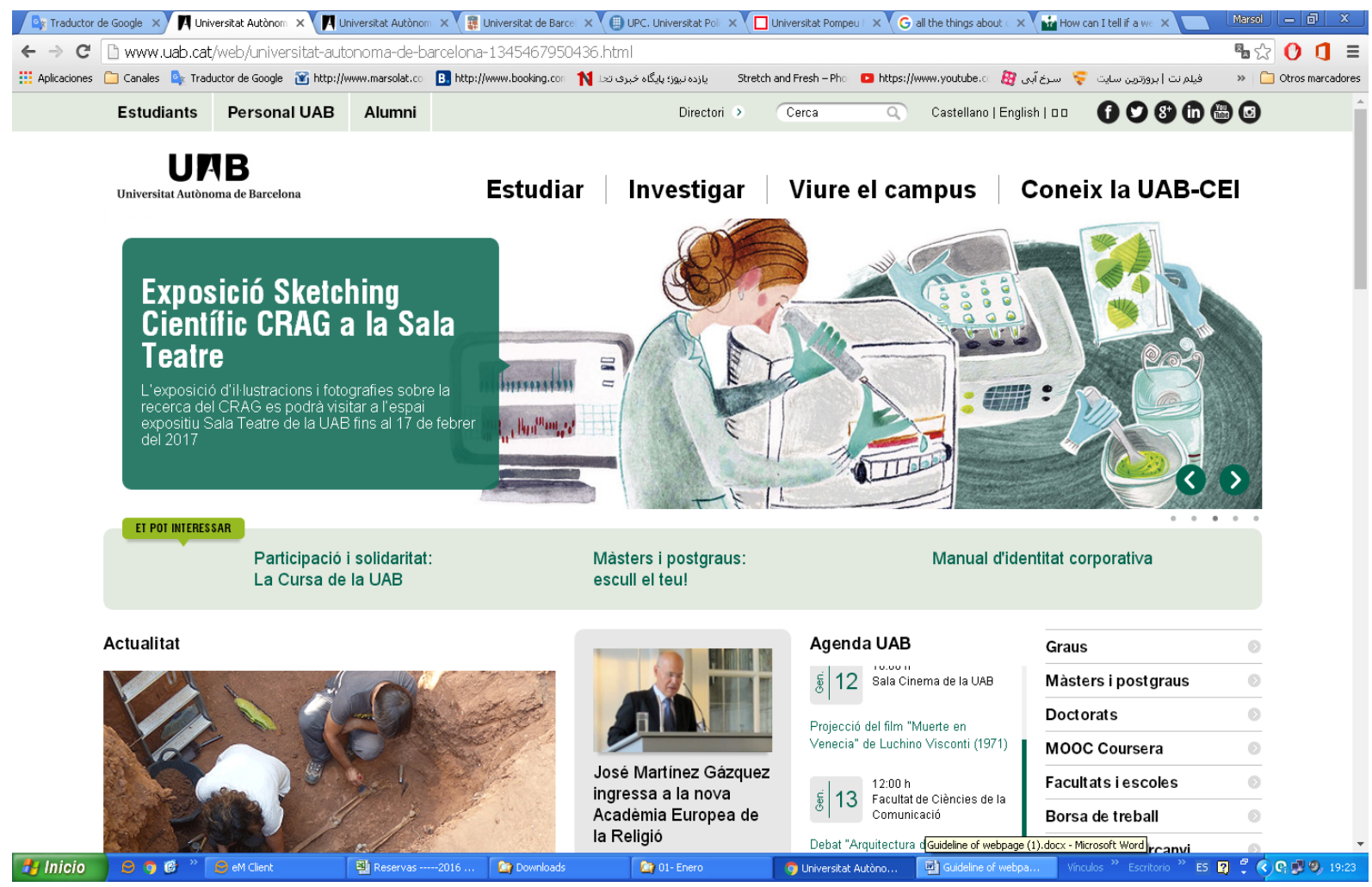

The exact location and arrangement of the components vary from site to site, but the overall design pattern of the UAB as you can see in the figure number six, is fairly consistent. In the case of the UAB website should be mentioned that this webpage as: sleekly designed, interactive, and easy to navigate and its admissions site and it's no surprise the admission part presents the information process very handy for interested students. There are a number of great design elements on this website and the playful fonts which pointed out are seemingly similar to the type used for reminiscent of higher education system, but with a sophisticated and perfect flair. Unique typography is an element of great modern web design, as it helps customers immediately identify them versus their competitors. For example, the UAB typography is 
recognized by audiences in the very first glance as its unique style and appearance. Usability which is global links where users most expect to see them are regarded in the case of the UAB. Semantic logic which is the collection of global links should be marked up as a list sound to be regarded very perfectly in the case of the UAB webpage. Regarding the credibility and validity of content in the UAB web it can be considered strongly and this issue is very important and often mentioned that the first point of contact for the customers, responsible for first impressions and of course sources of revenue. The university webpage that is designed for credibility have a strategic advantage over competition. Regarding the four types of credibility: presumed credibility, reputed credibility, surface credibility, earned credibility, all the mentioned items can be recognized in the UAB webpage. In the cases of the UAB the credibility and validity of contents regarding the awards and ranking is perfectly organized and updated upon the time. The credibility and validity of contents are a very essential and important issue for any university webpage as you can see in the web $U A B$ page. It can be challenging to determine whether a website is credible or not. The UAB website design can be regarded in the high level and a well-designed website with an indication of more reliable information.

Good design helps make information more easily accessible. Although, it could be some reliable websites that do not include all these qualities and regarding the credibility of content the website could be verified by the information that can be found its source on the reliable information data base. In some cases, it may be appropriate to use educational information from educational system and the university history which presents more about the educational institute goals and objectives. If the web page distracts or confuses the visitors, they will either need more time to find what they came for, or they might forget their initial goal all together. Either way, they will not experience the website as user friendly and chances are that they leave dissatisfied and with no intention of coming back. Visitors come to the website with certain goals in mind. It is the university job to help them reach these goals as quickly as possible. If the website considered to do that, the visitors will be pleased and the have laid the groundwork for a positive experience. 


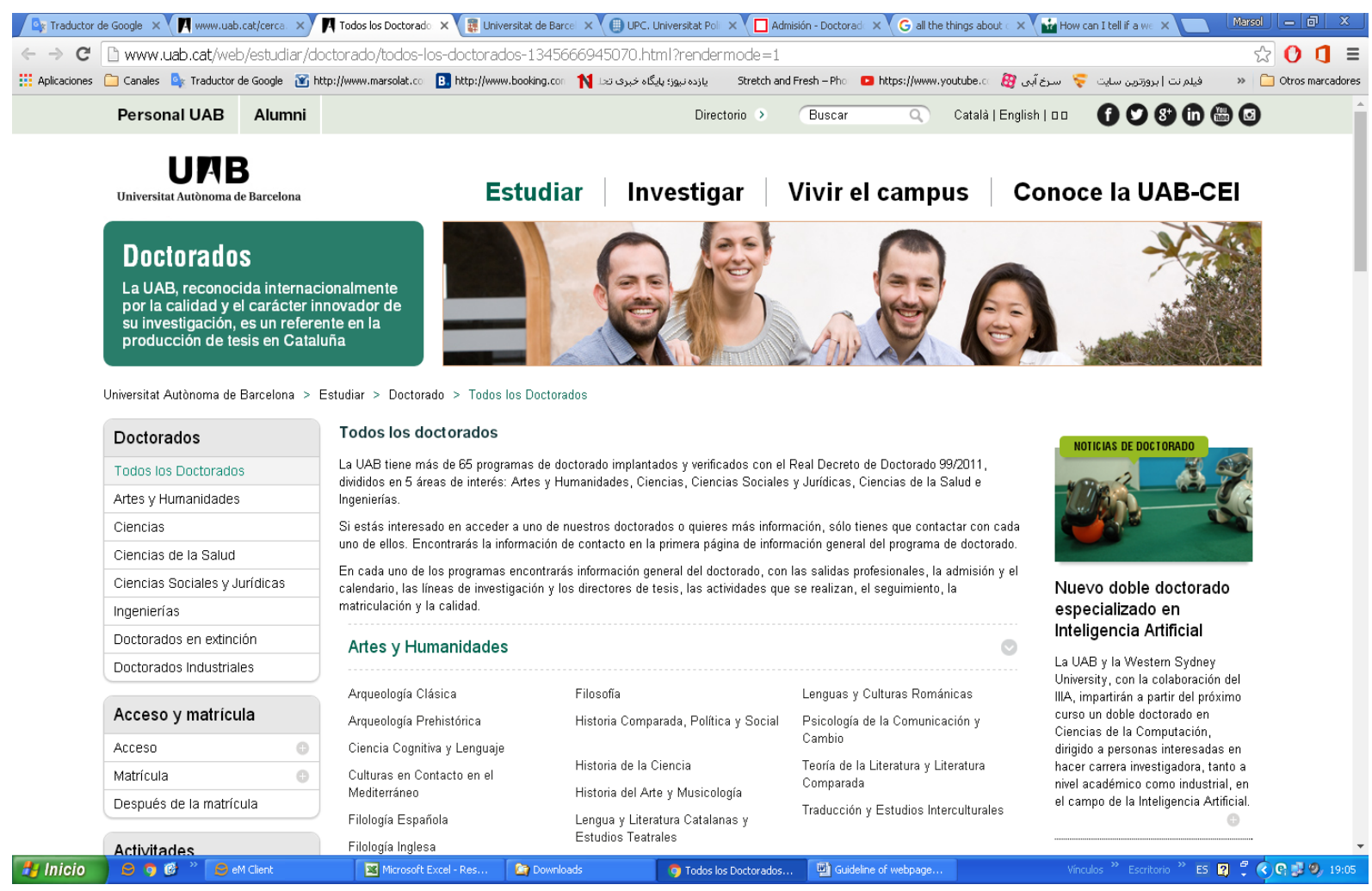

Regarding the marketing and rankings indicators of the UAB webpage it can be considered that presentation of the rankings news and good news were shared in real time and real place which is very clear that the first impression last impression all are regarded perfectly. The UAB webpage can be regarded as very eye-catching and full of useful contents in the first page which won't let you to shift to the other web pages, especially regarding the notification of rankings or the other news regarding the educational programs or seminars etc. Even if you nail the content, design and structure, it doesn't mean a thing if no one sees it. Presentations aren't merely documents or files; they are a dynamic experience shared between a presenter and their audience. A perfect presentation is as good as the delivery both by the presenter and by the presentation technology they use which all these mentioned issues and specification can be seen in the UAB webpage and although presenting in a boardroom, off an iPad, over the Web or as a 
print out, the right delivery can make all the difference between a great presentation, a missed opportunity or a presentation disaster and all aforementioned specifications of a good presented web page can be regarded for UAB webpage.

FIGURE 8. THE UAB WEBPAGE REGARDING THE MARKETING AND RANKINGS INDICATORS

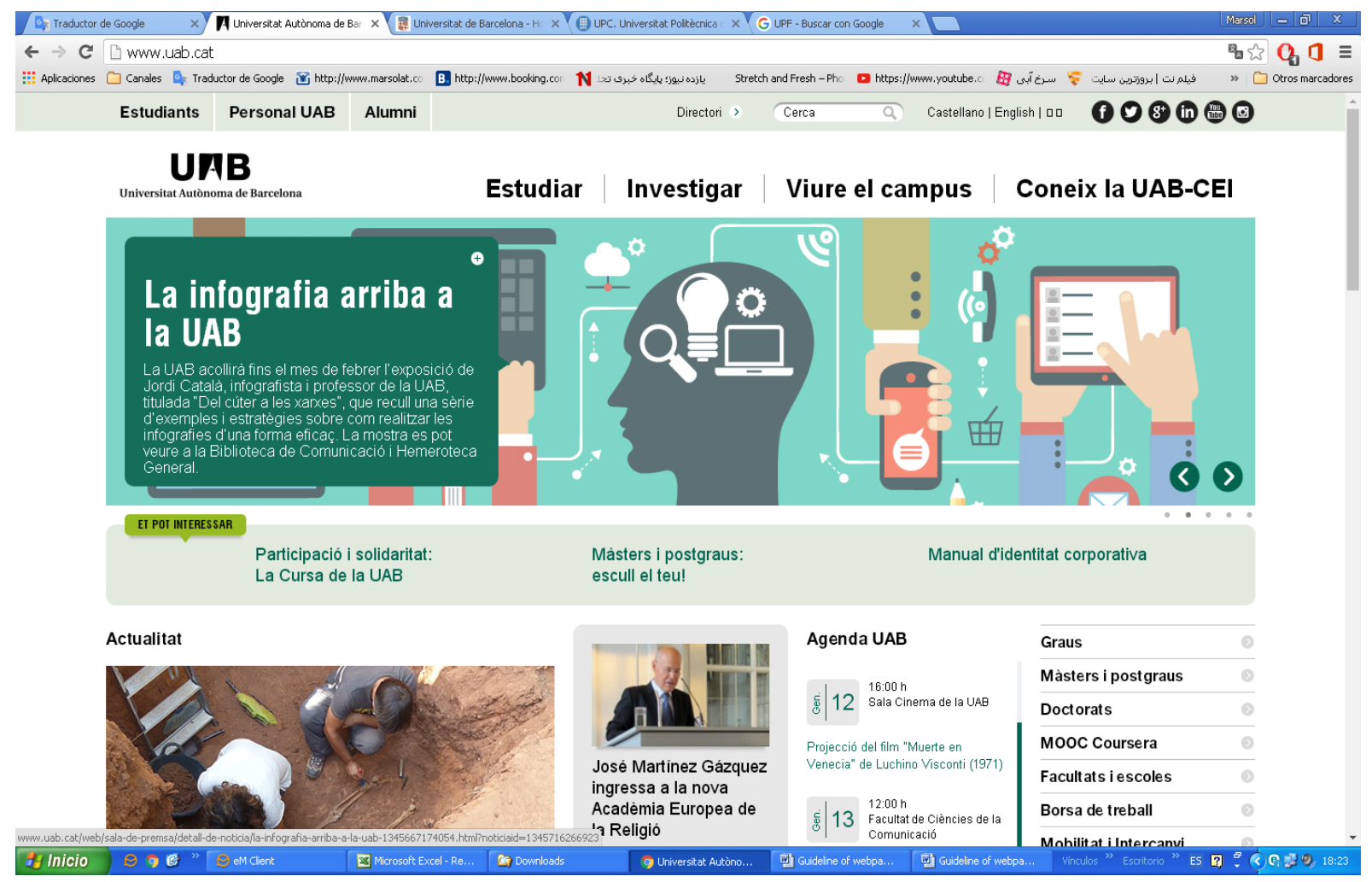

The other issue of the marketing and rankings for the UAB webpage would be the issue of compatibility with smart phone and tablets and easiness to open or any special format for smart phone. By new innovation and decade of high technology, the issue of compatibility with smart phone and tablets, easy to open or any special format for smart phone sounds to be more important than the other times and in the UAB case it is considered as a high level of compatibility. A mobile compatible website is an HTML based website that contains the Flash which in the UAB webpage there is as well. It is very noticeable when you attempt to browse them on any Smartphone or Tablet only the audiences have to scroll left, right, up or down and figure out how the site works, media may load slower, text is tiny so anybody has to zoom in to read it and the 
links are small and difficult to click with the fingertip and technically the UAB could be considered as the compatible one with smarts phone and tablets. A mobile optimized website doesn't require that someone pinch and zoom to read text. On a mobile optimized site, the navigation is built for efficiency, the images and media are optimized for quick loading and the content is succinct for maximum effectiveness as we can see it in the UAB webpage. Additionally, mobile only functionality includes tap-to-call, tap-to-email and map functionality. The UAB webpage presents its contents in 3 principal languages as: English, Spanish and Catalan although in some parts of the webpage the English links or contents not working properly but in majority all the principal links and pages are well organized and presented in 3 languages.

FIGURE 9. THE UAB WEBPAGE REGARDING THE MARKETING AND RANKINGS INDICATORS

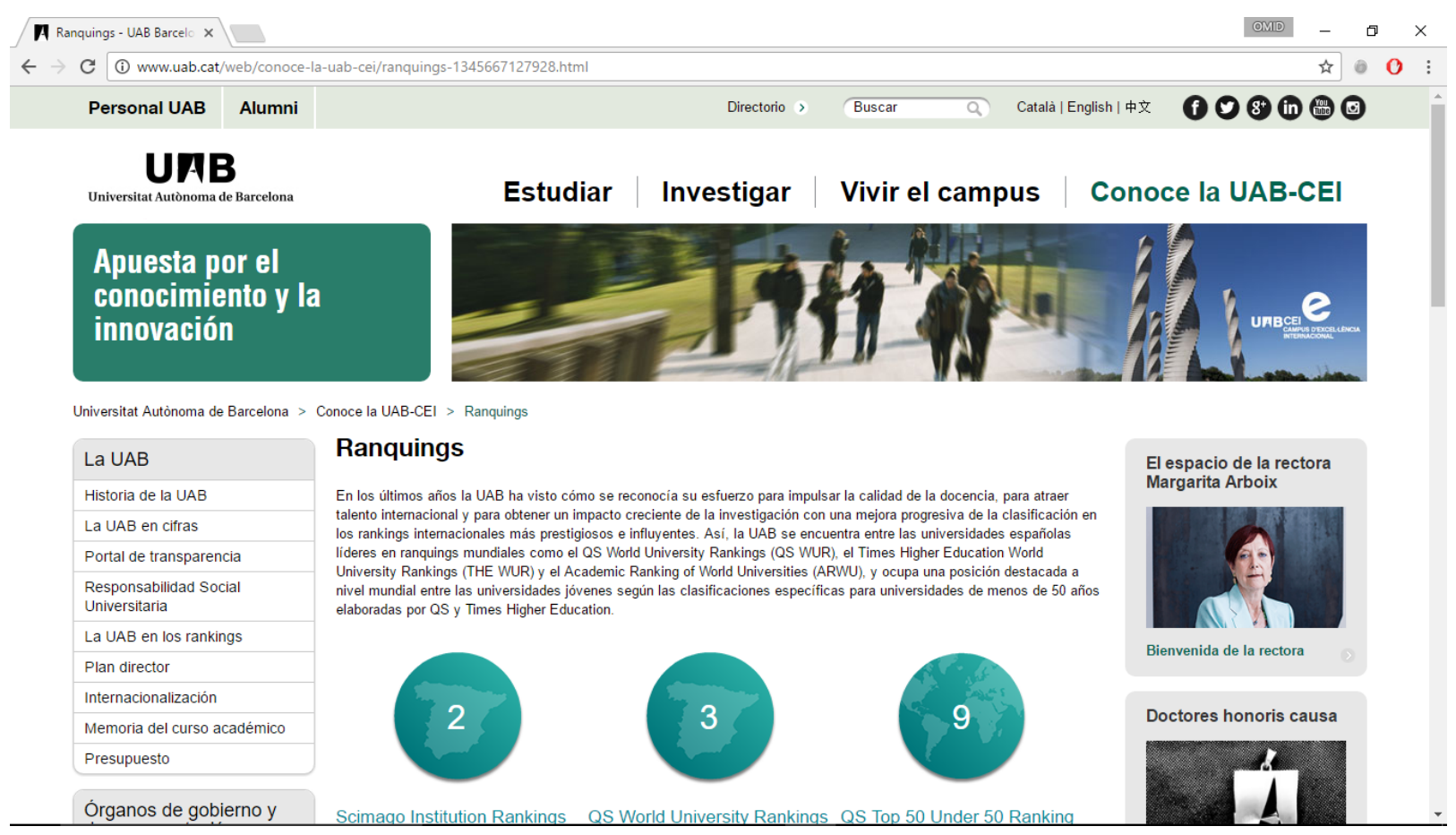

Regarding the target group of the UAB webpage generally is designed for all types of audiences and not only special type of target audiences. All webpages of the universities are built in a general way and for all types of audiences and but some of the websites a bit specialized for researcher and elite students. The UAB webpage is constructed very informative regarding all the 
educational plan or notifications of rankings and universities awards and researches fields. The defining a target audience is a very important and crucial part of any university webpage. But defining a target audience is a best practice for anyone that needs others to give them something which in the case of the UAB it is perfectly done and is very well designed. Whenever you need something from someone you go through at least some of the steps in defining a target audience. The target audience process even at an early age. Think back to when you were a kid. When you wanted a treat, you went through the target audience process. Considering the simplicity, the message of the webpage should be transferred clearly to audiences and specially for the UAB page is very well-structured and simplicity can be noticed for all the parts of the webpage, but in some cases like the departments and links of scholarships the UAB webpage is a bit complicated and this is noticeable.

It can be noticed that all the pages of UAB even with simple designing are transferring their message in a high level of presentation. Differentiation, the features that makes university different from the others is clearly focused and emphasized in the UAB webpage. The differentiation features that makes university different from the others it can be noticed for the UAB webpage and especially with the green color that was used for the frame of the webpage as differentiation. As it mentioned in the marketing section of literature review the be different, now a day really plays a very significant role in the marketing strategy of universities. Usability rather than Beauty, with respect to marketing aspects does the useful content and utile or just well designed to attract. Usability rather than Beauty, respecting to marketing aspects the useful contents are just well designed to attract the researchers and elite students and it is noticeable that the UAB have been regarded the usability rather than beauty and it is noticeable that almost beauty has got over come on the usability. Eye-catching, that won't let the audience move to other pages and can be considered that the UAB webpages is perfectly eye catching and full of news and notifications which are very interesting and attractive. Complementary images, for better transferring the message of university are images related and transferring the message can be seen as well in the UAB webpage. Complementary images for better transferring the message of university in the UAB webpage can be noticed and sufficiently are provided complementary 
images. Captions under images are read on average more than the body copy itself, so should be using them correctly, means missing out them will be losing an opportunity to engage a huge number of potential readers. The natural sequence for reading involves a very specific order. First we look at the image, if there is one. Then we scan the headline. Then we read the body copy (if the headline is interesting enough). An image at the top of the page is a common practice, to catch people's attention and draw them into the article. But if is not done well enough, it would be better to be sure that it's above the headline, which can be seen in the UAB webpage.

FIGURE 10. THE UAB WEBPAGE REGARDING THE MARKETING AND RANKINGS INDICATORS

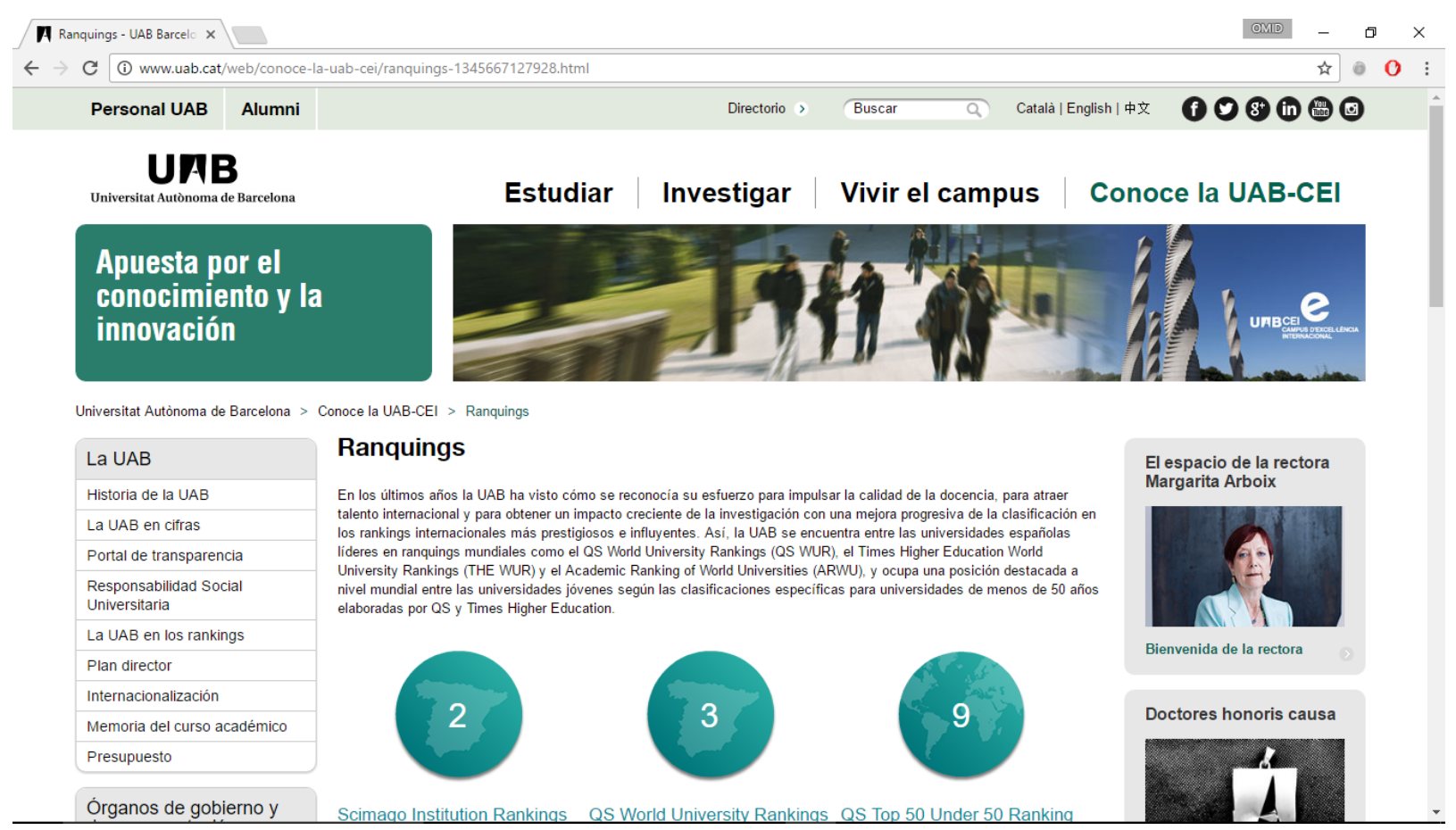

Regarding the connectivity with Social networks, (Facebook, Twitter, Instagram...etc.). it can be considered for the UAB web page and especially can be noticed which is strongly connected. The virtual tours, to give a primary insight and view to audiences about university's campus, library, classes, faculties and environment can be noticed specially for the UAB webpage which is a very important positive point among the other universities. Virtual tours which gives a primary insight and view to audiences about university's campus, library, classes, faculties and environment and these items could be noticed for the UAB in the strong level. Considering the 
first page visibility of the rankings notifications and this fact that it should be located in the first page and highlighted well-enough to present the success of the university, in the case of the UAB the first page visibility of the rankings notifications is regarded. Search engine of the UAB web page can be considered as the one of the best among the other Catalan universities, which is very complete and utile.

\subsubsection{ANALYSIS OF UPC WEBPAGE}

Part of the user interface design is affected by the quality of the page layout. For example, a designer may consider whether the site's page layout should remain consistent on different pages when designing the layout. Page pixel width may also be considered vital for aligning objects in the layout design. The most popular fixed width websites generally have the same set width to match the current most popular browser window, at the current most popular screen resolution, on the current most popular monitor size. Most pages are also center aligned for concerns of aesthetics on larger screens.

The UPC website sounds to be full of linked pages which share a common graphic and creates the illusion of continuity across a cohesive site and the design features that pages share. Regarding the analysis table 12 , the layout all sectors as main navigation, sub navigation, footer and search bar are regarded as a middle level. By regarding this fact that the structure of web pages in text driven information sites has become more uniform and all web pages not sharing the exact layout and features, most web pages incorporate some or all of these basic components. In the case of the UPC webpage page, the headers are like miniature versions of the home page. Web design itself refers to the process of creating a web page's appearance and to the choice of a right color scheme, page layout, fonts and more. Every single web page in a website has different content, but all the pages are using a similar graphic design. 


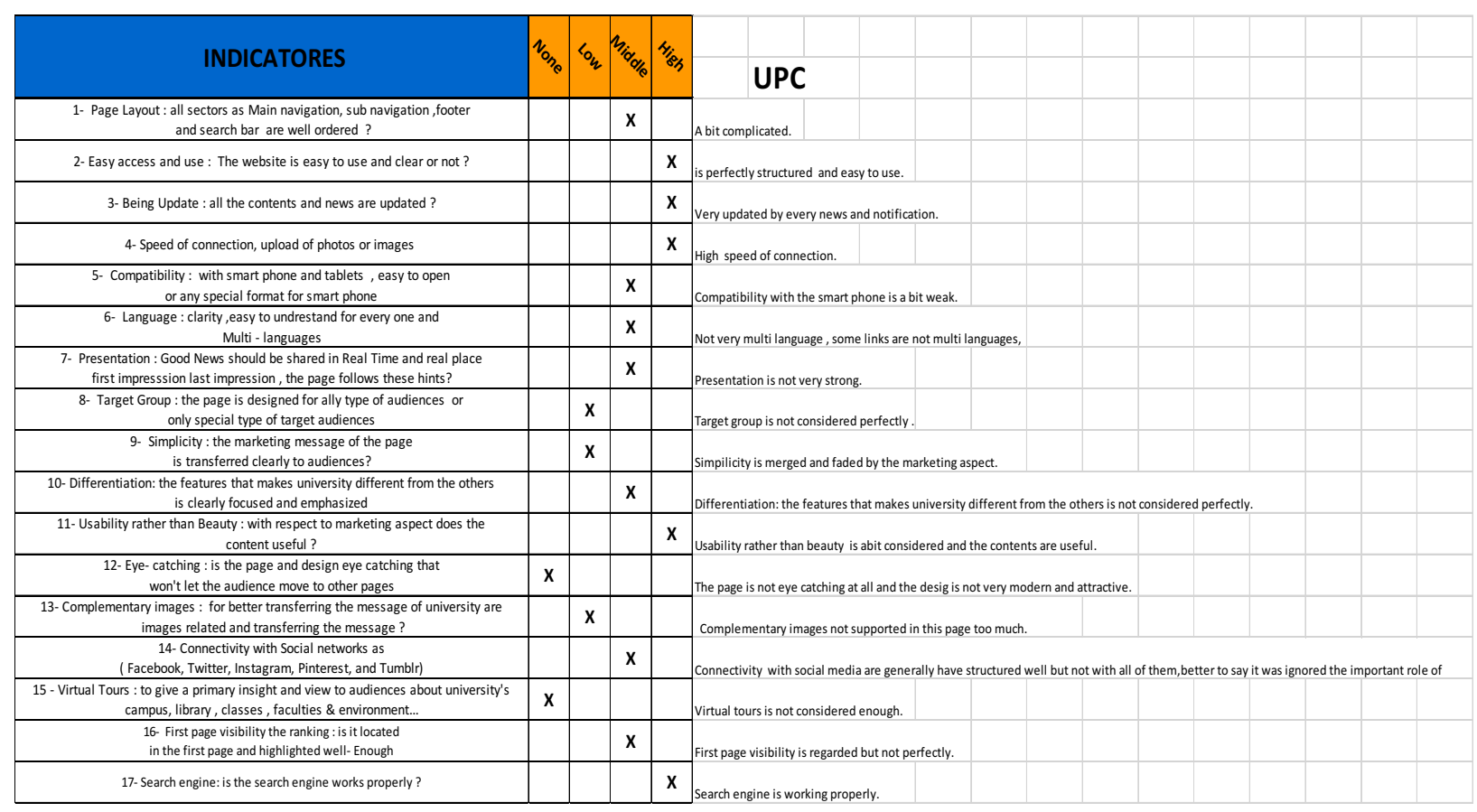

Often sites will use website templates, which contain all the basic elements of web design the website's CSS style, buttons, backgrounds, borders and various graphic elements like hover images, bullets and header banners. When the website template is applied to the website, all the pages assume its appearance, using the same styles, background and other graphical elements. Based on the table 11, the UPC webpage could be regarded as the page which is perfectly easy to access and use and the headers which provide site identity and navigation are the most visible component of this website identity (see figure 12 of the UPC). Respecting the UPC web on 2015, the layout and designing system and technologies can be regarded entirely different designing version. The header, the different links are well organized in the UPC webpage. Site logo in the upper left corner of the page and linking that logo to the home page is a widely-used convention and it was adopted perfectly in the case of the UPC webpage. 


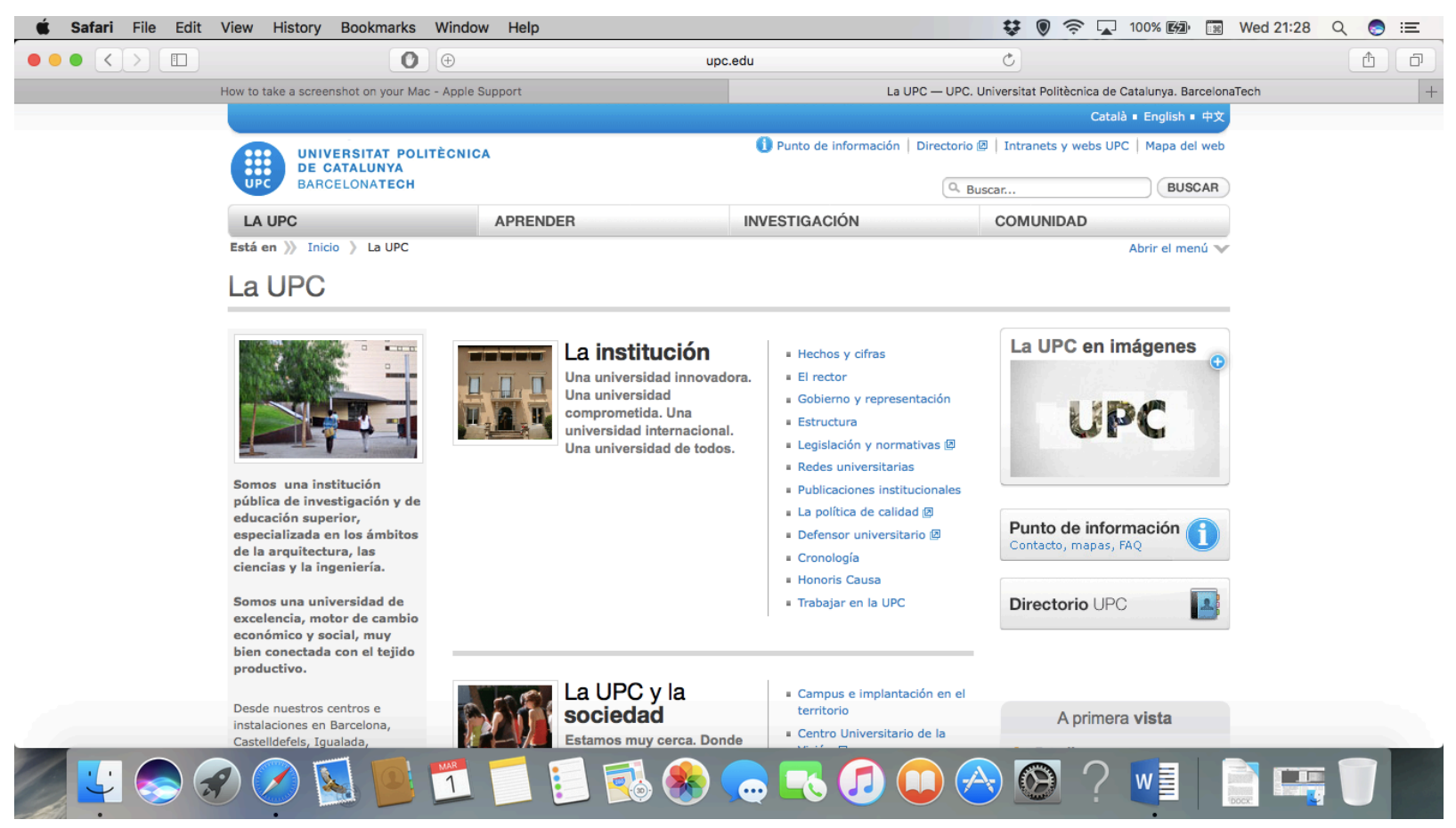

The exact location and arrangement of the components vary from site to site and the overall design pattern of the UPC as you can see in the figure 12 , is fairly consistent. With a website as sleekly designed, interactive, and easy to navigate as the UPC and its admissions site, it's no surprise the admission and information process will be very easy and accessible one for interested students. There are a number of great design elements on this site and the playful fonts which pointed out are seemingly similar to the type used for reminiscent of higher education system, but with a sophisticated flair. Unique typography is an element of great modern web design, as it helps customers immediately identify them versus their competitors which we can recognize this characteristic for UPC webpage. For example, typography of the UPC webpage is recognized by audiences in the very first glance as its unique style and appearance. Usability which is global links 
where users most expect to see them. Semantic logic which is the collection of global links should be marked up as a list sound to be regarded not very perfectly.

Regarding the credibility and validity of content the UPC web it can be considered strongly which is very important that the website is often the first point of contact for the customers, responsible for first impressions and of course sources of revenue. Companies that design for credibility have a strategic advantage over competition. There are 4 types of credibility: presumed credibility, reputed credibility, surface credibility, earned credibility. In the cases of the UPC the credibility and validity of contents regarding the awards and ranking is perfectly organized and revised. The credibility and validity of contents are a very essential and important issue for any university webpage as you can see in the web page. It can be challenging to determine whether a website is credible. The UPC site design this can be regarded in the middle level, but a welldesigned site can be an indication of more reliable information. Good design helps make information more easily accessible. Of course, there may be some reliable websites that do not include all these qualities and regarding the credibility of content the website could be verified by the information that can be found its source on the reliable information data base such as an encyclopedia or a book on the subject. The kind of websites you use for research can also depend on the topic you are investigating. In some cases, it may be appropriate to use information from a company or non-profit organization's website, such as when writing an industry or company overview. If the web page distracts or confuses the visitors, they will either need more time to find what they came for, or they might forget their initial goal all together. Either way, they will not experience the website as user friendly and chances are that they leave dissatisfied and with no intention of coming back. Visitors come to the website with certain goals in mind. It is the university job to help them reach these goals as quickly as possible. If the website considered to do that, the visitors will be pleased and the have laid the groundwork for a positive experience. 


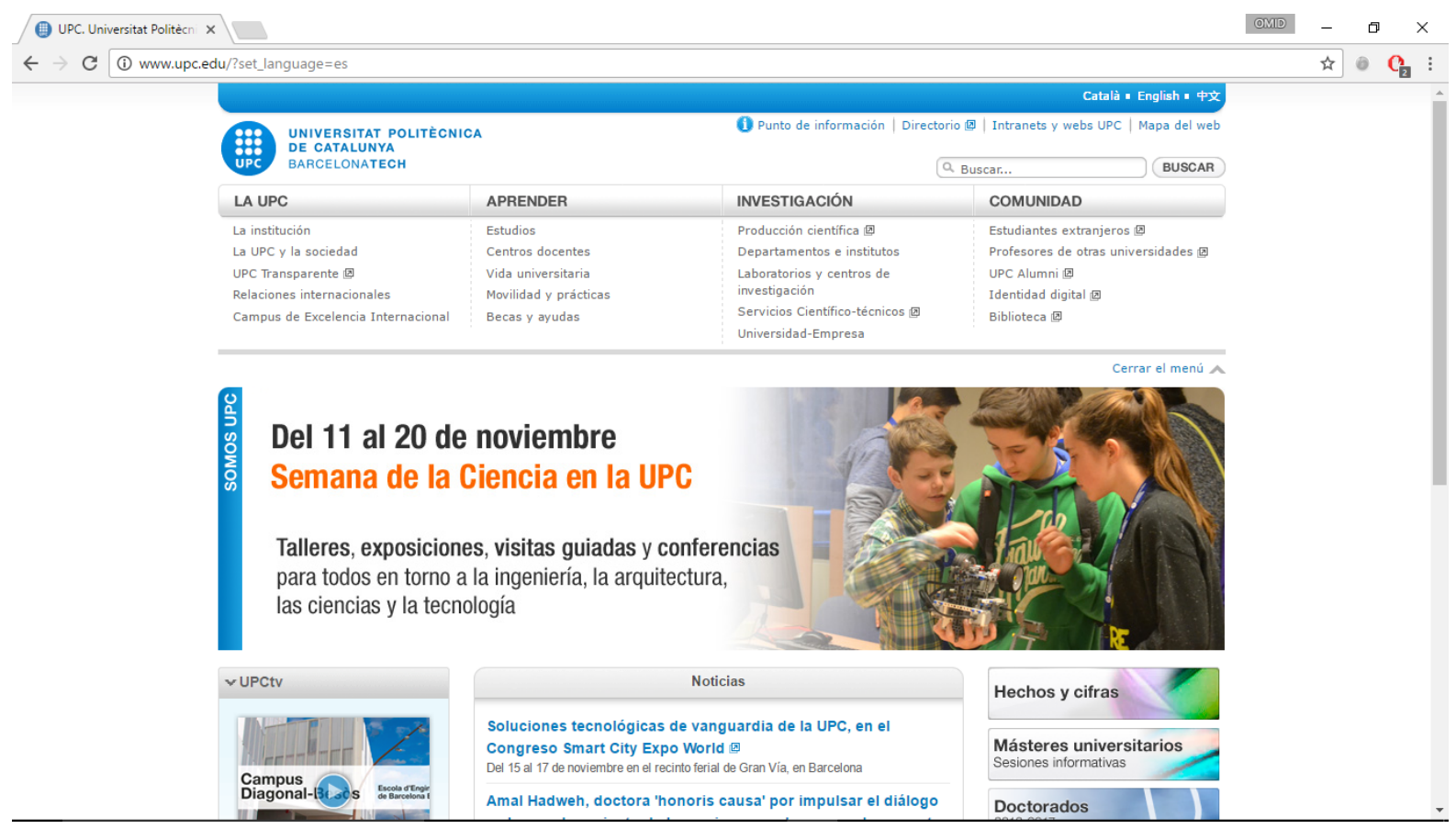

Regarding the marketing and rankings indicators of the UPC webpage it can be considered that presentation which good news should be shared in real time and real place first impression last impression all are regarded perfectly. The UPC webpage can be regarded as very eye-catching and full of useful contents in the first page which won't let you to shift to the other web pages, especially regarding the notification of rankings or the other news regarding the educational programs or seminars etc. Even if you nail the content, design and structure, it doesn't mean a thing if no one sees it. Presentations aren't merely documents or files; they are a dynamic experience shared between a presenter and their audience. A great presentation is only as good as the delivery both by the presenter and by the presentation technology they use which all these mentioned issues and specification can be seen in the UPC webpage and although presenting in a boardroom, off an iPad, over the Web or as a print out, the right delivery can make all the 
difference between a great presentation, a missed opportunity or a presentation disaster and all aforementioned specifications of a good presented web page can be regarded for UPC webpage.

The other issue for the UPC webpage can be regarded would be the issue of compatibility with smart phone and tablets and easiness to open or any special format for smart phone. By new innovation and decade of high technology, the issue of compatibility with smart phone and tablets, easy to open or any special format for smart phone sounds to be more important than the other times and in the UPC case we can consider this item as a high level of compatibility. A mobile compatible website is an HTML based website that doesn't contain Flash which we can see this in the UPC as well. It is very noticeable a few things about these websites when you attempt to browse them on any Smartphone or Tablet only the audiences have to scroll left, right, up or down and figure out how the site "works", media may load slower, text is tiny so anybody has to zoom in to read it and the links are small and difficult to click with the fingertip but generally could be considered the UPC webpage as compatible one with smarts phone and tablets. A mobile optimized website doesn't require that someone pinch and zoom to read text. On a mobile optimized site, the navigation is built for efficiency, the images and media are optimized for quick loading and the content is succinct for maximum effectiveness which we can see it in the UPC webpage as well. Additionally, mobile only functionality includes tap-to-call, tap-to-email and map functionality. The UPC webpage presents its contents in 3 principal languages principals as: English, Spanish and Catalan although in some parts of the webpage the English links or contents not working properly but in majority all the principal links and pages are well organized and presented in 3 languages.

Regarding the target group of the UPC webpage generally is designed for all types of audiences and only special type of target audiences. All webpages of the universities are built in a general way and for all types of audiences and but a bit specialized for researcher and elite students. It is constructed very informative regarding all the educational plan or notifications of rankings and universities awards and researches fields. The defining a target audience is a very important and crucial part of any university webpage. But defining a target audience is a best 
practice for anyone that needs others to give them something which in the case of the UPC it is complicated and is not very well designed. It might be a salary, an investment or money in exchange for a product or service, educational programs, scholarships and funds. Whenever you need something from someone you go through at least some of the steps in defining a target audience. The target audience process even at an early age. Think back to when you were a kid. When you wanted a treat, you went through the target audience process. Considering the simplicity which the message of the page should be transferred clearly to audiences the UPC page was well structured and simplicity can be noticed for all of them but in some cases like the departments and links of scholarships the UPC webpage is a bit complicated and this is noticeable for the UPC, and it can be noticed that all the pages even with simplicity transferring their message in a high level of presentation. Differentiation, the features that makes university different from the others is clearly focused and emphasized in the UPC webpage. The differentiation features that makes university different from the others it can be noticed only for UPC and especially with the blue color that was used for the frame of the webpage as differentiation. As it mentioned in the marketing section of literature review, the differ enation now a day really play a very significant role in the marketing strategy of universities. Usability rather than Beauty, with respect to marketing aspects does the useful content and utile or just well designed to attract. Usability rather than Beauty, respecting to marketing aspects the useful contents are just well designed to attract the researchers and elite students and it is noticeable that the UB have been regarded the usability rather than beauty and it is noticeable that almost beauty has got over come on the usability. Eye-catching webpage won't let the audience move to other pages, as discussed already, it can be considered that UPC webpages is not very eye catching and all the news and notifications which are very interesting and attractive regarding the rankings cannot be seen in the firsts page. Complementary images, for better transferring the message of university are images related and transferring the message. Complementary images for better transferring the message of university are images in the UPC webpage cannot be noticed perfectly and sufficiently. Captions under images are not used or not used very correctly, means missing out on an opportunity to engage a huge number of potential readers. The natural sequence for reading involves a very specific order. 
First we look at the image, if there is one. Then we scan the headline. Then we read the body copy. An image at the top of the page is a common practice, to catch people's attention and draw them into the article.

Regarding the connectivity with Social networks, (Facebook, Twitter, Instagram...etc.). Connectivity with Social networks: (Facebook, Twitter, Instagram, linked in ...), it can be considered for the UPC web pages is not strongly connected, but got a special web page or link for social medias. The virtual tours, to give a primary insight and view to audiences about university's campus, library, classes, faculties and environment cannot be noticed specially for the UPC webpage which is a negative point among the other universities. Virtual tours which gives a primary insight and view to audiences about university's campus, library, classes, faculties and environment only cannot be noticed for the UPC in the strong level and it cannot give some image to distanced university. Considering the first page visibility the ranking, which should be located in the first page and highlighted well-enough in the case of the UPC the first page visibility of the ranking is located in the first page highlighted well-enough. Search engine of the UPC web page can be considered as one of the good one.

\subsubsection{ANALYSIS OF UPF WEBPAGE}

One of the most notable trends in universities websites is the division between content sections. Composition is a huge subject flowing through the whole design into every page. Universities websites rely on visually significant elements to break apart pieces of the layout. Headers, carousels, calendar events and blog posts all tend to be organized into their own little blocks. A well-defined composition improves readability which allows visitors to skim content at a brisk pace. The website of the UPF looks a complete collection that share a common graphic which gives you the feeling and creates the illusion of continuity across a cohesive site and the design features that pages share. Regarding the analysis table 13, the layout all sectors as main navigation, sub navigation, footer and search bar are regarded as a middle. 
Results

TABLE 13. ANALYSIS GUIDELINE OF UPF WEBPAGE

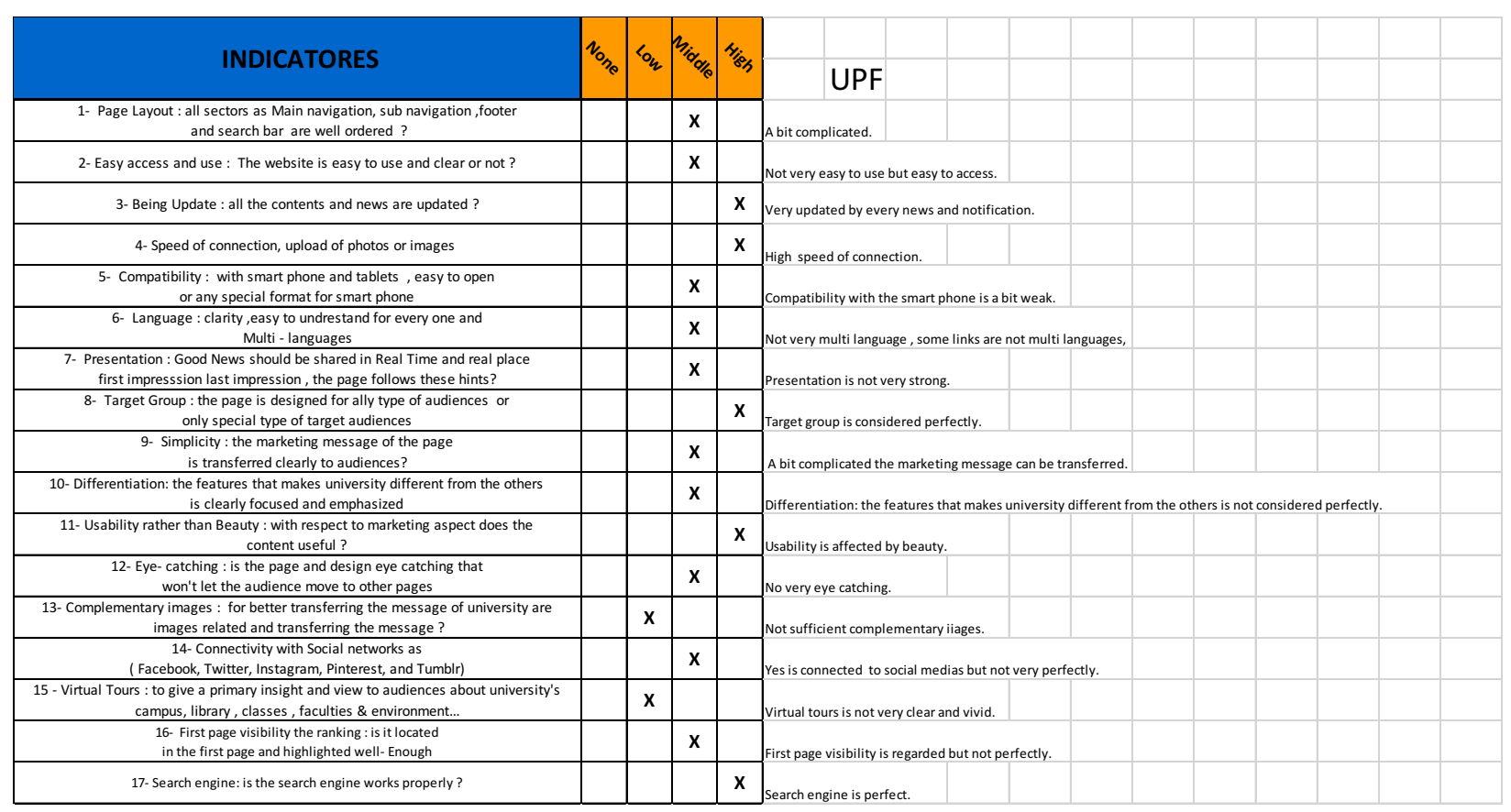

The structure of web pages in text has become more uniform and all web pages not sharing the exact layout and features, most web pages incorporate some or all of these basic components and in the case of UPF webpage page headers are considered professionally. Based on the table 12, the UPF webpage could be regarded as the page which is perfectly easy to access and use and the headers which provide site identity and navigation are the most visible component of this website identity (figure 14 of the UPF). Respecting the current UPF web layout and designing system and technologies entirely very different designing version could be regarded for the UPF webpage. The header, the different links are well organized in the UPF webpage. Site logo in the upper left corner of the page and linking that logo to the home page is a widely-used convention and it was adopted perfectly in the case of the UPF webpage. 


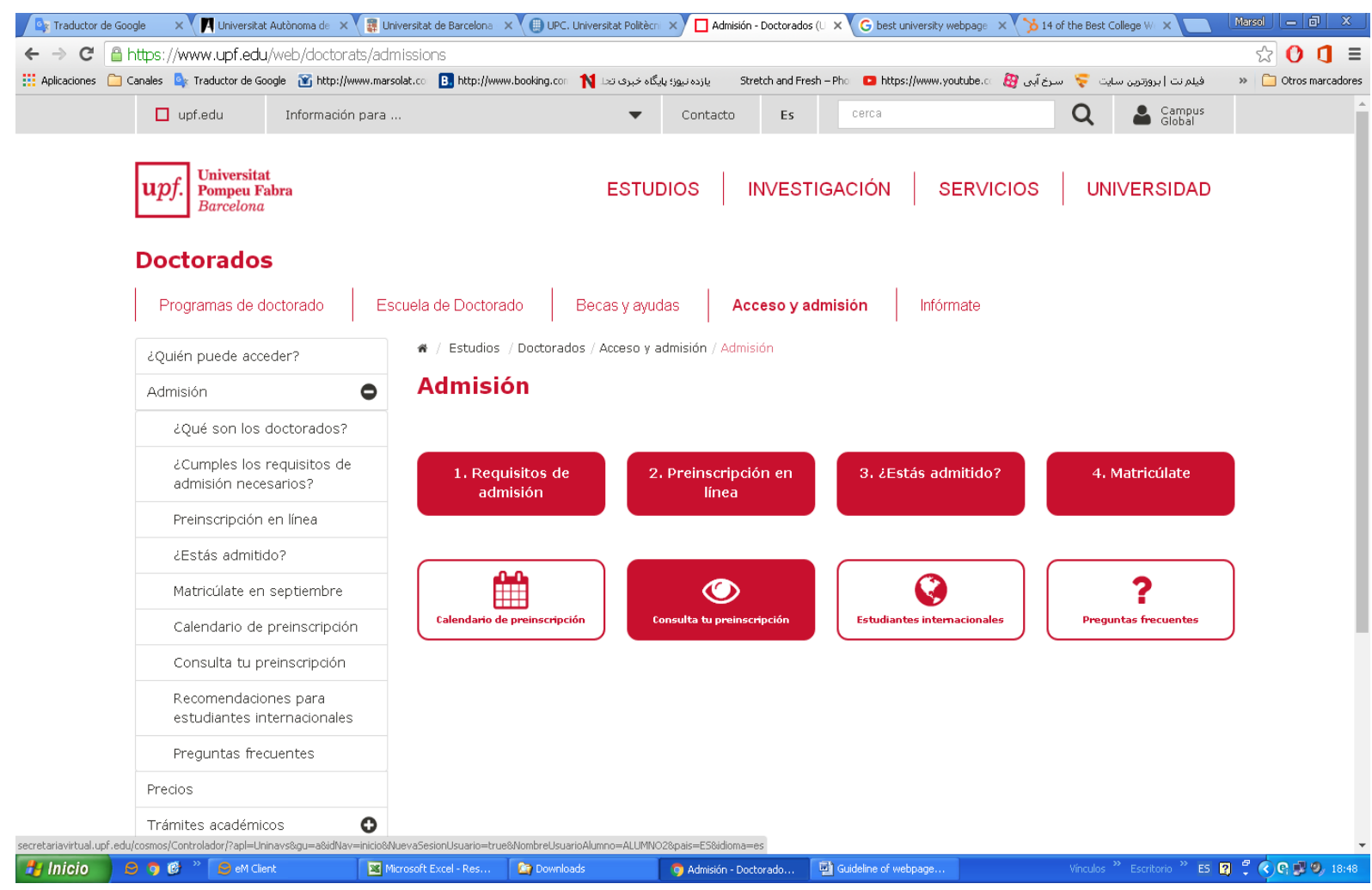

The exact location and arrangement of the components vary from site to site, but the overall design pattern Of the UPF as you can see in the figure 14, is fairly consistent. There are a number of perfect design elements on this site and the playful fonts which pointed out are seemingly similar to the type used for higher education system, but with a sophisticated flair. Unique typography is an element of great modern web design, as it helps customers immediately identify them versus their competitors. For example, UPF typography is recognized by audiences in the very first glance as its unique style and appearance. Usability which is global links where users most expect to see them are regarded in the case of UPF. Semantic logic which is the collection of global links should be marked up as a list sound to be regarded not very perfectly. Regarding the credibility and validity of content the UPF web it can be considered 
strongly which is very important that the website is often the first point of contact for the customers, responsible for first impressions and of course sources of revenue.

Companies that design for credibility have a strategic advantage over competition and types of credibly as presumed credibility, reputed credibility, surface credibility, earned credibility can be seen in the case of UPF. In the cases of the UPF the credibility and validity of contents regarding the awards and ranking is perfectly organized and revised. The credibility and validity of contents are a very essential and important issue for any university webpage as you can see in the web page. It can be challenging to determine whether a website is credible. The design of the UPF website can be regarded in the middle level, but a well-designed site can be an indication of more reliable information. Good design helps make information more easily accessible. Of course, there may be some reliable websites that do not include all these qualities and regarding the credibility of content the website could be verified by the information that can be found its source on the reliable information data base such as an encyclopedia or a book on the subject. In some cases, it may be appropriate to use information from a public or non-profit educational organization's website, such as when writing an industry or company overview. If the web page distracts or confuses the visitors, they will either need more time to find what they came for, or they might forget their initial goal all together. Either way, they will not experience the website as user friendly and chances are that they leave dissatisfied and with no intention of coming back. Visitors come to the website with certain goals in mind. It is the university job to help them reach these goals as quickly as possible. If the website considered to do that, the visitors will be pleased and the have laid the groundwork for a positive experience. Regarding the marketing and rankings indicators of the UPF webpage it can be considered that presentation which good news should be shared in real time and real place first impression last impression all are regarded perfectly. The UPF webpage can be regarded as an eye-catching webpage and full of useful contents in the first page which it can be considered that won't let you to shift to the other web pages. Even if you nail the content, design and structure, it doesn't mean a thing if no one sees it. Presentations aren't merely documents or files; they are a dynamic experience shared between a presenter and their audience. 


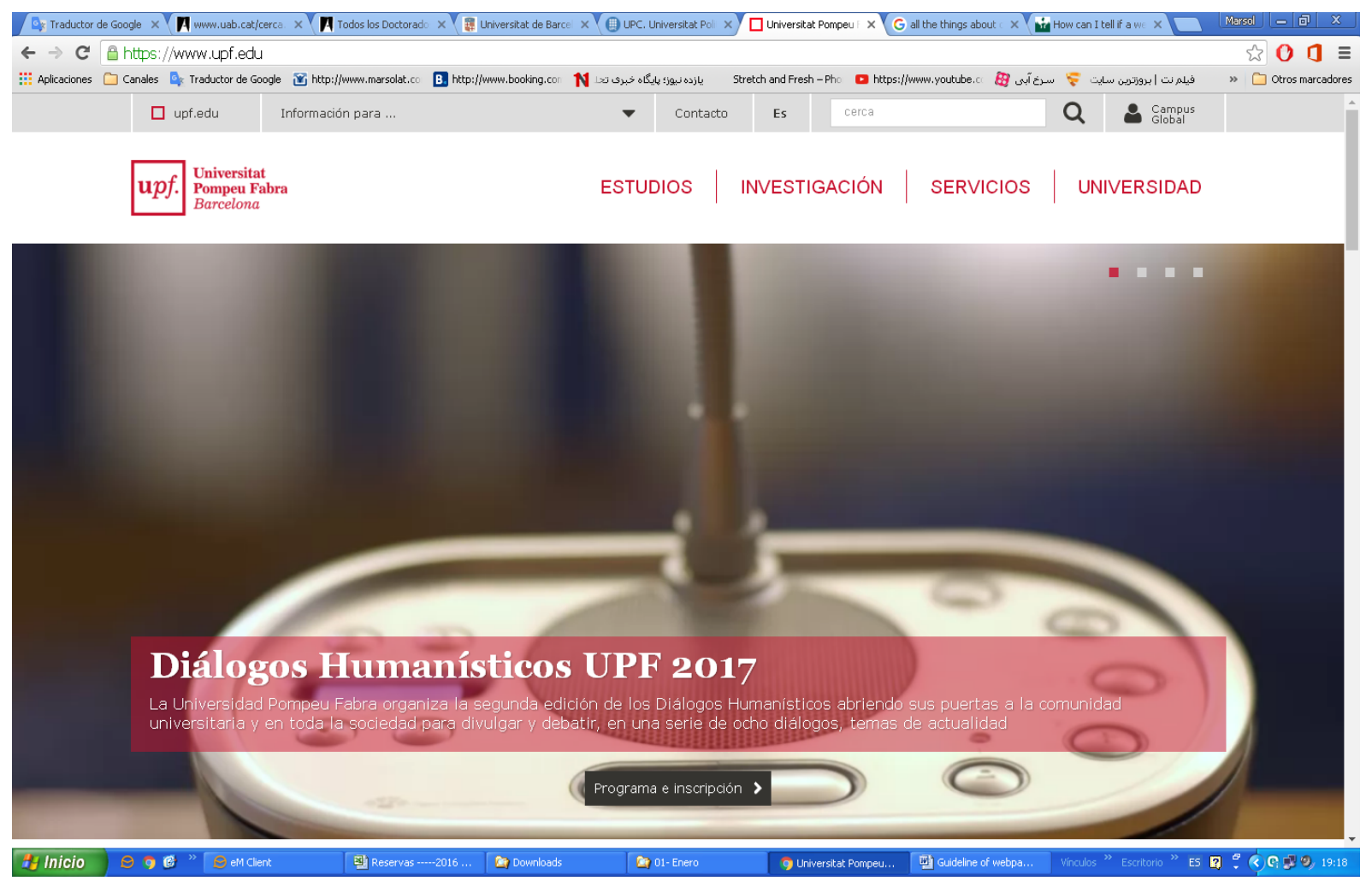

A great presentation is only as good as the delivery both by the presenter and by the presentation technology they use which all these mentioned issues and specification can be seen in the UPF webpage and although presenting over the Web or as a print out, the right delivery can make all the difference between a great presentation, a missed opportunity or a presentation disaster and all aforementioned specifications of a good presented web page can be regarded for the UPF webpage. The other issue for the UPF webpage can be regarded the issue of compatibility with smart phone and tablets and easiness to open or any special format for smart phone. By new innovation and decade of high technology, the issue of compatibility with smart phone and tablets, easy to open or any special format for smart phone sounds to be more important than the other times and in the UPF case we can consider this item as a high level of compatibility. A mobile 
compatible website is an HTML based website that doesn't contain Flash which we can see this in the UPF as well. It is very noticeable a few things about these websites when you attempt to browse them on any Smartphone or Tablet only the audiences have to scroll left, right, up or down and figure out how the site works, media may load slower, text is tiny so anybody has to zoom in to read it and the links are small and difficult to click with the fingertip but generally could be considered the UPF webpage as compatible one with smarts phone and tablets. A mobile optimized website doesn't require that someone pinch and zoom to read text. On a mobile optimized site, the navigation is built for efficiency, the images and media are optimized for quick loading and the content is succinct for maximum effectiveness which we can see it in the UPF webpage as well. Additionally, mobile only functionality includes tap-to-call, tap-to-email and map functionality. The UPF webpage presents its contents in 3 principal languages as: English, Spanish and Catalan although in some parts of the webpage the English links or contents not working properly but in majority all the principal links and pages are well organized and presented in 3 languages.

FIGURE 15. THE UPF WEBPAGE REGARDING THE RANKINGS AND MARKETING INDICATORS, 2015

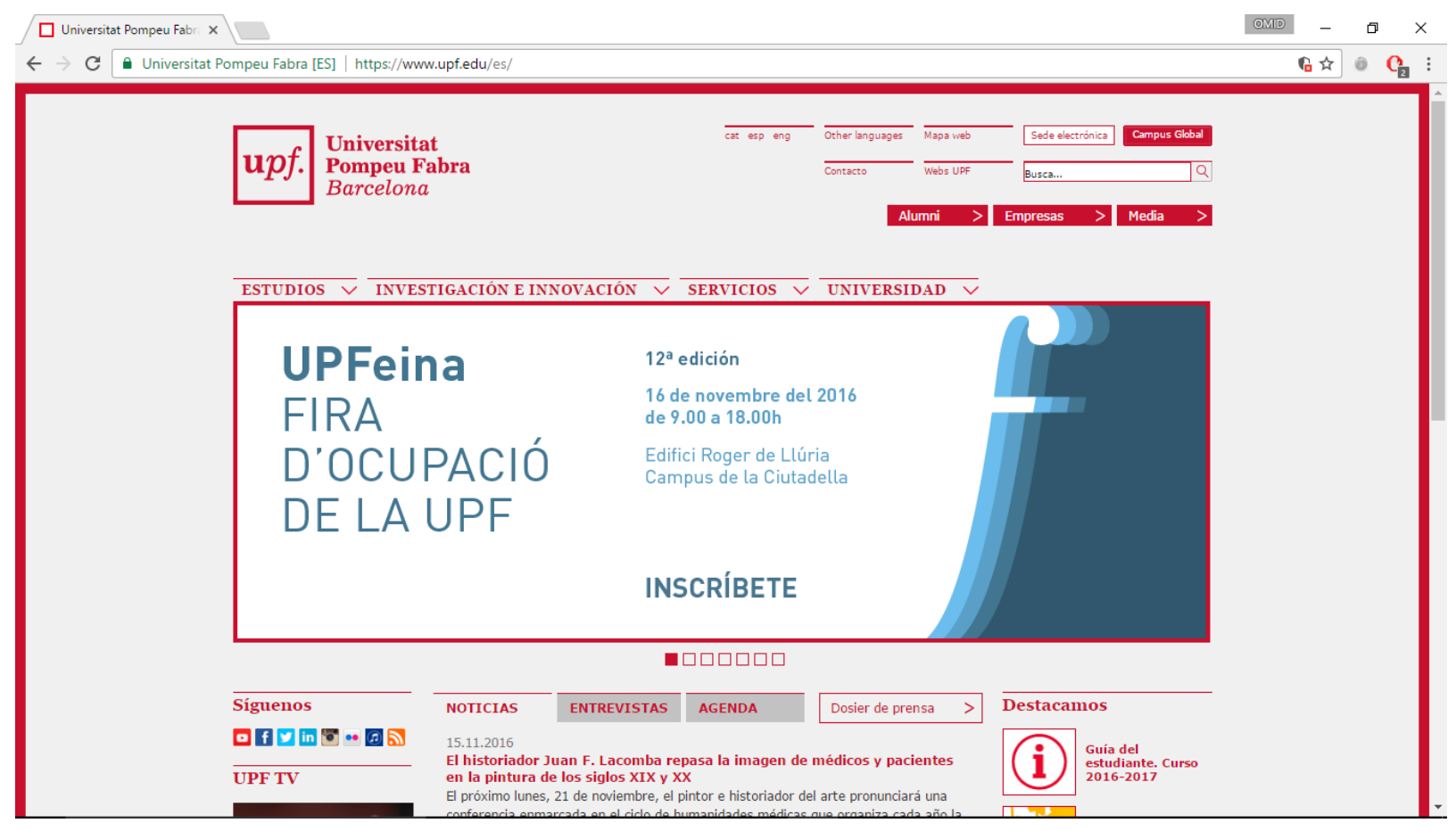


Regarding the target group of the UPF webpage generally is designed for all types of audiences and only special type of target audiences. All webpages of the universities are built in a general way and for all types of audiences and but a bit specialized for researcher and elite students. It is constructed very informative regarding all the educational plan or notifications of rankings and universities awards and researches fields. The defining a target audience is a very important and crucial part of any university webpage. But defining a target audience is a best practice for anyone that needs others to give them something which in the case of the UPF it is complicated and is not perfectly designed. Whenever you need something from someone you go through at least some of the steps in defining a target audience. The target audience process even at an early age. Think back to when you were a kid. When you wanted a treat, you went through the target audience process.

FIGURE 16. THE UPF WEBPAGE REGARDING THE RANKINGS AND MARKETING INDICATORS

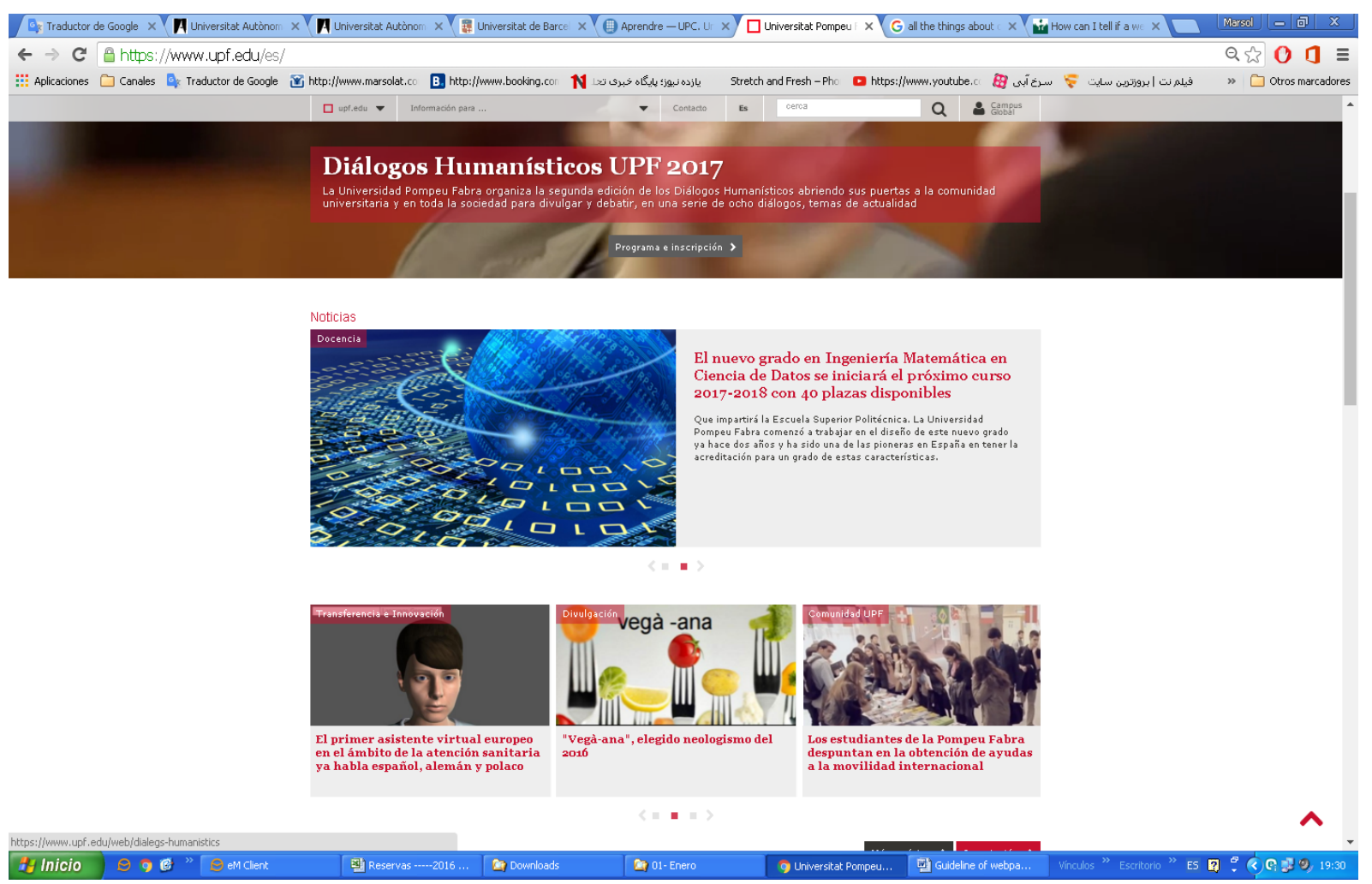

Considering the simplicity which the message of the page should be transferred clearly to audiences, the UPF page was well structured and simplicity can be noticed for all of them but in 
some cases like the departments and links of scholarships the UPF webpage is a bit complicated and this is noticeable for the UPF and it can be noticed that all the pages even with simplicity transferring their message in a high level of presentation. Differentiation, the features that makes university different from the others is clearly focused and emphasized in the UPF webpage. The differentiation features that makes university different from the others it can be noticed only for UPF and especially with the blue color that was used for the frame of the webpage as differentiation. As it mentioned in the marketing section of literature review, the differ enation now a day really play a very significant role in the marketing strategy of universities. Usability rather than Beauty, with respect to marketing aspects does the useful content and utile or just well designed to attract. Usability rather than Beauty, respecting to marketing aspects the useful contents are just well designed to attract the researchers and elite students and it is noticeable that the UPF have been regarded the usability rather than beauty and it is noticeable that almost beauty has got over come on the usability.

Eye-catching, is the page and design eye catching that won't let the audience move to other pages. It can be considered that only UPF webpages is one of the most eye catching and full of news and notifications, which are very interesting and attractive. Complementary images, for better transferring the message of university are images related and transferring the message. Complementary images for better transferring the message of university are images in the UPF webpage can be noticed that sufficiently were provided complementary images. Captions under images are read on average more than the body copy itself, so not using them, or not using them correctly, means missing out on an opportunity to engage a huge number of potential readers. The natural sequence for reading involves a very specific order. First we look at the image, if there is one. Then we scan the headline. Then we read the body copy (if the headline is interesting enough). An image at the top of the page is a common practice, to catch people's attention and draw them into the article. But if you're doing this, you'd better be sure it's above your headline, and all above mentioned items can be seen in the UPF webpage. 
Regarding the connectivity with Social networks, (Facebook, Twitter, Instagram...etc.). Connectivity with Social networks: (Facebook, Twitter, Instagram, linked in ...), it can be considered for the UPF web pages and especially can be noticed which is strongly connected and has got a special web page or link for that (figure 18). The virtual tours, to give a primary insight and view to audiences about university's campus, library, classes, faculties and environment cannot be noticed specially for the UPF webpage which is a negative point among the other universities. Virtual tours which gives a primary insight and view to audiences about university's campus, library, classes, faculties and environment only cannot be noticed for the UPC in the strong level and it cannot give some image to distanced university.

FIGURE 17. THE UPF WEBPAGE REGARDING THE CONNECTIVITY WITH SOCIAL MEDIAS

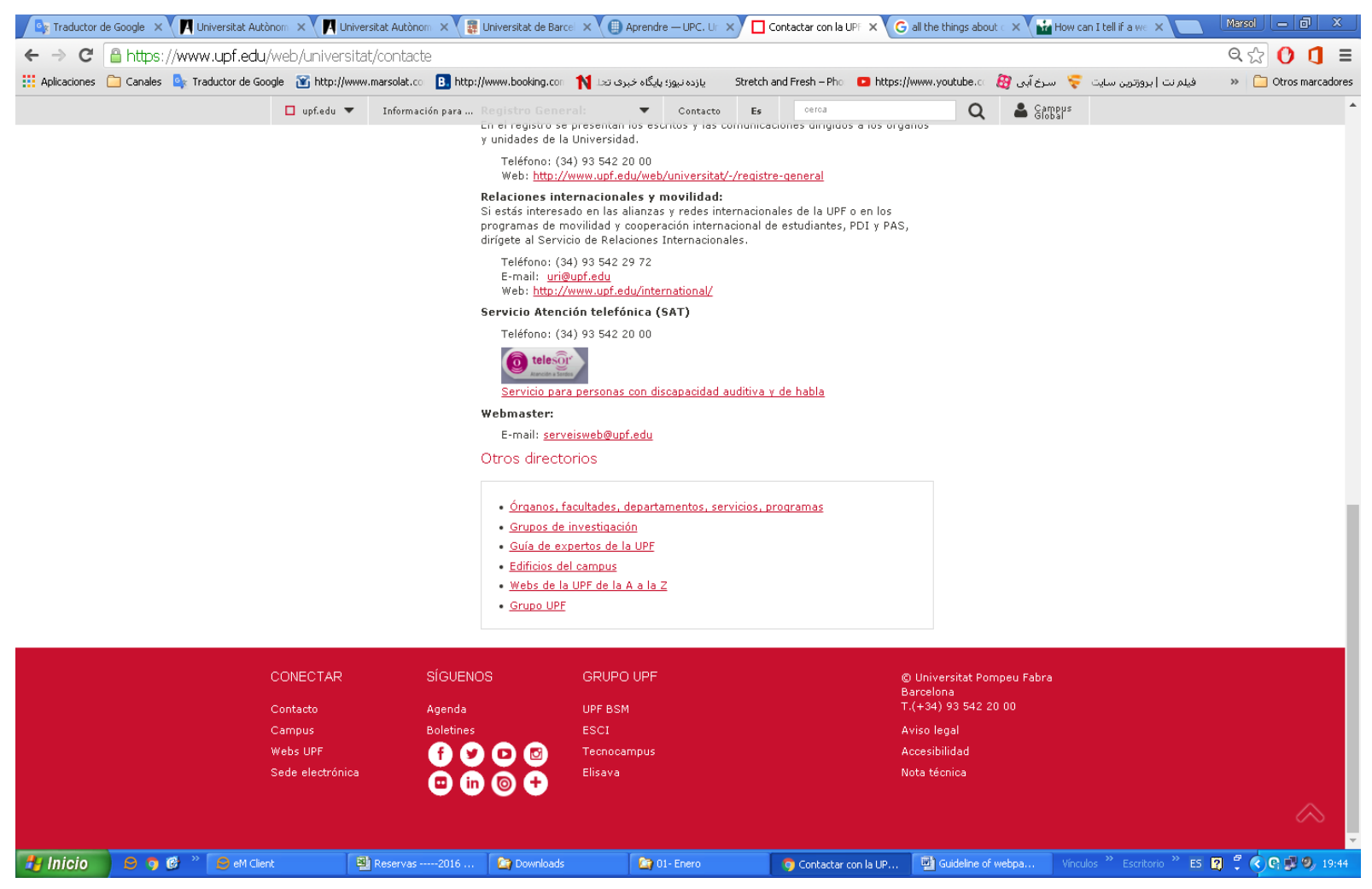

Considering the first page visibility the ranking, which should be located in the first page and highlighted well- enough in the case of the UPF the first page visibility of the ranking is located 
in the first page highlighted well- enough and the rest not presenting well-enough their rankings notifications in the first page. Search engine of the UPF web page can be considered as the one of the best among the other, which is very complete and utile.

\subsubsection{SUMMARY OF WEB PAGE GUIDELINE}

Regarding the results of table 14, the Page layout is considered as high level only for UAB and the rest as UB, UPC and UPF are regarded as middle level. Regarding the Easy access, UB and UPC are considered as the highest level but UAB and UB are regarded as middle level. Considering the indicator of Being update, the UAB is regarded as middle and the UB, UPC and UPF are the highest level. For the Speed of connection, all three universities UAB, UPC and UPF are considered as the highest level and only UB is considered as low level. Regarding the Compatibility, with the webpages $U A B$ has got the highest level and the others are in the middle level. Regarding the Language, only UAB and UB have the highest level and the rest are in the middle level. Based on the table, only UB has the highest level of Presentation, and the rest are ranked as the middle level. Considering the Target group, only UPF could be ranked as the highest level and the UAB and UB are ranked as the middle level and UPC as the lower level. Regarding the Simplicity, only UB is ranked as the highest level. Regarding the Differentiation of the webpage, only UAB and UB are considered as highest level and the rest as middle level. Based on the results, UPC and UPF are considered as highest level for the item Usability rather than beauty. Regarding the item of Eye catching only UB is regarded as highest level. Regarding the Complementary images, none of the universities are regarded as high level, only the UAB and UB are considered as middle level. Considering the Connectivity with the social network, only UAB and UB are considered as high level. Regarding the Virtual tour, only UB is ranked as high level and UB as low level. Considering the First page visibility, only UAB is ranked as high level. Considering the item of Search engine, the UP and UPC are ranked as high level and the rest UB and UAB as low level. 
Table 14.RESUME OF THE GUIDELINE OF UNIVERSITIES WEBPAGES

\begin{tabular}{|c|c|c|c|c|}
\hline INDICATORES & $v_{o_{p}}$ & Sou & $\eta_{\phi / / \beta}$ & 铭 \\
\hline 1- Page Layout & & & UB/ UPC/ UPF & UAB \\
\hline 2- Easy access and use & & & UAB/ UPF & UB/ UPC \\
\hline 3- Being Update & & & UAB & UB/ UPC / UPF \\
\hline 4- Speed of connection & & UB & & UAB /UPC/ UPF \\
\hline 5- Compatibility & & & UB / UPC / UPF & UAB \\
\hline 6- Language & & & UPC/ UPF & UB/ UAB \\
\hline 7- Presentation & & & UAB/ UPC / UPF & UB \\
\hline 8- Target Group & & UPC & UB/ UAB & UPF \\
\hline 9- Simplicity & & UPC & UAB/ UPF & UB \\
\hline 10- Differentiation & & & UPC /UPF & UB/ UAB \\
\hline $\begin{array}{c}\text { 11- Usability rather than } \\
\text { Beauty }\end{array}$ & & & UB/ UAB & UPC / UPF \\
\hline 12- Eye- catching & UPC & & UAB / UPF & UB \\
\hline 13- Complementary images & & UPC / UPF & UB /UAB & \\
\hline $\begin{array}{c}\text { 14- Connectivity with Social } \\
\text { networks as } \\
\text { ( Facebook, Twitter, }\end{array}$ & & & UPC /UPF & UB /UAB \\
\hline 15 - Virtual Tours & UPC & UPF & UAB & UB \\
\hline $\begin{array}{l}\text { 16- First page visibility the } \\
\text { ranking }\end{array}$ & & & UB/ UPC /UPF & UAB \\
\hline 17- Search engine & & UB-UAB & & UPC / UPF \\
\hline
\end{tabular}




\subsection{RESULTS OF INTERVIEWS}

Interviews are a systematic way of talking and listening to people and are another way to collect data from individuals through conversations. The researcher or the interviewer often uses open questions. Data is collected from the interviewee. The researcher needs to remember the interviewer's views about the topic is not of importance. The interviewee or respondent is the primary data for the study. Interviewing is a way to collect data as well as to gain knowledge from individuals. Interviews are ways for participants to get involved and talk about their views. In addition, the interviewees are able to discuss their perception and interpretation in regards to a given situation. By open-interview it was expected to discover and understand more issue and founding from the communication and promotion department of four Catalan universities who are the main responsible regarding the rankings contents and their official web pages to achieve the main objectives of this investigation. Interview were applied in this research to learn the opinions and experiences of the experts of communication and marketing department who are involving in the process of designing, constructing and updating the contents of the official websites of aforementioned Catalan universities. It was the great opportunity to have interviews with related staffs and responsible of those mentioned Catalan universities to recognize how basically and technically the marketing strategy of has being used in their webpage and to see how these universities designed their web page for having better presentation for their audiences. The interview was based on two dimensions as:

- Rankings

- Marketing aspects

In order to collect data, the researcher should be able to access the data that needs to be collected for the study. Data can be gathered from a number of sources including written documents, records, workplaces, the Internet, surveys or interviews. These three interviews helped this study to collect information about publishing and analyzing process of the rankings 
notifications in the official webpage of the aforementioned universities. By the help of these interviews tried to recognize, is there any direct influence of the rankings success on the design and construction of the official web page of universities or how rankings notifications affected the website design and frame of the aforementioned Catalan universities.

TABLE 15. DETAILS REGARDING THE INTERVIEWEES

\begin{tabular}{|c|c|c|c|c|c|c|c|}
\hline Interviews & University & Age of & Gender & $\begin{array}{c}\text { Years of } \\
\text { experiences } \\
\text { Interviewee }\end{array}$ & $\begin{array}{c}\text { Years of } \\
\text { dedication in } \\
\text { this position }\end{array}$ & $\begin{array}{c}\text { Duration of } \\
\text { interview }\end{array}$ \\
\hline E1 & U1 & 53 & female & 23 & 18 & $07 / 10 / 2016$ & $49 \mathrm{~min}$ \\
\hline E2 & U2 & 51 & male & 32 & 25 & $14 / 10 / 2016$ & $42 \mathrm{~min}$ \\
\hline E3 & U3 & 32 & female & 11 & 8 & $21 / 10 / 2016$ & $39 \mathrm{~min}$ \\
\hline
\end{tabular}

\subsubsection{RANKINGS ASPECTS OF THE INTERVIEWS}

The strengths of semi-structured interviews are that the researcher can prompt and probe deeper into the given situation. For example, the interviewer inquiries about using computers in English language teaching. Some respondents are more computer literate than others are. Hence, with this type of interview the interviewers are able to probe or asked more detailed questions of respondents' situations and not adhere only to the interview guide. In addition, the researcher can explain or rephrase the questions if respondents are unclear about the questions. The drawbacks are inexperienced interviewers may not be able to ask prompt questions. If this is the case, some relevant data may not be gathered. In addition, inexperienced interviewers may not probe into a situation. For example, if the respondents do not know how to use computers and do not want to use them in language teaching, the interviewer needs to probe and find out the reasons and ask for explanations. About the design of the university webpage, after interviewing 
the three experts of Catalan Universities as: UPF, UB and UAB, it was noticed that the design of the university webpage strongly was shaped and constructed by rankings notifications for these 3 Catalan universities. In the other words, it can be expressed that university design works as the manifestation of a university for attract the elite researcher and students.

It is very tangible that applying the modern graphic technologies for designing the university web page totally are replaced the old techniques of creating a web page: "The new university web page with the assistance of university gadgets and modern graphic technology looks like to be more professional with more attractiveness and useful information than the old one. All contents and features of the university webpage are optimized in a perfect way and even in the first glance you can realize it (E1)." The chief purpose of the University's website is to advance the university's mission, brand and message to core constituents (i.e. prospective students, their families, donors, trustees, alumni, organizations, the media and casual visitors). This will be done in a manner that is: 1) dynamic and user-friendly and can readily adapt to meet the diverse and changing needs of its constituents. 2) Provides targeted and user-friendly interaction (e.g. prospective student inquiries, requests for information, online applications, online giving, etc.) with key constituents. A secondary purpose is to provide information to the campus community (i.e. faculty, staff, administration, students, trustees, alumni, parents). This will be done in a manner that is relevant, fresh and engaging (i.e. mission centric, current information and easily navigable). "The strategic direction for and use of the website will be established and monitored by the University Marketing Team. The University Web Team is to oversee the production, functionality, management and deployment of the sites of the university (E3)." In this case, it is very easy to recognize that the design of the university webpage is very important to manifest the success of the university especially in rankings field which plays an important role in the competing system of universities.

Respecting the role of marketing on the design of the web site of your university, the University Marketing Team's role is to oversee the marketing direction and university initiatives for all print and web media. This includes ownership of the content, selection of creative and its 
vehicle of deployment. The university marketing team, comprised of both marketing / content units as well as technical units meets periodically and on an as needed basis to:

- Facilitate regular cross-functional communication and collaboration

- Identify, clarify and advance those shared activities, tasks, policies, practices and decisions necessary to

- Advancing the shared objective of developing, supporting and sustaining the university website in a manner that: 1) advances the university and its key sub-brands, 2) provides relevant, and timely information to external and internal constituents and, 3 ) is easily navigable.

The design of university web page is a significant and very complicated process: "The design and contents before publishing always passing through many filters and after revising and controlling by rectorate department and the committee of marketing and communication then it would be ready to be published and accessible (E1)." This is considerable that ranking is playing a very important role in designing and creating the university website to better manifest their success to their audiences such as: students, parents and researchers who show high level of interest on rankings positions on the universities. Ranking really helps students and other audiences to have more information regarding the selection process. "Definitely marketing indicator related to rankings in the university web page plays a very important role on the design and building the website of the university. We consider marketing aspects on our webpage design for having the very special and differentiated design and even we use some special complementary videos, like the presentation video to present our university perfectly (E2)."

About the role of rankings notifications on the main page of university and its attractive role on the audiences, the university web page experts believed that ranking notification really attracts students and has its effects on their future selection and larger universities with better ranking position surely can attract more elite students and researcher. "Understanding your university's reputation is incredibly important, particularly in an age of growing academic diversity. Rankings are complex and may not adequately capture your university's strengths, but 
emphasizing and building upon these measures is an important way to help grow your university. Knowing what data supports your own university's unique strengths is vital (E2)."

Every university is different; gone are the days when everyone competed for the same measures of success. Some universities exist to serve their communities both through teaching and research, while others are more exclusive and focused on national or international issues. Some partner extensively with the corporate world, while others don't. "Too many rankings are one-size-fits-all; they're using measures that may apply very well to some institutions and not very well to others, particularly the difference between private and public universities. Rankings and its indicators which have been applied through the university web pages of university really play a very important role for attracting elite students (E2)." Rankings notifications on the university webpage facilitate students and researcher to make their choice with more information. The ranking work as the manifestation the quality of the universities or better to say the education quality of any university in the current higher education system. About the updating of the contents and notifications of the university webpage, it is considerable this procedure is a very team work and is not only a project to be done by one person. There are a special team behind this issue who they are in charge of revising the contents and updating of them. "Web site content such as written text and images is supported and sustained by following a model of distributed publishing. The common standards are defined by the following and will be monitored by the University Web Team in collaboration with the Office of Marketing, Communications and Public Relations (E3)."

In adopting a distributed publishing model of website management, the universities are adopting a recognized best practice for the following reasons:

- $\quad$ Relevant website content lives with the offices and departments. They know their content best.

- Offices and departments know best the messages they need to convey to and the responses they need from their web constituencies. 
- $\quad$ Potential bottlenecks created by a centralized publishing model (one person or a small group of persons responsible for all website changes) are avoided.

Time sensitive information can be published more quickly because there is not a queue of other changes that take priority. "After the revising process, all contents before the publishing on the main page should be rechecked and revised by rectorate committee and after their confirmation, all the contents will be passed to the principal page and then all departments will take related parts to publish (E2)." Regarding the type of contents referring to the rankings, the issued contents will be derived from the official rankings web page and the contents which issued on this ranking institute will be revised and refined for publishing in the main website. Serving as the point person for content changes and updates to the departmental division site to which they are assigned to hands on operations of the division, department and office web site content and functionality. Adding and removing time sensitive or dated material (content, images, pages, etc.) in a timely manner.

The other responsibilities can be regarded as: Adhering to stylistic and image standards proper use of graphics images and formatting as established by the university and responsibility for the physical posting or creation of new content, including but not limited to posting of downloadable documents and the manipulation of images or graphics that are not part the website template and also providing the necessary downloadable forms and attending all Web Manager training sessions as scheduled by the Web Team. "The web contents before publishing should be passed through the process of filtering which this process really helps the university to have the more valid contents and avoid the possible errors (E1)." It considered that the rankings contents before publishing will be revised with the special committee and after they confirmation all the contents will be published on the official webpage.

Regarding the reputation of a university will be affected by rankings position, there is a strong correlation among all responses in a way that all respondents agreed and believed that the reputation of the university is highly engaged to the international ranking position. It is beyond doubt that rankings have become a significant part of the tertiary education landscape, both 
globally and locally. In this landscape, rankings have risen in importance and proliferated in unimaginable ways. It's become commercialized and, with it, so has the sophistication of companies and organizations that rank colleges and universities. Undoubtedly, rankings now play such a big role in shaping the opinions of current and potential students, parents, employers, and government about the quality of tertiary education institutions. The emergence of this rankings obsession is, at the same time, a legitimate source of concern about its misuse, especially when it is used solely for promotional purposes, or, even worse, when it becomes the main driver of policy decisions for governments and tertiary education institutions.

Nowadays, it is common to observe entire policies and programs from governments apparently more concerned with the position in the rankings than on the relevance of their tertiary education institutions. Sometimes, this results in diverting significant amount of resources to some institutions while limiting support for others. If rankings become the end rather than the means towards better tertiary education, then this should be a matter of concern. An excessive importance given by institutional and government decision-makers on rankings may be both disturbing and alarming. "It could be considered that rankings are totally engaged and highly affect the university reputation. On the other side, you have to take care of your position to be better seen by researchers and students (E3)." University reputation is acting like the branding in higher education and brings lots of advantages for the university and it would be a great marketing assistance. Everything have the same goals: attracting high-quality students, recruiting great faculty and staff, encouraging alumni to make donations to support school programs, and building up the school's brand recognition and reputation. In order to stand out from their many competitors, it is essential to focus on content marketing, making use of both traditional and digital strategies. Here are some effective tactics and outstanding examples of university content marketing. 


\subsubsection{MARKTINGS ASPECTS OF THE INTERVIEWS}

Regarding special marketing techniques, many schools use too many costly suppliers for their marketing. They invest in the declining and immeasurable print advertising, and advertise online to an audience of low relevance. For instance, if a school advertises on a newspaper's website, only a small fraction of the traffic will be related to education. Schools often struggle to optimize search engine results for the subjects they offer, and they only do it in English and perhaps a local language. Many also run ineffective and costly Google Ad Words campaigns due to a lack of expertise. Content Marketing can play a key role in engaging potential students and convincing them that your institution of higher learning is the right place for them. Social media is a critical component of any content marketing plan, especially when the target you are attempting to reach is comprised of some of the most social media savvy individuals in the world. "The four creative ways that a school can use content marketing and social media marketing to reach out to students and really have a positive impact on recruiting. So, read up and start creating content like digital magazines and newsletters, social media posts, blogs, and much more to reach your target audience and increase enrollment at your school (E3)."

Marketing techniques has been used in the web pages of the university all respondents except the $U 2$, they mentioned that there is a special marketing strategy that was regarded in the construction of the university webpage although the E2 believed in contrary and mentioned that "marketing strategy is not considered in the design of university webpage in a vivid and clear manner and not can be considered that (E2)." About the web page design and content which are designed for special audience or not, all respondents believed that the principal webpage is considered for all type of audiences and not only the special or specific category of audiences. One of the most notable trends in college websites is the division between content sections. Composition is a huge subject flowing through the whole design into every page. College websites rely on visually significant elements to break apart pieces of the layout. Headers, carousels, calendar events and blog posts all tend to be organized into their own little blocks. A well-defined composition improves readability, which allows visitors to skim content at a brisk pace. 
Educational sites are often built around hundreds of different pages. Collegiate institutions have to build truly captivating websites in this high-tech era. Moreover, just like a business's website can say a lot about the company, so can the website of a college or university. College websites are actually quite unique because their layout styles diverge into many avenues. The best layouts don't focus solely on aesthetics but instead design with content as a first priority.

Traditional design techniques are used for these content-heavy layouts which capture the essence of an institution's academic goals. "The design should be for general audience but they mentioned also in some parts the webpage is designed for its own audience. Now a day, the university has got their line of design and style for differentiate themselves with others (E3)". What college would be complete without showcasing the school in action? Photos are easily the most popular choice because they demonstrate the campus in a natural light. Prospective students can see the environment and catch a small glimpse of college life. For example, the color and the frame of the web page has been designed and oriented for attracting the elite researcher or elite students. Each section uses a full screen background color even though content is centered on the page. Header links and dropdown menus also feel like they can be grouped to the navigation visually, which makes traversing content a whole lot easier.

Regarding the marketing aspects of education like: promotions, special programs, free courses or special discounts on tuition fee on the university website, all interviewees agreed in this point that the mentioned above items are really help students or any audiences to reach the desired information about the university and can be regarded as the marketing aspect as well. "Marketing aspects are regarded as an important feature in the university webpage which play a very significant role in the presentation of university web page. (E2)"

Create an alumni magazine online or offline colleges were some of the earliest adopters of content marketing: Harvard University, for instance, has published its alumni magazine since 1898. Today, hundreds of schools publish alumni magazines on an annual or quarterly basis. The articles serve to share stories of faculty members' ground breaking research, spotlight alums' unique career paths, share innovative educational programs, and delve into more complex feature stories 
about education. Alumni magazines can be powerful tools for connecting to a broader audience: "A survey from our university support education committee found that 58 percent of students feel that such magazines strengthen their personal connections to universities. (E2)"

About the graphics design of the university, Graphic design is the creation of new solutions to problems within the medium of visual communication, either in 2D or 3D, on paper or digitally. The output is usually something that can be reproduced in order to deliver its objective many times. Graphic design output includes logos, web site user interfaces, tattoos, sketches for fashion or industrial design, typefaces, print, animated characters, advertisements, flyers, movie credits, newspaper headlines, and designs for textiles. This is just a small part of what can be designed graphically. What they have in common is output that will be consumed through visual media. All respondents they mentioned this issue that graphic elements they are very important to shape a strong web page and for example the color and the graphics design are very important for attracting the audience and the graphics elements always play an important role in the marketing strategy. "It is clear that graphic items are not an easy job and needs to pay attention a lot (E1)." Design is the discipline of creating a new solution to a problem. You can design anything, from a web site to a stadium, a sales pitch, a recipe, a logo, a social media campaign, or a component for a machine. If the solution did not already exist, you have done design. Every problem has its own unique requirements. If there is no existing solution to the problem, you have to make one. That's design. You look at what the thing needs to do, and use your imagination and experience to visualize something that does that. You know a design is good when it achieves the result it is designed to deliver. The result you aim to achieve may be purely functional, measurable with hard data, or it may be an experience, which it's less easy to measure. "For a web site to live up to its potential, it must attract the right audience, and in the right numbers. That means it must be optimized to be found for people searching for what the site offers, whether they find the site via organic search, through advertising, social media, or PR (E3)". It must also be easy to use and compelling enough to engage and to keep people's attention. It must be easy for most people to read, even if they have a visual impairment or are accessing the site over a slow Internet connection or on a handheld device. In addition, the site should be easy for everyone to use, 
regardless of disability, and should work on a range of devices. Otherwise, it will only reach a fraction of its possible audience, so it cannot reach its potential. A successful web site must also sell. Every site has a purpose, which should be to generate action by the visitor.

A site that sells is one that generates that action, whether it is to buy, to sign up, or just to read. Considering the presented languages in the webpage, the process of taking a website and adjusting it for another culture is known as localization. It is a great deal more involved than translating the words out of English, however. Other cultures have their own standards for design, symbolism, layout and color, and understanding these differences is important to your website's success. One solution is to offer customers a choice of languages when they first enter your website, using cookies to remember their choice. Giving customers options is a good way to start a relationship and makes them feel more comfortable. All the respondents they mentioned that languages are very important specially for international visitors of the webpage and all interviewees mentioned that all three languages are well organized and well prepared to serve perfectly the audiences with any location al around the world. "Languages option will give opportunity to audiences from all around the world to get their required information (E2)."

Regarding the speed of connection to web page, opening the photos, videos and totally navigation of the web page, all interviewees mentioned that the connection of the web page is prefect due to huge numerous server that they have prepared for this section. Speed test from multiple locations around the globe using real browsers and at real consumer connection speeds will show you our performance. Simple test or perform advanced testing including multi-step transactions, video capture, content blocking and much will provide rich diagnostic information including resource loading waterfall charts. "Page Speed optimization checks and suggestions for improvements and can affect the satisfaction of your audiences. Usability research has shown that the biggest factor in user satisfaction is speed of response (E3)." Optimizing your website for response speed means people will enjoy using it more. But it's more important than that. The number of Internet users in developing countries is estimated to have quadrupled between 2004 to 2015. 
These users could access an increasing amount of valuable information. Yet broadband connections are extremely expensive in the developing world. Most users cannot afford them, so have great difficulty using the many sites designed for high bandwidth connections. No matter how important its content, if a site takes too long to load it becomes unusable. About the web page compatibility with smart phone and tablets and all mentioned that all university webpage website totally is compatible with smart phone based on our new system of technology that we have applied on our webpage. The difference between a mobile compatible website and a mobile optimized website continues to be a source of confusion. According to a recent Google study, 61 per cent of shoppers will leave a website if it is not optimized for their mobile device. In other words, the experience of a non-optimized website can negatively impact a consumer's likeliness to book and overall perception of the brand. "All universities are aware of this consequence but are still struggling to understand what characterizes a mobile optimized hotel website and all of this mentioned above items show the level of importance of connection and compatibility with smart phone and tablets (E1)."

Regarding the web page is connected to social networks like Facebook, Instagram, linked in, Twitter ..., all interviewees said this issue that. The web page is perfectly connected to social networks and we have a special links in our web page for connecting to Facebook, twitter, Instagram, linked in. "At the time of issuing rankings, we revise and check all the items and positions of university and then we will post or publish this success in the main page of our website and in the social networks as well and for attracting investigators and elite students we will use special indicators in the web page, we have a special person who is professionally is in charge of social networks and all faculties have got their own account on twitter for example (E2)."

A mobile compatible website is an HTML based website that doesn't contain Flash. It means that a website is viewable on a Smartphone or Tablet, but it is not optimized for these devices. These websites have been designed for web browsers on PCs with much larger screens and navigation using a mouse. You will notice a few things about these websites when you attempt to browse them on your Smartphone or Tablet you have to scroll left, right, up or down and figure 
out how the site "works", media may load slower, text is tiny so you have to zoom in to read it and the links are small and difficult to click with your fingertip. That's because it is. If you have done nothing to optimize your website for mobile devices, then it is likely compatible by default. It is also likely that visitors are abandoning your site pretty quickly and because poor experiences do not convert customers. A mobile optimized website is a website that is designed specifically for a Smartphone or a Tablet, not a desktop computer or laptop. A mobile optimized website doesn't require that someone pinch and zoom to read text. On a mobile optimized site the navigation is built for efficiency, the images and media are optimized for quick loading and the content is succinct for maximum effectiveness. Additionally, mobile-only functionality includes tap-to-call, tap-to-email and map functionality. If your website has been optimized for mobile devices you will know - not only because it is much easier to navigate and use compared to the experience of a compatible website but because you will likely see less bounce rates, higher engagement levels and improved conversions. To help set the record straight, here is a table showcasing the main differences between the two and to illustrate the importance of having a hotel website that is optimized for mobile devices.

\subsubsection{HEADLIGHTS OF THE INTERVIEWES}

Regarding three interviews, there are noticeable issues, which really is a great assistance for this study regarding the process of constructing the official university webpage and how they use the rankings notifications with marketing techniques to present better their success among the other universities. For example, regarding the design one of them mentioned the new website of the university looks like to be very different and more professional with more attractiveness and information than the old one. All contents and features are optimized in a perfect way and even in the first glance you can realize it. It shows that an enormous job has been done and all these efforts fulfilled to make it better than the old one. One interviewee believed that that their university website is one of the most complete website among the Spanish universities for the reason of language presentation, which is presenting completely in three different languages. Regarding the design of the webpage, she believed that their principal page is influenced by the 
rankings notifications but not highly and the rankings notification occupies a short percentage of the total space of their webpage, although its presentation is very significant for the university webpage. She believed that their university webpage is designed to present and attract elite researcher and students based on the university successes.

Regarding the rankings notifications on the university webpage, they believed that it should be better explained and presented. Now a day, rankings are available for students, parents and the elite researchers. The rankings and its first impression are very important and she thinks, they have not been presented well enough for audience. Furthermore, she believed that rankings or the assessment of the performance of universities is not well formatted and it cannot fulfil all needs and desires of the students or audiences. Rankings should serve for all the target group as students, researcher, parents and governments, etc. About the updating the contents, there are a big team behind this issue who are responsible for updating the website contents and its validity. They are always keeping the contents updated and well organized and they try to present the news, promotions and notifications in the earliest possible and the right time. Totally, they are a big team who keep the data updated and manage the website in all sections. In the page of the university, all the techniques and segments of marketing is regarded to help the university to have the better presentation. At the time of issuing rankings, they revise and check all the items and positions of university and then we will post or publish this success in the main page of our website and in the social networks as well and for attracting investigators and elite students. They use special indicators in the web page and rankings and its indicators which have been used through the web pages of university really play a very important role for attracting elite students.

Regarding the contents, it is very interesting, that the contents on the official web pages after adopting and refining will be publishing in the main official webpage. Rankings of universities help them to make their choice easier and better. For example, larger universities with better ranking position surely can attract more elite students, investigator. Rankings normally act like manifestation of the university quality. The header of website is acting like showcase and shows all new notifications and important news by very nice and technological techniques. Every few 
seconds it pops up with new news and it is very eye catching. The contents will be revised thorough 3 times before publishing by the committee and then on the top by rectorate committee. Considering the university international reputation, one mentioned that the reputation somehow could be achieved by better rankings position. Spanish universities they are not a mostly liked destination for international students around the worlds. It can be concluded that the reputation of a university is engaged with the ranking position.

\subsection{RESULTS OF QUESTIONARIES}

To recognize how positively the rankings of universities played an essential role in the selection process for students, the questionnaire was designed and sent via the Google Drive to international and national PhD and master students of four mentioned universities. The number of 558 responses received from different disciplines and faculties of four mentioned Catalan universities. After analyzing and studying the results, it extremely cooperated this study to recognize the university selection process by students. The results are followed in this section. The questionnaire of this investigation was a close ended and composed of 4 blocks as:

* 1st Block: The role of rankings in higher education

* 2nd Block: Your selected university

* 3rd Block: Marketing strategy of the university

* 4th Block: Perception of students

This questionnaire had totally 14 questions and finally 558 students participated in it through the Google Drive, which really helped me to take advantage of this brilliant technology for precise and better analyzing and gathering the data for this research. It is necessary to mention that students of four metropolitan Catalan universities (UAB, UB, UPF and UPC) were chosen as samples of this study from 13 different faculties of those mentioned universities (see table 17):

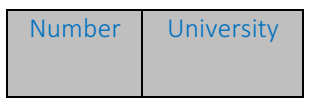


Results

TABLE 16.

\begin{tabular}{|c|c|}
\hline 1 & UPC \\
\hline 2 & UAB \\
\hline 3 & UB \\
\hline 4 & UPF \\
\hline
\end{tabular}

METROPOLITAN 4 CATALAN UNIVERSITIES AS CASE STUDY

TABLE 17.

FACULTIES OF PARTICIPANTS IN QUESTIONNAIRE

\begin{tabular}{|c|c|}
\hline Number & Faculty \\
\hline 1 & Marketing and business organization \\
\hline 2 & Education \\
\hline 3 & Mathematics \\
\hline 4 & Engineering \\
\hline 5 & Biology \\
\hline 6 & Electric Eng. \\
\hline 7 & Business \\
\hline 8 & Engineering \\
\hline 9 & System and project Engineering \\
\hline 10 & Barcelona Electric Eng. \\
\hline 11 & ECONOMICS Business \\
\hline 12 & Social education and health \\
\hline 13 & Chemistry \\
\hline
\end{tabular}

\section{Number of participants}

As you can see in the table 16, the 369 PHD students and 189 master students from 4 Catalan universities and 13 different faculties (table 17) have participated in this research which helped 
me to have extended primary data source. This number of responses sufficiently assisted my study to better analyzing the role of rankings on marketing strategy of universities.

TABLE 18. STUDENT'S TYPE DISTRIBUTION

\begin{tabular}{|l|c|c|}
\hline PHD & 369 & $66 \%$ \\
\hline Master & 189 & $34 \%$ \\
\hline
\end{tabular}

\section{* Gender}

In this questionnaire, 335 of participants were men and the 223 were women (Table 19), which all respondents were chosen randomly based on availability of participants and there was not any special choosing method or goal.

TABLE 19. GENDER TYPE DISTRIBUTION

\begin{tabular}{|l|l|l|}
\hline Men & 335 & $59.60 \%$ \\
\hline Women & 223 & $40.4 \%$ \\
\hline
\end{tabular}

\subsubsection{FIRST BLOCK: THE ROLE OF RANKINGS IN HIGHER EDUCATION}

\section{Question no1- In your opinion, the importance of university rankings in the current higher education system:}

Due to the result table 20 , it is noticeable that majority, $62.8 \%$ of participants believed in the importance of the university rankings in the current higher education system. It is a large number among 558 respondents. It shows the importance of rankings in the current higher education system and manifests impact of rankings on student's choice. It is understandable that the rankings attract a great deal of attention from the general public, politicians, parents and especially students. The other most important issue that we can recognize from this results is that 
the very low percentage $1.9 \%$ of participants they regarded importance of rankings as a low level of importance and the other interesting issue is none of the participants $0 \%$ even didn't believe that rankings has got no importance in the higher education and student's selection.

TABLE 20. IMPORTANCE LEVEL OF RANKINGS ON GENDER, STUDENTS AND HIGHER EDUCATION

\begin{tabular}{|l|l|l|l|l|}
\hline \multicolumn{1}{|c|}{ Question number 1 } & High & Middle & Low & None \\
\hline Importance of rankings on current higher education & $62.8 \%$ & $35.3 \%$ & $1.9 \%$ & 0.00 \\
\hline Importance of rankings on gender type: Male & $62 \%$ & $31 \%$ & $7 \%$ & 0.00 \\
\hline Importance of rankings on gender type: Female & $48 \%$ & $39 \%$ & $13 \%$ & 0.00 \\
\hline Importance of rankings on student's types: PhD & $75 \%$ & $23 \%$ & $2 \%$ & 0.00 \\
\hline Importance of rankings on student's types: Master & $32 \%$ & $55 \%$ & $13 \%$ & 0.00 \\
\hline
\end{tabular}

Regarding the results given in the table 20 , it is considerable that $62 \%$ of respondents which were male they regarded the importance of rankings as the high level of importance and $31 \%$ considered the rankings importance as middle level of importance which in comparison with the female respondent is notably higher, because the female respondents they considered that importance level of rankings as a $48 \%$ and for middle level of importance $39 \%$ and remarkably $13 \%$ considered that rankings importance has a very low level of importance for female respondents, although in the other side male respondents only $7 \%$ they believed that rankings importance has got a low level of importance in their mind which can be considered that for the male respondents rankings position of a university in the current higher education system plays a very significant role in their selection rather than the female. The role of rankings in this perspective is that of offering consumer information to the many buyers and sellers participating in the globalized game of higher education services. Global rankings offer players of the game information which claims to compare higher education institutions across national borders. As such, rankings are part of the standardization of institutions in society. Students invest considerable time and money (either in the form of fees or student loans) in higher education. As a result, the choice of the education option is important. Many people, however, consider that it is difficult to obtain satisfactory information about the actual differences in quality between different higher education programs 
and institutions. Rankings provide relatively simple and direct information about the quality of higher education. Straightforward information of this kind is often considered to be particularly important for students with no experience of universities and the higher education sector. It is beyond doubt that rankings have become a significant part of the tertiary education landscape, both globally and locally.

The other considerable issue is that the PhD students they considered the $75 \%$ high level of importance for the rankings of the university, which in comparison for the master students only $32 \%$ they believed that international ranking position has got high level of importance for the university in the current higher education system university and totally $68 \%$ of master students they considered the low level and middle level of importance for rankings. By regarding these percentages, it can be considered that the importance of rankings on current higher education system is regarded more important for the PhD students than the master students and PhD students based on their educational experiences they are more concerned about rankings positions than the master students and it could be concluded that the rankings importance in the higher education is an inevitable fact. In this landscape, rankings have risen in importance and proliferated in unimaginable ways. It's become commercialized and, with it, so has the sophistication of companies and organizations that rank colleges and universities. Undoubtedly, rankings now play such a big role in shaping the opinions of current and potential students, parents, employers, and government about the quality of tertiary education institutions. The emergence of this rankings obsession is, at the same time, a legitimate source of concern about its misuse, especially when it is used solely for promotional purposes, or, even worse, when it becomes the main driver of policy decisions for governments and tertiary education institutions. Nowadays, it is common to observe entire policies and programs from governments apparently more concerned with the position in the rankings than on the relevance of their tertiary education institutions. Sometimes, this results in diverting significant amount of resources to some institutions while limiting support for others. If rankings become the end rather than the means towards better tertiary education, then this should be a matter of concern. An excessive 
importance given by institutional and government decision-makers on rankings may be both disturbing and alarming.

It is evident that rankings do have a value as a reference and as basis for comparison. However, they do not always serve as the best proxy of quality and relevance of tertiary education institutions. Let's keep in mind that any ranking is eventually an arbitrary arrangement of indicators aimed at labeling what it is being predefined by the ranker as a "good" educational institution. Those in favor of rankings especially rankers may argue that in the absence of sound and comparable information, rankings are the best option for determining the quality of colleges and universities. However, as the saying goes, the devil is in the detail. This predefined vision of an ideal institution does not always take significant contextual differences into consideration. It tends to impose a one-sided vision of an institution mostly a traditional research oriented and highly selective university, which is not necessarily the most responsive to the varied needs of the communities where these institutions are located. Most well-known rankings tend to equate institutional quality with research productivity, which is measured either by the number and impact of their publications in peer reviewed journals, or the selectivity on their admission processes. Of course, such a proxy of quality downgrades institutions that place greater emphasis on teaching and prolongs the "publish or perish" principle. In pursuing better position in the rankings, most probably internal and external funding may tend to favor academic programs or research units that are more inclined to get involved in the dynamics of researching and publishing. Finally, it diminishes the role of other important functions of tertiary education institutions such as teaching and public service. There is also a demand and need for information about the quality of various education programs and institutions outside the higher education sector. This may be a question of potential employers who need information about which programs or institutions provide education and training for people the employer wishes to recruit. And members of the general public may also be interested in information about the quality of the education services that they help to finance in the form of taxes. 


\section{Question no2- In your view, the international reputation of universities, is influenced by their} rankings positions:

According to results table given below the majority, $75 \%$ of participants considered that the international reputation of a university is influenced by rankings positions of a university. It can be concluded that international reputation is really engaged and also interwoven with ranking position of the universities. The $22 \%$ of respondents considered the middle level of importance that the reputation of a university could be influenced by rankings position, which still is a considerable percentage. Rankings basically manifests the education quality of universities and as it was mentioned in the literature review, nowadays the universities all around the world paying more attention on it. The other most important issue that we can recognize from this results is that the very low percentage of participants only $3 \%$ they regarded influence of rankings in international reputation as the low level of importance and the other interesting issue is that none of the participants $0 \%$ even didn't believe that rankings position has no influence on international reputation. Colleges and universities compete intensively with each other for talent and funding.

TABLE 21. INFLUENCE OF RANKINGS ON INTERNATIONAL REPUTATION OF THE UNIVERSITY AND ITS INFLUENCE ON GENDER AND STUDENT'S TYPES

\begin{tabular}{|c|c|c|c|c|}
\hline Question number 2 & High & Middle & Low & None \\
\hline Influence of rankings on international reputation of the university & $75 \%$ & $22 \%$ & $3 \%$ & 0.00 \\
\hline Importance level of rankings and international reputation for gender type: Male & $62 \%$ & $31 \%$ & $7 \%$ & 0.00 \\
\hline Importance level of rankings and international reputation for gender type: Female & $48 \%$ & $39 \%$ & $13 \%$ & 0.00 \\
\hline Importance level of rankings and international reputation on student's types: PhD & $66 \%$ & $31 \%$ & $3 \%$ & 0.00 \\
\hline Importance level of rankings and international reputation on student's types: Master & $55 \%$ & $35 \%$ & $10 \%$ & 0.00 \\
\hline
\end{tabular}

Regarding the results given in the table 21 , it is considerable that $62 \%$ of respondents which were male they regarded the high level of importance for the influences of rankings on international reputation of a university and only $31 \%$ considered the rankings importance as middle level of importance which in comparison with the female respondent is notably higher, in the other hand the female respondents they considered that highest importance level of rankings 
as a $48 \%$ and for middle level of importance $39 \%$ and remarkably $13 \%$ considered that rankings importance as a low level of importance, although in the other side the male respondents only $7 \%$ they believed that rankings importance has got a low level of importance in their mind. It can be considered that the male respondents believed that rankings positions have got the highest influence on international reputation of a university rather than the female. For a long time, students, teachers, research partners and donors have based their decisions on the universities' historic reputations without the use of data to back up perceptions. The rapid growth of the international higher education system has brought with it the development of initiatives to build world class universities. Prospective students are looking for international exposure opportunities and want to compare institutions across borders. The general public is becoming increasingly interested in the activities and accomplishments of universities to solve today's grand challenges. The growing need to understand this complex system has led to the rise of rankings, metrics and surveys. There are over 30 ranking systems for higher education around the world. The results are used by universities as key performance indicators and serve as a powerful communication tool. By showcasing the distinctive strengths of research institutions, rankings help students select their university of choice, faculty to make career decisions, and university leaders to discuss strategic priorities. The other considerable issue is that the PhD students they considered the $66 \%$ high level of importance for the influence of rankings on international reputation of the university, which in comparison for the master students only 55\% they believed that international ranking position affects the university reputation and totally $45 \%$ the considered the low level and middle level of influence. By regarding these percentages, it can be considered that the influence of rankings on international reputation of the university is regarded more by the PhD students than the master students because of their broad impact, the accuracy and integrity of rankings is crucial. Rankings must deploy a range of techniques both qualitative and quantitative to provide a meaningful and balanced system by which universities can be compared. Quantitative data has increasingly played a role in providing key metrics that can supplement personal knowledge and experience. Of course, it is a challenging task to rank universities that are all unique; each has its own mission and focus and offers a diverse set of academic programs. The size of the organization and its financial 
resources can also vary greatly. Additionally, the structure of the academic organization is influenced by the country's higher education system, which in turn influences the set of metrics used for each institution.

Rankings can help institutions gain a perspective on their global position and will undoubtedly remain important. The globalization of the higher education system will continue, driven by the rapid growth of large research nations and changes in population density and demographics. More than ever, institutions will focus on their international standing; they will attract the best talent in the world and carve out their competitive advantages by establishing strong international partnerships to optimize their return on investment; by sharing expertise, equipment and financial investment, strategic alliances can be the key to success. So, with referring to the results it could be concluded that international reputation has its influence on rankings position and plays a very special role on higher education. It could be considered from this aspect that in the current higher education rankings play a very significant role and somehow is very depended on the rankings indicators. Rankings also address issues of accountability that we need to understand better. As mentioned earlier rankings may be seen as part of the accountability movement in society by which we all are affected. For higher education with its intangible products and services, accountability is a special challenge. This is probably why reputation is so important for many higher education institutions. Reputation can be used for accountability purposes, and could be an instrument of protection for those who enjoy high rating in academe and in society.

The reputation of the higher education institution affects the student's choice to a considerable extent, but this is more likely to be based on information from their immediate environment rather than on rankings. The most important information comes from parents, friends, student counsellors and the institutions themselves. Learning is the most commonly used indicator type, with 21 of 26 rankings systems using them. But the most consistently highly weighted area in rankings systems is research performance and research output, which is used in 18 of the 26 rankings and, on average, accounts for over a third of the weight in those rankings. 
Reputation is an important component of most national league tables and claims that their assessment of college and university reputation using the views of institutional administrators is aimed at measuring intangibles such as faculty dedication to teaching. The reputation score, however, correlates much more closely with high federal research and development expenditures than with good graduation rate performance as previously noted another problem with reputation is that while it may be relevant for ranking the best-known schools, even a sample of prominent people is unable to assess accurately the quality of all programs in all schools. Therefore, their opinion is likely to be influenced more by the existing reputation of the university than by actual knowledge of program quality. University leaders believe rankings help maintain and build institutional position and reputation; good students use rankings to shortlist university choice, especially postgraduates; and key stakeholders use rankings to influence their decisions about accreditation, funding, sponsorship and employee recruitment and the reputation derived from league tables is a critical determinant.

\section{Question no3- In your opinion, the news regarding the rankings position on the university web page influence student's selection:}

Regarding the results table given below, the $38 \%$ of participants they have considered that influences of rankings news on the official webpages of universities has got the middle level of importance and on the other side 59\% participants they have chosen the high level of importance on their selection. It shows that majority of participants they are agreed in this point that news and notification of rankings on the official web page of university has got influences on students selection process and the difference which is $21 \%$ shows that the intensity of rankings notification on the webpage is not the same for all students. Besides it matters that rankings notification on university webpage is playing an important role in the selection of process of students. It can be

noticed that students follow the ranking notifications on the university webpage before making their choice. Also, results show that some students with the rate of $3 \%$ have chosen the low middle of importance and the none of the participants that they have believed that the rankings 
notifications on the university webpage are not important on the selection process. The ranking phenomenon has expanded in line with the supply of higher education. Rankings are sometimes described as a way of simplifying and clarifying a complex scenario for students and other interested parties.

TABLE 22. INFLUENCE OF RANKINGS ON THE SELECTION OF STUDENTS, GENDER AND STUDENT'S TYPES

\begin{tabular}{|l|l|l|l|l|}
\hline \multicolumn{1}{|c|}{ Question number 3} & High & Middle & Low & None \\
\hline Influence of rankings on the selection of students & $59 \%$ & $38 \%$ & $3 \%$ & 0.00 \\
\hline Importance level of rankings on the selection of students for gender type: Male & $79 \%$ & $11 \%$ & $10 \%$ & 0.00 \\
\hline Importance level of rankings on the selection of students for gender type: Female & $28 \%$ & $69 \%$ & $3 \%$ & 0.00 \\
\hline Importance level of rankings on student selection based on student's types: PhD & $66 \%$ & $29 \%$ & $5 \%$ & 0.00 \\
\hline Importance level of rankings on student selection based on student's types: Master & $39 \%$ & $49 \%$ & $12 \%$ & 0.00 \\
\hline
\end{tabular}

Regarding the results given in the table 22 , it is considerable that $79 \%$ of respondents which were male they regarded the high importance level of rankings on the student's university selection and only $11 \%$ considered that the importance of the rankings news as middle level of importance which in comparison with the female respondent is notably higher, but in the other hand the female respondents they considered that highest importance level of rankings on their selection as $28 \%$ and for middle level of importance $69 \%$ and only $3 \%$ considered that rankings importance as a low level of importance, although in the other side the male respondents $10 \%$ they believed that rankings importance has got a low level of importance on the university selection process. It can be considered that the male respondents believed that rankings have got the highest influence on the student's choice rather than the female. Even if the ranking concept may cover many aspects, most rankings have a common factor in that they present indicators of quality explicit or implicit that is weighted to produce an outcome which, in its turn is ranked in comparison with all other such results. In other words, ranking is an attempt to measure the quality of higher education or research, but it differs from many other forms of quality assessment because it is relative there are no absolute criteria or norms for what may be regarded as minimum quality. This is partly because the ranking designers are often commercial entities newspapers or 
magazines with no direct responsibilities for the higher education sector. There is extensive discussion of the ranking concept. Ranking is frequently defended on the grounds that it is useful for students and for other stakeholders. There are positive effects on higher education institutions. Some students use the rankings when making their choices. Colleges and universities compete intensively with each other for talent and funding. For a long time, students, teachers, research partners and donors have based their decisions on the universities' historic reputations without the use of data to back up perceptions. The rapid growth of the international higher education system has brought with it the development of initiatives to build world-class universities. Prospective students are looking for international exposure opportunities and want to compare institutions across borders. The general public is becoming increasingly interested in the activities and accomplishments of universities to solve today's grand challenges.

The other considerable issue is that the PhD students they considered the $66 \%$ high level of importance for the influence of rankings on international reputation of the university and on the university selection process of students, which in comparison for the master students, the high level of importance is $39 \%$ and they believed that international ranking position affects the student's university selection and totally $61 \%$ of the master students they considered the low level and middle level of rankings influence on the student's selection process. By regarding these percentages, it can be considered that the influence of rankings on the student's university selection is highly regarded by the PhD students than the master students and PhD students they are more concerned with rankings position of universities. The growing need to understand this complex system has led to the rise of rankings, metrics and surveys. There are over 30 ranking systems for higher education around the world. The results are used by universities as key performance indicators and serve as a powerful communication tool. By showcasing the distinctive strengths of research institutions, rankings help students select their university of choice, faculty to make career decisions, and university leaders to discuss strategic priorities. They may also be used by the corporate world to guide industry investment in academic partnerships. The international agenda involves, for example questions regarding the quality of rankings, European challengers versus the international ranking system, and multidimensional, interactive rankings. 
Universities and other higher education institutions are ranked all over the world. There is a wide range of ranking systems in the United States with a relatively long tradition, but considerable protests against ranking have also been voiced.

Question no4- In your idea, the usefulness of the rankings news on the universities web page is:

The results table below shows that $54 \%$ of participants they believed that usefulness of rankings news on the university webpages has got the high level of importance and it could help the students to have better selection and it can be noticed from the results that the $43 \%$ of participants also believed that rankings notifications really is considered for student's attraction and it will help them to make their selection with better and more information. Only 3\% of participants they have chosen that ranking notification has got low level of importance in the selection process and usefulness of rankings on the university webpage. Totally $97 \%$ of total participants they have chosen the importance of notification rankings on the student's selection which shows the significant role of rankings in the current higher education system with the use of technology and the internet.

TABLE 23. IMPORTANCE LEVEL OF RANKINGS NOTIFICATION AND ITS IMPACT ON THE UNIVERSITY WEBPAGE BASED ON GENDER AND STUDENTS TYPES

\begin{tabular}{|l|l|l|l|l|}
\hline \multicolumn{1}{|c|}{ Question number 4} & High & Middle & Low & None \\
\hline Rankings notifications and its impact on the university webpage & $54 \%$ & $43 \%$ & $3 \%$ & 0.00 \\
\hline Importance level of web rankings notifications based on gender type: Male & $56 \%$ & $34 \%$ & $10 \%$ & 0.00 \\
\hline Importance level of web rankings notifications based on gender type: Female & $38 \%$ & $59 \%$ & $3 \%$ & 0.00 \\
\hline Importance level of web rankings notifications based on student's types: PhD & $51 \%$ & $38 \%$ & $11 \%$ & 0.00 \\
\hline Importance level of web rankings notifications based on student's types: Master & $45 \%$ & $39 \%$ & $16 \%$ & 0.00 \\
\hline
\end{tabular}

Considering the results given in the table 23 , it is considerable that $56 \%$ of respondents which were male they regarded the high importance level of the rankings notifications on the university webpage and the $34 \%$ considered that the rankings importance as middle level of importance which in comparison with the female respondent is notably higher, but in the other 
hand the female respondents they considered that highest importance level of the rankings notifications on university webpage as $38 \%$ and for middle level of importance $59 \%$ and only $3 \%$ considered that rankings importance as a low level of importance, although in the other side the male respondents $10 \%$ they believed that the web rankings notifications on the university webpage has got a low level of importance. It can be considered that the male respondents believed that the web ranking notifications on university webpage have got the highest influence on the student's choice rather than the female. Students regard both time and money in their education. As a result, it is important for potential students to have access to comprehensive and relevant information about higher education before they choose. Based on survey of rankings in general, and a couple of specific ranking systems, we conclude that most rankings do not provide all round, relevant or reliable information about the quality of higher education. Weighted rankings of entire higher education institutions are particularly problematical. Quite simply, they provide too little information. They also assume that all the potential target groups have a common and very precise definition of quality a definition which may be seriously questioned in terms of indicators, methods, reliability and in particular relevance. Multidimensional rankings, or rather student information systems, in which students or other stakeholders are themselves permitted to define quality, are a more attractive alternative. Quality and the selection of indicators also present problems in this context too, however. There is a great deal of information about higher education and much of this information is of satisfactory quality. But the quality of information to students does not merely depend on quality assured data sources and the reliability of the information. It is also important that the information is used for the purpose for which it was intended. Very little quality assured information is suitable for ranking of the kind that we have studied. Because of the broad impact of rankings, the accuracy and integrity of rankings is crucial. Rankings must deploy a range of techniques both qualitative and quantitative to provide a meaningful and balanced system by which universities can be compared. Quantitative data has increasingly played a role in providing key metrics that can supplement personal knowledge and experience. Of course, it is a challenging task to rank universities that are all unique; each has its own mission and focus and offers a diverse set of academic programs. The size of the organization 
and its financial resources can also vary greatly. Additionally, the structure of the academic organization is influenced by the country's higher education system, which in turn influences the set of metrics used for each institution.

The other considerable issue is that the PhD students they considered the $51 \%$ high level of importance for the influence of rankings notifications on the university web page, which in comparison for the master students $45 \%$ they believed that rankings notifications and its impact on the university webpage selection and totally $55 \%$ of the master students they considered the low level and middle level of importance for rankings notifications and its impact on the university webpage. By regarding these results and percentages, it can be considered that the influence of rankings notification and its impact on the university webpage is highly regarded by the PhD students than the master students which shows that the rankings notifications really matters more for PhD students than the master students. Rankings can help institutions gain a perspective on their global position and will undoubtedly remain important. The globalization of the higher education system will continue, driven by the rapid growth of large research nations such as China, India and Brazil, and changes in population density and demographics. More than ever, institutions will focus on their international standing; they will attract the best talent in the world and carve out their competitive advantages by establishing strong international partnerships to optimize their return on investment; by sharing expertise, equipment and financial investment, strategic alliances can be the key to success. It is obviously desirable that the information is transparent and accessible for students who are interested in comparing different higher education institutions or different programs, and there is certainly potential for further development in this area. An awareness that simplification of information also involves a loss of information is also required, and that information simplified to the extent called for in weighted ranking lists is hardly information worth the name, in the context of the quality of higher education.

\subsubsection{SECOND BLOCK: YOUR SELECTED UNIVERSITY}




\section{Question no5- Comparing with other Spanish universities, in the web page of your chosen university the reports of rankings are applied in a level:}

The result shows that most of the participants $49 \%$ declared that rankings report in their selected universities motivated them to choose their current university among the other Spanish universities. The rest of participants $32 \%$ agreed as well that rankings report in their selected university webpage has got the important role as middle level and it shows that totally $81 \%$ of participants all their believed that rankings reports in the university webpage played an ignorable role in their chosen process and they were really stimulated and attracted by rankings reports on the university web page in their selection process. This shows that why the universities nowadays pay more attention and invest more on their global rankings positions among the other universities. When students were asked to consider which factors were most important to them rankings were deemed the most crucial and generally only made a difference to a student's decision. Students consider a range of issues when making choosing a college and university; this includes, for example, price and cost, course or program, location, quality of facilities, social life and academic reputation and students have adopted a stronger consumerist approach, assessing their choice of an institution and educational programs as an opportunity-cost or the value-added.

TABLE 24. RANKINGS NOTIFICATION ON THE WEB PAGE OF YOUR SELECTED UNIVERSITY BASED ON GENDER AND STUDENT'S TYPES

\begin{tabular}{|c|c|c|c|c|}
\hline Question number 5 & High & Middle & Low & None \\
\hline Rankings notification on the web page of your selected university & $49 \%$ & $32 \%$ & $19 \%$ & 0.00 \\
\hline Importance level of web rankings notifications based on gender type: Male & $66 \%$ & $33 \%$ & $1 \%$ & 0.00 \\
\hline Importance level of web rankings notifications based on gender type: Female & $59 \%$ & $39 \%$ & $2 \%$ & 0.00 \\
\hline Importance level of web rankings notifications based on student's types: PhD & $60 \%$ & $29 \%$ & $11 \%$ & 0.00 \\
\hline Importance level of web rankings notifications based on student's types: Master & $55 \%$ & $32 \%$ & $13 \%$ & 0.00 \\
\hline
\end{tabular}

Considering the results given in the table 24 , it is considerable that $66 \%$ of respondents which were male they regarded the high importance level of the web rankings notifications on 
university webpage and $33 \%$ considered that the rankings importance as middle level of importance which in comparison with the female respondent is notably higher, but in the other hand the female respondents they considered that highest importance level of the web rankings notifications on selected university webpage as $59 \%$ and for middle level of importance $39 \%$ and only $2 \%$ considered that rankings importance as a low level of importance, although in the other side the male respondents $1 \%$ they believed that the web rankings notifications on university webpage has got a low level of importance. It can be considered that the male respondents believed that the web rankings notifications on university webpage have got the highest influence on the student's choice rather than the female student. The low percentage of participants they believed that rankings reports on their selected university applied in the low level and is very interesting that none of participants considered that ranking position in the webpage of university has got no importance. Arguments based on the assumption that ranking has certain effects are often voiced in the debate on the ranking of universities. One common view is that ranking affects the perceptions of both institutions and students in certain respects. Those in favor of the ranking of universities tend, for example, to claim that potential students use rankings to make a rational choice when selecting an institution or education program, and that ranking encourages the institutions concerned to improve the quality of their programs. On the other hand, the critics consider that the ranking of universities leads to irrational behavior on the part of both institutions and students. But what do we actually know about the impact of rankings on institutions and students are not definitely clear and complete. It is evident that rankings do have a value as a reference and as basis for comparison. However, they do not always serve as the best proxy of quality and relevance of tertiary education institutions. It should be kept in mind that any ranking is eventually an arbitrary arrangement of indicators aimed at labelling what it is being pre-defined by the ranker as a "good" educational institution. The other considerable issue is that the PhD students they considered the $60 \%$ high level of importance for the influence of rankings notifications on the university web page, which in comparison for the master students 55\% they believed that rankings notifications and its impact on the university webpage selection and totally $45 \%$ of the master students they considered the low level and middle level of importance for 
rankings notifications and its impact on the university webpage. By regarding these percentages, it can be considered that the influence of rankings notifications and its impact on the university webpage is highly regarded by the PhD students than the master students which shows that the rankings notifications really matters more for PhD students than the master students. Those in favor of rankings especially rankers may argue that in the absence of sound and comparable information, rankings are the best option for determining the quality of colleges and universities. This predefined vision of an ideal institution does not always take significant contextual differences into consideration. It tends to impose a one-sided vision of an institution mostly a traditional research oriented and highly selective university which is not necessarily the most responsive to the varied needs of the communities where these institutions are located.

Most well-known rankings tend to equate institutional quality with research productivity, which is measured either by the number and impact of their publications in peer reviewed journals, or the selectivity on their admission processes. Of course, such a proxy of quality downgrades institutions that place greater emphasis on teaching and prolongs the "publish or perish" principle. In pursuing better position in the rankings, most probably internal and external funding may tend to favor academic programs or research units that are more inclined to get involved in the dynamics of researching and publishing. Finally, it diminishes the role of other important functions of tertiary education institutions such as teaching and public service. Another dimension of rankings intends to measure reputation by gathering opinions from employers, field experts and/or alumni. Quite expectedly, people tend to favor certain institutions regardless of the quality of their academic programs just because the fame or recognition that precedes them. As such, other institutions and programs that may not have a famous name, but are providing meaningful contributions to the society by producing the graduates required for their local and regional economy, fall by the wayside. Global university rankings have cemented the notion of a world university competition or market capable of being arranged in a single league table for comparative purposes and given a powerful impetus to international and international competitive pressures in the sector. Global comparisons are possible only in relation to one model of institution: that of the comprehensive research-intensive university. This model of $\mathrm{HEI}$ is the 
only one sufficiently widespread throughout the world to lend itself to the formation of a single competition, though there is nevertheless significant variation in the size and scope of leading research universities, which range from small establishments focused on graduate education.

\section{Question n-6- In comparison with other Spanish universities, the level of attractiveness of the web page of your chosen university is:}

According to results, it can be concluded that $46.2 \%$ of participants responded that attractiveness of the webpage of their chosen university was a factor of high level of importance to choose a university. It is a significant percentage of responses that shows us the attractiveness of university webpage affects the student's selection. The results also show that $48.1 \%$ of the participants still believed that the attractiveness of university webpage has got a middle level in their perception and it shows that totally $94.3 \%$ of total respondents were agreed that university webpage design and attentiveness affects their selection process.

TABLE 25. WEB PAGE DESIGN AND ATTRACTIVENESS OF RANKINGS ON STUDENT'S SELECTION BASED ON GENDER AND STUDENT'S TYPES

\begin{tabular}{|c|c|c|c|c|}
\hline Question number 6 & High & Middle & Low & None \\
\hline Web page design and attractiveness of rankings on student's selection & $46.2 \%$ & $48.1 \%$ & $5.7 \%$ & 0.00 \\
\hline Importance level of web page design based on gender type: Male & $51 \%$ & $40 \%$ & $9 \%$ & 0.00 \\
\hline Importance level of web page design based on gender type: Female & $49 \%$ & $39 \%$ & $12 \%$ & 0.00 \\
\hline Importance level of web page design based on student's types: PhD & $60 \%$ & $29 \%$ & $11 \%$ & 0.00 \\
\hline Importance level of web page design based on student's types: Master & $55 \%$ & $32 \%$ & $13 \%$ & 0.00 \\
\hline
\end{tabular}

Considering the results given in the table 25 , it is considerable that $51 \%$ of respondents which were male they regarded the high importance level of web page design and attractiveness of rankings on student's selection and the $40 \%$ considered that the web page design and attractiveness of rankings on student's selection as middle level of importance which in comparison with the female respondent is notably higher, but in the other hand the female respondents they considered that highest importance level of the web page design and 
attractiveness of rankings on student's selection as $49 \%$ and for middle level of importance 39\% and only $12 \%$ considered that rankings importance as a low level of importance, although in the other side the male respondents $9 \%$ they believed that the web rankings notifications on university webpage has got a low level of importance. It can be considered that the male respondents believed that the web ranking notifications on university webpage have got the highest influence on the student's choice rather than the female student. The implicit ranking of institutional prestige is closely associated with entry scores. But students are not a homogeneous group; while ability, ambition and socioeconomic status influence choice, most students do not possess perfect information about the stream of costs and benefits of attending a particular institution rather than another. Undergraduate students usually attend a local university using a combination of local intelligence from peers and family, local rankings, college guides or entry scores, depending upon family or financial circumstances and/or availability of institutional or subject choice. Internationally mobile undergraduate students are a more varied cohort, choosing to study abroad because of the absence of choice or opportunity at home or to enhance their educational experience as part of an exchange program. Increasing participation rates, higher tuition costs and value for money concerns have helped transform decision making into a more complex process for students. At the same time, the rise of the internet and new forms of communication has revolutionized access to information, stimulating growth in publications marketed under the generic title of university guide.

The other considerable issue is that the PhD students they considered the $60 \%$ high level of importance for the web page design and attractiveness of rankings on student's selection, which in comparison for the master students 55\% they believed the high level of importance on the web page design and attractiveness of rankings on student's selection and totally $45 \%$ of the master students they considered the low level and middle level of importance for web page design and attractiveness of rankings on student's selection. By regarding these percentages, it can be considered that the web page design and attractiveness of rankings on student's selection is highly regarded by the PhD students than the master students which shows that the web page design really attracted more PhD students than the master students. National accreditation or 
quality agencies can set a framework for understanding higher education quality, in others national and/or global rankings dominate while in others student mobility within the country or to study abroad can be significant. The widespread availability, accessibility and publicity given to electronic media and rankings have had a big influence on students and student choice. Regarding the results, it can be concluded that only $5.7 \%$ the respondents believed that attractiveness of university webpage is not so important in their selection process and has got the low level of importance. Although the impact of ranking on institutions is a widely-debated topic, the empirical research in this area is relatively limited. A few investigations are frequently cited, but they are exclusively based on data from other countries, particularly the United States. It has not traced any scientific investigation concerning the way in which ranking affects Swedish higher education institutions. As regards the research that is available, it appears to be unanimously considered that ranking does affect the institutions in one way or another. On the other hand, there are differences of opinion about the extent of the impact of ranking, or what effects are actually involved. As a result of rankings, the institutions concerned had a vested interest in recruiting students who were regarded as an asset in terms of maintaining or improving the institution's ranking in other words students who were high achievers. Conversely, such institutions were less interested in recruiting students from low income groups or from ethnic minorities. Certain studies indicate that the ranking of universities has a considerable and predominantly negative impact on the behavior of higher education institutions. The American higher education institutions often employ more or less honorable methods to improve the ratings, in particular in the U.S. News and World Report's ranking. This may involve, for example, reducing the admissions ratio at the institution concerned, or manipulating information in another study.

\section{Question no 7- Comparing with other Spanish universities, the design of the webpage of your current university is:}

Regarding the result, the design of university webpage has got $48.8 \%$ of middle level of importance in the mind of participants and in the other hand $46.9 \%$ of participants believed that 
the design of their current university has got the high level of importance and played an important role in their selection. That reputational characteristic, such as rankings, influence student choice in explicit and implicit ways has often been explained as being symptomatic of a particular culture. However, this practice is both widespread and growing; academic reputation is now seen to be the most relevant student choice factor. Given the importance of the international market, the university will be spending more time and money on marketing overseas, especially aimed at postgraduate students. They will be sending teams to the various student recruitment fairs in a way which they have not done before. Given the mounting evidence that rankings can influence student choice, it's not surprising that rankings are an important ingredient of this strategy.

TABLE 26. THE WEB DESIGN OF THE CURRENT UNIVERSITY OF STUDENTS BASED ON GENDER AND STUDENT'S TYPES

\begin{tabular}{|l|l|l|l|l|}
\hline \multicolumn{1}{|c|}{ Question number 7 } & High & Middle & Low & None \\
\hline The web design of the current university of students & $46.9 \%$ & $48.8 \%$ & $4.3 \%$ & 0.00 \\
\hline Importance level of web page design based on gender type: Male & $53 \%$ & $37 \%$ & $9 \%$ & 0.00 \\
\hline Importance level of web page design based on gender type: Female & $50 \%$ & $38 \%$ & $12 \%$ & 0.00 \\
\hline Importance level of web page design based on student's types: PhD & $62 \%$ & $27 \%$ & $11 \%$ & 0.00 \\
\hline Importance level of web page design based on student's types: Master & $61 \%$ & $29 \%$ & $10 \%$ & 0.00 \\
\hline
\end{tabular}

Considering the results given in the table 26 , it is considerable that $53 \%$ of respondents which were male they regarded the high importance level of web page design and attractiveness of rankings on student's selection and 37\% considered that the web page design and attractiveness of rankings on student's selection as middle level of importance which in comparison with the female respondent is notably higher, but in the other hand the female respondents they considered that highest importance level of the web page design of current student's selection as $50 \%$ and for middle level of importance $38 \%$ and only $12 \%$ considered that rankings importance as a low level of importance, although in the other side the male respondents $9 \%$ they believed that the web rankings notifications on university webpage design has got a low level of importance in their mind. It can be considered that the male respondents believed that 
the web rankings notifications on university webpage design have got the highest influence on the student's choice selection rather than the female student.

The other considerable issue is that the PhD students they considered the $62 \%$ high level of importance for the web page design and attractiveness of rankings on student's selection, which in comparison for the master students $61 \%$ they believed the high level of importance on the web page design and attractiveness of rankings on student's selection and totally $39 \%$ of the master students they considered the low level and middle level of importance for web page design and rankings on student's current university web page. By regarding these percentages, it can be considered that the web page design and attractiveness of rankings notification on student's selection is highly regarded by the PhD students than the master students which shows that the web page design really attracted more PhD students than the master students. Accordingly, universities in all parts of the world have been adjusting admissions policies to enhance the selectivity of their student entry cohort. This is because many rankings both national and global use student entry data as a proxy for student achievement on the basic assumption that a roughly similar range of performance can be expected throughout their higher education career. So, by regarding these items mentioned above we can conclude that why universities pay more attention on their webpage design than before. Results, also shows only $4.3 \%$ of respondents believed that design of their current universities has got the low level of importance on their selection process and $0.0 \%$ shows there were no body that believed the design of webpage has no importance level. Take a look at some universities websites and you can start to get the feeling that you're seeing some similarities. This is definitely yet another very specific but very large group of websites that seem to have all come together. With a few exceptions, most of the sites following the same structure in around the world. They almost all cram tons of information into a small space with very little effective organization. Many of them contain an overall aesthetic ripped from cutting edge web design. And for some reason, quite a few of them have decided to go with awkwardly narrow page widths as if we're all cruising around on super low resolution monitors. Universities represent some of the highest concentrations of talented and intelligent individuals anywhere on the planet. These are institutions built around people literally engaging in lifelong education. They 
create amazing inventions, cure diseases, and move civilization forward in countless ways. There is a bit of insight into how major universities go about creating websites, and in my experience the major problem is the same that leads to poorest corporate design. Two heads may be better than one, but ten to twenty heads gets you an ugly website. As aesthetic decisions become subject to bureaucracy, inner office politics and groupthink, the quality of the finished product decreases exponentially. It can be guaranteed that if you let a single talented web design student take a stab at redesigning his university homepage, he/she could easily come up with something more attractive and more effective than the building full of people the university pays to oversee the site.

Question no 8-In comparison with other Spanish universities, the easiness level of navigation of the webpage of your chosen university is:

Regarding the results $53.2 \%$ of participants they considered that the easiness level of navigation of the webpage of their chosen university had high level of importance and it could be one of reasons that they have chosen their current university, because when you can access the information which you are looking for, then reasonably you will be staying on that page and there is no need to change your webpage. The other group of participants they regarded $40.7 \%$ the level of the navigation easiness regarding their current university which shows that totally $93.9 \%$ of the total participants they have agreed that easiness of navigation is a very important factor in their selection process. But students are not a homogeneous group; while ability, ambition and socioeconomic status influence choice, most "students do not possess perfect information about the stream of costs and benefits" of attending a particular institution rather than another. 
TABLE 27. THE EASINESS LEVEL OF NAVIGATION OF YOUR SELECTED UNIVERSITY WEBPAGE BASED ON GENDER AND STUDENT'S TYPES

\begin{tabular}{|l|l|l|l|l|}
\hline \multicolumn{1}{|c|}{ Question number 8} & High & Middle & Low & None \\
\hline The easiness level of navigation of your selected university web page & $53.2 \%$ & $40.7 \%$ & $6 \%$ & 0.00 \\
\hline Importance level of web easiness of navigation based on gender type: Male & $53 \%$ & $37 \%$ & $9 \%$ & 0.00 \\
\hline Importance level of web easiness of navigation based on gender type: Female & $50 \%$ & $38 \%$ & $12 \%$ & 0.00 \\
\hline Importance level of web easiness of navigation based on student's types: PhD & $62 \%$ & $27 \%$ & $11 \%$ & 0.00 \\
\hline Importance level of web easiness of navigation based on student's types: Master & $61 \%$ & $29 \%$ & $10 \%$ & 0.00 \\
\hline
\end{tabular}

Considering the results given in the table 27 , it is considerable that $53 \%$ of respondents which were male they regarded the high importance level of web page easiness of navigation on students' selected university and 37\% considered that the easiness level of navigation of student's selected university as middle level of importance which in comparison with the female respondent is notably higher, but in the other hand the female respondents they considered that highest importance level of web page easiness of navigation on students' selected university as $50 \%$ and for middle level of importance $38 \%$ and only $12 \%$ considered that rankings importance as a low level of importance, although in the other side the male respondents $9 \%$ they believed that the web easiness level of navigation of selected university has got a low level of importance in their mind. It can be considered that the male respondents believed that the easiness level of navigation of selected university has got the highest influence on the student's choice rather than the female student. Increasing participation rates, higher tuition costs and value for money concerns have helped transform decision making into a more complex process for students. At the same time, the rise of the internet and new forms of communication have revolutionized access to information, stimulating growth in publications marketed under the generic title of university guide. Only the $6 \%$ of participants regarded the low level of importance for this item and the $0.0 \%$ of the participant marked the none level of importance in this question which shows that the easiness of navigation plays an important role in university selection of students. Effective university websites can increase conversions, strengthen institutional credibility and brand, improve user satisfaction, and save time and money, should universities care about usability or 
aren't students smart and computer savvy. Well, even though you want high-IQ applicants, prospective undergraduate students haven't received the benefits of a college education yet and often have fairly poor research skills. While they know how to use computers, they are not always great at advanced strategies like query reformulation, and they are often perplexed by insider language filled with terms and concepts that they haven't encountered yet.

The other considerable issue is that the PhD students they considered the $62 \%$ high level of importance for the web page easiness level of navigation, which in comparison for the master students $61 \%$ they believed the high level of importance on the web page easiness of navigation and totally $39 \%$ of the master students they considered the low level and middle level of importance for web page navigation. By regarding these percentages, it can be considered that the web page design and navigation easiness is highly regarded by the PhD students than the master students which shows that the web page design and navigation facility attracted more PhD students than the master students. In any case, it's an empirical fact derived from observing many prospective students using many university sites that these users are often frustrated or thwarted by the frequent usability problems on university sites. The best university websites speak clearly, even to yet to be students, and make it easy for everybody to find what they want. The rest fail.

Question no 9 -Comparing with other Spanish universities, the connectivity level of the web page of your chosen university with Social networks like: Facebook, Twitter, Instagram is:

The connectivity level of the web page of your chosen university with Social networks like :( Facebook, Twitter, Instagram ...) is very crucial issue in current universities webpage and higher education system by the development of technologies. The result indicates that $46.2 \%$ of participants believed that connectivity to social medias it was very important for them to choose their selected and they gave the good level of connectivity to their selected university. 
TABLE 28. THE CONNECTIVITY LEVEL OF WEB PAGE WITH SOCIAL NETWORKS BASED ON GENDER AND STUDENT'S TYPES

\begin{tabular}{|c|c|c|c|c|}
\hline Question number 9 & High & Middle & Low & None \\
\hline The connectivity level of web page with social networks & $46.2 \%$ & $41 \%$ & $8.5 \%$ & $4.3 \%$ \\
\hline Importance of connectivity level of web page based on gender type: Male & $52 \%$ & $39 \%$ & $9 \%$ & 0.00 \\
\hline Importance of connectivity level of web page based on gender type: Female & $50 \%$ & $38 \%$ & $12 \%$ & 0.00 \\
\hline Importance of connectivity level of web page based on student's types: PhD & $52 \%$ & $37 \%$ & $11 \%$ & 0.00 \\
\hline Importance of connectivity level of web page based on student's types: Master & $51 \%$ & $39 \%$ & $10 \%$ & 0.00 \\
\hline
\end{tabular}

Considering the results given in the table 28 , it is considerable that $52 \%$ of respondents which were male they regarded the high importance level for the connectivity level of web page with social networks and 39\% considered that the connectivity level of web page with social networks as middle level of importance which in comparison with the female respondent is notably higher, but in the other hand the female respondents as 50\% they considered the highest importance level of the web page connectivity of web page with social networks and for middle level of importance $38 \%$ and only $12 \%$ considered that connectivity level of web page with social networks as the low level of importance, although in the other side the male respondents $9 \%$ they believed that connectivity level of web page with social networks has got a low level of importance in their mind. It can be considered that the male respondents believed that the connectivity level of web page with social networks has got the highest influence on the student's choice rather than the female student. The university intensification of competition between nations and their universities for a piece of the global marketplace has accelerated the battle for (top) talent. This trend has been reinforced by the strong correlation between higher qualifications and career opportunities/lifestyle and the creation of a single global higher education market which has eased and encouraged international talent mobility. While the boundary between elite and non-elite universities was heretofore known amongst a few people, today, this is no longer the case. In the era of globalization of information, the privileges associated with elite credentials are now widely acknowledged. Yet, people's access to what are called positional goods, such as elite credentials, remains restricted and is determined in accord not with absolute but relative real income, so the 
social networks have been become as one of the most technology that all people around the world are using it during a day or in their free time. Nowadays technology plays the very important role in our routine life. The percentage of $8.5 \%$ of total participants they believed that connectivity of the webpage of their selected university to social media is not a high level but they believed that is sufficient.

The other considerable issue is that the PhD students they considered the $52 \%$ high level of importance for the connectivity level of web page with social networks, which in comparison for the master students $51 \%$ they believed the high level of importance on the connectivity level of web page with social network and totally $49 \%$ of the master students they considered the low level and middle level of importance for connectivity level of web page. By regarding these percentages, it can be considered that the connectivity level of web page with social networks is highly regarded by the PhD students than the master students which shows that the connectivity level of web page with social networks mattered more for PhD students than the master students. The university intensification of competition between nations and their universities for a piece of the global marketplace has accelerated the battle for (top) talent. This trend has been reinforced by the strong correlation between higher qualifications and career opportunities/lifestyle and the creation of a single global higher education market which has eased and encouraged international talent mobility. While the boundary between elite and non-elite universities was heretofore known amongst a few people, today, this is no longer the case. In the era of globalization of information, the privileges associated with elite credentials are now widely acknowledged. Yet, people's access to what are called positional goods, such as elite credentials, remains restricted and is determined in accord not with absolute but relative real income, so the social networks have been become as one of the most technology that all people around the world are using it during a day or in their free time. Nowadays technology plays the very important role in our routine life. The percentage of $8.5 \%$ of total participants they believed that connectivity of the webpage of their selected university to social media is not a high level but they believed that is sufficient. 
The other small part of $4.3 \%$ they chose that their university webpage has got insufficient level of connection to social Medias. It's no surprise that colleges have embraced social media. Today's students have grown up communicating and sharing experiences on social media sites like Facebook and are now helping grow the popularity of newer platforms such as Instagram, Twitter, etc. Using the power of different networks and engaging content, schools are using social media to attract students, interact with current students and stay connected with alumni. When searching for a college or university, students want the world class program, facility and faculty, but they are also looking for a place to fit in and call home. Move over printed booklets, campus visits and overnights; students can now connect with a school's campus life through the power of social media. Universities have taken notice of what students are looking for, and are using social media to share their campus culture with prospective students and their parents. Universities are sharing campus life as it happens, using Instagram photos, YouTube videos, tweets and more. Most contemporary social media giants once started out as informal platforms for networking (Facebook), for exchanging user generated content (YouTube), or for participating in opinionated discussions (Twitter). It is generally assumed that in the new social media space, all users were equal. However, platforms' algorithms measured relevance and importance in terms of popularity rankings, which subsequently formed the quantifiable basis of data driven interactivity wrapped in social rhetoric such as following, trending, or sharing. In this platform, mediated ecosystem, sponsored and professionally generated content soon received a lot more attention than user generated content. Platforms like YouTube and Facebook gradually changed their interfaces to yield business models that were staked in two basic variables: attention and user data. One informal social traffic between users had become fully formalized, automated, and commoditized by platforms owned and exploited by fast growing corporate giants. Although each of these platforms nurses its own proprietary mechanisms, they are staked in the same values or principles: popularity, hierarchical ranking, quick growth, large traffic volumes, fast turnovers, and personalized recommendations. A like is not a retweet, but most algorithms are underpinned by the norms of popularity and fast trending topics. The cultivation of online sociality is increasingly dominated by four major chains of platforms: Google, Apple, Facebook, and Amazon. 
These chains share some operational principles even if they differ on some ideological premises. Some consider social media platforms as alternatives to the old mass media, praising their potential to empower individual users who can contribute their own opinions or content to a media universe that was before pretty much closed to amateurs. Although it should not be underestimated this newly acquired power of the web as a publishing medium for all, it is hard to keep up the tenet that social media are alternatives to mass media. Over the past few years, it has become increasingly obvious that the logics of mass media and social media are intimately intertwined. Not just on the level of platforms mechanics and content (tweets have become the equivalent of sound bites) but also on the level of user dynamics and business models; YouTube, Google now collaborates with many former foes to turn their platform into the gateway to the entertainment universe. Newspapers and television stations are inevitably integrated in the ecosystem of connective media where the mechanisms of data driven user traffic determines who and what gets most attention, hence drawing customers and eyeballs. This new connective media system has reshaped the power relationships between platform owners and users, not only in terms of who may steer information but also who controls the vast amount of user data that rushes through the combined platforms every day. What are the larger political and social concerns behind deceptively simple interfaces and celebrated user convenient tools? Where in 2006 the notion of user power still seemed unproblematic, the relationship between users and owners of social media platforms is now contentious and embattled. In the wake of the growing monopolization of niches (Facebook for social networking, Google for search, Twitter for microblogging) it is important to redefine and reappraise the meaning of social, public, community, and non-profit. The ecosystem of connective media has no separate spaces for the public; it is a nirvana of interoperability, which major players argue for deregulation and which imposes American neoliberal conditions on a global space where boundaries are considered disruptions of user convenience. Common public values, such as independence, trust, or equal opportunities, are ready for reassessment if they need to survive in an environment that is defined by social media logic. 


\section{Question no 10-Comparing to other Spanish universities, the information regarding the tuition fees and study programs available on the university webpage, influenced you when you have chosen the university.}

The results show that university information regarding the tuition fee and study programs available on the university webpage has got the most important level and $53.5 \%$ of participants they have agreed on it. Increasing participation rates, higher tuition costs and value for money concerns have helped transform decision-making into a more complex process for students. At the same time, the rise of the internet and new forms of communication have revolutionized access to information, stimulating growth in publications marketed under the generic title of university guide. College guides emerged to meet the growing demand for information. Undergraduate students usually attend a local university using a combination of local intelligence from peers and family, local rankings, college guides or entry scores, depending upon family or financial circumstances and/or availability of institutional or subject choice.

TABLE 29. THE INFORMATION REGARDING TUITION FEE AND STUDY PROGRAMS ON YOUR SELECTION WEBPAGE BASED ON GENDER AND STUDENT'S TYPES

\begin{tabular}{|c|c|c|c|c|}
\hline Question number 10 & High & Middle & Low & None \\
\hline The information regarding tuition fee and study programs on your selection & $53.5 \%$ & $38.6 \%$ & $7.9 \%$ & 0.00 \\
\hline Importance of web page presentation based on gender type: Male & $62 \%$ & $30 \%$ & $8 \%$ & 0.00 \\
\hline Importance of web page presentation based on gender type: Female & $60 \%$ & $28 \%$ & $12 \%$ & 0.00 \\
\hline Importance of web page presentation based on student's types: PhD & $62 \%$ & $35 \%$ & $3 \%$ & 0.00 \\
\hline Importance of web page presentation based on student's types: Master & $41 \%$ & $49 \%$ & $10 \%$ & 0.00 \\
\hline
\end{tabular}

Considering the results given in the table 29 , it is considerable that $62 \%$ of respondents which were male they regarded the high importance level of the web page web page presentation and $30 \%$ considered that the web page web page presentation as middle level of importance which in comparison with the female respondent is notably higher, but in the other hand the 
female respondents they considered that highest importance level of the web page presentation as $60 \%$ and for middle level of importance $28 \%$ and only $12 \%$ considered that the web page presentation as a low level of importance, although in the other side the male respondents $8 \%$ they believed that the web page presentation has got a low level of importance in their mind. It can be considered that the male respondents believed that the web page presentation and web information regarding tuition fee and study programs on student's selection has got the highest influence on the student's choice rather than the female student. Internationally mobile undergraduate students are a more varied cohort, choosing to study abroad because of the absence of choice or opportunity at home or to enhance their educational experience as part of an exchange programmed. In the latter case, decisions are likely to be made on the basis of institutional partnerships, while in the former; choices are influenced by family or institutional connections, ease of residency and/or future employment and career opportunities. Graduate students are most keenly attuned to the perceived after sale value of their qualifications, and are likely to use rankings to inform their choice, especially if that choice is outside the country. This is especially true for international graduate students, who are a growing and strategically important percentage of student's world Wide.

The other considerable issue is that the PhD students they considered the $62 \%$ high level of importance for the web page presentation and web information regarding tuition fee and study programs on student's selection, which in comparison for the master students $41 \%$ they believed the high level of importance on the web page presentation and web information regarding tuition fee and study programs on student's selection and totally 59\% of the master students they considered the low level and middle level of importance for the web page presentation and web information regarding tuition fee and study programs on student's selection. By regarding these percentages, it can be considered that the web page presentation and web information regarding tuition fee and study programs on student's selection is highly regarded by the PhD students than the master students which shows that the web page presentation and web information regarding tuition fee and study programs mattered more PhD students than the master students. Now a day, students make a great invest in their education and it is important for potential students to have 
access to comprehensive and relevant information about higher education before they choose. As we can see in the results the $38.6 \%$ of participants they have agreed that they have been influenced by information regarding the tuition fee study programs available on the university webpage and totally $91.6 \%$ agreed that these notification and information regarding the tuition fee study programs available on the university webpage influenced their selection and none of the participants agreed that information regarding the tuition fee study programs available on the university webpage has not any influence in their selection process.

Question no 11-The presentation style of virtual tour, campus, library, classes, facilities and university environment in the web page of your chosen university, comparing with other Spanish universities is:

The presentation style of virtual tour, campus, library, classes, facilities and university environment in the web page of the chosen university is various among the other Spanish universities and they have got their own style. The results indicate that $47.6 \%$ of participant believed that presentation style of virtual tour, campus, library, classes, facilities and university environment in the web page of the chosen university, comparing with other Spanish universities has got the $47.6 \%$ of high level of importance. The $41.9 \%$ of participants they believed that presentation style of virtual tour, campus, library, classes, facilities and university environment in the web page of the chosen university, comparing with other Spanish universities and it shows that this information is very important for participants and totally $89.40 \%$ of people they believed with the help of these information they can have better selection. 
TABLE 30. THE PRESENTATION OF VIRTUAL TOUR, CAMPUS, LIBRARY, FACILITIES AND TUITION FEE ON UNIVERSITY SELECTION WEBPAGE BASED ON GENDER AND STUDENT'S TYPES

\begin{tabular}{|c|c|c|c|c|}
\hline Question number 11 & High & Middle & Low & None \\
\hline The presentation of virtual tour, campus, library, facilities and tuition fee on your selection & $47.6 \%$ & $41.9 \%$ & $10 \%$ & $0.5 \%$ \\
\hline Importance of web page presentation based on gender type: Male & $61 \%$ & $31 \%$ & $8 \%$ & 0.00 \\
\hline Importance of web page presentation based on gender type: Female & $62 \%$ & $32 \%$ & $6 \%$ & 0.00 \\
\hline Importance of web page presentation based on student's types: PhD & $58 \%$ & $30 \%$ & $12 \%$ & 0.00 \\
\hline Importance of web page presentation based on student's types: Master & $40 \%$ & $50 \%$ & $10 \%$ & 0.00 \\
\hline
\end{tabular}

Considering the results given in the table 30 , it is considerable that $61 \%$ of respondents which were male they regarded the high importance level of the web page web page presentation regarding virtual tour, library and university facilities and 31\% considered that the web page web page presentation as middle level of importance which in comparison with the female respondent is notably higher, but in the other hand the female respondents they considered that highest importance level of the web page presentation as $62 \%$ and for middle level of importance $32 \%$ and only $6 \%$ considered that the web page presentation as a low level of importance, although in the other side the male respondents $8 \%$ they believed that the web page presentation has got a low level of importance in their mind. It can be considered that the male respondents believed that the web page presentation and web information regarding tuition fee and study programs and virtual tour on student's selection has the highest influence on the student's choice rather than the female student. Global rankings are controversial because they focus primarily on research, which is usually seen to be less relevant for undergraduate students. Nonetheless, in the absence of alternative international comparable information, rankings are now widely used by a variety of stakeholders, including students. In some countries, national accreditation or quality agencies can set a framework for understanding higher education quality, in others national and/or global rankings dominate while in others student mobility within the country or to study abroad can be significant. The widespread availability, accessibility and publicity given to electronic media and rankings have had a big influence on students and student choice. Only $10 \%$ of people they have believed that this information has the low level of importance and $0.50 \%$ thought that 
it is not important at all. In the rush to promote the use of computer mediated technologies for both traditional and distance learning, relatively little research has been conducted about learner feelings of isolation, alienation and frustration. We communicate visually all the time; we do not have to visit an art gallery or read an art/design book to experience visual communication. We use visual communication to navigate and understand the world. Most of us may already know that basic elements work together to form the principles of all visual communication. These basic elements include but are not limited to line, shape, color, volume, texture, tone and proportion. Visual communication has been used since the birth of human civilization: to reveal the mystic, to illustrate the complicated, to explain the complex, and to shed light on the dark. The intention here is not to prove visual communication is more important than language. We are all visual learners, in a sense; studies show that people learn and remember more accurately when information is presented to them visually. Recent research supports the idea that visual communication can be more powerful than verbal communication, suggesting in many instances that people learn and retain information that is presented to them visually much better than that which is only provided verbally. While using visual communication through mainstream and trade media is important in a high quality public relations program, there are more efficient ways to reach your target audience.

The other considerable issue is that the PhD students they considered the $58 \%$ high level of importance for the web page presentation and web information regarding virtual tour, campus, library, facilities and tuition fee and study programs on student's selection, which in comparison for the master students $40 \%$ they believed the high level of importance on the web page presentation and web information regarding tuition fee and study programs on student's selection and totally $60 \%$ of the master students they considered the low level and middle level of importance for the web page presentation and web information regarding tuition fee and study programs on student's selection. By regarding these percentages, it can be considered that the web page presentation and web information regarding tuition fee and study programs on student's selection is highly regarded by the PhD students than the master students which shows that the web page presentation and web information regarding virtual tour, campus, library, 
facilities and tuition fee mattered more PhD students than the master students. More recent technologies such as web logs may provide a wider range of tools for bridging learners' feelings of isolation and some findings indicate that the use of blogs helped prevent feelings of isolation and alienation for distance learner. Public relations work has changed as a result of people using easily accessible online resources and platforms for visual communication. The Internet has made public relations public again, after years of almost exclusive focus on media. Blogs, online video, news releases, and other forms of web content let organizations communicate directly with buyers. Communicating visually online has become relatively easy and popular with the growth of technology. Numerous tools and services are now available on the Web to business owners for promoting their brands and attracting customers. The use of Internet technology has turned business users into active participants that can use words and images to communicate with customers and make their brands more visible to the world. Marketers should be aware of the proper use of visual aids available online. For example, an interactive visual map needs to have properly sized and accurately relevant images to avoid misleading the user. Visual communication has played an important role in evolving universities and colleges into what they are today and to plan for a better future. The major claim of visual communication is one influence of our technological culture. Books are out of date while hypertext is trend setting and in vogue. Students do not go from one page to the next anymore. Rather, they navigate on the Internet and go through hyperlinks. Today, students navigate on the Internet and use hyperlinks for getting information. Not only the form of communication need to be faster, but also the structure of presentation needs to be different to challenge the current body of students.

\section{Question no 12-Comparing with other Spanish universities, the design style of the webpage of your chosen university is:}

According to results it can be concluded $48 \%$ of participants they have responded that the design style of the webpage of the chosen university has got the high level of importance in comparison with the other universities and it made them to choose their current university. It is interesting that $42 \%$ of participants they have considered the design of the webpage as the good 
level of importance and it shows that total $90 \%$ of participants all believed that the webpage design has got the high level of importance in selection process and motivated them to choose their selected university.

TABLE 31. LEVEL OF IMPORTANCE OF THE DESIGN STYLE OF THE WEBPAGE ON YOUR SELECTION BASED ON GENDER AND STUDENT'S TYPES

\begin{tabular}{|c|c|c|c|c|}
\hline Question number 12 & High & Middle & Low & None \\
\hline Level of importance of the design style of the webpage on your selection & $48 \%$ & $42 \%$ & $10 \%$ & 0.00 \\
\hline Importance of design style of the webpage based on gender type: Male & $58 \%$ & $32 \%$ & $8 \%$ & 0.00 \\
\hline Importance of design style of the webpage based on gender type: Female & $49 \%$ & $41 \%$ & $10 \%$ & 0.00 \\
\hline Importance of design style of the webpage based on student's types: PhD & $52 \%$ & $45 \%$ & $3 \%$ & 0.00 \\
\hline Importance of design style of the webpage based on student's types: Master & $41 \%$ & $49 \%$ & $10 \%$ & 0.00 \\
\hline
\end{tabular}

Considering the results given in the table 31 , it is considerable that $58 \%$ of respondents which were male they regarded the high importance level of the web page design style of selected university and $32 \%$ considered that the web page presentation as middle level of importance which in comparison with the female respondent is notably higher, but in the other hand the female respondents they considered that highest importance level of the web page design style of selected university as $49 \%$ and for middle level of importance $41 \%$ and only $10 \%$ considered that the web page presentation as a low level of importance, although in the other side the male respondents $8 \%$ they believed that the web page presentation has got a low level of importance in their mind. It can be considered that the male respondents believed that the web page presentation and design style of selected university has got the highest influence on the student's choice rather than the female student.

The other considerable issue is that the PhD students they considered the $52 \%$ high level of importance for the web page presentation and web information regarding tuition fee and study programs on student's selection, which in comparison for the master students $41 \%$ they believed the high level of importance on the web page presentation design style of selected university on student's selection and totally $59 \%$ of the master students they considered the low level and 
middle level of importance for the web page presentation and web information regarding tuition fee and study programs on student's selection. By regarding these percentages, it can be considered that the web page presentation and web information design style of selected university student's selection is highly regarded by the PhD students than the master students which shows that the web page presentation and design style of selected university mattered more PhD students than the master students. The Students taking professional focused programs are more likely to use rankings in contrast to students on traditional academic programs. International students are especially receptive to rankings. That reputational characteristic, such as rankings, influence student choice in explicit and implicit ways has often been explained as being symptomatic of a particular culture. However, this practice is both widespread and growing; academic reputation is now seen to be the most relevant student choice factor. As the traditional student market declines, relative to nontraditional student groups and as competition for high achieving and internationally mobile students intensifies, universities worldwide have adopted more professional and aggressive approaches to student recruitment. For students, the downside is being attracted to a university because of the largesse of its merit scholarship only to find the university offered more scholarships than it planned to renew the following year. Merit scholarship programs can help universities buy smarter students to enhance their cachet and rise in the rankings.

The other factors, such as institutional performance relative to peers, may be at play; for example, the performance of local and direct competitors may have a great impact depending upon how each institution performs. The intensification of competition between nations and their universities for a piece of the global marketplace has accelerated the battle for top talent. This trend has been reinforced by the strong correlation between higher qualifications and career opportunities/lifestyle and the creation of a single global higher education market which has eased and encouraged international talent mobility. While the boundary between elite and non-elite universities was heretofore known amongst a few people, today, this is no longer. the case. In the era of the globalized information, the privileges associated with elite credentials are now widely acknowledged. Only few percentage of respondents believed that the design of their university 
webpage is sufficient enough and is not something special in comparison with the other Spanish universities and $0.5 \%$ they believed that university webpage of their own selected one is not adequate one.

\subsubsection{TH BLOCK: PERCEPTION OF STUDENTS}

\section{Question no 13-In your view, the influence level of international rankings on student's perception to choose a university.}

According to results the influence level of international rankings on student's perception to choose a university was considered in a high level of importance by $61 \%$ of by participants. In the other hand $34 \%$ of participants they considered the middle importance level of influence level of international rankings on student's perception to choose a university is $34 \%$, which shows that approximately $95 \%$ of the participants all they believed that influence level of international rankings on student's perception to choose a university plays an importance role of their selection and perception. International students are especially receptive to rankings. Overseas students, especially engineering students, were interested in quality rankings.

TABLE 32. THE INFLUENCE OF RANKINGS ON STUDENT'S PERCEPTION TO CHOOSE A UNIVERSITY BASED ON GENDER AND STUDENT'S TYPES

\begin{tabular}{|c|c|c|c|c|}
\hline Question number 13 & High & Middle & Low & None \\
\hline The influence of rankings on student's perception to choose a university & $61 \%$ & $34 \%$ & $5 \%$ & 0.00 \\
\hline Importance of rankings on student's perception based on gender type: Male & $62 \%$ & $30 \%$ & $8 \%$ & 0.00 \\
\hline Importance of rankings on student's perception based on gender type: Female & $60 \%$ & $28 \%$ & $12 \%$ & 0.00 \\
\hline Importance of rankings on student's perception based on student's types: PhD & $62 \%$ & $35 \%$ & $3 \%$ & 0.00 \\
\hline Importance of rankings on student's perception based on student's types: Master & $41 \%$ & $49 \%$ & $10 \%$ & 0.00 \\
\hline
\end{tabular}


Considering the results given in the table 32 , it is considerable that $62 \%$ of respondents which were male they regarded the high importance level of the influence of rankings on student's perception to choose a university and $30 \%$ considered that the influence of rankings on student's perception to choose a university as middle level of importance which in comparison with the female respondent is notably higher, but in the other hand the female respondents they considered that highest importance level of influence of rankings on student's perception to choose a university as $60 \%$ and for middle level of importance $28 \%$ and only $12 \%$ considered that the influence of rankings on student's perception to choose a university as a low level of importance, although in the other side the male respondents $8 \%$ they believed that the influence of rankings on student's perception to choose a university has got a low level of importance in their mind. It can be considered that the male respondents believed that the influence of rankings on student's perception to choose a university has got the highest influence on the student's choice rather than the female student. That reputational characteristic, such as rankings, influence student choice in explicit and implicit ways has often been explained as being symptomatic of a particular culture. However, this practice is both widespread and growing; academic reputation is now seen to be the most relevant student choice factor. Universities in all parts of the world have been adjusting admissions policies to enhance the selectivity of their student entry cohort. This is because many rankings both national and global use student entry data as a proxy for student achievement on the basic assumption that a roughly similar range of performance can be expected throughout their higher education career. Conversely, university entry scores, preparatory examinations or secondary school scores as well as the applicant rejection rates have been shown to affect reputation and prestige as students and their parents assume higher entry requirements or the level of selectivity into a university or onto a program of study is equivalent to better academic quality. As we can see in the results only $5 \%$ of participants they considered the influence level of international rankings on student's perception to choose a university as low level of important and none of the participants they considered that influence level of international rankings on student's perception has got any importance. 
The other considerable issue is that the PhD students they considered the $62 \%$ high level of importance for influence of rankings on student's perception to choose a university, which in comparison for the master students $41 \%$ they believed the high level of importance on the influence of rankings on student's perception to choose a university and totally $59 \%$ of the master students they considered the low level and middle level of importance for the influence of rankings on student's perception to choose a university. By regarding these percentages, it can be considered that the influence of rankings on student's perception to choose a university is highly regarded by the PhD students than the master students which shows that the web page presentation and web information regarding rankings mattered more PhD students than the master students. University rankings are of relatively limited importance for students' choice of higher education institution. Instead, factors such as geographical location, the range of courses offered, study fees and social activities appear to be more important. In some case, the reputation of the higher education institution affects the student's choice to a considerable extent, but this is more likely to be based on information from their immediate environment rather than on rankings. The most important information comes from parents, friends, student counsellors and the institutions themselves.

\section{Question no 14-As a student, at what grade your selection was affected by the rankings position of the university:}

According to the results given in the table below $73 \%$ of participants they considered their selection was affected by the rankings position of the university in a high level which is very interesting. The other group of participants 23\% they have considered that their selection was affected by the rankings position of the university has got a level of middle of importance. Only $2 \%$ of participants they have mentioned that their selection of a university did not affect by the rankings position and also $2 \%$ of participants they have mentioned as well that ranking position affected their selection in a low level. 
TABLE 33. THE GRADE OF YOUR SELECTION BY THE RANKINGS POSITION OF THE UNIVERSITY BASED ON GENDER AND STUDENT'S TYPES

\begin{tabular}{|c|c|c|c|c|}
\hline Question number 14 & High & Middle & Low & None \\
\hline The grade of your selection by the rankings position of the university: & $73 \%$ & $23 \%$ & $2 \%$ & $2 \%$ \\
\hline Importance of rankings on selection based on gender type: Male & $59 \%$ & $31 \%$ & $10 \%$ & 0.00 \\
\hline Importance of rankings on selection based on gender type: Female & $60 \%$ & $28 \%$ & $12 \%$ & 0.00 \\
\hline Importance of rankings on selection based on student's types: PhD & $60 \%$ & $37 \%$ & $3 \%$ & 0.00 \\
\hline Importance of rankings on selection on student's types: Master & $41 \%$ & $49 \%$ & $10 \%$ & 0.00 \\
\hline
\end{tabular}

Considering the results given in the table 33 , it is considerable that $59 \%$ of respondents which were male they regarded the high importance level of the rankings influence and impact on selection process of university and 31\% considered that the affections of rankings on selection process of university which in comparison with the female respondent is notably higher, but in the other hand the female respondents they considered that highest importance level of the perception of rankings on selection process of university as $60 \%$ and for middle level of importance $28 \%$ and only $12 \%$ considered that the influences of rankings on selection process of university, although in the other side the male respondents $10 \%$ they believed that the web page presentation has got a low level of importance in their mind. It can be considered that the male respondents believed that the impact of rankings on selection process of university has got the highest influence on the student's choice rather than the female student. The most important category for prospective students is employability assessed through indicators such as employment rate and university reputation among employers. Some students involved in the project also called for more specific measures, such as the proportion of students employed in roles relevant to their degree, or the employment rate for international students in the local area. Furthermore, there's high demand for comparisons based on the wider student experience, reflected in indicators such as student satisfaction surveys and the diversity of the university community. The rankings notifications and news are viewed by many prospective students as an important way to ensure their experience is as enriching as possible, with opportunities to meet and learn from people of all backgrounds. Students are not a homogeneous group; while ability, 
ambition and socioeconomic status influence choice, most students do not possess perfect information about the stream of costs and benefits of attending a particular institution rather than increasing participation rates, higher tuition costs and value for money concerns have helped transform decision making into a more complex process for students. At the same time, the rise of the internet and new forms of communication have revolutionized access to information, stimulating growth in publications marketed under the generic title of university guide. College guides emerged to meet the growing demand for information.

The other considerable issue is that the PhD students they considered the $60 \%$ high level of importance for the perception of rankings on selection process of university, which in comparison for the master students $41 \%$ they believed the high level of importance on the perception of rankings on selection process of university and totally $59 \%$ of the master students they considered the low level and middle level of importance for the impact of rankings on selection process of. By regarding these percentages, it can be considered that the perception of rankings on selection process of university is highly regarded by the PhD students than the master students which show that the perception of rankings on selection process of university mattered more PhD students than the master students. Student reaction is discernibly different than the latter part of 20th or early years of this century when rankings existed principally; national context is also important. In some countries, national accreditation or quality agencies can set a framework for understanding higher education quality, in others national and/or global rankings dominate while in others student mobility within the country or to study abroad can be significant. The widespread availability, accessibility and publicity given to electronic media and rankings have had a big influence on students and student choice.

\subsubsection{STATISTICAL SUMMARY OF THE QUESTIONNAIRES RESULTS}

University rankings are potentially useful in helping students choose an appropriate university, be it in their home country or abroad. However, fully exploiting this would require rankings to provide better explanations of what indicator scores actually mean. The use of a more 
democratic indicator base for selecting universities would also be helpful, as this would mean that rankings would no longer be limited to the world's top research universities. It is becoming increasingly difficult for universities just to ignore the global rankings. The universities included in the rankings systems, by deciding to submit the data requested by the ranking providers, they are entering into a relationship with them. Highly ranked universities, as already indicated, have to invest in maintaining or improving their position in a highly competitive global environment, and one in which there is also often strong media interest in universities' performances in the rankings. While national or regional opinion will warmly welcome a high position achieved by their university, the media tends to be less understanding if an institution drops down a few places in the rankings. This has led universities to increasingly develop rankings strategies. Global university rankings continue to focus principally on the research function of the university and are still not able to do justice to research carried out in the arts, humanities and the social sciences. Moreover, even bibliometric indicators still have strong biases and flaws. The limitations of rankings remain most apparent in efforts to measure teaching performance. Regarding the results of 558 questionnaires it is understandable that the items as: rankings on current higher education , influences of rankings on international reputation and rankings impact on the university webpage have been marked as high level of importance with the percentage more than $60 \%$ which is a high rate and shows that these items in the mind of respondents have got more importance than other items, and as it shows in the given below table, the rankings play a very significant role on higher education system and can be concluded that ranking is really a manifestation of university education in the terms of education quality and standards (table 34).

TABLE 34. HIGH LEVEL OF IMPORTANCE FOR THE MOST IMPORTANT ITEMS

\begin{tabular}{|l|l|}
\hline \multicolumn{1}{|c|}{ Questions } & High \\
\hline Importance of rankings on current higher education & $62.8 \%$ \\
\hline The international reputation of universities is influenced by rankings positions & $75 \%$ \\
\hline Influence of rankings on the selection of students & $59 \%$ \\
\hline Rankings notification and its impact on the university webpage & $54 \%$ \\
\hline
\end{tabular}


Rankings help all educational institutions to gain a very competitive perspective on their global position. The globalization of the higher education system keeps developing and growing, and in the very close future by the assistance of technology it would be more utile. More than ever, institutions are focusing on their international position and they are trying to attract the best elite potentialities around the world and carve out their competitive advantages by establishing strong international imagine of their universities to optimize their return on investment: by sharing expertise, equipment and financial investment, strategic alliances can be the key to success. Rankings are beginning to impact on public policy making as demonstrated by their influence in the development of immigration policies in some countries, in determining the choice of university partner institutions, or in which cases foreign qualifications are recognized. The attention paid to rankings is also reflected in discussions on university mergers in some countries. One of the considerable issue is that the PhD students they considered the $76 \%$ high level of importance for the rankings of the university, which in comparison for the master students only $24 \%$ they believed that international ranking position has got high level of importance for the university in the current higher education system and totally $68 \%$ of master students they considered the low level and middle level of importance for rankings.

By regarding these percentages, it can be considered that the importance of rankings on current higher education system is regarded more important for the PhD students than the master students and PhD students based on their educational experiences they are more concerned about rankings positions than the master students and it could be concluded that the rankings importance in the higher education is an inevitable fact. The other issue that can be regarded is that the $62 \%$ of respondents which were male they regarded the importance of rankings as the high level of importance which in comparison with the female respondent is notably higher, because the female respondents they considered that importance level of rankings as a $48 \%$ and by regarding these results it can be considered that for male rankings position of a university in the current higher education system plays a very significant role in their selection rather than the female. Regarding the results, it is considerable that $62 \%$ of respondents which were male they regarded the high level of importance for the influences of rankings on international reputation of 
a university which in comparison with the female respondent is notably higher. It can be considered that the male respondents believed that rankings positions have got the highest influence on international reputation of a university rather than the female. In the other hand, the other considerable issue is that the PhD students they considered the $66 \%$ high level of importance for the influence of rankings on international reputation of the university, which in comparison for the master students the $55 \%$ believed that international ranking position affects the university reputation in high level of importance.

By regarding these percentages, it can be considered that the influence of rankings on international reputation of the university is regarded more by the PhD students than the master students. Regarding the results, it is considerable that $79 \%$ of respondents which were male they regarded the high importance level of rankings on the student's university selection which in comparison with the female respondent is notably higher, but in the other hand the female respondents they considered that highest importance level of rankings on their selection as $28 \%$ and by considering these results it can be considered that the male respondents believed that rankings have got the highest influence on the student's choice rather than the female. The other considerable issue is that the PhD students they considered the $66 \%$ high level of importance for the influence of rankings on international reputation of the university and on the university selection process of students, which in comparison for the master students, the high level of importance is $39 \%$ and by regarding these percentages, it can be considered that the influence of rankings on the student's university selection is highly regarded by the PhD students than the master students and PhD students they are more concerned with rankings position of universities. Considering the results, it is considerable that $56 \%$ of respondents which were male they regarded the high importance level of the rankings notifications on the university webpage which in comparison with the female respondent is notably higher, but in the other hand the female respondents they considered that highest importance level of the rankings notifications on university webpage as $38 \%$. It can be considered that the male respondents believed that the web ranking notifications on university webpage have got the highest influence on the student's choice rather than the female. On the other hand, is very a considerable issue that the PhD students they 
considered the $51 \%$ high level of importance for the influence of rankings notifications on the university web page, which in comparison for the master students $45 \%$ they believed that rankings notifications and its impact on the university webpage selection as high level of importance. It can be considered that the influence of rankings notification and its impact on the university webpage is highly regarded by the PhD students than the master students which shows that the rankings notifications really matters more for PhD students than the master students. Considering the results, it is considerable that $51 \%$ of respondents which were male they regarded the high importance level of web page design and attractiveness of rankings on student's selection which in comparison with the female respondent is notably higher but in the other hand the female respondents they considered that highest importance level of the web page design and attractiveness of rankings on student's selection as $49 \%$.

It can be considered that the male respondents believed that the web ranking notifications on university webpage have got the highest influence on the student's choice rather than the female student. The other considerable issue is that the PhD students they considered the 60\% high level of importance for the web page design and attractiveness of rankings on student's selection, which in comparison for the master students 55\%. By regarding these percentages, it can be considered that the web page design and attractiveness of rankings on student's selection is highly regarded by the PhD students than the master students which shows that the web page design really attracted more PhD students than the master students. Considering the results, it is considerable that $52 \%$ of respondents which were male they regarded the high importance level for the connectivity level of web page with social networks which in comparison with the female respondent is notably higher, but in the other hand the female respondents as $50 \%$ they considered the highest importance level of the web page connectivity of web page with social networks. It can be considered that the male respondents believed that the connectivity level of web page with social networks has got the highest influence on the student's choice rather than the female student. The other considerable issue is that the PhD students they considered the $52 \%$ high level of importance for the connectivity level of web page with social networks, which in comparison for the master students $51 \%$ they believed the high level of importance on the 
connectivity level of web page with social network. By regarding these percentages, it can be considered that the connectivity level of web page with social networks is highly regarded by the PhD students than the master students which show that the connectivity level of web page with social networks mattered more PhD students than the master students. Considering the results, it is considerable that $62 \%$ of respondents which were male they regarded the high importance level of the web page web page presentation which in comparison with the female respondent is notably higher, but in the other hand the female respondents they considered that highest importance level of the web page presentation as $60 \%$ and by considering these results It can be considered that the male respondents believed that the web page presentation and web information regarding tuition fee and study programs on student's selection has got the highest influence on the student's choice rather than the female student. The other considerable issue is that the PhD students they considered the 62\% high level of importance for the web page presentation and web information regarding tuition fee and study programs on student's selection, which in comparison for the master students $41 \%$ they believed the high level of importance on the web page presentation and web information regarding tuition fee and study programs on student's selection. By regarding these percentages, it can be considered that the web page presentation and web information regarding tuition fee and study programs on student's selection is highly regarded by the PhD students than the master students.

Considering the results, it is considerable that $62 \%$ of respondents which were male they regarded the high importance level of the influence of rankings on student's perception to choose a university which in comparison with the female respondent is notably higher, but in the other hand the female respondents they considered that highest importance level of influence of rankings on student's perception to choose a university as $60 \%$. It can be considered that the male respondents believed that the influence of rankings on student's perception to choose a university has got the highest influence on the student's choice rather than the female student. The other considerable issue is that the PhD students they considered the $62 \%$ high level of importance for influence of rankings on student's perception to choose a university, which in comparison for the master students $41 \%$ they believed the high level of importance on the influence of rankings on 
student's perception to choose a university By regarding these percentages, it can be considered that the influence of rankings on student's perception to choose a university is highly regarded by the PhD students than the master students which shows that the web page presentation and web information regarding rankings mattered more PhD students than the master students.

These items mostly are relating to the rankings and its effect on university webpage and reputation. By analyzing the results table above, it can be understood that rankings play an essential role on the selection process of student or we can consider that the student's choice process. The other issue that could be noticed that the average level of importance that respondents have been regarded for these items is $36.75 \%$ which is more than the lowest rate of importance. It is very interesting that even the average rate of importance still is higher than the lower rate of importance level. It sends us a message that rankings really matter for all students who have been participated in these questionnaires. Regarding the results table, the lowest level of importance is dedicated to "the connectivity level of web page with social networks" with the rate of $41 \%$ which the lowest rate among the other items. It shows that all the respondents they are not using the social networks in their routine life and although the social networks are inseparable elements of their routine life and in some how they got used to these applications more than anything in their life. Influence of rankings on the selection of students has got the rate of $44 \%$ of importance and the middle rate of importance $51.4 \%$ which it could be considered that rankings has got the remarkable rate of importance with the average rate of $47.85 \%$ which the high rate of importance. The connectivity level of web page with social networks shows the highest rate $4.2 \%$ in the none level of importance among the other items and as the matter of fact it can be regarded that less than one $0.02 \%$ of respondents they believed that this item is not playing very potential role on the selection process of students. Based on the results table it can be recognized that all items related to rankings are rated more than the other items which is very interesting and amazing. It shows that rankings are really an essential item which were came to mind of respondents in the first place. Regarding the results of reputations items and rankings it can lead us to this point that ranking has got a very significant effect of international reputation of a university as it works as a manifestation of university education quality and on the other hand 
Results

reveals this issue that rankings are affecting directly higher education and international reputation of a university. International reputation is not easy to achieve and even though in this decade of technology the reputation can be spread very fast and this can help a university to present its self to all around the world faster and easier than before. The other issue which is very important to consider is that all related items related to rankings and webpage are rated highly more than 60\% of importance. It shows that the rankings attract audiences with any intention of higher education. The other issue that is considerable is that the web design is ranked less than $50 \%$ of importance which it shows that the web design has an importance level lower than rankings notifications and rankings presentation. The information regarding tuition fee and study programs on your selection shows the importance level of $53.5 \%$ which is considerable among the other items. By revising the table in the column of middle level of importance it can be recognized that the web design of universities and level of connectivity to social networks are rated lower than $48 \%$ but more than the other items. 


\section{Chapter 5}

\section{Conclusions and discussions}




\section{CONCLUSION AND DISCUSSION}

The structure of this section follows the objectives of this study and this section presents conclusions achieved through results. Rankings simplify and clarify matters for interested parties outside the higher education sector. As a result, the choice of the education option is important and by analyzing the findings and results of this study, it is noticeable that the rankings play a very important role. According to the results those aforementioned Catalan universities apply ranking publication in their official webpage to compete better between other Catalan and Spanish university. By analyzing the results, it is noticeable that those Catalan universities with the highest rankings positions make advantage of their rankings success to manifest their education quality more than those with low ranking position and those with highest position try to be differentiated in comparison with the others. The ranking also manifest the quality level of education of universities and provides information to the public, the elite students, researchers, etc. Most participants of the questionnaire have been considered rankings as an important factor in choosing their future university. Based on the questionnaires, the reputation derived from league tables is a critical determinant for students (especially for PhD students) to choose their future university where they want to make their future in the best possible way. Based on the results, it is noticeable that rankings are acting as a manifestation of global competition and being used as a policy instrument. The rankings pioneers believe that rankings inflate the academic arms race locking institutions and governments into a continual quest forever increasing resources (Hazelkorn, 2011). In the majority of responses of the questionnaires of this study, the influences of rankings on international reputation and its impact on the university webpage have been marked as high level which shows rankings help all educational institutions to gain an opportunity to compete differently and stronger among other universities.

Based on findings of this study, it is noticeable that university ranking influence the student's selection and based on the results, majority of students regarded the important role for ranking in their university selection process. The results of this study support the answer of the questions posed in the introduction of this study which manifest that the four aforementioned 
Catalan universities use their international rankings positions in their marketing strategies for better competing among other Catalan and Spanish universities. Also, based on the interviews results, it is highly noticeable that all four Catalan universities constructed and designed their official webpage based on their success of international ranking position to manifest and highlight more their success to inform and attract more elite researcher and students. University rankings is an attempt to arrange universities in descending order of merit and the rankings publications attract lots of attention and currently are taken too literally and even too seriously. The results in this study were obtained from four metropolitan Catalan universities with the international rankings position less than 250 in the world and listed on the top Spanish universities. The influence of universities rankings was examined through questionnaires to understand how strongly rankings played a role in the selection of students and the results show that the majority of students and specially PhD students regarded the rankings as the important factor to choose their university. In this study, four international Catalan universities with the highest-ranking position among other Catalan university were selected, which for the next study would be very interesting to analyze and study the rankings positions of the other successful Spanish universities and how effectively rankings positions play a role in their marketing strategy through their website. Based on the interviews with community and marketing staff of aforementioned universities, these Catalan universities are noticeably caring and paying attention to their rankings positions and rankings publications in order to compete stronger among the other Spanish universities to fascinate more international and national elite students and researchers than the other universities. In an ideal world, families and students would have the information needed to make good choices; that is, they would choose institutions that are a good fit, are affordable, and will provide a high-quality education leading to positive outcomes such as a good job, civic engagement, and overall well-being. Of course, every single one of these constructs fit affordability, quality, and educational outcomes is hotly debated and difficult to measure. The existence of rankings in Higher Education is now entirely accepted in the university context. According to Hazelkorn (2009), they are a barometer of international competence. Even if the presence of rankings is embedded in the university culture, their application and typology is not 
to the same degree. The ranking debate will probably continue to become more intense. Perhaps it will also become more consistent than the current discussions. At the moment, the advocates of ranking and its critics are often talking about different things. This study could be extended through all Catalan universities or in the extended range of all Spanish universities which ranked under 250 position in the international rankings, to study how they choose their marketing strategy, how they make advantage of their international position to compete with other Spanish university to attract more elite researchers and students and it could be extended the subject of marketing strategy as well

\subsection{CONCLUSION REGARDING ROLE OF RANKINGS IN HE}

Analysis the results show that the role of rankings is regarded as a highly important level by most of the participants and it is noticeable that the majority of respondents who specially were PhD students considered high level of importance for rankings and a few percentage of respondents regarded low level of importance for rankings that it shows the important role of rankings in the university selection of students. Rankings affect their selection and perception. Many people, however, consider that it is difficult to obtain satisfactory information about the actual differences in quality between different higher education programs and institutions but currently by the help of rankings notifications and publications it is facilitated extremely. Rankings provide relatively simple and direct information about the quality of higher education. Rankings are one way of enabling higher education institutions and their operations to make them known an efficient and cheap method, as claimed in the responses of participants. There is also a demand and need for information about the quality of various education programs and institutions outside the higher education sector. This maybe a question of potential employers who need information about which programs or institutions provide education and training for people the employer wishes to recruit. According to the results and the interviews, it could be concluded that currently the rankings play a very significant role for universities all around the world and specially for those four aforementioned Catalan universities therefore, the competition between them, somehow is carried on by the means of international rankings positions. Based on the questionnaires 
respondents believed that the reputation derived from league tables is a critical determinant for applicants. This includes embedding rankings in target agreements with faculties, establishing a new section to monitor rankings, providing more scholarships and staff appointments and ensuring senior staff are well briefed on the significance of improving performance. Rankings also influence national and international partnerships and collaborations. Leaders say they consider a potential partner's rank prior to entering into discussion about research and academic programmes. In addition, rankings influence the willingness of others to partner with them or support their membership of academic/professional associations. Not surprisingly, higher education leaders try to influence critical input indicators, e.g. student selectivity or devote resources to activities which may not directly enhance educational quality. Rankings are a manifestation of global competition and are used as a policy instrument. Rankings are propelling a growing gap between elite and mass higher education with greater institutional stratification and research concentration and those institutions which do not meet the criteria or do not have brand recognition will effectively be devalued. According to the results, the influences of rankings on international reputation and impact of rankings on the university webpage have been marked and regarded in questionnaires as high level of importance with the high percentage which shows rankings help all educational institutions to gain a potential opportunity to compete stronger among other universities. The globalization of the higher education system keeps developing and growing, and in the very close future by the assistance of technology it would be more utile. More than ever, institutions are focusing on their international position and they are trying to attract the best elite potentialities around the world and carve out their competitive advantages by establishing strong international imagine of their universities to optimize their return on investment: by sharing expertise, equipment and financial investment, strategic alliances can be the key to success. 


\subsection{CONCLUSION REGARDING ADVANTAGE OF CATALAN UNIVERSITIES}

\section{FROM RANKINGS}

According to the results, those aforementioned Catalan universities apply ranking publications and notifications in their official webpage to compete better between other Catalan and Spanish university. By analyzing the results, it is noticeable that those Catalan universities with the highest rankings positions make advantage of their rankings success to manifest their education quality more than those with low ranking position and those with highest position try to be differentiated in comparison with the others. The ranking also manifest the quality level of education of universities and provides information to the public, the elite students, researchers, etc. Most participants of the questionnaire have been considered rankings as an important factor in choosing their future university. Based on the questionnaires, the reputation derived from league tables is a critical determinant for students (especially for PhD students) to choose their future university where they want to make their future in the best possible way. Based on the results, it is noticeable that rankings are acting as a manifestation of global competition and being used as a policy instrument. The rankings pioneers believe that rankings reflect the academic quality of the institutions and the continual quest of governments for increasing resources (Hazelkorn, 2011). In the majority of responses of the questionnaires of this study, the influences of rankings on international reputation and its impact on the university webpage have been marked as high level which shows rankings help all educational institutions to gain an opportunity to compete differently and stronger among other universities. Highly ranked universities, as already indicated, have to invest in maintaining or improving their position in a highly competitive global environment, and one in which there is also often strong media interest in universities performances in the rankings. This has led universities to increasingly develop rankings strategies. University leaders and administrators are gaining experience by working with rankings. From this brief review of current developments, initiatives and research it can be concluded that rankings influence many areas crucial to the performance of higher education. They can be of assistance in such areas as strategic positioning and planning, staffing and organization, quality assurance, 
resource allocation, marketing and fundraising, admissions and financial aid, student and academic mobility. It is very true that the domains of activities performed by higher education institutions that are then reflected in rankings are directly related to quality and performance (as well as excellence and reputation). In the world of today, it is growing difficult for leaders of higher education institutions to contest external assessment using a shield of exceptionality for each study program or institution. In such a context, 'quality' and 'prestige' become important distinctions in brand battles and one of the key elements in a competition for scarce resources and talents. It is not surprising, then, that, in the present education world characterized by increased global competition for students, the number of rankings has grown as governments and the public at large are ever more preoccupied with the relative performance of education institutions and with getting the best perceived value as consumers of education. Based on the interviews with experts and staff universities it revealed that all mentioned Catalan universities are highly caring about their international rankings potions and their marketing strategies are in line and built fundamentally on their rankings positions and they reflect their rankings position highly through their website. The manifestation of their success of rankings is a very systematic process and all mentioned universities have got the main page as mother page to gather all notifications and news to filter and revise before publishing on the official webpage on the university. There are a team consist of experts of marketing, webpage designer, communication and promotion to revise and check and validate all the contents of webpage for competing better among the other universities. After confirming the contents by the communication department, the rector of the university will affirm and approve the contents to be published. It is a very significant process that all universities passing through before publishing their notifications and news regarding the rankings in their official webpage. According to the webpage analysis, the UAB has got the better presentation of rankings notifications on the official website and applied the rankings notifications as a higher level than the others and the other three universities applied their rankings notification not as high as the UAB. Based on the comments of the interviewee, the marketing strategy of any university is very different by the others to attract elite researchers and students. 


\subsection{CONCLUSION REGARDING MARKETING STRATEGY OG CATALN}

\section{UNIVERSITIES}

Regarding the interviews and results, could be noticed that the marketing strategy of aforementioned universities are influenced highly by the rankings publications and their official webpages designed in order to present and manifest their rankings notifications and news in a special way. It can be said that rankings were used as a differentiated feature of marketing technique to enable those Catalan universities with highest ranking position to highlight their success in versus those universities with low ranking position. The globalization of the higher education system keeps developing and growing, and in the very close future by the assistance of technology, it would be more utile (Hazelkorn, 2011). Also, based on interviews, it is noticeable that university webpages are being constructed and designed highly by the impact of the ranking position to present more their education quality among the other universities. More than ever, institutions are focusing on their international position and they are trying to attract the best elite potentialities around the world and carve out their competitive advantages by establishing strong international imagine of their universities to optimize their return on investment, by sharing expertise, equipment and financial investment, strategic alliances can be the key to success. Also, regarding the results, it can be considered that the importance of rankings on current higher education system, is regarded more important for the PhD students than the master students and the student's perception is highly influenced by rankings notifications. The PhD students based on their educational experiences they are more concerned about the rankings positions than the master students for their future educational carrier. Considering the results, it the male respondents believed the web ranking notifications on university webpage have got the highest influence on the student's choice rather than the female student and the web page design and attractiveness of rankings notifications on student's selection is highly marked by the PhD students than the master students which shows that the web page design really attracted more PhD students than the master students and as discussed already the web design is one of the most important aspect of marketing in the current higher education. Considering the results, it can be 
considered that the male respondents believed that the connectivity level of web page with social networks has got the highest influence on the student's choice rather than the female student and the connectivity level of web page with social networks is highly regarded by the PhD students more than the master students which show that the connectivity level of web page with social networks mattered more for the PhD students than the master students. The other issue which can be concluded is that the male respondents believed that the web page presentation and web information such as tuition fee and study programs has got the highest influence on the student's choice selection rather than the female student and the web page presentation and information regarding tuition fee and study programs on student's selection is highly regarded more by the PhD students than the master students. The mentioned items so far show, that marketing strategy and its important aspects are highly being regarded in all mentioned Catalan universities, which this shows the importance of marketing in the current higher education and how universities make advantage of their rankings positions.

\subsection{CONCLUSION REGARDING THE STUDENT PERCEPTION}

Considering the results, it can be considered that the male respondents believed the web ranking notifications on university webpage have got the highest influence on the student's choice and perception rather than the female student and the web page design and attractiveness of rankings notifications on student's selection is highly marked by the PhD students than the master students which shows that the web page design really attracted more PhD students than the master students. Also, it can be considered that the male respondents believed that the connectivity level of web page with social networks has got the highest influence on the student's choice rather than the female student and the connectivity level of web page with social networks is highly regarded by the PhD students more than the master students which show that the connectivity level of web page with social networks mattered more for the PhD students than the master students. Also, it can be concluded that the male respondents believed that the web page presentation and web information has got the highest influence on the student's choice selection rather than the female student and the web page presentation and study programs on student's 
selection is highly regarded more by the PhD students than the master students. It can be considered that the male respondents believed that the influence of rankings on student's perception to choose a university has got the highest influence for male students rather than the female student, and it can be considered that the influence of rankings on student's perception is highly regarded by the PhD students than the master students which shows that the web page presentation and web information regarding rankings mattered more PhD students than the master students.

Highly ranked universities, as already indicated, have to invest in maintaining or improving their position in a highly competitive global environment, and one in which there is also often strong media interest in universities performances in the rankings. This has led universities to increasingly develop rankings strategies. University leaders and administrators are gaining experience by working with rankings. Universities gain from establishing an institutional policy on communicating with ranking providers. From this brief review of current developments, initiatives and research it can be concluded that rankings influence many areas crucial to the performance of higher education. They can be of assistance in such areas as strategic positioning and planning, staffing and organization, quality assurance, resource allocation, marketing and fundraising, admissions and financial aid, student and academic mobility. It is very true that the domains of activities performed by higher education institutions that are then reflected in rankings are directly related to quality and performance (as well as excellence and reputation). In the world of today, it is growing difficult for leaders of higher education institutions to contest external assessment using a shield of exceptionality for each study program or institution. The other issue that can be regarded is that for male student, rankings position of a university in the current higher education system plays a very significant role in their selection rather than the female. It is noticeable that, the male respondents believed that rankings positions have got the highest influence on international reputation of a university rather than the female. All mentioned issues so far, manifest that rankings are important and valued highly by respondents in the very first step and shows that the student's perception is highly influenced by the rankings position. The importance of the international reputation of the university and rankings notifications chosen by respondents, 
lead us to this point that ranking has got a very significant effect on international reputation of a university, as it works like a manifestation of university education quality and on the other hand reveals this issue that rankings are affecting directly higher education and international reputation of a university. International reputation is not easy to achieve and even though in this decade of technology the reputation can be spread very fast and this can help a university to present its self

to all around the world faster and easier than before. Highly ranked universities, as already indicated, have to invest in maintaining or improving their position in a highly competitive global environment, and one in which there is also often strong media interest in universities performances in the rankings. While national or regional opinion will warmly welcome a high position achieved by their university, the media tends to be less understanding if an institution drops down a few places in the rankings. This has led universities to develop increasingly their rankings strategies. University leaders and administrators are gaining experience by working with rankings. Universities gain from establishing an institutional policy on communicating with ranking providers.

\subsection{LIMITATION OF THIS STUDY}

The most important problem, which occurred during this study was the interview with the responsible of communication department of UPC, who could not participate in the interview, due to the policy of their university. They did not accept to make it according their confidential privacy. Having interview with more persons could be very useful and utile for this study for gathering more information regarding the webpages design, marketing strategy of the university through the webpage and the contents regarding the rankings publications. More interview with universities staffs could highly assist this study in order to know more about the marketing strategies of the aforementioned universities and to see how they built their webpages based on their ranking position. The other issue was the questionnaires, which was very difficult to get more participants and responses from them, according to the factors as lack of cognition of the subject, 
confidential issue and proper time of participants, finally 558 responses could be collected out of $\mathrm{PhD}$, and master students of four mentioned Catalan universities. It could be better, if we could have more than 1000 responses, but due to time limitation and mentioned issues, which discussed above; in this study, it was not possible to get more than this number of responses.

\subsection{PROSPECTIVE AND FUTURE RESEARCH LINES}

Based on the finding of this study, rankings now play an important role in shaping the opinions of current and potential students. It is beyond doubt that rankings have become a significant part of the tertiary education landscape, both globally and locally. In this landscape, rankings have risen in importance and proliferated in unimaginable ways. This study would be more completed and accomplished by additional studies about the rankings publications style of other Catalan universities or even all Spanish universities with the highest international ranking position and to study how they choose their marketing style based on the ranking publication and how would be their reaction to the rankings positons every years and in what extent they dedicate special budget to construct and design their webpage to be more distinguished and different than the others. The other future line of research could be, investigating and studying to what extent the publication of universities rankings has changed the priorities of universities? To recognize and understand, to what extent the priorities of universities are influenced and dependent on the university rankings publications. Another aspect, which could be studied, is to see in what areas of knowledge, students are most influenced when choosing university? The PhD students regarding the findings of this study, based on their educational experiences were more concerned about the rankings positions than the master students and male students considered the ranking's role in the current higher education system more significant in their selection rather than the female, which this aspect could be very interested aspect to study, to see what reasons and factors caused this issue. This study was based on four Catalan universities, which could be extended for all Catalan universities and even all Spanish universities to see how they deal with rankings publications and how they make advantage of the rankings publications in their competition with other universities. The other research line could be to see, how these universities combine the 
marketing aspects with the rankings issues to gain more reputation among the other universities all around the world. The other future aspect to study could be, about the universities rankings publications strategies of other European universities versus Spanish universities. Also, it could be interested to study how Catalan universities with highest ranking position precisely deal with rankings publications in their official webpage and how intensively they work on their rankings notifications and publications for better presentation among the other universities, on the other hand what should do the other universities with lowest rankings position to gain more success and approach to the successful universities. Current global crises imperil exactly the kinds of progress higher education has helped to create. Higher education must contribute now like never before. But the sector must get its own house in order and do a better job of conveying its transformative potential. One the most interesting future research could be about, what big challenges must higher education confront over the next five years to use the best of rankings publications? If rankings become the end rather than the means towards better tertiary education, then this should be a matter of concern. An excessive importance given by institutional and government decision-makers on rankings may be both disturbing and alarming. It is evident that rankings do have a value as a reference and as basis for comparison. However, they do not always serve as the best proxy of quality and relevance of tertiary education institutions. It would be naive to assume that rankings will lose their importance in the future. However, while recognizing that they are here to stay, we must be aware of their many limitations, their intended and unintended biases, and their convenience-based usage by institutions and even national governments. 
Chapter 6

\section{References}




\section{REFERENCES}

Altbach, P. G. (2006). The dilemmas of rankings. Journal of Bridge Organization. Retrieved from http://www.ostina.org/content/view/1669/638/

Altbach, P.G. (2012). World university news. The Globalization of University Rankings. Retrieved from http://www.universityworldnews.com/article.php?story=20120717134058780

Baty, P. (2009). New data partner for world university rankings. Times Higher Education. Retrieved from http://www.timeshighereducation.co.uk/story.asp?storycode=408881

Bloom, D. (2005). Raising the pressure of globalization and the need for higher education reform. The Changing Role of Higher Education, 3, 21-41.

Boulton, G. (2010). University rankings diversity excellence and the European initiative. League of European Research Universities (LERU). Retrieved from http://www.leru.org/les/ publications/LERU_AP3_2010_Ranking.pdf

Brinkley, I. (2008). Work foundation organization. Reshaping the Economic Life of Nations by the Knowledge and Its Effects on the Economic Life of the Nations. Retrieved from http://www.workfoundation.com/assets/docs/publications/41_KE_life_of_nations.pdf

Brooks, R. (2005). Measuring university quality. Review of Higher Education, 29(1), 1-21.

Caglar, E., \& Mentes, S. A. (2012). The usability of university websites a study on European university of Lefke. International Journal of Business Information Systems, 9(6), 36-35.

Claridge, N., \& Kwiatkowski, J. (2011). Website analysis and measurement inventory questionnaire. WAMMI. Retrieved form http://www.wammi.com/samples/index.html 
Clarke, M. (2005). Quality assessment lessons from Australia and New Zealand. Higher Education in Europe, 30(2), 183-197.

Clarke, M., (2007). The impact of higher education rankings on student access. Higher Education in Europe, 32, 59-70.

Cheng, Y. (2010). To better measuring social sciences performance review of the ranking indicators. The IREG Observatory Organization. Retrieved from http://www.iregobservatory.org/index.php?option=com_content\&task=view\&id=92\&lte mid=86

Dill, D. \& Soo, M. (2005). Academic quality league tables and public policy across national analysis of university rankings. Higher Education, 49, 495-533.

Doyle, P. (2000). Valuing based marketing's contribution. European Management Journal, 18(3), 233-245.

Federkeil, G. (2008). Rankings and quality assurance in higher education. Higher Education in Europe, 33(3), 219-231. doi:10.1080/03797720802254023

Florian, R.V. (2007). Irreproducibility of the results of the Shanghai academic ranking of world universities. Scientometrics, 72(1), 25-32.

Griffith, A. \& Rask, K. (2007). The Influence of the US news and world report collegiate rankings on the matriculation decision of high-ability students. Economics of Education Review, 26, 244-55.

Hazelkorn, E. (2007). The impact of league tables and ranking systems on higher education decision making. Higher Education Management and Policy,19(2), 87-110.

Hazelkorn, E. (2009). The impact of global rankings on higher education research and the production of knowledge. Education Management and Policy, 19(2), 31-68. 
Hazelkorn, E. (2011). Rankings and the reshaping of higher education. The Battle for World-Class Research and Knowledge,49(1), 51-58.

Hemsley-Brown, J.V. \& Oplatka, I. (2006). Universities in a competitive global marketplace a systematic review of the literature on higher education marketing. International Journal of Public Sector Management, 19(4), 316-338.

Hemsley-Brown, J.V. \& Oplatka, I. (2010). Market orientation in universities and a comparative study of two national higher education systems. International Journal of Educational Management, 24(3), 204-220.

Hemsley-Brown, J.V. (2011). Market heal thyself and the challenges of a free marketing in higher education. Journal of Marketing for Higher Education,21, 115-132.

Huang, M. (2010). Performance ranking of scientist paper for world universities. Ranking HEEACT Education. Retrieved from http:// ranking.heeact.edu.tw/en-us/2010/Page/Background

King, R., Locke, W., et al. (2008). Counting what is measured or measuring what counts. League Tables and Their Impact on Higher Education Institutions in England. Retrieved from http://www.hefce.ac.uk/pubs/hefce/2008/08_14/

Kruzhalinin, V., \& Artjushina, I. (2008). Rankings and quality of education. Journal of Reitor. Retrieved 5 Aug. 2010 from http://reitor.ru/ru/observatory/global/index.php?id19=474

Lalancette, D. (2010). Assessment of higher education learning outcomes. A Ground-Breaking Initiative to Assess Quality in Higher Education on an International Scale. Retrieved 17 Dec. 2010 from http://www.ireg-observatory. org/prezentacje/2010/S2_2_Lalancette.pdf

Liu, N. C. \& Cheng, Y. (2005). The academic ranking of world universities. Higher Education in Europe, 30, 127-136.

Liu, N. C. (2009). The story of academic rankings. International Higher Education, 54, 2-3. 
Marmolejo, F. (2010). The madness of rankings. Chronicle of Higher Education. Retrieved from http://chronicle.com/blogPost/The-Madness-of-Rankings-/27100/

Marginson, S., \& Van Der Wende, M.C. (2007). To rank or to be ranked. The Impact of International and Global Rankings Positions in the Higher Education. Retrieved from http://www.studiekeuzeenranking.leidenuniv.nl/content_docs/paper_marginson_van_de r_wende.pdf

Nielsen, J. (2000). Designing web usability and practice of simplicity. World Higher Education News, 13, 384-397.

Noel- Levitz, (2013). Marketing and student recruitment practices benchmark. Report for FourYear and Two-Year Institutions. Retrieved from www.noellevitz.com/BenchmarkReports

OECD. (2008). Measuring Improvements in Learning Outcomes. Best Practices to Assess the Value Added of Schools. ISBN: 9789264050228.

OECD. (2010). AHELO (assessment of higher education learning outcomes). OECD Project Update. Retrieved from http://www.oecd.org/dataoecd/ 8/26/45919053.pdf

Olds, K. (2010). Governing world university rankers an agenda for much needed reform. Global Highered. Retrieved from http://globalhighered. wordpress.com/2010/09/21/governingworld-university-rankers-an-agenda-for-much-needed-reform/

OECD (2012). Higher education at a glance and the important highlights. The OECD Publishing, 2,32-35. doi: 10.1787/eag_highlights-2012-en

Patterson, K. \& Ellis, A. (2004). Usability and meeting the needs of educational web site users proceedings. World Higher Education News, 10(09),184-197. 
Pratt, S. (2010). Times higher education world university rankings global institutional professional project. IREG Observation. Retrieved from www.ireg-observatory.org/prezentacje/2010/ S4_1_Pratt.pdf

Provan, D. \&Abercromby, K. (2008). University league tables and rankings a critical analysis CHEMS. World Education News, 03,184-197.

Saldak, J., Merisotis, J. \& Liu, N. C. (2008). University rankings seeking prestige, raising visibility and embedding quality. Higher Education in Europe, 33, 195-199.

Salmi, J., \& Saroyan, A. (2007). League tables as policy instruments uses and misuses higher satisfaction management science services. Journal of the Association for Information Systems, 4(5), 206-232.

Salmi, J., \& Saroyan, A. (2007). League tables as policy instruments uses and misuses. Higher Education Management and Policy, 19(2), 31-68.

Salmi, J. (2009). The challenge of world class universities. World Bank. Retrieved from http://siteresources.worldbank.org/EDUCATION/Resources/2782001099079877269/547 664-1099079956815/547670- 1237305262556/WCU.pdf

Salmi, J. (2010). If ranking is the disease or the benchmarking the cure. World Bank. Retrieved from http://siteresources.worldbank.org/EDUCATION/Resources/2782001099079877269/547 664-1099079956815/547670- 1237305262556/WCU.pdf

Shackel, B. (2009). Usability context framework definition design and evaluation. Interacting with Computers, 21(5), 339-346.

Siegel. P. (2009). Helpfulness golden path to web success. Research Methods for Business Student, $12,106-132$. 
Sindhuja, P.N., \& Surajith, G.D. (2009). Impact of the factors influencing website usability on user satisfaction. The IUP Journal of Management Research, 8 (12), 54-66.

Stella, A., \& Woodhouse, D. (2006). Ranking of higher education institutions. AQUA Education. Retrieved from http://www.auqa.edu.au/files/publications/ranking

Steinaker, B. (2003). Transparency and transformation the impact of external quality monitoring in higher education. Quality in Higher Education, 9(2), 151-159.

Stensaker, B. (2007). Branding in higher education exploring an emerging phenomenon EAIR series research. Policy and Practice in Higher Education, 12, 6-13.

Tomas-Folch, M. \& Castro, D. (2015). Trends of higher education rankings. The International Journal of Learning in Higher Education and Rankings, 21,2-12. Retrieved from http://www.thelearner.com,ISSN 2327-7955

Usher, A., \& Savino, M. (2006). A world of difference and global survey of university league tables. Education Policy Journal. Retrieved from http://www.educationalpolicy.org/pdf/world-ofdifference-200602162.pdf

Usher, A. \& Medlow, J. (2009). A global survey of university rankings and league tables. Journal of Higher Strategy. Retrieved from http://higheredstrategy.com/the-times-highereducation-research-rankings/

Usher, A. (2012). The times higher education research rankings. Higher Strategy. Retrieved from http://higheredstrategy.com/the-times-higher-education-research-rankings/

Van Dyke, N. (2007). Self-assessment disparities in university ranking schemes. Higher Education in Europe, 33(3),285-293.

Westerheijden, D.F., Stensaker, B., \& Rosa, M. (2007). Quality assurance in higher education. Website Usability and Content Accessibility of The Top US, 9(2), 151-159. 


\section{ANNEXES}

\subsection{VALIDATION OF WEBPAGE GUIDELINE (1ST PHASE)}

The guideline composed of three main parts as: Techniques indicators based on: page layout, credibility and validity of content, easy access, accuracy, relevance of the content of page, primary navigation avoiding complexity, avoiding of repeating some items many times, update, content features, interactive features, speed of connection, upload of photos or images, any restricted access, compatibility with smart phone and tablets, design , news identifier, cleanness of the web ,adaptability within the universities brand aesthetic, images: quality, size and design of location, links, language, clarity, easy to understand for everyone and use of RWD, use flexible images, fluid layouts and media. Marketing indicators will be focused on: presentation, target group, simplicity and transferring of the marketing message, visibility, and differentiation, informative and related content, presence as eye- catching, header for the site, complementary images, squeeze page, brand presentation, university pride and brand, connectivity with social networks: (Facebook, Twitter, Instagram...), virtual tours, promotion. Ranking indicators as: first page visibility, articles on ISI databases, research output: papers published in nature and science ,international students and the PHD, master international students and talented international ,quality of education: alumni of an institution winning Nobel prizes and fields medals, quality of faculty, per capita performance, international students, award, papers presented in international conferences, alumni: alumni are defined as those who obtain bachelor, master's or doctoral degrees from the institution. The questionnaire was presented based in 3 sections of indicators as already mentioned in a form of evaluation table and was passed to professors of the department of education at UAB and some other university for making evaluation, by considering following aspects for each indicator:

Uniqueness: to realize indicators respect to uniqueness issue, to see that are them uniquely has been applied in the website? 
Relevancy: are suitable indicators in relation to the object of study? Importance: Refers to the priority given to each question in relation to the object of study (from 1 Minimum and 5 Maximum). This study was passed to the professors of the education department for evaluation and 7 out of 13 professors made the evaluation and done it.

TABLE 35-PRESENTS THE UNIQUENESS, RELEVANCY AND IMPORTANCE LEVEL OF TECHNIQUE INDICATORS

\begin{tabular}{|c|c|c|c|c|c|c|c|c|c|}
\hline \multirow{2}{*}{$\begin{array}{l}\text { TECHNIQUES } \\
\text { INDICATORES }\end{array}$} & \multicolumn{2}{|c|}{ Uniqueness } & \multicolumn{2}{|c|}{ Relevancy } & \multicolumn{5}{|c|}{ Importance } \\
\hline & Yes & NO & Yes & No & $20 \%$ & $40 \%$ & $60 \%$ & $80 \%$ & $100 \%$ \\
\hline Page layout & 4 & 2 & 7 & 0 & 0 & 0 & 2 & 2 & 3 \\
\hline Credibility and validity & 5 & 1 & 7 & 0 & 0 & 0 & 1 & 2 & 4 \\
\hline Easy access and use & 4 & 2 & 7 & 0 & 0 & 0 & 1 & 2 & 4 \\
\hline Accuracy & 3 & 3 & 7 & 0 & 0 & 0 & 1 & 4 & 2 \\
\hline Primary navigation & 5 & 1 & 7 & 0 & 0 & 1 & 2 & 2 & 2 \\
\hline Being Update & 6 & 0 & 7 & 0 & 0 & 0 & 0 & 3 & 4 \\
\hline Content features & 4 & 2 & 7 & 0 & 0 & 0 & 1 & 4 & 2 \\
\hline Interactive features & 5 & 1 & 7 & 0 & 0 & 0 & 1 & 4 & 2 \\
\hline Access & 3 & 3 & 7 & 0 & 1 & 0 & 1 & 3 & 2 \\
\hline Compatibility & 6 & 0 & 7 & 0 & 0 & 0 & 1 & 3 & 3 \\
\hline Design & 5 & 1 & 6 & 1 & 0 & 0 & 2 & 3 & 2 \\
\hline News identifier & 6 & 0 & 5 & 2 & 1 & 1 & 0 & 4 & 1 \\
\hline Cleanness of the web & 5 & 1 & 5 & 2 & 0 & 1 & 0 & 3 & 3 \\
\hline Adaptability & 5 & 1 & 6 & 1 & 0 & 1 & 1 & 3 & 2 \\
\hline Images & 5 & 1 & 5 & 2 & 0 & 1 & 0 & 4 & 2 \\
\hline Language & 4 & 2 & 6 & 1 & 0 & 0 & 0 & 4 & 3 \\
\hline Use of RWD & 4 & 2 & 6 & 1 & 0 & 0 & 0 & 4 & 3 \\
\hline
\end{tabular}




\section{Annexes}

TABLE 36-PRESENTS THE UNIQUENESS, RELEVANCY AND IMPORTANCE LEVEL OF RANKING INDICATORS

\begin{tabular}{|c|c|c|c|c|c|c|c|c|c|}
\hline \multirow{2}{*}{$\begin{array}{l}\text { RANKING } \\
\text { INDICATORES }\end{array}$} & \multicolumn{2}{|c|}{ Uniqueness } & \multicolumn{2}{|c|}{ Relevancy } & \multicolumn{5}{|c|}{ Importance } \\
\hline & Yes & NO & Yes & No & $20 \%$ & $40 \%$ & $60 \%$ & $80 \%$ & $100 \%$ \\
\hline First page visibility & 5 & 1 & 7 & 0 & 0 & 0 & 0 & 3 & 3 \\
\hline Research Output & 5 & 1 & 6 & 1 & 0 & 0 & 2 & 2 & 3 \\
\hline International students & 5 & 1 & 7 & 0 & 0 & 0 & 0 & 3 & 3 \\
\hline Quality of Education & 5 & 1 & 7 & 0 & 0 & 0 & 1 & 2 & 3 \\
\hline Per Capita Performance & 5 & 1 & 6 & 1 & 0 & 0 & 0 & 3 & 3 \\
\hline International students & 5 & 1 & 7 & 0 & 0 & 0 & 1 & 3 & 2 \\
\hline Award & 6 & 0 & 7 & 0 & 0 & 1 & 0 & 3 & 2 \\
\hline Papers presented in internationally & 6 & 0 & 6 & 1 & 0 & 0 & 0 & 4 & 2 \\
\hline Alumni & 6 & 0 & 6 & 1 & 0 & 0 & 0 & 2 & 4 \\
\hline
\end{tabular}

TABLE 37-PRESENTS THE UNIQUENESS, RELEVANCY AND IMPORTANCE LEVEL OF MARKETING INDICATORS

\begin{tabular}{|c|c|c|c|c|c|c|c|c|c|}
\hline \multirow{2}{*}{$\begin{array}{l}\text { MARKETING } \\
\text { INDICATORES }\end{array}$} & \multicolumn{2}{|c|}{ Uniqueness } & \multicolumn{2}{|c|}{ Relevancy } & \multicolumn{5}{|c|}{ Importance } \\
\hline & Yes & NO & Yes & No & $20 \%$ & $40 \%$ & $60 \%$ & $80 \%$ & $100 \%$ \\
\hline Presentation & 5 & 1 & 7 & 0 & 0 & 0 & 1 & 4 & 2 \\
\hline Simplicity & 6 & 0 & 6 & 1 & 0 & 0 & 1 & 2 & 4 \\
\hline Visibility & 6 & 0 & 6 & 1 & 0 & 0 & 2 & 2 & 3 \\
\hline
\end{tabular}




\begin{tabular}{|c|c|c|c|c|c|c|c|c|c|}
\hline Differentiation & 6 & 0 & 7 & 0 & 0 & 0 & 0 & 3 & 4 \\
\hline Informative \& Related Content & 5 & 2 & 7 & 0 & 0 & 0 & 1 & 3 & 3 \\
\hline Usability rather than Beauty & 5 & 1 & 7 & 0 & 0 & 0 & 1 & 3 & 3 \\
\hline Eye- catching & 5 & 1 & 7 & 0 & 0 & 0 & 0 & 5 & 2 \\
\hline Header for the site & 6 & 0 & 7 & 0 & 0 & 0 & 0 & 4 & 3 \\
\hline Complementary images & 5 & 1 & 6 & 1 & 0 & 0 & 1 & 3 & 3 \\
\hline Squeeze Page & 6 & 0 & 7 & 0 & 0 & 0 & 1 & 3 & 3 \\
\hline Connectivity with Social networks & 5 & 1 & 7 & 0 & 0 & 0 & 0 & 2 & 5 \\
\hline Virtual Tours & 5 & 1 & 7 & 0 & 0 & 0 & 0 & 4 & 3 \\
\hline Languages & 6 & 0 & 7 & 0 & 0 & 0 & 0 & 4 & 3 \\
\hline Promotion & 5 & 1 & 7 & 0 & 0 & 0 & 0 & 4 & 3 \\
\hline
\end{tabular}

By considering the evaluation tables above, it is easily recognizable the frequency and medium of the variable like "uniqueness" at the first step. It shows that uniqueness plays important role and most of the participant in this questionnaire agreed with this fact and majority marked it as positive one instead of negative. 
Variable I Obs Mean Std. Dev. Min Max

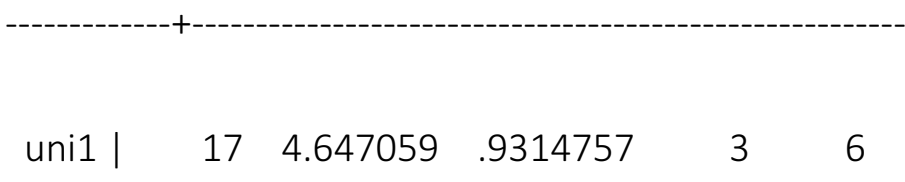

The mean is 4.64 and the minimum value is 3 and the maximum value is 6 . The maximum value for the uniqueness regarded is 6 which is belongs to indicators as: being update, news identifier, compatibility, which means these indicators plays technically an ignorable role in the websites of university and we can consider them as the most significant indicators among the others.

Variable I Obs Mean Std. Dev. Min Max

relyes | $\quad \begin{array}{lllll}17 & 6.411765 & .7952062 & 5 & 7\end{array}$

Regarding relevancy of techniques indicators the mean shows is 6.41 which is very close to the maximum value 7 , and shows that more than $60 \%$ of the techniques indicators are highly related as positive ( yes ) which shows that techniques indicators are one of the essential elements of the website of any universities, and the rest which took the values less than 7 are : Design ,News identifier, Cleanness of the web ,Adaptability, Images, Language, Use of RWD that still can be regarded as positive and they are not ranked as negative indicators .

Variable | Obs Mean Std. Dev. Min Max

$\begin{array}{lllllll}\text { imp100 | } & 17 & 2.588235 & .8702603 & 1 & 4\end{array}$


It is noticeable that; the mean is 2.5 and the maximum value is 4 and the lowest value is 1 . Due to table 9-1 we can conclude that the most important indicators among techniques indicators is "Being update". It is very easy to see that being update play a very important role in any website and especially in the web sites of universities and due to evaluation questionnaires, all the professors marked it with the highest values.

Variable | Obs Mean Std. Dev. Min Max

$\begin{array}{llllll}\text { uni1 | } & 17 & 5.529412 & .5144958 & 5 & 6\end{array}$

We can see again that uniqueness is positively marked by majority of participants and this shows that it significantly assists the website to compete with others. The mean is 5.52 and the maximum value is 6 and the minim value is 5 which shows that the differences between low value and maximum value is not too much and it shows that totally marketing indicators has been regarded as important indicators by participants which really they are. The situation for the relevancy is the same as uniqueness and shows that the relevancy of marketing indicators was approved by participants in the majority of positive. As the mean shows value of 6.76 between maximum value of 7 and minimum of 6, it's easy to conclude that the relevancy of marketing indicators is clearly approved as positive and important indicators.

Variable | Obs Mean Std. Dev. Min Max

$$
\begin{array}{llllll}
\text { relyes | } & 17 & 6.764706 & .4372373 & 6 & 7
\end{array}
$$

By considering the importance level of marketing indicators, it will be concluded that most of them are rated as over $80 \%$ importance level and the maximum value stands as 5 and minimum one as 1 , and the mean 3.17 which shows the good value. The most rated indicators are: Header for the 
site, Complementary images, Squeeze Page, Brand presentation, University pride and brand, Connectivity with Social networks, Virtual Tours, Languages, Promotion. In compare with techniques indicators, marketing indicators are rated as more important which means that marketing significantly influence the website of university and indicators as eye-catching, promotion and multi languages are most important among the others. This shows that universities must pay attention more to marketing indicators as the means of competence.

Variable Obs Mean Std. Dev. Min Max

imp100 | $\quad \begin{array}{lllll}17 & 3.176471 & .7276069 & 2 & 5\end{array}$

\section{Ranking Indicators:}

This table approves the objective of this study which was mainly tried to recognize the role of ranking in the marketing strategy of university. The indicators like: First page visibility, Articles on ISI databases Research Output, International students, Quality of Education, Quality of Faculty, shows more importance rather than others and like marketing indicators shows more positive importance than techniques indicators.

Variable | Obs Mean Std. Dev. Min Max

uni1 | $\quad 11 \quad 5.454545 \quad .522233 \quad 5$


Regarding uniqueness is very clear that uniqueness is rated as a positive element and the means shows the good value as 5.45 while the maximum value is 6 and the minimum is 5 . This value of the mean shows the significance of uniqueness for ranking indicators. By considering the relevancy of the indicators, it will be easily understood over $90 \%$ rated the relevancy as the important segments and less than $5 \%$ rated no for relevancy. The mean is 6.54 which is again good value for maximum value of 7 and minimum of 7 . It signifies that relevancy exists for ranking indicators in the high level.

Variable | Obs Mean Std. Dev. Min Max

$\begin{array}{llllll}\text { relyes | } & 11 & 6.545455 & .522233 & 6 & 7\end{array}$

By regarding the evolution of importance results, it could be concluded that Ranking indicators for attracting elite student and better marketing are very important. The indicators as: the First page visibility, Articles on ISI databases, Research Output, International students, Quality of Education, Quality of Faculty, Per Capita Performance, show more significance level than others. The mean is 2.90 which seems the good value for a maximum value of 4 and minimum value of 2 . It shows that importance of ranking indicators is confirmed as well and we can consider that ranking and marketing indicators are acting complementary in the website of the university.

Variable | Obs Mean Std. Dev. Min Max

imp100 | $\quad \begin{array}{llll}11 & 2.909091 & .700649 \quad 2\end{array}$

Regarding instruments applied in UAB website, the weak point and strong point will be discussed through applied indicators. With referring to techniques indicators applied in UAB after evaluation 
it is recognizable that page layout, all sectors as Main navigation, sub navigation, footer is applied in $U A B$ website in the good way and search bar are well ordered and is not complicated and working very well. Credibility and validity of content, regarding awards and Ranking is authorized in the good level and in the first page being built in a very professional way and in the top parts of the main page there is part which acts like exhibition that shows all notifications of university in the first glance. In the heading of the page you will be encountered with amazing style of pop up and automatically the most important and eye catching notification comes up. Easy access of the website is perfect and servers working properly and very well and the instruments like easy to navigate and clarity and ease of use has been applied in the UAB website as well and you see that they are working very well. Accuracy and relevance of the content of page is regarded as well, although it could be in the higher level and they have been built very ordered. Primary navigation, avoiding complexity and repeated items is regarded in the good level and shows that the department of communication attempted a lot to prepare such a website. Update of the contents and news which is the most important instrument due to evaluation of questionnaires, in the website of UAB has been regarded very well and perfectly, especially in the part of notification which plays a very significant role in marketing strategy of any university. Content features, primary content, secondary content and lower level content are in order and is not confusing. Interactive features, video player, contact form are not very well - designed, but is OK and can be rated as the middle level of proficiency. Speed of connection, Upload of images is super perfect and there is no any restricted access in the UAB website. Compatibility with smart phone and tablets is in the middle level of proficiency because is not specified and characterized especially for smart phone and tablets, it launches as like as PC, but it is easy to open. Appropriate form of design, graphic and colors are synchronized to content and University brand in the good manner due to in fact that UAB is always green even in winter, it was a good strategy to highlight and differentiate $U A B$ brand by this color. $A s \cup A B$ is located in the mountain and center of pure nature which always you can see it in green picture. It was a perfect idea to choose this green as the main theme of $U A B$. 
News identifier, is clarified and cleanness of the web is well- ordered and is not out of order, the contents are not disorderly and irrelevantly located. Images, quality, size and design of links is regarded perfectly. Language section is considered in the good level of performance and is easy to understand for every one especially for international user, because the matter of international student was carefully regarded. Providing the website in 3 languages in a complete way it is not an easy job but in UAB website it is regarded. Use of RWD, use of flexible images, fluid layouts, media and virtual tour is not very far from the best websites and is in the good level. Regarding Marketing instruments which applied in the UAB website we can recognize that Presentation of good news and important notification shared in Real Time and real place and the website follows these hint "first impression, last impression" which easily we can see in the pop up of the UAB. About Target Group, the web page is designed professionally for all type of audiences or better to say that is designed to satisfy any desire by any audiences. Simplicity of the marketing message of the page, is transferring clearly to audiences by the means of a means which being built in the bar aside of the nay page to filter all your needs. Visibility of marketing oriented-features is recognizable easily and it function to attract special target groups and is professionally welldesigned. Differentiation as the most important segments of marketing that makes university different from the others is clearly focused and demonstrated trough the exclusive strategy. Having the campus of living for students, Physical Activity Service - SAF, Healthy and Sustainable Campus, Vila Universitària which is not easy to find in every university and even in Spain and gives the UAB a power for competing strongly and unreachably form the other rivals. Informative and Related Content are clear and relative and perfectly presented in the good manner. Usability rather than Beauty in somehow is regarded with respect to marketing aspect and the contents are useful and utile and not only well designed to attract audiences. Eye- catching of the page and design is eye catching oriented and gives lots of opportunity to any audiences to reach his or her required information. Header for the site is visible enough and very attractive to make the audience to continue the rest of the page. Complementary images, for better transferring the message of university are regarded in the main page but it can be better than this. Squeeze Page, using language that prompts the visitor to provide their contact information for further 
communications is considered perfectly. Brand presentation of university which should be posted as a message in the website is tangible which followed by color concept well enough. University pride and brand and a strong visual identity contributes the university reputation is regarded professionally. Connectivity with Social networks. (Facebook, Twitter, Instagram, Pinterest, and Tumblr) is considered as much as it should be. Virtual Tours as the most important marketing segments to give a primary insight and view to audiences about universities in the sectors as: campus, library, classes, faculties and environment of university is presented perfectly. Regarding Languages, 3 languages in a complete way to attract all local students and international students is focused as much as it should be and every content is available in all languages which is very important. Promotion as the most important and significant instruments which was marked by all evaluators presented as international and local promotion in the web site well enough and recognizably it persuades audiences to continue with the page. Regarding ranking indicators which applied in UAB website, by referring to evaluation it can be concluded that, first page visibility of the ranking is it located in the first page and highlighted well enough to attract the audiences and burnish the success of university and designed very well and inform all ranking notification perfectly .In the other hand articles on ISI databases presented not very strongly but the website tries to manifests how this ranking was gained and these ranking was granted by which agency according to what indicators in a very professional manner. Research Output and Papers published in Nature and Science or even other departments is tangible weakly in the university website. About International students and the PhD and master international students and talented international students which really worth for credibility of university nothing is mentioned in the website about their success, awards, academic life at UAB and their noble prizes and researches. International students are playing very important role to show the academic quality of education and it is acting like the eye-catcher to attract elite students among the world. Regarding quality of education and alumni of an institution winning Nobel prizes and fields medals you can be found practically. Quality of faculty and staff of an institution winning Nobel prizes and fields medals has got the same story and presented weakly. By considering the per capita performance and per capita academic performance of an institution, it manifested not very strongly in the website. 
International students: talented and elite international student especially PHD students and their success is mentioned in the ranking link and right close to ranking indicators in the website, cannot be found easily in the UAB website. As mentioned already, award which indicates the total number of the staff of an institution winning Nobel prizes in physics, chemistry, medicine and economics and fields medals in mathematics or any other filed, it can't be recognized very tangible related to this indicator. Papers presented in international conferences and alumni who obtain bachelor degree and their destiny of future career is demonstrated in the website.

\subsection{PROTOCOL OF INTERVIEW}

\subsubsection{INTRODUCTION}

The development of university rankings has enough tradition in Anglo-Saxon countries and in recent years have proliferated university rankings in Europe and particularly in Spain. Among the rankings of world universities highlights prepared by the Shanghai Jiao Tong University (China), recently updated. This rating ranks the 500 best universities in the world in terms of quality criteria such as the level of students, teachers and schools, research activities, publications, etc. Rankings of universities have become both popular with the public and increasingly important for academic institutions. This study is an analysis study which is a combination of both qualitative and quantitative study to inspect the role of rankings through applied indicators in the official website of 4 metropolitan Catalan universities. This paper principally discusses about the rankings role in the marketing strategy of the 4 Catalan universities and how these universities implement international rankings position through their websites to enhance their marketing strategies in compare with other universities. This investigation tries to recognize the significant role of ranking being used in the website of a university by applying 3 instruments as: guideline analysis of the web page, interviews with university communication and marketing staffs and questionnaires from PhD and master students. 


\subsubsection{RESEARCH QUESTIONS}

This study tries to answer the questions mentioned below which will be the most concentration and the main objective of this study as:

- How do universities use the ranking position in their marketing strategies?

- What are the consequences for 4 metropolitan Catalan universities: UAB, UPC, UB, UPF by highlighting their rankings positions in their marketing strategy through their official website?

This paper analyses the marketing strategy of 4 Catalan universities for better understanding how these universities implemented their international rankings position to reach more advantages and successes among other universities through their official webpages. In the other hand this study tries to verify student's perception regarding the rankings positions of universities and how possibly their selection could be affected by the rankings position. Also, will try to understand the role of official web pages of universities to present the notification regarding the rankings. In this thesis, I would like to apply the semi-structured interviews and opened interviews to have better outcome which fits better my investigation approach. By open interview I would expected to face the new issues and contents from the communication department of any university regarding rankings and official web pages which are unpredictable and will be so useful for the future of my investigation. Interview will be conducted in this research to learn the opinions and experiences of the experts of communications and marketing who are involving and engaging in the process of designing and constructing the official websites of universities. It will be the great

chance to have interviews with related staffs and responsible of university to see how basically and technically the marketing strategy of theses universities got affected by the rankings positions. 


\subsubsection{PROFILE OF THE INTERVIEWEE WILL BE EXPERTS OF THESE FIELD:}

Preferably, I would like to have interview with responsible staffs of communication department and web page section of 4 metropolitan Catalan universities: UAB, UB, UPF y UPC which profile of the respondents of the universities will be as following:

- Ranking

- Marketing

- Techniques of Informatics

- Management

\subsubsection{Guideline of the interview}

This interview will be based on 2 significant related dimensions which are very essential for this investigation as:

- The role of rankings

- Marketing and the webpage of university

As given below you can see the questions of the interviews with staffs of the communication department of Catalan universities:

\section{$\checkmark$ Role of rankings}

1- What is your idea regarding the design and rankings notifications in the web page of selected university?

2- What is your idea about the role of marketing on the design of the web site of your university?

3- What is the role of rankings notifications on the main page of university for attracting the students? 
4 -What is your idea about updating the contents and notifications of the University of the Webpage?

5- What kind of content is included when referring to the rankings notify?

6- In your opinion, in what level do you think the reputation of a university will be affected by rankings position?

\section{$\checkmark$ Marketing aspects}

7 - Do you believe that any special marketing technique or strategy has been used in the web pages of your university?

8 -Do you believe that, the university web design and contents are regarded for any special audience?

9 - Is there any marketing aspects of education like promotions, special programs, free courses or special discount on tuition fee on your website?

10- What is your idea regarding the graphics and design of your university?

11 - In how many languages the web page is presented and all the languages are presented and worked properly in all contents and links?

12 - How does the speed of connection to webpage, opening the photos, videos and totally navigation of the web page is easy or not?

13- Is the web page compatible with smart phone and tablets?

14 Is the web page connected properly to social networks like Facebook, Instagram, Linkedln, twitter, ....? 
6.2.4. DATA OF INTERVIEWED PERSON

In this part, we will have data of the interviewed persons as:

- NAME AND SURNAME:

- AGE:

- GENDER:

- DURATION:

- DATE:

- YEARS OF PROFESIONAL EXPREINCES:

- yEASR OF DEICATION IN THIS POSITION:

. Educational center of interviewed person:

- UNIVERSITY:

- PLACE:

- TYPE OF UNIVERSTY: 


\subsection{INTERVIEWS TRANSCRIPTION}

\subsubsection{UAB INTERVIEW}

\section{Role of ranking}

The new website of UAB looks like to be very different and more professional with more attractiveness and information than the old one. All contents and features are optimized in a perfect way and even in the first glance you can realize it. It shows that an enormous job has been done and all these efforts fulfilled to make it better than the old one. I believed that that this website is one of the most complete website of university among the Spanish universities and because it is presented in 3 complete languages which is not an easy job at all and in somehow the design of the webpage I think is influenced by the rankings but not too much and regarding the rankings notification, I can say rankings has got a short percentage of the total space of our webpage but its presentation is very significant for us and especially for our audiences and based on success of rankings position we designed our web page to present and attract elite researcher or students based on our success among the other Spanish universities. The design of our university web page has been passed through many filters and after then the committee of marketing and communication departments has been decided this new design. I do believe that ranking is playing a very important role in designing and creating our website to better manifest our university to audiences such as: students, parents and researchers who show high level of interest on rankings positions on the universities. Ranking really helps students and other audiences to have more information regarding the selection process. Definitely marketing plays and important role on the design and building the website of the university. We consider marketing aspects on our webpage design for having the very special design and even we use some special complementary videos, like the presentation video to present our university more complete. I think the rankings should be better explained and presented. I mean it should be 
explained what is ranking and what they try to manifest. Now a day's rankings are available for students, parents and the elite researchers.

The rankings and its first impression are very important but in my mind, I think they have not been presented well enough for audience. Sometimes are very complicated and sometimes have been presented very. Furthermore, I believe that rankings or better to say assessment of the performance of universities are not formatted perfectly. I meant it cannot fulfil all issues that students or audiences are looking for. Rankings can be for all the tastes or for all universities. Now you find all indicators of ranking in the website which shows perfectly the success of university in every fields. I believed that There are 3 personas responsible for updating the website and they are always keeping the contents very updated and well - organized and they try to present the news, promotions and notification in the earliest possible time. Totally, I can say they are 300 people who keep the data updated and manage the website in all section. In the page of UAB, all the techniques and segments of marketing is regarded to help the university to have the better presentation. At the time of issuing rankings, we revise and check all the items and positions of university and then we will post or publish this success in the main page of our website and in the social networks as well and for attracting investigators and elite students we will use special indicators in the web page. Rankings and its indicators which have been used through the web pages of university really play a very important role for attracting elite students.

The contents will be based on the official web pages of rankings and the contents which issued on this ranking institute will be adopted and refine for publishing in our website. Rankings of universities help them to make their choice easier and better. For example, larger universities with better ranking position surely can attract more elite students and investigator and ranking. Rankings normally act like manifestation of the university quality. The header of website is acting like vitrine and shows all new notifications and important news by very nice and technological techniques. Every few seconds it pops up with new news and it is very eye catching. The contents will be revised thorough 3 times before publishing by 3 committees and on top by rectorate committee. In my mind and due to my years of experiences I believe that reputation somehow 
can be achieved by rankings. Spanish universities they are not a mostly liked destination for international students around the worlds. In my point of view, the reputation is really related to of the university rankings and its position on the international rankings and could be considered that totally related and highly affects the university reputation and this is an issue that we are studying it through many factors. The reputation of university is engaged with the ranking position. For one side, you have to take care of your position to be better seen by researchers and students. And finally, we are still studying and researching this terms and issues for finding more authentic information.

\section{$\checkmark$ Marketing aspects}

Of course, we have our own marketing strategy but I can't not say that that is very special marketing strategy and I think is very logical that all universities have their own marketing system or strategy like special logo. Spanish system is very based on the budget of ministry of education and based on this budget. The theme of the website looks like such as newspaper and informative rather than marketing theme. In the first page, you can find everything that you desire to reach. In the header, there is a big notification regarding ranking when you click on it heads you to the full page including lots of information about ranking and how it got received and which agency granted it. There is a nice and brilliant banner in the side bar which acts like filter and makes easier the navigation and prevents the loosing of time. In the footer, you can find the best strategy of marketing which shows some marvelous item regarding Physical Activity Service - SAF, Healthy and Sustainable Campus, Vila Universities and lots of facilities for invalid persons which makes UAB very powerful in marketing with the rest of the Spanish universities. Campus and its features make $U A B$ very different with other rivals and it was perfect differentiation strategy. In some how it can be, because as I have explained, there is a mother page with all contents and any department due to their needs will take the required contents and documents for their publishing. The design should be for general audience but also in some parts is designed for its own audience. Now a day, the university has got their line of design and style for differentiate themselves with others. For 
example, the color and the frame of the web page has been designed and oriented for attracting the elite researcher or elite students.

The website of UAB acts as a marketing instrument which presents some eye-catching promotions and offers about education in any level as bachelor, master and PhDs. For reaching your desired program just you need to narrow down your search in less than 2 second and reach to your target. Even there is lots of offers about language learning and summer classes which makes UAB very strong in marketing competition. The very brilliant item which was considered in all pages of UAB is the footer and lower part that makes visitors capable of leaving his or her email for more information in the case if she or he were not satisfied with her/his searches. In this part, you can leave your email and contact details to get all required information in a few times later. The wed page is monitoring by department of communication and they are following some marketing strategy. Of course, in all languages we are trying to present our university facilities and programs to the students all around the world and the web page is the only and the easiest way to present our university to the audience. A great tour guide does, though - and that's your website's job. It presents your business to visitors and welcomes them, showing them around and introducing them to points of interest they should definitely see before they leave. As tour guide, your website has the task of providing visitors with the right guidance to direct them to where they want to go - and to where you want them to go as well.

Is it bad to be pretty? No, I wouldn't go that far. If you can have both a beautiful design and get results, then go for it. If you find yourself having to choose between one or the other though, stick with getting results. Winning design awards may be nice, but it doesn't pay the bills. Yes, graphic elements they are very important to shape a strong web page and for example the color and the graphics design are very important for attracting the audience and the graphics elements always play an important role in the marketing strategy. It is clear that graphic items are not an easy job and needs to pay attention a lot. Ever had a run-in with a graphic designer who promised you a brilliant design but all you got was a big mess? No, you're not an expert, but you know what's good and what's not. You also know when you're being taken advantage of. All you 
wanted was a website that would help you succeed online, and what you got instead wasn't worth the pixels it was painted on. And what's worse is you have to start over. You've lost months of time, burned through thousands of dollars, hurt your business reputation, and gone through the emotional turmoil of it all, and now you have to do the whole thing over again. It's scary, because let's be honest. What if Take Two is just as much of a nightmare? Well, we're not going to let it happen again. Here are some secrets many graphic designers won't tell you, and knowing them can save you a bundle of both time and money.

Among the university website it is not easy to find such a website like ours. As I already mentioned, the base core of the website is updated to all latest technology and version of HTML to serve better. The main core is presented in 3 languages perfectly and all links and contents are working properly. You can find lots of information in all pages for any subject that you desire. We are trying to present all information in three languages and of course will be some differences between 3 languages and the target of audiences any language for. For example, the English part will be presented for international students and researcher and should be definitely in a way to present the required information but, due to the matter of cost the English part has got its own problem and in many parts, it's not well designed or prepared. I mean that all languages in $90 \%$ of the contents are the same but in some technical parts are different. The connection the web page is prefect and really I can claim this issue is one of the faster in the Spain to hipper numerous server that we have prepared for this section. Run a free website speed test from multiple locations around the globe using real browsers and at real consumer connection speeds will show you our performance. You can run simple tests or perform advanced testing including multi-step transactions, video capture, content blocking and much more. Your results will provide rich diagnostic information including resource loading waterfall charts, Page Speed optimization checks and suggestions for improvements. Al the items mentioned above will show you what exactly what we have done for our website. Yes, our website totally is compatible with smart phone based on our new system of technology that we have applied on our webpage. The difference between a mobile compatible website and a mobile optimized website continues to be a source of confusion. According to a recent Google study, 61 per cent of shoppers will leave a 
website if it is not optimized for their mobile device. In other words, the experience of a nonoptimized website can negatively impact a consumer's likeliness to book and overall perception of the brand. Many hoteliers are aware of this consequence but are still struggling to understand what characterizes a mobile optimized hotel website. A mobile compatible website is an HTML based website that doesn't contain Flash. It means that a website is viewable on a Smartphone or Tablet, but it is not optimized for these devices. These websites have been designed for web browsers on PCs with much larger screens and navigation using a mouse. You will notice a few things about these websites when you attempt to browse them on your Smartphone or Tablet you have to scroll left, right, up or down and figure out how the site works, media may load slower, text is tiny so you have to zoom in to read it and the links are small and difficult to click with your fingertip. Sound cumbersome? That's because it is. The web page is perfectly connected to social networks and we have a special links in our web page for connecting to Facebook, twitter, Instagram, linked in .... At the time of issuing rankings, we revise and check all the items and positions of university and then we will post or publish this success in the main page of our website and in the social networks as well and for attracting investigators and elite students we will use special indicators in the web page, we have a special person who is professionally is in charge of social networks and all faculties have got their own account on twitter for example.

\subsubsection{UB INTERVIEW}

\section{$\checkmark$ Role of rankings}

Yes, the design of the webpage I think is influenced by the rankings but not too much and notification of rankings and I can say in rankings has got a short percentage of the total webpage but has got its presentation. It shows and explain methodological how rankings work and being selected thorough specified indicators and I don't think there is any special and specific philosophy behind the design on webpage based on rankings notification. At the time of issuing rankings, we revise and check all the items and positions of university and then we will post or publish this success in the main page of our website and in the social networks as well and for attracting 
investigators and elite students we will use special indicators in the web page. Rankings is playing very important role for students and I have seen it many times and students, parents and researchers show high level of interest on it. Ranking really helps students and other audiences to have more information regarding the selection process. Definitely marketing plays and important role on the design and building the website of the university. We consider marketing aspects for having the best design and even we use special videos like video the presentation to present our university better and completely. For students, I think the rankings should be better explained. I meant it should be explained what is ranking and what they try to manifest. Rankings are available for students and their parents. The rankings and its first impression are very important but in my mind, I think they have not been presented well for audiences. Sometimes are very complicated. Furthermore, I believe that rankings or better to say assessment of the performance of universities are not formatted perfectly. I meant it cannot fulfil all issues that students or audiences are looking for. Rankings can be for all the tastes or for all universities. Ranking and its indicators which have been used through the web pages of university really play a very important role for attracting elite students. Rankings of universities help them to make their choice easier and better. For example, larger universities with better ranking position surely can attract more elite students and investigator and ranking. Yes, it is very important and for example in our university it is totally dependent on university board (Cabinet university rectory) and comities of analysis which are specialized for this item to revise and recheck all contents regarding the rankings and etc. And after revision and recheck everything they issue the permission to technician of webpage to publish the valid contents. After their confirmation, the public and communication department will publish and update the contents of the webpage. The contents will be based on the official web pages of rankings like: Shanghai, US times ... The contents which issued on this ranking institute will be adopted and refine for publishing in our website. Regarding QS and US times rankings the reputation can be achieved by rankings. Spanish universities they are not a mostly liked destination for all students around the worlds or like other top universities. In my point of view is really related to reputation of the university. It is totally related and highly affects the university reputation and this is an issue that we are studying that through many factors. The 
reputation of university is engaged with the ranking position and it is like a circle in my mind to $40 \%$, so we are very concerned about our ranking position and how we can make it better. For one side, you have to take care of your position to be better seen by researchers and students. And finally, we are still studying and researching this terms and issues.

\section{$\checkmark$ Marketing aspects}

Of course, we have our own marketing strategy but I can't not say that that is very special marketing strategy and I think is very logical that all universities have their own marketing system or strategy like special logo. Spanish system is very based on the budget of ministry of education and based on this budget they

In some how it can be, because as I have explained to you, there is a mother page with all contents and any department due to their needs will take the required contents and documents for publishing. The design should be for general audience but also in some parts is designed for its own audience. Now a day the university has got their line of design and style for differentiate themselves with others. For example, the color and the frame of the web page has been designed and oriented for attracting the elite researcher or elite students.

The wed page is monitoring by department of communication and they are following some marketing strategy. Of course, in all languages we are trying to present our university facilities and programs to the students all around the world and the web page is the only and the easiest way to present our university to the audience. Yes, graphic elements they are very important to shape a strong web page and for example the color or the graphics design are very important for attracting the audience and the graphics elements always play an important role in the marketing strategy.

We are trying to present all information in three languages and of course will be some differences between 3 languages and the target of audiences any language for. For example, the English part will be presented for international students and researcher and should be definitely in a way to present the required information but, due to the matter of cost the English part has got its own 
problem and in many parts, it's not well designed or prepared. I mean that all languages in $90 \%$ of the contents are the same but in some technical parts are different. The connection the web page is prefect to numerous server that we have prepared for this section the web page is perfectly being connected to social networks and we have a special links in our web page for connecting to Facebook, twitter, Instagram, linked in. We have a special person who is professionally is in charge of social networks and all faculties have got their own account on twitter for example.

\subsubsection{UPF INTERVIEW}

\section{Role of rankings}

Yes, of course, we have an internal website which is dedicated to rankings and analysis of the rankings and then we have a public page which is in 3 languages which we present the rankings notifications and successes. And furthermore, transfer our information to students by catalogues, flyers, magazine.... At the time of issuing rankings, we revise and check all the items and positions of university and then we will post or publish this success in the main page of our website and in the social networks as well and for attracting investigators and elite students we will use special indicators in the web page.

Definitely marketing plays and important role on the design and building the website of the university. We consider marketing aspects for having the best design and even we use special videos like video the presentation to present our university better and completely. It is very clear that investigator or students before make their selection they are checking the rankings positions of universities and this helps them to make their choice easier and better. For example, larger universities with better ranking position surely can attract more elite students and investigator and ranking. Yes, it is very important and for example in our university it is totally dependent on university board (Cabinet university rectory) and comities of analysis which are specialized for this item to revise and recheck all contents regarding the rankings and etc. After their confirmation, the public and communication department will publish and update the contents of the webpage. The contents will be based on the official web pages of rankings like Shanghai, US, QW.... The 
contents which issued on this ranking institute will be adopted and refine for publishing in our website. It is totally related and highly affects the university reputation and this is an issue that we are studying that through many factors. The reputation of university is engaged with the ranking position and it is like a circle in my mind to $40 \%$, so we are very concerned about our ranking position and how we can make it better. For one side, you have to take care of your position to be better seen by researchers and students. And finally, we are still studying and researching this terms and issues.

\section{$\checkmark$ Marketing aspects}

¿Utilizan alguna técnica especial o estrategia de marketing que ha utilizado en las páginas web de la universidad en competencia con otras universidades? Do you believe that any special marketing technique or strategy has been used in the web pages of your university? Of course, we have our own marketing strategy like special logo (for example it has been from 4 years the old logo has been changed) as our marketing brand and a leaflet or booklet to present our university and all activities of our university with the links to the social networks. The resources and policies that support a website dictate content and how the site will be managed. This university has welldeveloped policies, procedures, and guidelines that define the web presence, set accessibility standards, and guide and approve content. The technology and marketing departments play important roles in helping departments set up and maintain their own content. Not uncommon in organizations with large amounts of content, this structure allows content management to be spread across several resources instead of residing solely with the university's only webmaster. Templates, which all content managers at the university site use, dictate color schemes, layout, and design. The student page is designed using one of the standard templates; however, it does not have a dedicated content manager and is infrequently updated. Web Interface The student page is designed in a site map style layout with information listed alphabetically and categorized in broad groups that are also listed alphabetically. The links connect to publicly available information, which can also be accessed elsewhere from within the university's website. A quick link section provides access to the frequently used student portals. The interface is 
straightforward: links, breadcrumb navigation, and one graphic link. Rothwell's environments of human performance illustrate other resources and competition, web design, and web interface to shape the environment in which the user will work. Finally, the user is analyzed to determine if he or she has the skills and capacity to navigate and use the student page. For better being searched by Google, we are very concerned with the marketing strategy. In some how it can be, because as I have explained to you, there is a mother page with all contents and any department due to their needs will take the required contents and documents for publishing. Of course, in all languages we are trying to present our university facilities and programs to the students all around the world and the web page is the only and the easiest way to present our university to the audience. Yes, graphic elements they are very important to shape a strong web page and for example the color or the graphics design are very important for attracting the audience and the graphics elements always play an important role in the marketing strategy. We are trying to present all information in three languages and of course will be some differences between 3 languages and the target of audiences any language for. For example, the English part will be presented for international students and researcher and should be definitely in a way to present the required information. I mean that all languages in $90 \%$ of the contents are the same but in some technical parts are different. The connection the web page is prefect to numerous server that we have prepared for this section. The web page is perfectly being connected to smart phones and tablets and you can connect easily without any problem. The web page is connected to social networks like Facebook, Instagram, linked in, twitter, the web page is perfectly being connected to social networks and we have a special links in our web page for connecting to Facebook, twitter, Instagram, linked in. We have a special person who is professionally is in charge of social networks and all faculties have got their own account on twitter for example. 